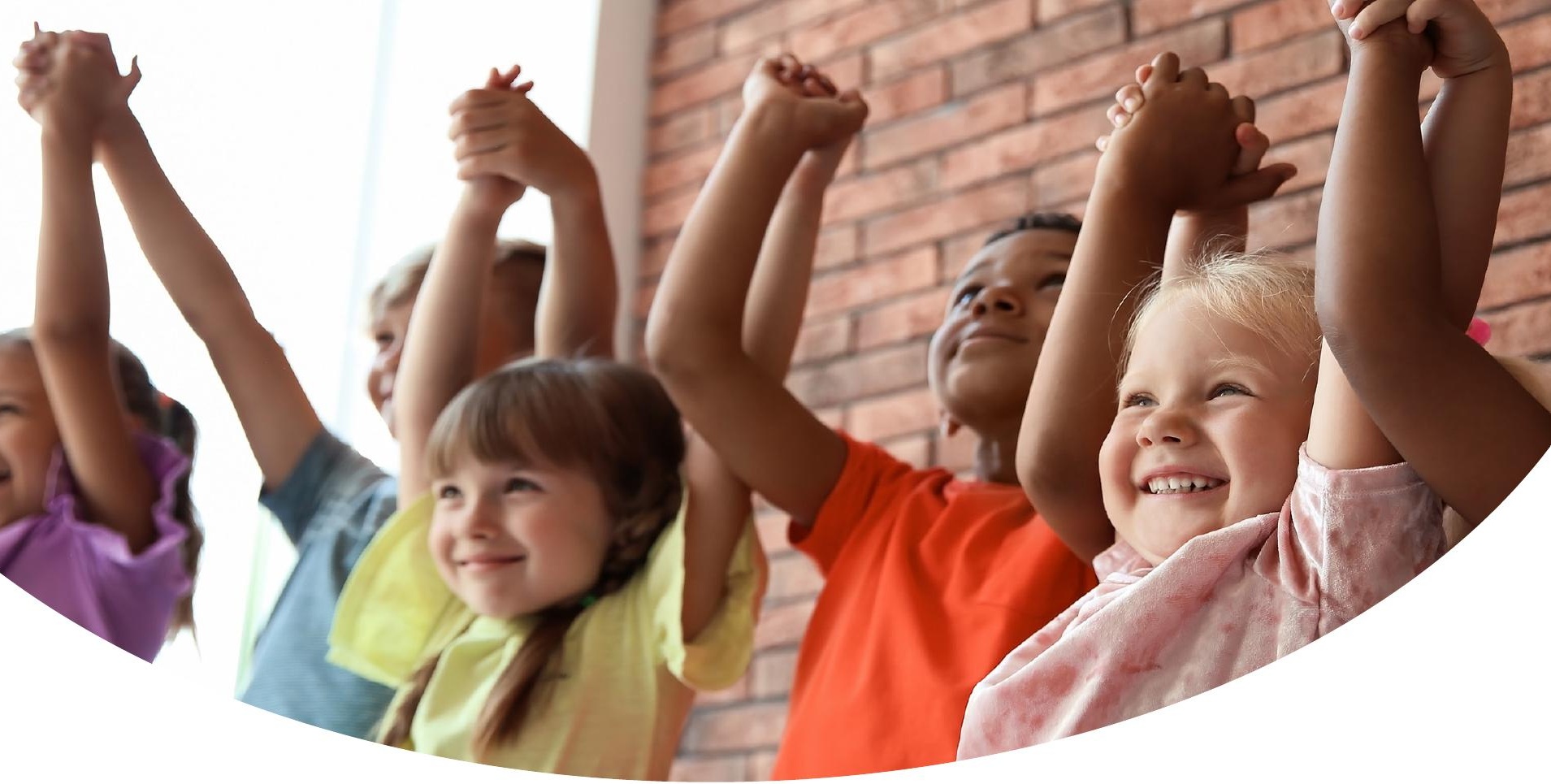

\title{
CÓMO MOTIVAR EN EDUCACIÓN FÍSICA \\ APLICACIONES PRÁCTICAS PARA EL PROFESORADO \\ DESDE LA EVIDENCIA CIENTíFICA
}

\section{Coordinador}

Luis García-González

\section{Autores}

Alejandro Jiménez-Loaisa

Alexander Gil-Arias

Alexandra Valencia-Peris

Ángel Abós

Antonio Méndez-Giménez

Bartolomé J. Almagro

Cristina Conde

David González-Cutre

Eduardo J. Fernández-Ozcorta

Francisco M. Leo

Javier Fernández-Rio
Javier Sevil-Serrano

Jorge Lizandra

Juan J. Pulido

Laura Cañadas

Luis García-González

Luis M. García López

Miguel A. López-Gajardo

Pedro Sáenz-López

Rafael Burgueño

Roberto Ferriz

Sebastián Fierro-Suero

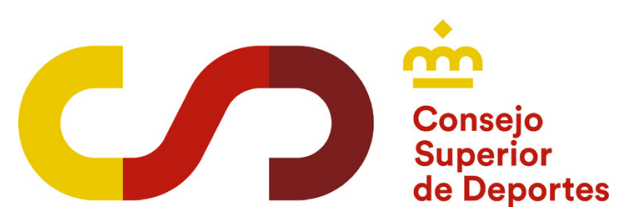


( ) Los autores. Red internacional de investigación en Educación Física y Promoción de Hábitos Saludables

$1^{\text {a }}$ edición. Zaragoza, 2021.

Edita: Servicio de Publicaciones. Universidad de Zaragoza

ISBN: 978-84-18321-22-1

DOI: $10.26754 /$ uz.978-84-18321-22-1

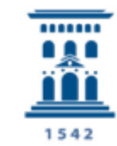

Servicio de

$\underline{\underline{1542}}$ Universidad Zaragoza

\section{(c) $\left.(1)(9)()_{\mathrm{BV}}\right)$}

Esta obra se encuentra bajo una licencia Creative Commons Reconocimiento - NoComercial - SinObraDerivada (cc BY-NC-ND). Ver descripción de esta licencia en https://creativecommons.org/licenses/ by-nc-nd/4.0/ 


\section{ÍNDICE}

PARTE 1.

BASES TEÓRICAS Y CONCEPTUALES DE LA MOTIVACIÓN EN EDUCACIÓN FÍSICA.

Capítulo 1.1. Teoría de la autodeterminación: Necesidades psicológicas básicas y motivación. Alejandro Jiménez-Loaisa, David González-Cutre y Roberto Ferriz .....

Capítulo 1.2. El modelo trans-contextual de la motivación: Conectando contextos para promocionar la actividad física. Roberto Ferriz, David González-Cutre, Alejandro Jiménez-Loaisa y Alexander Gil-Arias.

\section{PARTE 2.}

¿QUÉ HERRAMIENTAS O ESTRATEGIAS PUEDE UTILIZAR EL PROFESORADO DE EDUCACIÓN FÍSICA PARA MOTIVAR A SU ALUMNADO?

Capítulo 2.1. Los modelos pedagógicos y su efecto sobre la motivación del alumnado. Javier Fernández-Rio, Luis M. García López y Alexander Gil Arias.

Capítulo 2.2. Los climas motivacionales en Educación Física: estrategias para desarrollar un clima tarea y evitar un clima ego. Luis García-González, Antonio Méndez-Giménez, Javier FernándezRío y Javier Sevil-Serrano 59

Capítulo 2.3. La importancia de las conductas motivacionales docentes en Educación Física: estrategias didácticas de intervención. Luis García-González, Javier Sevil-Serrano, Rafael Burgueño y Ángel Abós.

Capítulo 2.4. Estrategias motivacionales para incluir novedad y variedad en Educación Física. David González-Cutre, Alejandro Jiménez-Loaisa, Ángel Abós y Roberto Ferriz.

Capítulo 2.5. ¿Cómo influyen las destrezas docentes en la motivación del alumnado en Educación Física? Luis García-González, Jorge Lizandra y Javier Sevil-Serrano ..... 117

Capítulo 2.6. Desarrollo de la cohesión y las relaciones sociales en clase para optimizar la motivación e implicación en Educación Física. Francisco M. Leo, Miguel A. López-Gajardo, Javier Fernández-Río, y Juan J. Pulido.

Capítulo 2.7. Emociones y motivación del alumnado en Educación Física. Bartolomé J. Almagro, Sebastián Fierro-Suero, Eduardo J. Fernández-Ozcorta, Cristina Conde y Pedro Sáenz-López ....147

Capítulo 2.8. Cómo aplicar la evaluación formativa para favorecer la motivación y el aprendizaje en Educación Física. Laura Cañadas, Alexandra Valencia-Peris y Javier Sevil-Serrano. 


\section{PRÓLOGO}

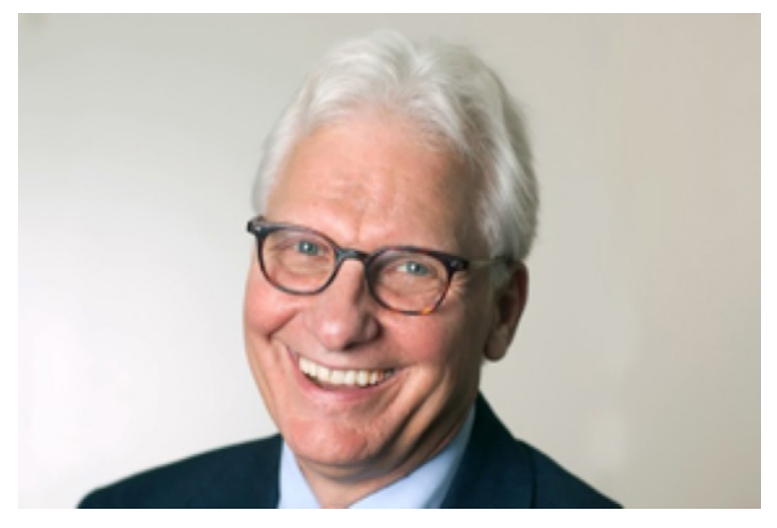

\section{Richard M. Ryan}

Australian Catholic University

North Sydney, NSW, AU.

Creador de la teoría de la autodeterminación junto a Edward L. Deci

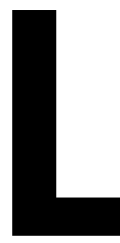

a Educación Física es hoy más importante que nunca. Nuestros estudiantes viven en un mundo que conspira para alejarlos de un ejercicio físico saludable para su cuerpo. Se enfrentan a fuertes tentaciones como los medios de comunicación, jugar a videojuegos y conectarse con otros a través de las redes sociales. Al mismo tiempo, las políticas y los recursos educativos se centran principalmente en objetivos cognitivos estrictamente definidos, como el avance del aprendizaje STEM (Ciencia, Tecnología, Ingeniería y Matemáticas) o la obtención de las puntuaciones más altas en pruebas estandarizadas. Todas estas son actividades sedentarias e intelectuales que implican poca actividad física. Y mientras estos jóvenes son inactivos, los especialistas en marketing les presionan para que consuman comida rápida y bebidas azucaradas, lo que conduce a una obesidad creciente en los países desarrollados. Los publicistas también focalizan en la imagen personal de los jóvenes, cultivando ideales corporales poco realistas e incluso poco saludables, que a menudo crean inseguridad e insatisfacción con el propio físico. En resumen, estamos ante una era en la que los estudiantes necesitan 
especialmente apoyos educativos para comprender, ejercitar y apreciar su naturaleza física.

Estos son objetivos que una Educación Física de calidad debería lograr. La Educación Física debe despertar el interés por la actividad física y el deseo de participar y mejorar. Debe entusiasmar a los estudiantes para progresar y ser físicamente más activos y capaces, independientemente de su punto de partida. Debe crear interés y motivación para que el alumnado sea activo fuera de las clases de Educación Física, en la vida diaria. Teniendo en cuenta la competencia que hay para captar la atención e interés de los estudiantes, estas no son tareas fáciles.

Esto nos lleva a destacar la importancia de este libro en el que se presentan con detalle técnicas y modelos contemporáneos para motivar a los estudiantes en Educación Física. Basándose en la teoría de la autodeterminación, los diferentes capítulos se centran especialmente en cómo aumentar el interés, el aprendizaje y el valor de las actividades en Educación Física. Como muestran los autores desde diferentes perspectivas, se puede fomentar la participación autónoma o "voluntaria" en Educación Física si proporcionamos el clima y las estrategias adecuadas para la enseñanza. Idealmente, si catalizamos esta participación activa en clase también se transferirá a la vida fuera de la escuela, ya que el propósito central de la Educación Física debe ser ayudar a los estudiantes a desarrollar un estilo de vida activo para toda la vida.

Sabemos que las clases de Educación Física, al menos como se impartían tradicionalmente, no solían cumplir con estos objetivos. De hecho, las experiencias de muchos estudiantes en las clases tradicionales de Educación Física han sido 
desalentadoras. Las clases de Educación Física recompensan y nutren con demasiada frecuencia a los estudiantes que ya son más capaces motrizmente, mientras que enseñan a los demás, a través de comparaciones sociales y un feedback negativo, que la actividad física "no es para ellos". Razón de más para implementar técnicas como las detalladas en la teoría de la autodeterminación, que focalizan en apoyar las necesidades psicológicas de los estudiantes de todos los niveles de habilidad motriz, para fomentar una experiencia agradable, desafiante, que desarrolle la curiosidad y que mejore la competencia en Educación Física.

En este importante y oportuno libro, los autores muestran cómo el profesorado puede proporcionar los apoyos motivacionales necesarios para generar compromiso con la Educación Física y que este se transfiera. Se trata de la obra más completa de este tipo para el mundo hispanohablante y se espera que tenga una influencia mundial. No ha habido un momento en el que un llamamiento para mejorar la enseñanza de la Educación Física haya sido más importante, y este original e innovador libro señala el camino. 
PARTE 1.

BASES TEÓRICAS

Y CONCEPTUALES

DE LA MOTIVACIÓN EN

EDUCACIÓN FÍSICA 



\section{1.- EVIDENCIAS CIENTÍFICAS: TEORÍA DE LA AUTODETERMINACIÓN APLICADA A LA EDUCACIÓN FÍSICA}

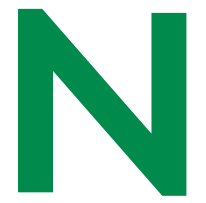

uestra materia, la Educación Física, representa una poderosa herramienta para hacer frente a una realidad social que, al menos por ahora, no resulta demasiado alentadora. Por poner algunos ejemplos, la ciencia señala que tanto los niños como las niñas de las sociedades desarrolladas actuales cada vez dedican menos tiempo a jugar de forma activa y libre "en la calle", lo que repercute negativamente en su salud (Gray, 2011). En línea con esta idea, sabemos también que alrededor del $81 \%$ del estudiantado no cumple con las recomendaciones mínimas de actividad física establecidas para alcanzar beneficios en su salud (Guthold et al., 2020). Podríamos pensar que el hecho de que los jóvenes "se muevan cada vez menos" es un fenómeno social complejo que se escapa enteramente de nuestras manos como docentes. No obstante, lo cierto es que existen multitud de evidencias científicas que apoyan el rol fundamental del profesorado de Educación Física a la hora de promocionar estilos de vida activos en el alumnado (Rink et al., 2010), sin olvidar su importancia para el desarrollo personal, social y emocional de sus estudiantes, incluyendo la formación en valores como el esfuerzo, el respeto y la cooperación (Sánchez-Oliva et al., 2014; Sun et al., 2017).
Indudablemente, influir de manera positiva y significativa en las actitudes que presentan los niños y adolescentes hacia la Educación Física no es tarea fácil. En nuestras clases contamos a menudo con alumnado que presenta un perfil motivacional muy distinto, desde aquellos que disfrutan con la práctica totalidad de los contenidos y actividades que les planteamos, hasta aquellos que se muestran poco motivados o interesados con cualquier propuesta didáctica que llevamos a cabo. Ante tal realidad, parece razonable tratar de identificar y comprender qué mecanismos psicológicos y sociales conducen a nuestro alumnado a involucrarse más o menos en las sesiones de Educación Física. Solo así podremos basar nuestra intervención docente en estrategias didácticas que favorezcan ( $y$, además, no perjudiquen) la motivación de los jóvenes hacia la asignatura y los propósitos de esta, al igual que los vínculos socioafectivos que surjan de nuestra interacción con ellos.

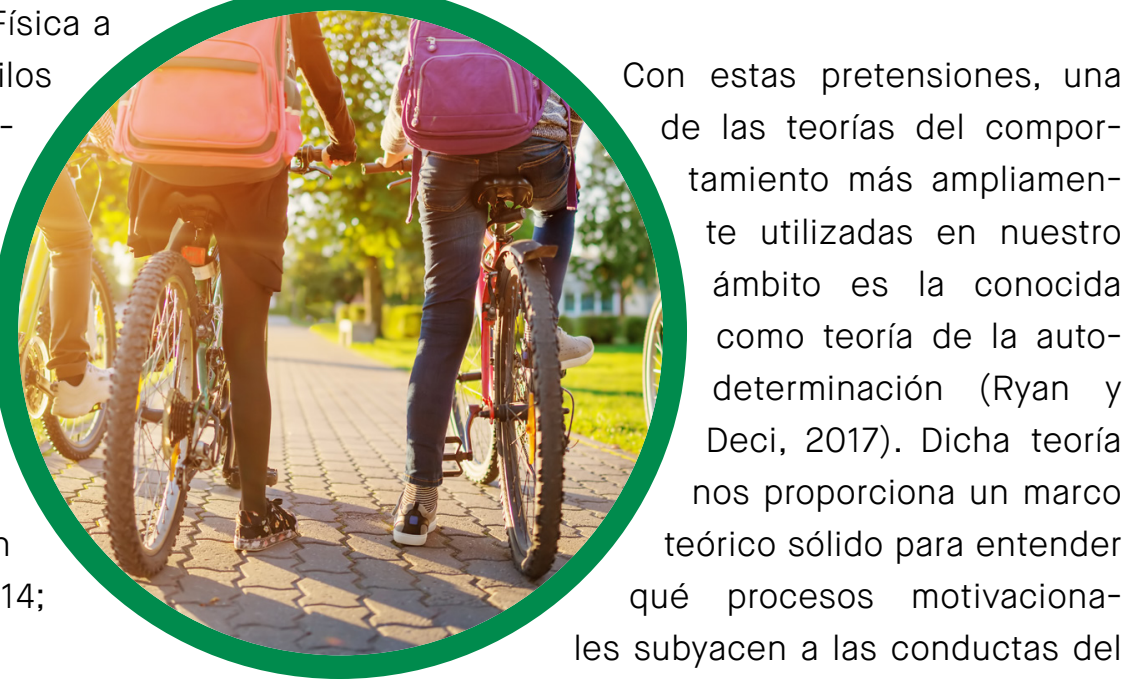


alumnado en Educación Física. En esencia, la teoría de la autodeterminación establece que el profesorado desempeña un papel clave a la hora de satisfacer o frustrar ciertas necesidades psicológicas básicas que son comunes a todo el estudiantado. Estas necesidades son la autonomía, la competencia y la relación. La necesidad de autonomía se vería satisfecha si le damos al alumnado la posibilidad de elegir y ser partícipe del proceso de enseñanza-aprendizaje. La necesidad de competencia tendría que ver con las oportunidades que otorgamos al estudiante para experimentar éxito, así como con su percepción sobre el aprendizaje conceptual y de habilidades durante la asignatura y su progreso con el paso de nuestras sesiones. Por su parte, la necesidad de relación estaría cubierta gracias al esfuerzo del profesorado por promover la interacción social en el aula a través de las diferentes situaciones de aprendizaje que propone, así como por mantener un buen clima y un trato cercano con el estudiantado. Junto a estas tres necesidades contempladas tradicionalmente por la teoría de la autodeterminación, también podríamos señalar la reciente propuesta de algunos in- vestigadores sobre la existencia de una cuarta necesidad: la novedad (González-Cutre et al., 2016, 2020). Esta proposición parece cumplir con los criterios establecidos por Ryan y Deci (2017) para ser considerada también una necesidad psicológica básica (ver Vansteenkiste et al., 2020), y podría definirse en contextos de Educación Física como la necesidad del alumnado de vivir experiencias que no ha vivenciado previamente o que son diferentes a las de su rutina habitual (González-Cutre et al., 2016). De esta forma, la satisfacción o frustración de estas cuatro necesidades psicológicas básicas mencionadas se relacionaría con diferentes formas de motivación, organizadas en un continuo de autodeterminación (proceso por el cual una persona es el principal agente causal de una acción, ver Figura 1). A continuación, procedemos a explicar qué tipos de motivación y consecuencias asociadas ocurren cuando logramos satisfacer las necesidades de autonomía, competencia, relación y novedad de los/as estudiantes. Más tarde, expondremos qué ocurre cuando frustramos o no logramos satisfacer dichas necesidades.

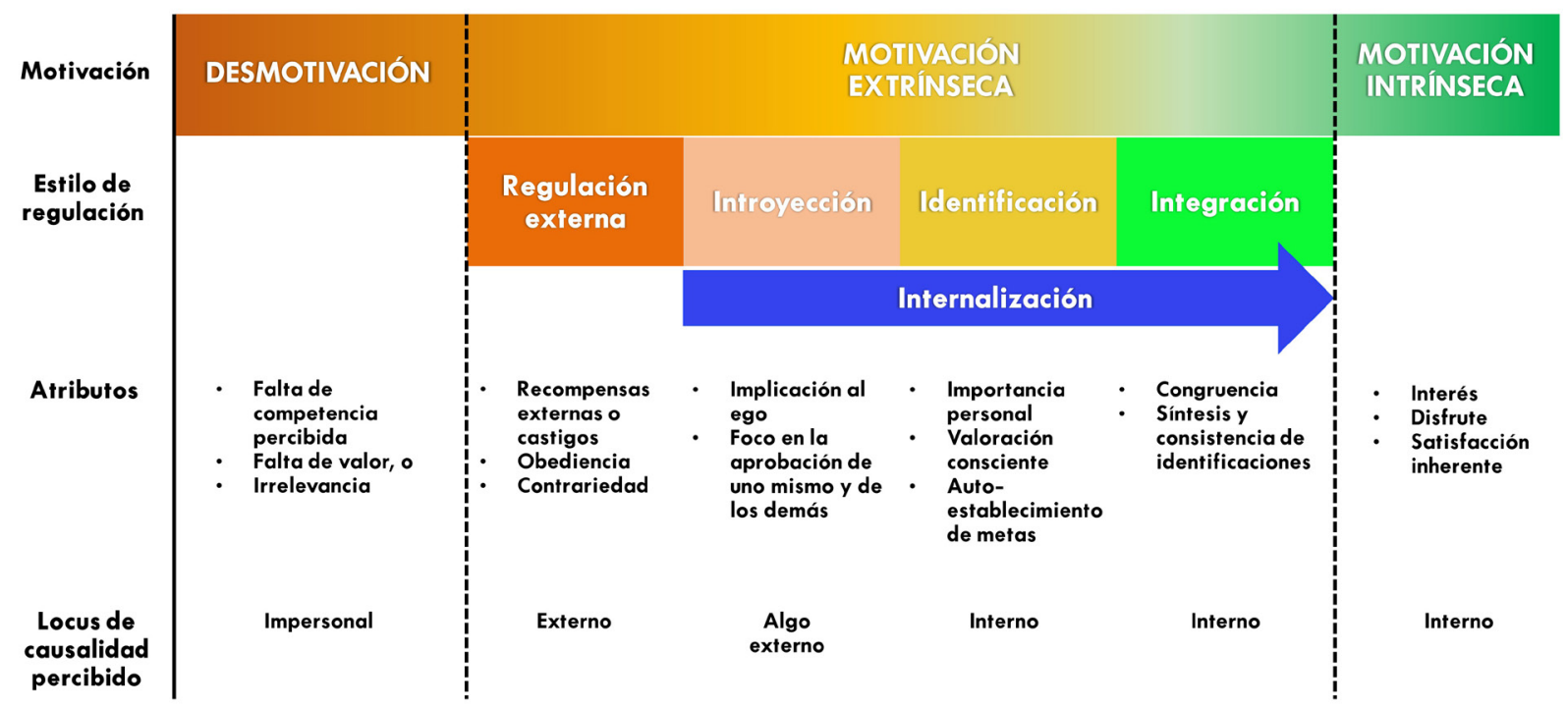

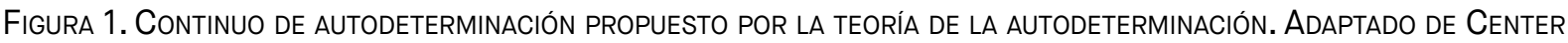
for Self-Determination Theory, RyAn y DeCi (2020). 
Cuando nuestro alumnado siente que en Educación Física se da un ambiente que apoya sus necesidades psicológicas básicas, la investigación demuestra que es probable que aparezcan formas de motivación más autodeterminadas (González-Cutre et al., 2016; Vasconcellos et al., 2020; White et al., 2021). En el continuo de autodeterminación, estas formas de motivación se representarían a través de las regulaciones identificadas, integradas e intrínsecas, respectivamente. La regulación identificada es aquella que posee el estudiante cuando identifica o reconoce los beneficios de la Educación Física y valora conscientemente el papel que juega la asignatura en su formación y los aprendizajes que se tratan de transmitir en ella. Por ejemplo, el caso de un alumno/a que aprende la importancia del consumo adecuado de frutas y verduras para su salud y lo extrapola a su vida diaria, o un alumno/a que está interesado en aprender ciertas habilidades motrices y fundamentos técnico-tácticos porque luego los podrá transferir a su práctica deportiva extraescolar. Por su parte, la regulación integrada supondría un nivel más avanzado de autodeterminación. Sería el caso de un estudiante que está motivado para realizar actividad física (y Educación Física) porque forma parte de su identidad y sus valores personales. Es decir, el estudiante ya no solo considera importante la actividad, sino que además es un reflejo de lo que uno es (González-Cutre, 2017). Finalmente, a la derecha del todo del continuo de autodeterminación nos encontraríamos con la motivación intrínseca, la cual representa el nivel más elevado de autodeterminación. Aquí, el alumnado estaría completamente auto-motivado e impulsado por el verdadero placer, satisfacción o disfrute que le supone participar en las actividades que proponemos desde la Educación Física.

Según la teoría de la autodeterminación, el hecho de que como docentes fomentemos la satisfacción de las necesidades psicológicas básicas y el desarrollo de formas de motivación autodeterminadas en el aula va a conllevar, a su vez, consecuencias positivas de diversa índole para nuestro alumnado. Algunas de estas incluyen un mayor interés por parte de los estudiantes sobre los aspectos que rodean a la actividad física, menos conductas disruptivas, mayor disfrute, concentración y esfuerzo durante nuestras clases, emociones positivas, estados psicológicos óptimos y, además, mayores niveles de actividad física e intenciones de realizarla fuera de la escuela (González-Cutre y Sicilia, 2019; Vasconcellos et al., 2020; White et al., 2021). Lograr estas consecuencias a través de nuestra intervención didáctica nos acercaría, por tanto, a la consecución de nuestros objetivos como docentes de Educación Física.

Sin embargo, la teoría de la autodeterminación no solo nos dice qué sucede cuando logramos satisfacer las necesidades psicológicas de los discentes. A lo largo de estos últimos años, ha habido una preocupación creciente en la comunidad científica por conocer qué sucede cuando el docente frustra o no consigue satisfacer la autonomía, competencia, relación y novedad del alumnado. De este modo, si esto ocurre, es más probable que el alumnado experimente formas de motivación no autodeterminadas, representadas en el continuo de la autodeterminación por las regulaciones introyectadas, externas y la desmotivación, respectivamente. Un estudiante motivado de forma introyectada participará en nuestras propuestas con la intención principal de obtener recompensas internas (p. ej., mejorar su ego y orgullo) o evitar sentimientos de culpabilidad y vergüenza (p. ej., participar en las actividades de clase para evitar sentirse mal o para que los demás no crean que no es habilidoso/a). Por tanto, el alumno/a no realiza la actividad por los beneficios que pueda conllevar, porque forme parte de su identidad 
o porque disfrute de la misma, sino más bien con fines "algo externos". Avanzando en el camino hacia la desmotivación con la Educación Física, la regulación externa sería aquella en la cual los estudiantes participan o hacen la actividad "porque no les queda más remedio", ya que así consiguen alguna recompensa externa dictada por el profesorado de la asignatura o la escuela (p. ej., premiar la realización de una determinada conducta motriz con la obtención de puntos que son sumados a un ranking global; obtención de una calificación en la asignatura) y evitan ser castigados o que tomen represalias contra ellos (p. ej., el docente llama la atención, grita o castiga obligando a dar vueltas al patio o a realizar determinados ejercicios como sentadillas o flexiones). La propia desmotivación, a la izquierda del todo del continuo de autodeterminación, supondría la forma más alejada de nuestros intereses como docentes, puesto que es una forma de motivación no autodeterminada caracterizada por el absoluto desinterés y la falta de implicación del alumnado con nuestra intervención y con la asignatura.

Como el lector ya se imaginará, frustrar las necesidades psicológicas básicas y propiciar formas de motivación no autodeterminadas en el aula también conllevará consecuencias para el alumnado, pero en esta ocasión probablemente serán de corte negativo o desfavorable. De nuevo, las revisiones sistemáticas llevadas a cabo por Vasconcellos et al. (2020) y White et al. (2021) enumeran algunas de ellas, incluyendo el aburrimiento, la falta de disfrute, mayor número de conductas disruptivas en clase (abarcando aquellas que tienen que ver con el bullying), estados psicológicos negativos relacionados con el estrés, la ansiedad o la vergüenza, menor participación del estudiantado y menores niveles de actividad física e intenciones de realizarla fuera del contexto escolar. Todas ellas, por ende, nos alejan de la filosofía en la que debería basarse una Educación Física verdaderamente formativa y de calidad.

De manera recapitulativa, la teoría de la autodeterminación establece que el estilo interpersonal del profesorado de Educación Física juega un papel capital a la hora de satisfacer (y no frustrar) las necesidades psicológicas básicas de su alumnado. Esto conducirá hacia formas de motivación autodeterminadas que, a su vez, aumentarán las probabilidades de que el estudiantado experimente consecuencias positivas durante nuestra intervención. La Figura 2 ilustra de forma esquemática la secuencia recién descrita. Ahora bien, llegados a este punto del capítulo podríamos preguntarnos: entonces, ¿qué estrategias didácticas concretas podemos adoptar como docentes para favorecer la satisfacción de las necesidades psicológicas básicas del alumnado? El Capítulo 2.3 del presente libro ofrece toda una serie de estrategias específicas basadas en la evidencia científica que pueden ser de utilidad a la hora de guiar nuestros estilos motivacionales docentes y las conductas que los representan. El resto de los capítulos de este libro también nos aportan muchas ideas de cómo satisfacer las necesidades psicológicas básicas de nuestro alumnado para desarrollar formas de motivación autodeterminadas (incluyendo un capítulo dedicado a la necesidad de novedad). 


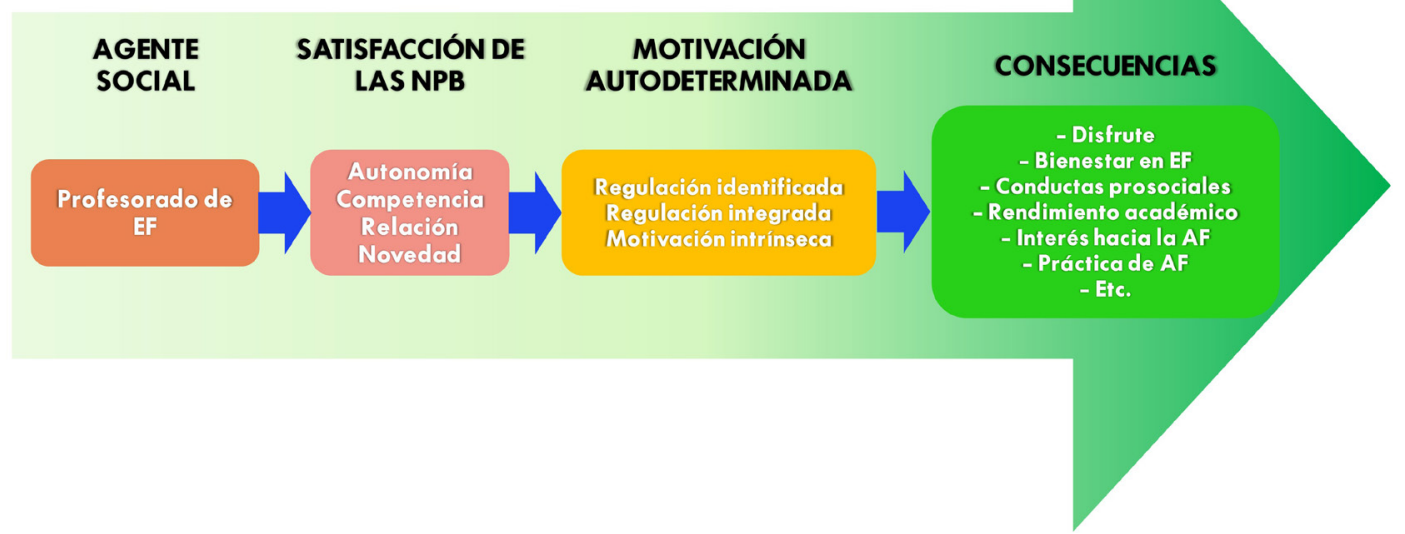

Figura 2. Secuencia motivacional de la teoría de la aUtodeterminación en Educación Física NotA. NPB $=$ NECESIDADES PSICOLÓGICAS BÁSICAS. EF = EdUCACIÓN FísICA. AF = ACTIVIDAD FíSICA.

Para terminar con este breve capítulo teórico e introductorio, no quisiéramos dejar escapar algunas consideraciones finales que podrían ayudar a complementar nuestro entendimiento de la teoría de la autodeterminación en nuestra área. Por un lado, es probable que se nos hayan ido ocurriendo ejemplos de alumnos y alumnas concretos a medida que hemos ido presentando las diferentes formas de motivación (autodeterminadas y no autodeterminadas). Como comentábamos previamente, entra dentro de la normalidad tener alumnado con perfiles motivacionales distintos en un mismo grupo. Es nuestra labor como profesorado de Educación Física tratar de atender y adaptarnos a todos ellos, individualizando nuestra intervención en la medida de lo posible. Por ejemplo, sabemos que las chicas muestran más desmotivación hacia la Educación Física que los chicos cuando los comportamientos docentes crean un ambiente de frustración de las necesidades psicológicas básicas (Abós et al., 2021). Sabemos también que algunas decisiones didácticas que tomamos en nuestro día a día como docentes, como podría ser dejar que sean los propios estudiantes quienes elijan sus equipos de forma libre y pública, poseen un fuerte impacto negativo sobre la percepción de competencia y relación social del alumnado elegido en último lugar en sus equipos (habitualmente, los percibidos como poco hábiles a nivel motriz; White et al., 2021). Todo ello nos hace pensar que deberíamos elaborar estrategias específicas que sean sensibles con el estudiantado que presenta un perfil más vulnerable en el aula de Educación Física.

Por otro lado, la motivación del alumnado podría variar en función de sus preferencias y de las unidades didácticas que planteemos. Así, un mismo estudiante podría estar motivado de forma introyectada para la unidad didáctica de baloncesto, pero estarlo de forma intrínseca para la unidad de saltos y comba. Entendiendo que la diversidad de intereses y gustos también es habitual, otro de nuestros objetivos como docentes podría encaminarse hacia el descubrimiento por parte del alumnado de actividades y propuestas novedosas que les permitan ver y entender esas unidades didácticas de manera distinta. El Capítulo 2.4., centrado fundamentalmente en estrategias motivacionales para fomentar la novedad y variedad en Educación Física, podría dar ideas a los lectores sobre esta cuestión. Con ello, será más probable que podamos evolucionar desde las formas no autodeterminadas de motivación hacia aquellas que sí lo son. 


\section{2.- PARA SABER MÁS...}

¿Cómo puedo conocer la percepción del alumnado sobre si mi intervención docente apoya sus necesidades psicológicas básicas? ¿Es posible medir y evaluar la satisfacción de estas necesidades en mi alumnado? ¿Cómo puedo saber qué tipo de motivación predomina en mis estudiantes? Existen varios instrumentos validados en Educación Física que nos permiten conocer este tipo de cuestiones. Entre ellos, el Cuestionario de Apoyo a las Necesidades Psicológicas Básicas (CANPB; Sánchez-Oliva et al., 2013), junto a las adaptaciones propuestas por Fierro-Suero, Almagro, Sáenz-López, y Carmona-Márquez (2020), nos permitiría conocer la percepción de nuestro alumnado sobre si nuestra actuación docente apoya (o no) su autonomía, competencia, relación con los demás y novedad. De forma complementaria, la Herramienta de Observación del Clima Interpersonal Motivacional (OCIM; FierroSuero, Almagro, Castillo, y Sáenz-López, 2020) nos ofrece la posibilidad de llevar a cabo un auto-registro de nuestras propias conductas docentes mediante una hoja de observación, que podemos cumplimentar ya sea al finalizar una sesión concreta o grabándola para analizarnos a posteriori. Incluso, podríamos pedirle a un compañero o compañera de Educación Física que nos evalúe mientras impartimos nuestra propia docencia. Adicionalmente, para conocer el grado de satisfacción de las necesidades en el alumnado, podríamos hacer uso de la Escala de Satisfacción de las Necesidades Psicológicas Básicas (BPNES; Moreno et al., 2008), mientras que para la novedad podríamos utilizar la versión en castellano de la Novelty Need Satisfaction Scale (NNSS; González-Cutre y Sicilia, 2019; GonzálezCutre et al., 2016). Por su parte, administrar la Escala del Locus Percibido de Causalidad-2 (PLOC-2, Ferriz et al., 2015) entre nuestro alumnado nos posibilitaría conocer el grado en que se dan los diferentes tipos de motivación explicados anteriormente. Los cuestionarios aquí descritos se proporcionan en el apartado de Anexos, ubicado en la parte final de este capítulo. Para profundizar en la utilización del instrumento observacional (OCIM), recomendamos la lectura del trabajo que lo desarrolla: https://ccd.ucam.edu/index.php/revista/article/view/1647/528. Igualmente, algunas páginas webs (p. ej., Centro de Investigación del Deporte de la Universidad Miguel Hernández de Elche, https://www.cid-umh.es/herramientas/ cuestionarios/motivacion-en-la-actividad-fisicay-el-deporte/ nos ofrecen la posibilidad de descargar herramientas adicionales de interés para el profesorado, como podrían ser aquellas que miden las consecuencias (p. ej., disfrute, conductas prosociales, etc.) de nuestra actuación docente sobre el alumnado. Además, estos instrumentos también podrían ser empleados antes de que se dé nuestra intervención docente, a modo de evaluación inicial o diagnóstica, para que podamos obtener información que nos permita ajustar nuestra actuación en función del tipo de motivación o "predisposición" con la que nuestro estudiantado, por ejemplo, inicia las primeras semanas del curso académico. Realizar tertulias dialógicas en clase o lanzar preguntas representativas de las necesidades psicológicas básicas o tipos de motivación también podría aportarnos información interesante en este sentido.

Para preguntar cualquier cuestión relativa a la administración y/o interpretación de todos los recursos mencionados en este apartado, puedes contactar con los autores de este capítulo (alejandro.jloaisa@uclm.es; dgonzalez-cutre@ umh.es; roberto.ferriz@uv.es). Para conocer más sobre la teoría de la autodeterminación y 
tener acceso a diferentes recursos (artículos, cuestionarios, noticias) en lengua inglesa, resulta imprescindible la siguiente página web: https://selfdeterminationtheory.org/.

Finalmente, el artículo de González-Cutre et al. (2017) sobre estrategias didácticas y motivacionales en clases de Educación Física también podría ser de interés para saber más y profundizar en el uso práctico de la teoría de la autodeterminación. Es posible acceder gratuitamente al texto completo de la referencia a través del siguiente enlace: http://uhu.es/publicaciones/ojs/index.php/e-moti-on/article/ viewFile/3268/2976 


\section{3.- REFERENCIAS BIBLIOGRÁFICAS}

Abós, A., Burgueño, R., García-González, L., y Sevil-Serrano, J. (2021). Influence of internal and external controlling teaching behaviors on students' motivational outcomes in physical education: Is there a gender difference? Journal of Teaching in Physical Education. Publicación en línea avanzada. https://doi.org/10.1123/jtpe.2020-0316

Ferriz, R., González-Cutre, D., y Sicilia, A. (2015). Revisión de la Escala del Locus Percibido de Causalidad (PLOC) para la inclusión de la medida de la regulación integrada en educación física. Revista de Psicología del Deporte, 24, 329-338.

Fierro-Suero, S., Almagro, B. J., Castillo, I., y Sáenz-López, P. (2020). Herramienta de Observación del Clima Interpersonal Motivacional (OCIM) para docentes de Educación Física. Cultura, Ciencia y Deporte, 15(46), 575-596.

Fierro-Suero, S., Almagro, B. J., Sáenz-López, P., y Carmona-Márquez, J. (2020). Perceived novelty support and psychological needs in physical education. International Journal of Environmental Research and Public Health, 17, 4169. https://doi.org/10.3390/ijerph17114169

González-Cutre, D. (2017). Estrategias didácticas y motivacionales en las clases de Educación Física desde la teoría de la autodeterminación. E-motion: Revista de Educación, Motricidad e Investigación, 8, 44-62.

González-Cutre D., Romero-Elías, M., Jiménez-Loaisa, A., Beltrán-Carrillo, V. J., y Hagger, M. S. (2020). Testing the need for novelty as a candidate need in basic psychological needs theory. Motivation and Emotion, 44(2), 295-314. https://doi.org/10.1007/s11031-019-09812-7

González-Cutre, D., y Sicilia, A. (2019). The importance of novelty satisfaction for multiple positive outcomes in physical education. European Physical Education Review, 25(3), 859-875. https://doi.org/10.1177/1356336X18783980

González-Cutre, D., Sicilia, A., Sierra, A. C., Ferriz, R., y Hagger, M. S. (2016). Understanding the need for novelty from the perspective of self-determination theory. Personality and Individual Differences, 102, 159-169. http://dx.doi.org/10.1016/j.paid.2016.06.036

Gray, P. (2011). The decline of play and the rise of psychopathology in children and adolescents. American Journal of Play, 3(4), 443-463.

Guthold, R., Stevens, G. A., Riley, L. M., y Bull, F. C. (2020). Global trends in insufficient physical activity among adolescents: A pooled analysis of 298 population-based surveys with $1 \cdot 6$ million participants. The Lancet Child \& Adolescent Health, 4(1), 23-35.

https://doi.org/10.1016/S2352-4642(19)30323-2
Moreno, J. A., González-Cutre, D., Chillón, M., y Parra, N. (2008). Adaptación a la educación física de la escala de las necesidades psicológicas básicas en el ejercicio. Revista Mexicana de Psicología, 25(2), 295-303.

Rink, J. E., Hall, T. J., y Williams, L. H. (2010). Schoolwide physical activity: A comprehensive guide to designing and conducting programs. Human Kinetics.

Ryan, R. M., y Deci, E. L. (2017). Self-determination theory: Basic psychological needs in motivation, development, and wellness. Guilford Publications. https://doi.org/10.1521/978.14625/28806

Ryan, R. M., y Deci, E. L. (2020). Intrinsic and extrinsic motivation from a self-determination theory perspective: Definitions, theory, practices, and future directions. Contemporary Educational Psychology, 61, 101860. https://doi.org/10.1016/j.cedpsych.2020.101860

Sánchez-Oliva, D., Leo, F. M., Amado, D., Cuevas, R., y García-Calvo, T. (2013). Desarrollo y validación del Cuestionario de Apoyo a las Necesidades Psicológicas Básicas en Educación Física. European Journal of Human Movement, 30, 53-71.

Sánchez-Oliva, D., Viladrich, C., Amado, D., GonzálezPonce, I., y García-Calvo, T. (2014). Predicción de los comportamientos positivos en educación física: una perspectiva desde la Teoría de la Autodeterminación. Revista de Psicodidáctica, 19(2), 387-406. https://doi.org/10.1387/RevPsicodidact.7911

Sun, H., Li, W., y Shen, B. (2017). Learning in physical education. A self-determination theory perspective. Journal of Teaching in Physical Education, 36(3), 277-291. https://doi.org/10.1123/jtpe.2017-0067

Vansteenkiste, M., Ryan, R. M., y Soenens, B. (2020). Basic psychological need theory: Advancements, critical themes, and future directions. Motivation and Emotion, 44(1), 1-31. https://doi.org/10.1007/s11031-019-09818-1

Vasconcellos, D., Parker, P. D., Hilland, T., Cinelli, R., Owen, K. B., Kapsal, N., Lee, J., Antczak, D., Ntoumanis, N., Ryan, R. M., y Lonsdale, C. (2020). Self-determination theory applied to physical education: A systematic review and meta-analysis. Journal of Educational Psychology, 112(7), 1444-1469. https://doi.org/10.1037/edu0000420

White, R. L., Bennie, A., Vasconcellos, D., Cinelli, R., Hilland, T., Owen, K. B., y Lonsdale, C. (2021). Self-determination theory in physical education: A systematic review of qualitative studies. Teaching and Teacher Education, 99, 103247.

https://doi.org/10.1016/j.tate.2020.103247 


\section{4.- ANEXOS}

\section{Cuestionario de Apoyo a las Necesidades Psicológicas Básicas (CANPB, Fierro-Suero, Almagro, Sáenz-López, y Carmona-Márquez, 2020; Sánchez-Oliva et al., 2013)}

En mis clases de Educación Física, nuestro profesor/a...

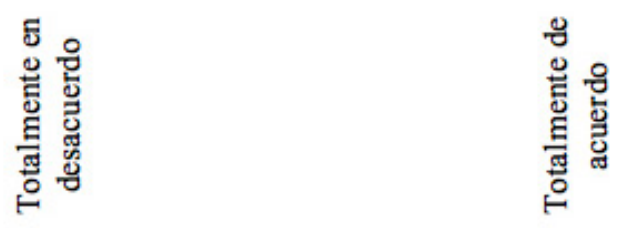

1. Nos pregunta a menudo sobre nuestras preferencias respecto a las actividades a realizar

2. Nos anima a que confiemos en nuestra capacidad para hacer bien las tareas

3. Fomenta en todo momento las buenas relaciones entre los/as compañeros/as

4. Hace cosas distintas respecto a lo que estamos acostumbrados/as

5. Trata de que tengamos libertad a la hora de realizar las actividades

6. Nos propone actividades ajustadas a nuestro nivel

7. Favorece el buen ambiente entre los/as compañeros/as de clase

8. Nos propone actividades novedosas con frecuencia

9. Tiene en cuenta nuestra opinión en el desarrollo de las clases

10. Siempre intenta que consigamos los objetivos que se plantean en las actividades

11. Promueve que todos los/as alumnos/as nos sintamos integrados

12. Nos ayuda a descubrir cosas nuevas

13. Nos deja tomar decisiones durante el desarrollo de las tareas

14. Fomenta el aprendizaje y la mejora de los contenidos de la asignatura

15. Nos ayuda a resolver los conflictos amistosamente

16. Con frecuencia despierta nuestra curiosidad

1

2

1

1

2

1

2


Escala de Satisfacción de las Necesidades Psicológicas Básicas (BPNES, Moreno et al., 2008) integrando la satisfacción de novedad (González-Cutre y Sicilia, 2019; González-Cutre et al., 2016)

En mis clases de Educación Física...

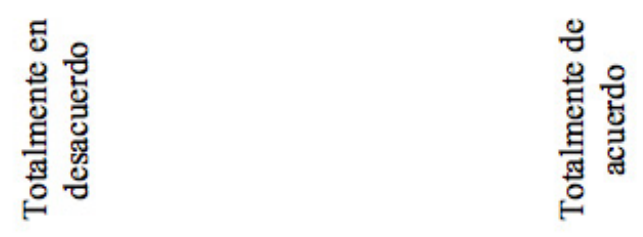

1. Siento que hago cosas novedosas

2. Los ejercicios que realizo se ajustan a mis intereses

3. Siento que he tenido una gran progresión con respecto al objetivo final que me he propuesto

4. Me siento muy cómodo/a cuando hago ejercicio con los/as demás compañeros/as

5. Siento que a menudo hay novedades para mí

6. La forma de realizar los ejercicios coincide perfectamente con la forma en que yo quiero hacerlos

7. Realizo los ejercicios eficazmente

8. Me relaciono de forma muy amistosa con el resto de los/as compañeros/as

9. Experimento sensaciones nuevas

10. La forma de realizar los ejercicios responde a mis deseos

11. El ejercicio es una actividad que hago muy bien

12. Siento que me puedo comunicar abiertamente con mis compañeros/as

13. Creo que se plantean situaciones novedosas para mí 14. Tengo la oportunidad de elegir cómo realizar los ejercicios

15. Pienso que puedo cumplir con las exigencias de la clase

16. Me siento muy cómodo/a con los/as compañeros/as

17. Creo que descubro cosas nuevas a menudo

$\begin{array}{lllll}1 & 2 & 3 & 4 & 5 \\ 1 & 2 & 3 & 4 & 5 \\ 1 & 2 & 3 & 4 & 5 \\ 1 & 2 & 3 & 4 & 5 \\ 1 & 2 & 3 & 4 & 5 \\ 1 & 2 & 3 & 4 & 5 \\ 1 & 2 & 3 & 4 & 5 \\ 1 & 2 & 3 & 4 & 5 \\ 1 & 2 & 3 & 4 & 5 \\ 1 & 2 & 3 & 4 & 5 \\ 1 & 2 & 3 & 4 & 5 \\ 1 & 2 & 3 & 4 & 5 \\ 1 & 2 & 3 & 4 & 5 \\ 1 & 2 & 3 & 4 & 5 \\ 1 & 2 & 3 & 4 & 5 \\ 1 & 2 & 3 & 4 & 5 \\ 1 & 2 & 3 & 4 & 5\end{array}$

Para obtener la puntuación de cada una de las dimensiones hay que calcular la media de los siguientes ítems: Satisfacción de autonomía: 2, 6, 10, 14; Satisfacción de competencia: 3, 7, 11, 15; Satisfacción de relación: 4, 8,12,16; Satisfacción de novedad: 1, 5, 9,13,17. 
Escala del Locus Percibido de Causalidad-2 (PLOC-2, Ferriz et al., 2015)

Participo en esta clase de Educación Física...

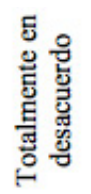

1. Porque la Educación Física es divertida

2. Porque está de acuerdo con mi forma de vida

1

3. Porque quiero aprender habilidades deportivas

4. Porque quiero que el profesor/a piense que soy un/a buen/a

$$
\text { estudiante }
$$

5. Porque tendré problemas si no lo hago

6. Pero no sé realmente por qué

7. Porque disfruto aprendiendo nuevas habilidades

8. Porque considero que la Educación Física forma parte de

mí

9. Porque es importante para mí hacerlo bien en Educación

Física

10. Porque me sentiría mal conmigo mismo si no lo hiciera

11. Porque eso es lo que supone que debo hacer

12. Pero no comprendo por qué debemos tener Educación

Física

13. Porque la Educación Física es estimulante

14. Porque veo la Educación Física como una parte fundamental de lo que soy

15. Porque quiero mejorar en el deporte

16. Porque quiero que los/as otros/as estudiantes piensen que

$$
\text { soy hábil }
$$

17. Para que el/la profesor/a no me grite

18. Pero realmente siento que estoy perdiendo mi tiempo en Educación Física

19. Por la satisfacción que siento mientras aprendo nuevas habilidades/técnicas

20. Porque considero que la Educación Física está de acuerdo con mis valores

21. Porque puedo aprender habilidades que podría usar en otras áreas de mi vida

22. Porque me preocupa cuando no lo hago

$$
\text { 23. Porque esa es la norma }
$$

24. Pero no puedo comprender lo que estoy sacando de la Educación Física

Para obtener la puntuación de cada una de las dimensiones hay que calcular la media de los siguientes ítems: Motivación intrínseca: 1, 7, 13, 19; Regulación integrada: 2, 8, 14, 20; Regulación identificada: 3, 9, 15, 21; Regulación introyectada: 4, 10, 16, 22; Regulación externa: 5, 11, 17, 23; Desmotivación: $6,12,18,24$. 



\section{1.- EVIDENCIAS CIENTÍFICAS: EL MODELO TRANS-CONTEXTUAL DE LA MOTIVACIÓN EN EDUCACIÓN FÍSICA}

\section{1.- ¿Por qué apoyar mi intervención docente en el modelo trans-contextual de la motivación?}

través del área de Educación Física, los docentes tienen una oportunidad única de motivar a su alumnado para que adopte comportamientos saludables a lo largo de la vida, entre los que se incluye la práctica de actividad física regular. El profesorado de Educación Física es consciente del importante papel que juega la escuela y, en concreto, del rol de liderazgo atribuido a los profesionales del área para que, por medio de su intervención docente durante las clases de Educación Física, los niños y adolescentes en edad escolar inicien y mantengan estilos de vida saludable. A la hora de abordar un reto de esta magnitud, es comprensible que el profesorado de Educación Física pueda plantearse cuestiones como: ¿qué puedo hacer en mis clases de Educación Física para que el alumnado realice actividad física fuera del contexto escolar?, ¿qué teclas debo tocar?, de todos los recursos a los que puedo tener acceso para abordar este fin, ¿en cuáles puedo confiar para guiar mi intervención docente?, ¿fomentar la práctica de actividad física entre mi alumnado es una responsabilidad que debo abordar de manera unilateral o involucrar a otros agentes de la comunidad educativa sería más positivo para mis estudiantes? Estas son algunas de las cuestiones que los docentes podrían plantearse en el desempeño de un objetivo nada sencillo, pues si en el día a día ya es todo un reto motivar al alumnado para que participe activamente en las clases de Educación Física, la labor de lograr que el alumnado realice y mantenga comportamientos saludables en el tiempo de ocio, como la práctica de actividad física regular, resultaría un reto de mayor magnitud.

En este sentido, el fin del presente capítulo es presentar un marco teórico avalado por la evidencia científica, para que a través de su conocimiento y de entender cómo llevarlo a la práctica, los docentes de Educación Física dispongan de recursos para abordar tal desafío. Concretamente, para tratar de arrojar luz a la necesidad que pueden tener algunos docentes de

Educación Física de influir positivamente en que los niños 
y adolescentes en edad escolar realicen actividad física en su tiempo libre, sugerimos tomar como referencia uno de los marcos teóricos más relevantes identificados en la literatura científica, el modelo trans-contextual de la motivación (MTC). Este modelo proporciona una base teórica sólida que explica la conexión entre el contexto educativo y de ocio, identificando los procesos motivacionales que suceden en Educación Física y que serían transferidos al contexto de ocio a fin de predecir patrones de actividad física (Hagger y Chatzisarantis, 2007, 2016; Hagger et al., 2003).

Llegados a este punto y recapitulando algunas ideas clave expuestas, primero, es una realidad que a día de hoy el profesorado se encuentra con dificultades para influir en las conductas de actividad física del alumnado a través de sus intervenciones, lo que seguramente sea una de las múltiples razones que expliquen por qué no adoptan estilos de vida saludables (Moreno et al., 2019). Segundo, el profesorado de Educación Física tendría que liderar, como así lo establece la legislación educativa, la promoción de la práctica de actividad física del alumnado en su tiempo de ocio. Una vez identificadas tales cuestiones, el siguiente paso sería plantear una posible solución que tenga cabida dentro del currículo educativo para Educación Física y que contribuya a ayudar al profesorado en su devenir diario. El conocimiento científico nos ofrece posibles soluciones en relación a la interven- ción docente para motivar hacia la práctica de actividad física. Concretamente, en este capítulo daremos a conocer el MTC.

Como se ha presentado en el Capítulo 1.1. de este libro, la teoría de la autodeterminación (Ryan y Deci, 2017) es un marco teórico de referencia para entender los procesos motivacionales que se dan en Educación Física o, dicho de una manera más sencilla, una teoría que puede ser una aliada del profesorado a la hora de poner en práctica estrategias motivacionales con el fin de obtener consecuencias positivas en las clases de Educación Física ( $p$. ej., aumentar los niveles de actividad física en clase, la satisfacción o los comportamientos prosociales). En este sentido, si la teoría de la autodeterminación nos permite aplicar estrategias motivacionales para el contexto de Educación Física, el modelo que nos ocupa en este capítulo, el MTC, se caracteriza principalmente por su utilidad para que el profesorado saque partido al tiempo que pasa con el alumnado, con el objetivo de alcanzar uno de los fines de la Educación Física comentados previamente: conseguir que a través del contexto educativo (Educación Física) se transfieran conocimientos, habilidades y actitudes para que el alumnado adopte un estilo de vida activo y saludable fuera de dicho contexto. Así, el MTC se postula como un marco importante teniendo en cuenta el continuo descenso general de práctica de actividad física entre los escolares (Guthold et al., 2020). 


\subsection{El modelo trans-contextual de la motivación: un marco multi-teórico}

Los postulados del MTC surgieron después de que los profesores Martin S. Hagger y Nikos L. D. Chatzisarantis se plantearan la siguiente pregunta: ¿El apoyo que el profesorado de Educación Física puede ofrecer para motivar a sus estudiantes se transfiere de algún modo en la motivación de su alumnado hacia la actividad física fuera de la escuela? Es decir, el MTC trata de explicar el proceso a través del cual la motivación en el ámbito educativo (Educación Física) se puede transferir a contextos extraescolares en los que el alumnado puede poner en práctica lo aprendido en Educación Física a la hora de realizar actividad física individualmente, con sus amigos o familiares, entre otras opciones. Esta inquietud que animó a Hagger y Chatzisarantis a desarrollar teóricamente el MTC, es la que nos ha llevado a disponer en la actualidad de multitud de evidencias científicas que se traducen en estrategias de intervención para su puesta en práctica en Educación Física.

EI MTC es un marco multi-teórico, es decir, un modelo que se compone de varias teorías científicas, que fue desarrollado para tratar de identificar los factores psicológicos clave que permitan desarrollar intervenciones eficaces de promoción de la actividad física durante el tiempo de ocio de niños y adolescentes en edad escolar. En otras palabras, este modelo es el resultado de fusionar varias teorías complementarias con el propósito de ser de utilidad para que el profesorado aplique estrategias didácticas de intervención durante sus clases de Educación Física, con el objetivo de que lo trabajado durante las clases tenga impacto o transferencia en el día a día del alumnado, especialmente respecto a la práctica de actividad física, que ha sido la consecuencia conductual más investigada en el MTC. Por tanto, es un modelo que nace con el propósito de dar herramientas para optimizar nuestra intervención en Educación Física en la tarea compleja de promocionar la actividad física en el tiempo de ocio.

Antes de profundizar en las teorías que lo complementan, vamos a poner un ejemplo del fin que perseguiría un proyecto de Educación Física sustentado en el MTC. Programamos un proyecto para $4^{\circ}$ de Educación Secundaria que tiene como objetivo que el alumnado conozca e identifique activos de salud (cualquier factor o recurso que fortalece la habilidad de los estudiantes para mantener y mejorar su salud y bienestar), evalúe su viabilidad y tome decisiones acerca de la práctica de actividad física, desarrollando como producto sus propios programas de actividad física relacionados con la salud con el fin de que tengan transferencia al contexto de ocio (ver apartado "Para saber más...", proyecto EVA). Si queremos multiplicar las posibilidades de éxito para que finalmente el alumnado termine poniendo en práctica lo aprendido en Educación Física en su día a día, tomar como referencia la secuencia del MTC, como parte del sustento metodológico del proyecto, podría ser una opción muy válida de cara a motivar a nuestro alumnado en las clases y en su tiempo de ocio para que realice actividad física, especialmente cuando finalice nuestra intervención docente.

Concretamente, el MTC (ver Figura 1) está compuesto por tres teorías/modelos. Siguiendo el orden de aparición de las mismas desde la parte izquierda a la parte derecha del modelo, se identifica en primer lugar la teoría de la autodeterminación (Ryan y Deci, 2017), 
en segundo lugar, el modelo jerárquico de la motivación intrínseca y extrínseca (MJMIE; Vallerand, 2007) y, en último lugar, antes de predecir el comportamiento (p. ej., actividad física), la teoría del comportamiento planeado (TCP; Ajzen, 1991, 2012).

Sin profundizar en la teoría de la autodeterminación, ya que ha sido desarrollada en el Capítulo 1.1., vamos a explicar cada una de estas teorías tomando como referencia a nuestro alumnado de Educación Física y, más adelante, explicaremos la secuencia completa del MTC integrando los tres marcos teóricos que lo forman. En primer lugar, la teoría de la autodeterminación es una teoría organísmica (teoría que trata de explicar el crecimiento y desarrollo inherente a cada individuo) que aplicada al contexto educativo pone el foco en conocer cómo los agentes sociales significativos, especialmente el docente de Educación Física, las familias o los iguales, influyen positiva o negativamente (apoyo a las necesidades o estilo controlador) en que el alumnado perciba satisfechas o frustradas sus necesidades psicológicas básicas de autonomía, competencia, relaciones sociales y novedad. De manera general, si nuestros estudiantes vivencian un cúmulo de situaciones en Educación Física que satisfacen sus necesidades psicológicas básicas en este contexto, estas contribuirán a que experimenten una motivación autodeterminada (motivación intrínseca, regulación integrada y regulación identificada), mientras que si perciben que sus necesidades son frustradas experimentarán una motivación no autodeterminada (regulación introyectada y regulación externa) y desmotivación. Continuando con la secuencia motivacional de la teoría de la autodeterminación, los últimos estudios que resumen la evidencia científica disponible hasta la fecha (Vasconcellos et al., 2020; White et al., 2021) han revelado cómo la motivación autodeterminada conduciría a nuestros estudiantes hacia consecuencias adaptativas a nivel cognitivo, afectivo y/o conductual (p. ej., mayores niveles de actividad física en Educación Física, disfrute, aumento del rendimiento académico o conductas prosociales) y, sin embargo, la motivación no autodeterminada y la desmotivación les llevaría a experimentar consecuencias desadaptativas (p. ej., menores niveles de actividad física en Educación Física, aburrimiento o conductas antisociales). Haciendo un inciso, recordamos que las estrategias didácticas de intervención de la teoría de la autodeterminación para Educación Física referentes a las conductas motivacionales docentes pueden consultarse en el Capítulo 2.3 del libro. También, en el Capítulo 2.4. se presentan las estrategias motivacionales para dar apoyo a la novedad en Educación Física, candidata a necesidad psicológica básica de la teoría de la autodeterminación.

Por su parte, el MJMIE fue desarrollado por Robert J. Vallerand a partir de la secuencia motivacional de la teoría de la autodeterminación con el objetivo de explicar cómo la motivación que se experimenta en la vida en general, en un contexto determinado o en una situación concreta, están interrelacionadas. En concreto, a través del MJMIE se explica cómo existen tres niveles de motivación que se dan a nivel global (p. ej., motivación general que nuestro alumnado tiene hacia adoptar un estilo de vida saludable), contextual (p. ej., motivación específica que tiene nuestro alumnado hacia las clases de Educación Física o hacia la actividad física de ocio) y situacional (p. ej., motivación que se está experimentando en una actividad concreta durante una sesión de Educación Física). De este modo, la aportación del MJMIE viene a explicar cómo el hecho de que un estudiante tenga experiencias positivas durante las actividades de una sesión de Educación Física de voleibol (motivación situacional), contribuiría a que desarrolle actitudes positivas hacia la Educación Física (motivación 
contextual) que se transfieran a la práctica de este deporte en su tiempo libre (motivación contextual), pudiendo contribuir a un estilo de vida saludable (motivación global). Si ponemos el foco únicamente en el MJMIE y su principal aportación a efectos prácticos, nuestra labor será tratar de influir positivamente para que la motivación autodeterminada se transfiera del contexto de Educación Física (motivación situacional y contextual) al contexto de ocio. En resumen, la parte del MJMIE que nos interesa a la hora de entender los procesos motivacionales del MTC, es la que explica que la motivación autodeterminada que se da en Educación Física se puede transferir a situaciones similares del día a día de nuestro alumnado, de modo que a la hora de involucrarse en actividades físicas u otras conductas saludables esté motivado por el placer que le generan, porque valora los beneficios que se obtienen y/o porque forman parte de su estilo de vida (motivación autodeterminada).

Como hemos explicado, debido al contacto directo que tenemos a través de las clases de Educación Física con nuestro alumnado, es razonable que nuestros esfuerzos vayan dirigidos principalmente a generar motivación autodeterminada en Educación Física. No obstante, respaldados por los postulados del MJMIE, para que el alumnado también desarrolle este tipo de motivación al realizar conductas similares en su tiempo libre, podemos diseñar situaciones de aprendizaje para que ambos contextos se retroalimenten. En este caso, tendríamos que pensar en acciones que vayan dirigidas directamente a promover la motivación autodeterminada durante el tiempo de ocio del estudiantado, así como esas competencias clave que estamos trabajando en Educación Física, ya sea a nivel cognitivo, afectivo o conductual. Por ejemplo, si planteamos un proyecto para $6^{\circ}$ de primaria $01^{\circ}$ de secundaria que ponga el foco en aprender a mantener un ritmo de carrera constante (ver apartado "Para saber más...", CALADU-CAPAS 2.0), el profesorado puede proponer que la culminación de ese proyecto consista en que el alumnado y sus familias o amigos participen en una carrera popular fuera del horario escolar. De este modo, además de aplicar las estrategias motivacionales en Educación Física expuestas en este libro para la teoría de la autodeterminación, sumaríamos una experiencia más relacionada con la motivación autodeterminada hacia la actividad física en el tiempo de ocio, que según el MJMIE también podría contribuir a que el alumnado tuviera una mejor predisposición hacia la Educación Física.

Respecto al tercer marco teórico, la TCP trata de identificar cómo a través de los procesos cognitivos o pensamientos se puede dar la intención de actuar y, consecuentemente, el propio comportamiento (p. ej., actividad física). Es decir, ¿qué tipo de pensamiento o creencias son las que conducen al alumnado a adoptar un determinado comportamiento? La TCP tiene como objetivo identificar las creencias del alumnado basadas en las actitudes hacia el comportamiento (¿qué pienso yo?), normas subjetivas (¿qué piensan otros?) y control conductual percibido (¿puedo hacerlo?) que conducen a la intención, es decir, el deseo o predisposición de realizar una conducta, que se materializaría en realizar el comportamiento (p. ej., actividad física). La intención representa la medida en la que nuestro alumnado está motivado para realizar un comportamiento futuro. Según la TCP, la intención de hacer algo (p. ej., aprender a bailar) sería el predictor más próximo de la conducta (bailar). No obstante, ya sabemos por nuestras propias experiencias personales que una cosa es tener la intención de hacer algo, y otra bien distinta es llevarla a cabo. Siendo esto así, lo cierto es que, como ha evidenciado la TCP, el hecho de tener la intención de adoptar un comportamiento aumenta las probabilidades de materializar la conducta. Por tanto, poner 
en práctica estrategias didácticas para motivar a nuestro alumnado para que tenga la intención de realizar actividad física en su tiempo de ocio, parece una buena forma de lograr esta última meta, que realmente se adopte dicha conducta.

Para que nuestros estudiantes experimenten la intención de ser físicamente activos, antes deben tener creencias basadas en tres factores; la evaluación que realizan de los beneficios y perjuicios que pueden obtener de la conducta (actitudes), la percepción de que sus agentes significativos quieren que adopten la conducta (normas subjetivas) y la capacidad que el alumnado percibe que tiene para llevar a cabo la conducta (control). Por tanto, las creencias más o menos favorables que nuestro alumnado tenga hacia la conducta que queramos promover fortalecerán o debilitarán la intención y posibilidades de que el comportamiento se adopte. Como podemos deducir, a través de las creencias asociadas a la actitud, normas subjetivas y control conductual percibido, la TCP nos ofrece una pista más sobre cómo favorecer la intención y práctica de actividad física autónoma en el ocio.

A continuación, siguiendo al creador de la TCP (Ajzen, 2020), vamos a profundizar en estos tres factores o determinantes de la intención y del comportamiento; las actitudes, las normas subjetivas y el control:

- La actitud representa el grado en el que la realización de un comportamiento se valora como positivo o negativo. La evaluación positiva o negativa que nuestros estudiantes pueden hacer respecto a una conducta estaría determinada por todas las creencias que relacionan la conducta con diversas consecuencias y experiencias esperadas. Por ejemplo, el hecho de que un/a adolescente crea que jugar al fútbol en su tiempo de ocio (comportamiento que cree que le resulta interesante) le conducirá a vivenciar experiencias positivas como hacer nuevas amistades o estar en forma (consecuencias esperadas o expectativas), despertará su intención de practicar ese deporte y le llevará a su práctica. En síntesis, podríamos decir que la actitud haría referencia a las creencias acerca de las consecuencias (positivas o no) que obtendré de realizar la conducta.

- Las normas subjetivas, entendidas como la influencia social percibida para realizar un comportamiento, estarían determinadas por las creencias del alumnado respecto a que un referente para él (p. ej., docente de Educación Física, familiar o amistades) apruebe o no la realización de una conducta (p. ej., "mis padres y/o amigos creen que yo debería hacer actividad física"), unido a la creencia de que ese agente social importante realice esa conducta (p. ej., "como mis padres y/o amigos hace actividad física, yo siento que tengo que hacerlo también"). Es decir, ambos tipos de creencias reflejan la percepción del alumnado sobre la opinión que les manifiestan los agentes sociales de referencia para ellos respecto a que realicen una conducta.

- El factor control conductual percibido se refiere a las percepciones del alumnado sobre su capacidad para realizar una conducta. Según la TCP, el control percibido está determinado por las creencias que tienen nuestros estudiantes acerca de los factores que entienden que son facilitadores o barreras para realizar la conducta. Así, cuando desde la perspectiva de la TCP se habla del factor "control", entre otras cosas, se hace referencia a las habilidades y destrezas requeridas, a la disponibilidad de tiempo para realizar la conducta, recursos económicos, o a la necesidad de cooperación de otras personas para materializar la conducta, que pueden ser entendidos como factores que facilitan o dificultan la conducta. Por ejemplo, en Educación Física una estudiante ha 
experimentado una unidad de hockey patines y se percibe competente y quiere formar parte de un equipo federado, pero para ir a entrenar depende de sus padres porque la instalación deportiva está lejos de casa y, sin embargo, ellos no están dispuestos a llevarle a los entrenamientos. En este caso, su percepción de competencia será un facilitador y la inacción de sus padres una barrera. Por tanto, diremos que las creencias sobre la capacidad (o no) de realizar una conducta en el futuro representan el control conductual percibido.

En definitiva, los postulados de la TCP sugieren que una actitud favorable y percibir que los demás significativos quieren que adoptemos esa conducta y/o la creencia de que ellos también la adoptan, proporciona la motivación necesaria para llevarla a cabo. Pero, a través de la TCP, también sabemos que la intención concreta de hacerlo solamente se produce cuando el control percibido sobre la conducta es lo suficientemente fuerte. Además, parece que el control percibido puede influir directamente, además de sobre la intención, sobre la conducta. Por este motivo, sería recomendable que durante nuestra intervención docente le dedicáramos especial atención a ofrecer facilitadores y minimizar barreras respecto a la/s conducta/s que queremos fomentar. Se trataría de enseñar u ofrecer recursos para la práctica autónoma de actividad física que dependan principalmente de las acciones o recursos que los estudiantes puedan movilizar por sí mismos. Por ejemplo, si estamos pensando en aplicar una unidad en la que se den acciones motrices de oposición a través de actividades de cancha dividida con implemen- to (p. ej., bádminton, mini-tenis, pádel o tenis de mesa), una forma de ofrecer facilitadores sería valorar previamente qué instalaciones deportivas públicas hay próximas al centro que permitan poner en práctica lo que vamos trabajar en Educación Física durante el tiempo libre, mientras que una manera de minimizar barreras sería hacer un convenio que facilite la inscripción para practicar ese deporte (p. ej., se aplique algún descuento).

Por último, según la TCP, los tres factores (actitud, normas subjetivas y control conductual percibido) predecirán positivamente la intención (representación cognitiva de los planes o proyectos conductuales del individuo) y esta a su vez el comportamiento (p. ej., actividad física). Además, a la hora de influir en la intención y la conducta de nuestro alumnado, la evidencia nos dice que también sería fundamental conocer las experiencias pasadas relacionadas con el comportamiento que queremos promover (p. ej., experiencias previas positivas que un estudiante ha vivenciado aprendiendo a bailar), pues su conocimiento puede ayudar a entender las razones por las que ese comportamiento se da (o no) o podría darse. Es decir, el comportamiento pasado sería un predictor positivo adicional o "extra", junto a la actitud, normas subjetivas y control percibido del comportamiento. Un momento propicio para conocer las experiencias previas de nuestro alumnado podría ser al inicio de la unidad didáctica como parte de la evaluación diagnóstica, de modo que nos sirva para realizar los ajustes necesarios a fin de que la unidad que queremos aplicar aumente sus posibilidades de éxito. 


\section{3. ¿Cómo se integran las teorías? Explicación de cómo se trasfiere la motivación a través del modelo trans-contextual}

Una vez descritas las tres teorías/modelos que componen el MTC (ver Figura 1), vamos a realizar una explicación integrando todos los constructos o variables que contribuyen a entender los procesos a través de los cuales la motivación se "traslada" de las clases de Educación Física al contexto de ocio.

Iniciando la explicación desde el lado izquierdo de la Figura 1, en el que se encuentran los factores de la teoría de la autodeterminación, el MTC plantea que percibir apoyo a las necesidades psicológicas básicas (apoyo a la autonomía, competencia, relaciones sociales y novedad) por parte del docente de Educación Física, contribuirá a que el alumnado satisfaga sus necesidades psicológicas básicas en las clases de Educación Física. Siguiendo la secuencia del modelo y, aún en la teoría de la autodeterminación, tener satisfechas las necesidades psicológicas básicas en Educación Física contribuirá a experimentar una motivación autodeterminada en Educación Física. Estas predicciones forman la primera premisa del MTC: aplicar estrategias didácticas para dar apoyo a las necesidades psicológicas básicas del alumnado contribuye a generar motivación autodeterminada en Educación Física.

En este punto, es cuando entra en juego el MJMIE, de modo que el hecho de experimentar una motivación autodeterminada en Educación Física hará que se trasfiera esta misma motivación autodeterminada al tiempo de ocio, por ejemplo, para realizar actividad física en el tiempo libre. Si recordamos el MJMIE, sabemos que la motivación de nuestros estudiantes en un contexto puede influir en otro.

\begin{abstract}
Pues bien, el MTC explica cómo en este caso la motivación que se experimenta en Educación Física influye en otros contextos similares de actividad física como el tiempo de ocio. En esta transferencia de motivación de un contexto a otro, se estarían dando los denominados "efectos trans-contextuales", conectando la motivación autodeterminada en Educación Física con la motivación autodeterminada en el tiempo de ocio. En consecuencia, todo esto constituye la segunda premisa del MTC: es clave promover la mayor cantidad de experiencias positivas en Educación Física para generar una motivación autodeterminada que termine transfiriéndose al tiempo de ocio del alumnado, con el fin de que se realice actividad física porque se disfruta, porque se valoran los beneficios de la misma y porque forma parte del estilo de vida.
\end{abstract}

La teoría de la autodeterminación ha identificado cómo, además de los agentes sociales que pueden influir desde el contexto educativo (p. ej., docentes de Educación Física), existen otros agentes sociales significativos como los padres y los iguales que, a través del contexto de ocio, también tienen una gran influencia a la hora de que se desencadenen los procesos motivacionales. Por tanto, a partir de esta evidencia previa (González-Cutre, Sicilia et al., 2014; Hagger et al., 2009; Kalajas-Tilga et al., en prensa), en el MTC se incluye también el apoyo a las necesidades psicológicas básicas de los padres e iguales en el tiempo de ocio como predictores de la satisfacción de las necesidades en ese mismo contexto, que a su vez predicen la motivación autodeterminada en el tiempo de ocio. Además, estos 
dos agentes sociales también predicen la motivación autodeterminada en el tiempo de ocio y, de forma más específica, los estudios han revelado cómo el apoyo a la autonomía de los padres predice directamente las actitudes, normas subjetivas y percepción de control conductual en el tiempo de ocio (GonzálezCutre, Sicilia et al., 2014).

Por último, en la parte derecha de la Figura 1 que representa el MTC, se produce la interacción entre la teoría de la autodeterminación y la TCP. En concreto, la integración de ambas teorías se da de modo que la motivación autodeterminada que se experimenta en el tiempo de ocio hacia la práctica de actividad física va a influir en que el alumnado experimente una actitud positiva hacia la conducta, perciba que los agentes sociales significativos le apoyan para adoptar esa conducta (normas subjetivas) y que tiene control para realizar la conducta en su tiempo de ocio. Si estos factores de la TCP tienen una connotación positiva, se desencadenaría la intención y seguidamente la realización de la conducta. Consecuentemente, esto constituye la tercera premisa del MTC: la conexión entre la motivación autodeterminada en el tiempo de ocio y la conducta está determinada por las actitudes, normas subjetivas, control conductual percibido y la intención, que conforman la TCP. 


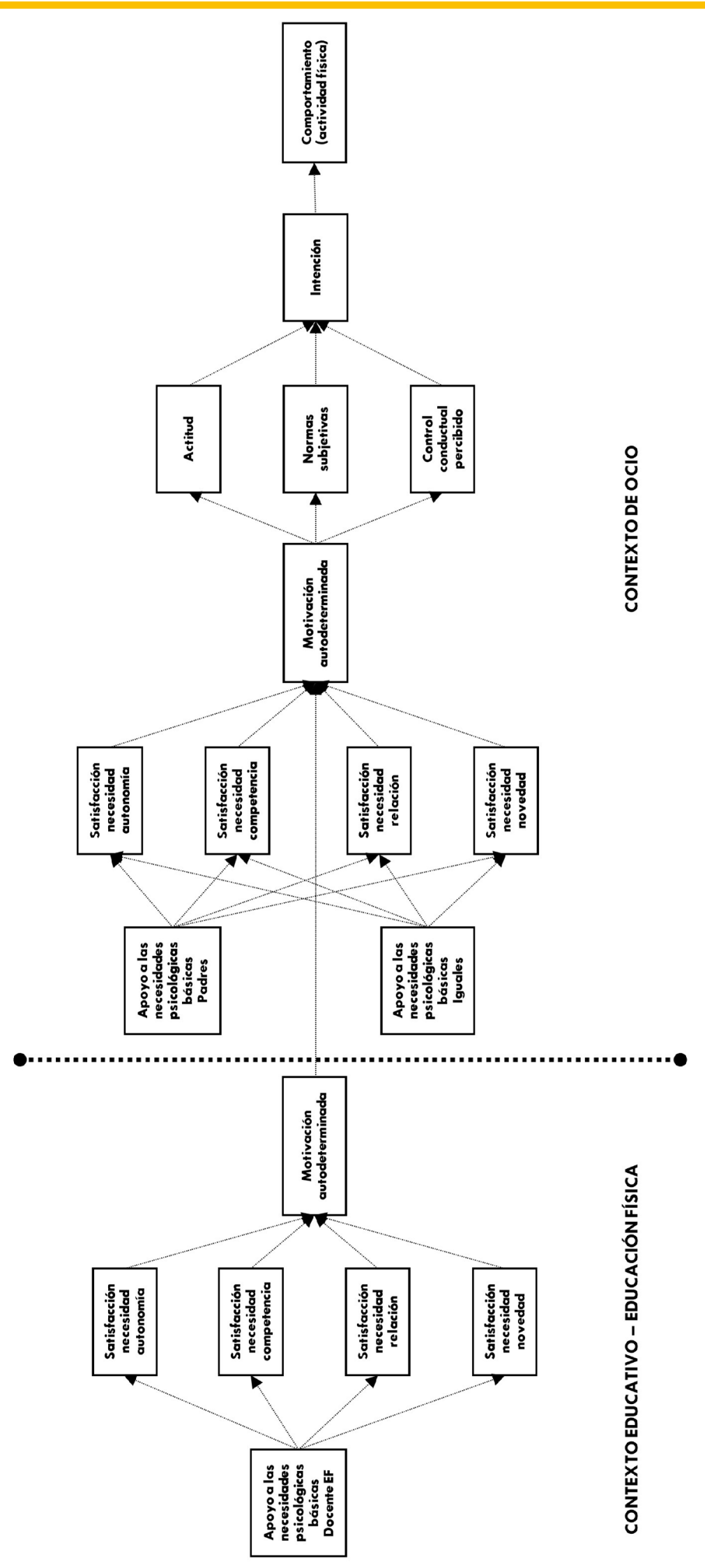

Figura 1. Modelo trans-Contextual de La motivación. 
Ahora que ya conocemos las tres teorías/modelos por separado y acabamos de ver cómo se integran para dar lugar al MTC, podríamos deducir que la razón por la que el MTC fue diseñado como un marco multi-teórico surge de la necesidad de que las teorías "solucionen" las limitaciones que la literatura científica ha identificado para cada una de ellas. Por tanto, podría decirse que cada teoría/modelo aporta sus fortalezas y entre ellas minimizan las debilidades que podrían ofrecer al actuar de forma aislada. Por ejemplo, un punto fuerte de la teoría de la autodeterminación es conocer cómo los factores sociales influyen en la motivación (antecedentes de la motivación) y una de sus debilidades radica en que desde que se experimenta la motivación hasta que se produce la conducta se dan una serie de procesos que no son objeto de estudio desde este marco teórico. Esta debilidad de la teoría de la autodeterminación la cubre la TCP con una de sus fortalezas, que radica en profundizar en las creencias o factores que anteceden la conducta. Sin embargo, la TCP está limitada a la hora de explicar qué procesos previos se dan para que las personas generen sus motivaciones, creencias e intenciones que les llevan a actuar de una determinada manera ( $p$. ej., realizar o no actividad física). Pero, aunque la teoría de la autodeterminación y la TCP son el pilar fundamental sobre el que se sustenta el MTC, el MJMIE es el nexo imprescindible para que se dé la conexión entre los procesos motivacionales que suceden en diferentes contextos de la vida de nuestros estudiantes.

Sin ánimo de extendernos o presentar con excesivo detalle los estudios científicos, sí que nos gustaría mostrar brevemente algunos de los últimos trabajos que se han Ilevado a cabo sobre el MTC, para poner de manifiesto la universalidad del modelo y la evidencia que lo sustenta, con el fin de que el profesorado conozca algunos matices interesantes que se han investigado y que pueden despertar su interés a la hora de aplicar estrategias didácticas de intervención en Educación Física.

Por un lado, el MTC se ha testado tanto a nivel internacional (p. ej., Hutmacher et al., 2020; Kalajas-Tilga et al., en prensa; Mieziene et al., 2021; Pasi et al., 2021; Soos et al., 2019; YliPiipari et al., 2018) como en el contexto español (p. ej, Fernández-Barrionuevo et al., 2021; González-Cutre, Sicilia et al., 2014). Además de confirmar la secuencia teórica por la cual se dan los procesos motivacionales en el MTC, también se han llevado a cabo estudios que han apoyado los postulados del modelo por medio de intervenciones en Educación Física tanto a nivel internacional (p. ej., en la etapa de primaria, Mavropoulou et al., 2019; y en la etapa de secundaria, Koka et al., 2020; Lee et al., 2021; Polet et al., 2019, 2020, 2021; Schneider et al., 2020) como a nivel nacional (p. ej., en la etapa de primaria, González-Cutre, Ferriz, Beltrán-Carrillo, Andrés-Fabra et al., 2014).

Por otro lado, los últimos estudios sobre el MTC han revelado interesantes hallazgos que pueden traducirse en orientaciones didácticas a la hora de poner en práctica estrategias motivacionales que activen la secuencia del MTC. Al igual que ha sucedido con la teoría de la autodeterminación, la mayoría de la evidencia del MTC nos ha permitido conocer "el lado claro o bueno del modelo" o lo que la evidencia "recomienda hacer". En este sentido, los últimos estudios del MTC también han revelado que si nuestros estudiantes perciben que guiamos nuestra intervención docente por el camino del "lado oscuro o negativo" (adoptar un estilo controlador $\rightarrow$ frustrar las necesidades psicológicas básicas $\rightarrow$ motivación controlada) no contribuiremos a que realicen actividad física en su tiempo de ocio (KalajasTilga et al., en prensa; Koka et al., 2020). Un estudio reciente aporta evidencia en este sentido, alertándonos de que el profesorado 
de Educación Física tiene que llevar especial atención para no frustrar la necesidad de competencia entre su alumnado, ya que esta es un predictor negativo directo de la actividad física en el ocio (Koka et al., 2020). Esto que a priori parece evidente, creemos que es digno de reflexión, pues tan importante es saber qué se recomienda hacer y sus consecuencias positivas, como tener presente qué comportamientos docentes debo evitar para no dar lugar a consecuencias negativas (sobre esta cuestión se profundizará en el Capítulo 2.3.).

Además, el MTC se ha aplicado tradicionalmente con el fin de predecir la práctica de actividad física en el tiempo de ocio a través del desarrollo de estrategias motivacionales en Educación Física. Sin embargo, hay dos estudios que difieren del resto y que han resultado ser eficaces en Educación Física. Por un lado, el MTC se ha vinculado a una unidad didáctica en la que se trabajaron acciones motrices en situaciones de índole artística o de expresión (Mavropoulou et al., 2019) y, por otro lado, se ha vinculado con el trabajo del cuidado de la salud a la hora de prevenir lesiones cuando se practica actividad física o deporte durante el ocio (p. ej., protocolos de calentamiento o vuelta a la calma) (Lee et al., 2021). El primer estudio respalda la importancia de poner en práctica una unidad en la que se experimenten diferentes formas libres de baile como una estrategia de apoyo a la autonomía (p. ej., expresión corporal, danza, hip-hop, zumba o coreografías libres) para predecir la actividad física en el ocio, lo que nos anima a plantearnos otras alternativas para promocionar la actividad física en el ocio que van más allá de las clásicas estrategias. La última aportación, por su parte, muestra la utilidad de aplicar el MTC para enseñar aspectos relacionados con la preparación física por medio de acciones motrices individuales, siempre desde una perspectiva educativa. 


\section{2.- CONCLUSIONES}

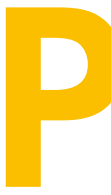

rimero, la evidencia científica da soporte a los tres grandes postulados del MTC; (1) el apoyo a las necesidades psicológicas básicas del alumnado por parte del docente de Educación Física contribuye a predecir la motivación autodeterminada en Educación Física, (2) la motivación autodeterminada en Educación Física predice positivamente la motivación autodeterminada en el tiempo de ocio, y (3) las actitudes, normas subjetivas, control conductual percibido y la intención son determinantes para explicar el paso de la motivación en el tiempo de ocio a la conducta.

Segundo, a la hora de que el profesorado trate de influir positivamente en los procesos motivacionales contemplados por el MTC, lo recomendable sería aplicar estrategias didácticas o motivacionales dirigidas a los factores que sabemos que activan la secuencia. Es decir, si aplicamos estrategias didácticas para dar apoyo a la autonomía, competencia, relaciones sociales y novedad, se dará la satisfacción de las necesidades psicológicas básicas, y esta a su vez "activará" la motivación autodeterminada en Educación Física, que se transferirá al contexto de ocio, influyendo positivamente en que niños y adolescentes desarrollen creencias relacionadas con una actitud favorable, normas subjetivas o percepción de control, que desencadenarán la intención y realización de actividad física. Por tanto, aunque a lo largo de este capítulo y en un ejemplo propuesto de proyecto para aplicar el MTC (ver apartado "Para saber más...", proyecto ¡Salto, salto y salto de Educación Física al circo de mi ciudad!) se ofrezcan estrategias específicas para otros constructos del modelo, como las variables de la TCP, la recomendación sería que el profesorado priorice la aplicación de estrategias motivacionales o didácticas dirigidas a dar apoyo a las necesidades psicológicas básicas de la teoría de la autodeterminación, pues la evidencia avala que de esa forma se desencadenará toda la secuencia del MTC.

Tercero, según el MTC sabemos que para reforzar nuestra intervención desde el contexto educativo (Educación Física), debemos contar con aliados (p. ej., padres e iguales) que apoyen la satisfacción de las necesidades psicológicas básicas, ya que resulta fundamental para que el estudiantado realice actividad física en su tiempo de ocio. En este sentido, se anima al profesorado de Educación Física a que involucren especialmente a las familias de forma activa en los proyectos o iniciativas que se llevan a cabo desde sus escuelas.

Cuarto, a la hora poner en práctica estrategias didácticas o motivacionales con el fin de que nuestro alumnado experimente creencias positivas relacionadas con las normas subjetivas, tenemos que ir con cautela. Debemos tratar de no excedernos y no generar confusión entre las familias, de modo que la consecuencia no sea que el alumnado reciba mensajes que le alienten a practicar actividad física percibiendo que debe actuar bajo la 
presión de sus padres o iguales, o motivado por satisfacerles a ellos y no por su propia voluntad. Por ejemplo, una cosa es que nuestros estudiantes perciban por parte de sus padres que resulta positivo realizar actividad física y que sus padres son consecuentes y predican con el ejemplo, y otra cosa bien distinta es que los escolares perciban la orden u obligación por parte de sus padres para que lo hagan ( $p$. ej., "mis padres y/o amigos creen que debo realizar actividad física porque es bueno para mi salud y son un buen ejemplo ya que ellos también lo hacen" vs. "debo realizar actividad física de la manera que quieren mis padres y tengo la sensación de que lo tengo que hacer porque prácticamente ellos me lo imponen cuando hablamos").

Quinto, aún son necesarios más estudios para conocer el papel que juega cada uno de los apoyos a las necesidades psicológicas básicas dentro del MTC, incluyendo el apoyo a la novedad, tanto en lo referente al docente de Educación Física como a otros agentes significativos en el tiempo de ocio. Además, para reforzar el valor del área de Educación Física frente al resto de la comunidad educativa, sería interesante que en un futuro pudiéramos conocer el papel que ocupan, dentro de la secuencia del MTC, otros agentes sociales importantes para nuestros estudiantes como los tutores (especialmente en primaria) o resto de profesorado (pensando en la puesta en práctica de proyectos interdisciplinares). Esto sería clave para evidenciar la importancia de sumar aliados a la difícil labor del profesorado de Educación Física de promover la actividad física en el tiempo de ocio. Bajo el marco de la teoría de la autodeterminación ya se apunta a que el rol de los tutores (Ferriz et al., 2020) junto con el del docente de Educación Física, padres e iguales, parecen claves para predecir la actividad física en el tiempo libre (Sevil et al., 2018), por lo que podríamos esperar que estos agentes sociales también tuvieran un efecto positivo al ser incluidos como parte del MTC. Por tanto, animamos al profesorado a que sumen la mayor cantidad de agentes sociales posibles "a esta causa compartida".

Para terminar, una nueva aportación de interés estaría relacionada con analizar el efecto de intervenciones basadas en el MTC vinculadas a diferentes bloques de contenidos de Educación Física (p. ej., actividades artísticoexpresivas o actividad física en el medio natural), a los modelos pedagógicos consolidados (p. ej., aprendizaje cooperativo, modelo de educación deportiva o enseñanza comprensiva del deporte), o a la promoción de consecuencias conductuales que vayan más allá de la promoción de la actividad física en el ocio (p. ej., dieta saludable, reducción del comportamiento sedentario, mejora de la calidad del sueño o no consumo de sustancias nocivas). De este modo, generar nueva evidencia a partir de la práctica, contribuiría a expandir el MTC y a acercar el modelo a la realidad que hoy en día tenemos en los centros educativos y en concreto en el área de Educación Física. 


\section{3.- PARA SABER MÁS...}

- Para ampliar información acerca de la conceptualización y aplicación del MTC para la promoción de la actividad física y otras conductas saludables en niños y adolescentes, consultar el capítulo de libro de GonzálezCutre, Ferriz, y Beltrán-Carrillo (2014): https:// sede.educacion.gob.es/publiventa/descarga. action?f_codigo_agc=16802_19

- Cuenta de twitter de uno de los creadores del MTC, el profesor Martin S. Hagger (@martinhagger), y páginas web de sus grupos de investigación (https://www.fidiproimpact.com/; https://sites.ucmerced.edu/martinhagger/ home).

- Para conocer más sobre la TCP, consultar la web del profesor Icek Ajzen, creador de la teoría: https://people.umass.edu/aizen/index.html
- Para conocer estrategias motivacionales del MTC, consultar el libro de Ferriz et al. (2018) y el artículo de divulgación científica de Ferriz y González-Cutre (2019) de acceso gratuito a través de: https://www.reefd.es/index.php/ reefd/article/view/872

- Para ver un ejemplo de la propuesta didáctica " $i S a l t o$, salto y salto de Educación Física al circo de mi ciudad!" y otros ejemplos más que pueden estar vinculados con el MTC, acceder aquí: https://drive.google.com/drive/folders/ 1z7vt98uEPezLgPOXzFGGNtUAS1IInxo5?usp= sharing 


\section{4.- REFERENCIAS BIBLIOGRÁFICAS}

Ajzen, I.(1991). The theory of planned behavior. Organizational Behavior and Human Decision Processes, 50(2), 179-211. https://doi.org/10.1016/0749-5978(91)90020-T

Ajzen, I. (2012). The theory of planned behavior. En P. A. M. Lange, A. W. Kruglanski, y E. T. Higgins (Eds.), Handbook of theories of social psychology (Vol. 1, pp. 438-459). Sage. http://dx.doi.org/10.4135/9781446249215.n22

Ajzen, I. (2020). The theory of planned behavior: Frequently asked questions. Human Behavior and Emerging Technologies, 2(4), 314-324. https://doi.org/10.1002/hbe2.195

Fernández-Barrionuevo, E., Baena-Extremera, A., y VilloriaPrieto, J. (2021). La Educación Física bilingüe como forma de motivar hacia el aprendizaje en una lengua extranjera. Estudio preliminar basado en el Modelo TransContextual. Retos, 42, 244-255. https://doi.org/10.47197/retos.v42i0.77382

Ferriz, R., y González-Cutre, D. (2019). Promoción de la actividad física a través del modelo trans-contextual de la motivación. Revista Española de Educación Física y Deportes, 427, 139-150.

Ferriz, R., González-Cutre, D., y Balaguer-Giménez, J. (2020). Agentes sociales de la comunidad educativa, satisfacción de novedad y actividad física. Cultura, Ciencia y Deporte, 15(46), 519-528.

http://dx.doi.org/10.12800/ccd.v15i46.1602

Ferriz, R., González-Cutre, D., Sicilia, A., y Beltrán-Carrillo, V. J. (2018). Estrategias motivacionales para la promoción de la actividad física en niños y adolescentes desde el contexto escolar. INDE.

González-Cutre, D., Ferriz, R., y Beltrán-Carrillo, V. J. (2014). El modelo trans-contextual de la motivación: Revisión conceptual y aplicación para la promoción de la actividad física y otros hábitos de vida saludables en niños y adolescentes. En E. Generelo, J. Zaragoza, y J. A. Julián (Eds.), Promoción de la actividad física en la infancia y la adolescencia: En el camino de soluciones reales (pp.47-63). Consejo Superior de Deportes.

González-Cutre, D., Ferriz, R., Beltrán-Carrillo, V. J., AndrésFabra, J. A., Montero-Carretero, C., Cervelló, E., y MorenoMurcia, J. A. (2014). Promotion of autonomy for participation in physical activity: A study based on the trans-contextual model of motivation. Educational Psychology, 34(3), 367384. https://doi.org/10.1080/01443410.2013.817325

González-Cutre, D., Sicilia, A., Beas-Jiménez, M., y Hagger, M. S. (2014). Broadening the trans-contextual model of motivation: A study with Spanish adolescents. Scandinavian Journal of Medicine \& Science in Sports, 24(4), e306e319. https://doi.org/10.1111/sms.12142

Guthold, R., Stevens, G. A., Riley, L. M., y Bull, F. C. (2020). Global trends in insufficient physical activity among adolescents: A pooled analysis of 298 population-based surveys with 1.6 million participants. The Lancet Child \& Adolescent Health, 4(1), 23-35. https://doi.org/10.1016/ s2352-4642(19)30323-2
Hagger, M. S., y Chatzisarantis, N. L. D. (2007). The transcontextual model of motivation. En M. S. Hagger y N. L. D. Chatzisarantis (Eds.), Intrinsic motivation and self-determination in exercise and sport (pp. 53-70). Human Kinetics.

Hagger, M. S., y Chatzisarantis, N. L. D. (2016). The transcontextual model of autonomous motivation in education: Conceptual and empirical issues and meta-analysis. Review of Educational Research, 86(2), 360-407. https://doi.org/10.3102/0034654315585005

Hagger, M. S., Chatzisarantis, N. L. D., Culverhouse, T., y Biddle, S. J. H. (2003). The processes by which perceived autonomy support in physical education promotes leisuretime physical activity intentions and behavior: A transcontextual model. Journal of Educational Psychology, 95(4), 784-795. https://doi.org/10.1037/00220663.95.4.784

Hagger, M., Chatzisarantis, N. L. D., Hein, V., Soós, I., Karsai, I., Lintunen, T., y Leemans, S. (2009). Teacher, peer, and parent autonomy support in physical education and leisuretime physical activity: a trans-contextual model of motivation in four nations. Psychology and Health, 24(6), 689-711. https://doi.org/10.1080/08870440801956192

Hutmacher, D., Eckelt, M., Bund, A., y Steffgen, G. (2020). Does motivation in physical education have an impact on out-of-school physical activity over time? A longitudinal approach. International Journal of Environmental Research and Public Health, 17(19), 7258. https://doi.org/10.3390/ijerph17197258

Kalajas-Tilga, H., Hein, V., Koka, A., Tilga, H., Raudsepp, L., y Hagger, M.S. (en prensa). Trans-contextual model predicting change in out-of-school physical activity: A one-year longitudinal study. European Physical Education Review.

Koka, A., Tilga, H., Kalajas-Tilga, H., Hein, V., y Raudsepp, L. (2020). Detrimental effect of perceived controlling behavior from physical education teachers on students' leisure-time physical activity intentions and behavior: An application of the trans-contextual model. International Journal of Environmental Research and Public Health, 17(16), 5939. https://doi.org/10.3390/ijerph17165939

Lee, A. S., Standage, M., Hagger, M. S., y Chan, D. K. (2021). Applying the trans-contextual model to promote sport injury prevention behaviors among secondary school students. Scandinavian Journal of Medicine \& Science in Sports, 31(9), 1840-1852. https://doi.org/10.1111/sms.14002

Mavropoulou, A., Barkoukis, V., Douka, S., Alexandris, K., y Hatzimanouil, D. (2019). The role of autonomy supportive activities on students' motivation and beliefs toward out-of-school activities. The Journal of Educational Research, 112(2), 223-233. https://doi.org/10.1080/00 220671.2018.1503580

Mieziene, B., Emeljanovas, A., Putriute, V., y Novak, D. (2021) The direct and indirect relationships within the extended trans-contextual model for moderate-to-vigorous physical activity. Frontiers in Pediatrics, 9, 265. https://doi.org/10.3389/fped.2021.666040 
Moreno, C., Ramos, P., Rivera, F., Sánchez-Queija, I., JiménezIglesias, A., García-Moya, I. Moreno-Maldonado, C., Paniagua, C., Villafuerte-Díaz, A., Ciria-Barreiro, E., Morgan, A., y Leal-López, E. (2019). La adolescencia en España: salud, bienestar, familia, vida académica y social. Resultados del estudio HBSC 2018. Ministerio de Sanidad, Consumo y Bienestar Social.

Pasi, H., Lintunen, T., Leskinen, E., y Hagger, M. S. (2021). Predicting school students' physical activity intentions in leisure-time and school recess contexts: Testing an integrated model based on self-determination theory and theory of planned behavior. PLOS ONE, 16(3), e0249019. https://doi.org/10.1371/journal.pone.0249019

Polet, J., Hassandra, M., Lintunen, T., Laukkanen, A., Hankonen, N., Hirvensalo, M., Tammelin, T., y Hagger, M. S. (2019). Using physical education to promote out-of school physical activity in lower secondary school students-a randomized controlled trial protocol. BMC Public Health 19(1), 157. https://doi.org/10.1186/s12889-019-6478-x

Polet, J., Lintunen, T., Schneider, J., y Hagger, M. S. (2020). Predicting change in middle school students' leisuretime physical activity participation: A prospective test of the trans-contextual model. Journal of Applied Social Psychology, 50(9), 512-523. https://doi.org/10.1111/jasp.12691

Polet, J. J., Schneider, J., Hassandra, M., Lintunen, T., Laukkanen, A., Hankonen, N., Hirvensalo, M., Tammelin, T., Hamilton, K., y Hagger, M. S. (2021). Predictors of school students' leisure-time physical activity: An extended trans-contextual model using Bayesian path analysis. Research Square. Publicación en línea avanzada. https://doi.org/10.21203/rs.3.rs-23231/v3

Ryan, R. M., y Deci, E. L. (2017). Self-determination theory: Basic psychological needs in motivation, development, and wellness. Guilford Publications. https://doi.org/10.1521/978.14625/28806

Schneider, J., Polet, J., Hassandra, M., Lintunen, T., Laukkanen, A., Hankonen, N., Hirvensalo, M., Tammelin, T. H., Törmäkangas, T., y Hagger, M. S. (2020). Testing a physical education-delivered autonomy supportive intervention to promote leisure-time physical activity in lower secondary school students: the PETALS trial. BMC Public Health, 2O(1), 1438.

https://doi.org/10.1186/s12889-020-09518-3
Sevil, J., García-González, L., Abós, A., Generelo, E., y Aibar, A. (2018). Which school community agents influence adolescents' motivational outcomes and physical activity? Are more autonomy-supportive relationships necessarily better? International Journal of Environmental Research and Public Health, 15(9), 1875. https://doi.org/10.3390/ijerph15091875

Soos, I., Dizmatsek, I., Ling, J., Ojelabi, A., Simonek, J., Boros-Balint, I., Szabo, P., Szabo, A., y Hamar, P. (2019). Perceived autonomy support and motivation in young people: A comparative investigation of physical education and leisure-time in four countries. Europe's Journal of Psychology, 15(3), 509-530. https://doi.org/10.5964/ejop.v15i3.1735

Vallerand, R. J. (2007). A hierarchical model of intrinsic and extrinsic motivation for sport and physical activity. En M. S. Hagger y N. L. D. Chatzisarantis (Eds.), Intrinsic motivation and self-determination in exercise and sport (pp. 255-279). Human Kinetics.

Vasconcellos, D., Parker, P. D., Hilland, T., Cinelli, R., Owen, K. B., Kapsal, N., Lee, J., Antczak, D., Ntoumanis, N., Ryan, R. M., y Lonsdale, C. (2020). Self-determination theory applied to physical education: A systematic review and metaanalysis. Journal of Educational Psychology, 112(7), 1444-1469. https://doi.org/10.1037/edu0000420

White, R. L., Bennie, A., Vasconcellos, D., Cinelli, R., Hilland, T., Owen, K. B., y Lonsdale, C. (2021). Self-determination theory in physical education: A systematic review of qualitative studies. Teaching and Teacher Education, 99 103247. https://doi.org/10.1016/j.tate.2020.103247

Yli-Piipari, S., Layne, T., Hinson, J., e Irwin, C. (2018). Motivational pathways to leisure-time physical activity participation in urban physical education: A cluster-randomized trial. Journal of Teaching in Physical Education, 37(2),123-132. https://doi.org/10.1123/itpe.2017-0099 
PARTE 2.

¿QUÉ HERRAMIENTAS

O ESTRATEGIAS PUEDE

UTILIZAR EL PROFESORADO

DE EDUCACIÓN FÍSICA PARA

MOTIVAR A SU ALUMNADO? 


\section{LOS MODELOS PEDAGÓGICOS COMO ESTRUCTURAS PARA PROMOVER LA MOTIVACIÓN DEL ALUMNADO}

os modelos pedagógicos son considerados "estructuras de andamiaje para que los docentes puedan desarrollar unidades didácticas en base a ellos" (Fernández-Río et al., 2021, p. 16). Incluyen una base teórica consolidada, un plan concreto de enseñanza, unos resultados de aprendizaje esperados, unas tareas de aprendizaje específicas, unos planteamientos de evaluación adaptados, los comportamientos docentes y discentes esperados y los mecanismos para comprobar su correcta implementación (Metzler, 2005). Para Haerens et al. (2011), en los modelos pedagógicos se interrelacionan de una manera directa y equilibrada el papel del docente, del discente, del contenido y del contexto. Más aún, los modelos pedagógicos son planteamientos a largo plazo, en los que las metas se logran utilizando unidades didácticas de varias sesiones que proporcionan un plan de trabajo concreto acorde con unos objetivos de aprendizaje concretos (Casey y Kirk, 2021), y que no sustituyen a los es- tilos o las estrategias de enseñanza, sino que los incorporan en las diferentes tareas según las necesidades (Fernández-Río et al., 2021). Partiendo de estas ideas, se comienza a imponer en las clases de Educación Física (e incluso en algunos países en el contexto deportivo extraescolar) una práctica basada en modelos (Models-based practice; Casey y Kirk, 2021) para proporcionar al alumnado experiencias personalmente relevantes para sus vidas presentes y futuras (Haerens et al., 2011). Existen diferentes clasificaciones de los modelos pedagógicos, pero en el presente capítulo nos vamos a centrar en tres de los plenamente consolidados por la academia internacional: el aprendizaje cooperativo, la educación deportiva y el modelo de responsabilidad personal y social. Para cada uno de ellos, citamos a continuación las evidencias científicas halladas en relación a la motivación, para a continuación realizar una serie de consejos pedagógicos que garanticen ese efecto motivacional a través del modelo en cuestión. 


\section{APRENDIZAJE COOPERATIVO}

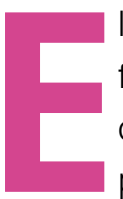
I aprendizaje cooperativo ha sido definido de manera simple como el uso de pequeños grupos de estudiantes para que estos trabajen juntos, maximizando así su aprendizaje y el de sus compañeros (Johnson et al., 2013). De manera más detallada, el aprendizaje cooperativo se define como un "modelo pedagógico en el que los estudiantes aprenden con, de y por otros estudiantes a través de un planteamiento de enseñanza-aprendizaje que facilita y potencia esta interacción e interdependencia positivas y en el que docente y estudiantes actúan como co-aprendices" (Fernández-Río, 2014, p. 6). La mayoría de autores coinciden que toda estructura de trabajo en grupo para que sea considerada cooperativa debe contemplar los siguientes cinco elementos clave: 1) Interdependencia positiva: se resume en que "nadie de la clase pierde, sale derrotado y es eliminado durante la actividad", 2) Interacción promotora: se resume en que "los estudiantes se ayudan unos a otros para aprender", 3) Responsabilidad individual: se resume en que "cada miembro del grupo tiene una tarea (responsabilidad) que hacer en el trabajo global", importantes (Kagan, 1992): 6) Participación equitativa: se resume en que "el grupo debe regular su actuación para que los niveles de actividad de sus componentes sean similares" e 7) Igualdad de oportunidades de éxito: se resume en que "todos los estudiantes deben tener la posibilidad de tener al menos cierto nivel de éxito en todas las tareas".

La investigación desarrollada de manera específica en el campo de la Educación Física señala que el aprendizaje cooperativo, cuando es planteado de manera adecuada (Cecchini et al., 2020), es capaz de aumentar de manera significativa la motivación intrínseca del alumnado de Educación Secundaria que lo experimenta (Fernández-Río et al., 2017). En Educación Primaria también se ha encontrado que este planteamiento es capaz de disminuir la desmotivación del alumnado en clase (Fernández-Argüelles y González, 2018). Finalmente, en contextos educativos de otros países se ha observado que el aprendizaje cooperativo es capaz de mejorar el clima motivacional de las clases de Educación Física (Barker y Quennerstedt, 2017).

4) Procesamiento grupal: se resume en que "el grupo debe reflexionar sobre lo que hace para mantener dinámicas adecuadas 0 modificar las necesarias", $y$

5) Habilidades interpersonales: se resume en que "los estudiantes aprenden a animarse unos a otros, a compartir espacios, ceder material, debatir respetuosamente, discrepar sin herir, etc.". Algunos autores han añadido otros dos elementos muy

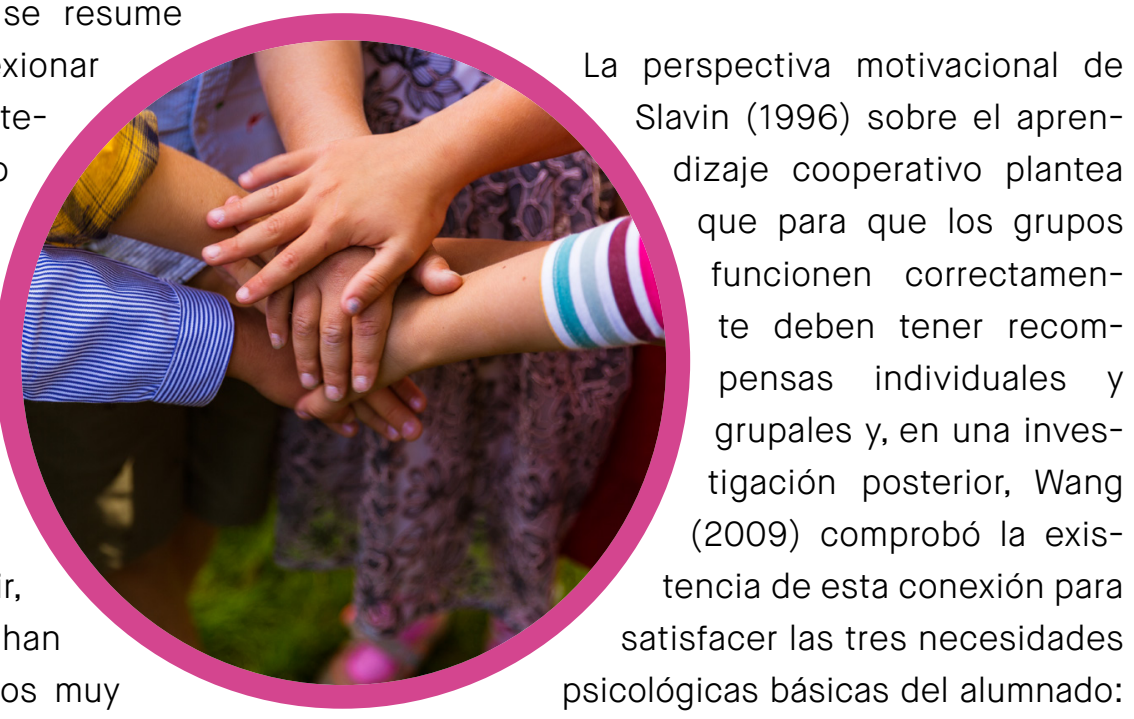


autonomía, competencia y relación (Deci y Ryan, 2000).

No obstante, la teoría de la autodeterminación plantea que eventos controladores externos como las recompensas dañan la motivación intrínseca de los individuos porque cambian el locus de causalidad de interno a externo (Deci y Ryan, 1985) (para profundizar ver Capítulo 1.1. del presente libro). Sin embargo, cuando estas son presentadas de manera informativa (Deci et al., 1999) o relacionadas con el rendimiento (Deci y Ryan, 1985) su efecto negativo sobre la motivación intrínseca es menor. Esta teoría también señala que aquellos contextos que apoyan la autonomía de los individuos contribuyen a la satisfacción de sus tres necesidades psicológicas básicas, así como a la aparición de consecuencias adaptativas (Vasconcellos et al., 2020). El aprendizaje cooperativo es un planteamiento de enseñanza que apoya el desarrollo de las tres necesidades psicológicas básicas (Casey y Goodyear, 2015).

Por otro lado, la teoría de metas de logro (Nicholls, 1989) plantea la existencia de seis tipos de metas, de las cuáles dos han sido relacionadas de manera directa con el aprendizaje cooperativo (para profundizar ver Capítulo 2.2. del presente libro): aproximación-tarea (el individuo focaliza en hacer bien la tarea encomendada) y aproximación-yo (el individuo focaliza en hacer la tarea encomendada mejor que la ha hecho antes). Investigaciones recientes han mostrado que los climas de trabajo cooperativos están conectados con este tipo de metas (Rivera-Pérez et al., 2021), que a su vez han sido conectados con resultados positivos como las formas de motivación más autodeterminadas (Méndez-Giménez et al., 2017). En el aprendizaje cooperativo, el alumnado trabaja en grupos para aprender, sin compararse con otros grupos y únicamente preocupados en hacer bien la tarea (individualmente y como grupo), por eso promueven las orientaciones de meta antes señaladas. Elementos esenciales de este modelo como la responsabilidad individual han sido señalados como las más importantes a desarrollar en los grupos cooperativos (Rivera-Pérez et al., 2021), pero también los más difíciles de conseguir.

A continuación presentamos algunas ideas para asegurar unas condiciones en las que estas tres necesidades psicológicas básicas se desarrollen correctamente. 


\section{1.- Aprendizaje cooperativo y autonomía}

- El docente debe establecer claramente el rol o roles que debe/n desempeñar cada miembro del grupo en la tarea propuesta. De esta manera cada uno sabrá lo que tiene que hacer, y podrá él, el grupo y el docente evaluar su "actuación" para mejorarla (responsabilidad individual).
- El grupo debe tener tiempo para debatir su forma de trabajar al terminar la actividad o la sesión, incluso evaluándola mediante rúbricas u otros instrumentos de auto y coevaluación para que queden reflejados por escrito (procesamiento grupal).

\section{2.- Aprendizaje cooperativo y competencia}

- Se deben plantear actividades en las que no haya una única solución válida, sino que haya varias, a diferentes niveles, para que los distintos grupos e individuos puedan tener éxito en la tarea aunque el resultado no sea idéntico para todos (igualdad de oportunidades de éxito).

- Los procesos de coevaluación ayudan a "trasladar" la responsabilidad del docente al discente, logrando que este se responsabilice de su propio proceso de aprendizaje y del de sus compañeros, mejorando de este modo, su competencia. Este transvase también debe ser progresivo a través de diferentes técnicas y procedimientos (Fernández-Río, 2021).

- Cuando se aplica el aprendizaje cooperativo como único modelo pedagógico (no hibridado con otros) absolutamente en ninguna actividad debe haber alguien que pierda o sea eliminado (aunque sea brevemente) para generar un clima de competencia (interdependencia positiva). 


\subsection{Aprendizaje cooperativo y relación}

- Los miembros de un grupo deben ayudarse mutuamente durante la tarea y para ello es preciso que el grupo comparta la regulación del mismo, es decir, que todos tengan la oportunidad de aportar y liderar del grupo y consecuentemente todos se sientan implicados e importantes (interacción promotora).

- Cuando un grupo repite una actividad, porque la debe hacer otra vez o porque no la ha hecho bien, la persona que "va en primer lugar" debe ser distinta a la que lo hizo antes (no comienza otra vez la misma persona), para que todos tengan oportunidades de liderar el grupo (participación equitativa).

Finalmente, se destacan una serie de estrategias sobre el profesorado y cómo debe ser su labor para integrar satisfactoriamente el aprendizaje cooperativo en sus clases:

- Transición: no es posible cambiar el clima competitivo de una clase "de la noche a la mañana", por lo que se recomienda comenzar a implementar el aprendizaje cooperativo tras un período largo "no escolar" (vacaciones de verano, Navidad o Semana Santa); además son necesarios periodos de implementación largos para que los modelos sean, de verdad, integrados por el profesorado y estudiantado.

- Implementación progresiva: en línea con el anterior es importante usar estrategias progresivas de implementación como el ciclo del aprendizaje cooperativo (Fernández-Río, 2017) donde, en primer lugar, se forja una adecuada cohesión grupal, posteriormente el alumnado aprende a cooperar a través del uso de técnicas simples y finalmente aprenden a usar técnicas complejas. Desafortunadamente, el "día o la semana de la cooperación" no ayudan a integrar el aprendizaje cooperativo en el aula.
- Actitud docente: debe ser activa, enfatizando y valorando las acciones "cooperativas" de sus estudiantes durante la práctica; debe resaltarlas para que sean imitadas, señalando el nombre de la persona que ha realizado esa acción "cooperativa".

- Lenguaje apropiado: el profesorado debe evitar términos que inciten a la competición como "a ver quién es el primero que..." o "gana quien..." o "preparados, listos, ya". En su lugar debe usar términos que no tengan "carga competitiva" como: "esforzaros al máximo" o "cuando estéis preparados comenzad la actividad".

- Feedback: en línea con los dos anteriores, se trata de un elemento esencial y que muchos docentes olvidan porque piensan que el trabajo en grupos debe ser "totalmente autónomo"; muy al contrario, es importante que el docente adquiera un rol activo monitorizando la actividad e interviniendo siempre que sea necesario, no solo cuando se lo pidan los estudiantes.

- Refuerzo positivo: el profesorado debe valorar de manera positiva todas aquellas actuaciones positivas que tengan lugar durante la tarea (ayudar, animar, compartir, etc.), señalándolo al resto de la clase y anotándolo para tenerlo en cuenta en la evaluación.

- Reflexión final: el docente debe revisar al final de la sesión las actitudes cooperativas aparecidas, destacándolas con "nombre y apellidos", y las negativas y/o competitivas ( $\sin$ decir quién las ha realizado); debe "dinamizar" esta charla, aunque debe lograr que sean los propios estudiantes los que "hablen". 


\section{MODELO DE EDUCACIÓN DEPORTIVA}

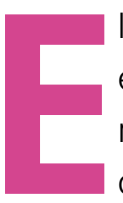

I modelo de educación deportiva, que está basado en una pedagogía cooperativa, democrática e inclusiva, tiene como objetivo primordial fomentar en Educación Física experiencias deportivas auténticas, por medio de un entorno de aprendizaje donde el alumnado asumirá una serie de responsabilidades de gestión y desarrollo dentro del proceso de enseñanza-aprendizaje. Se trata, por tanto, de un enfoque pedagógico que fue diseñado para buscar formas más educativas de presentar los contenidos deportivos dentro del currículo de Educación Física, permitiendo ello que las actividades deportivas tengan un mayor significado y valor para todo el alumnado (Siedentop, 1994). Así pues, la combinación de prácticas pedagógicas sólidas y comportamientos deportivos adaptados a la Educación Física proporcionaría la oportunidad al estudiantado de aprender más allá del rol de participante, convirtiéndoles de este modo, en deportistas cultos, entusiastas y competentes (Siedentop, 1994).

En este sentido, un/a alumno/a culto comprende y valora las reglas y rituales que definen a cada deporte, además de diferenciar entre buenas y malas prácticas, ya sea como espectador o deportista. Un/a alumno/a entusiasta demuestra un comportamiento participativo y protector hacia la cultura deportiva, manteniendo un espíritu de juego verdadero y honesto, $y$, finalmente, un/a deportista competente tiene un nivel de habilidad que le permite participar con éxito (Siedentop et al., 2011).
Para lograr lo anteriormente indicado, se estima necesario adaptar ciertos aspectos del deporte institucionalizado, incorporando a las sesiones de Educación Física determinadas características del mismo, a fin de otorgar al alumnado una serie de experiencias más formativas y enriquecedoras en el contexto de Educación Física (Siedentop et al., 2019). Las características que definen al modelo de educación deportiva son las siguientes: 1) organización de una unidad didáctica en formato de temporada deportiva; 2) el alumnado forma equipos estables que se mantienen a lo largo de la unidad; 3) la competición es la idea nuclear del desarrollo de la unidad; 4) asignación de roles diferentes al de deportista (p. ej., entrenador, capitán, periodista, preparador físico, estadístico, etc.); 5) registro de acontecimientos; 6) festividad y evento final. Asimismo, estas características cumplen un doble objetivo, por un lado, sumergen al alumnado en la cultura deportiva $y$, por otro, cada una de las características ostenta el potencial de desarrollar objetivos educativos incluidos en el currículo (García-López y Gutiérrez, 2016).

El ambiente de aprendizaje que se genera con el modelo de educación deportiva permite al profesorado de Educación Física fomentar formas de motivación más autodeterminadas entre el alumnado, ya que ellos tienen la oportunidad de socializar, tomar decisiones y disfrutar de situaciones competitivas donde los niveles de esfuerzo son fuertemente valorados. La investigación relevante 
en torno al modelo de educación deportiva ha demostrado cómo este enfoque pedagógico posee unas características estructurales que apoyan las necesidades psicológicas básicas de autonomía, competencia y relaciones sociales, promoviendo así, una motivación más autónoma entre el alumnado y, consecuente- mente, otros beneficios educativos, entre los que se puede destacar, el desarrollo de habilidades sociales, la confianza, la autoestima y el compromiso por adoptar un estilo de vida físicamente activo (Chu y Zhang, 2018; Wallhead et al., 2014).

\subsection{Autonomía: la piedra angular del modelo de educación deportiva}

Además de buscar una mayor contextualización del fenómeno deportivo en Educación Física, Siedentop (1994) diseñó también el modelo de educación deportiva con el objetivo de que el alumnado reciba y perciba más oportunidades para experimentar el control y la elección sobre su propio aprendizaje, ya sea tomando decisiones (p.ej., establecimiento de estrategias en la fase de competición formal) o ejerciendo funciones de liderazgo (p. ej., desempeño de roles), generándose así, un entorno de aprendizaje de menor dependencia hacia el docente. Investigaciones realizadas en esta línea han sugerido que el entorno de apoyo a la autonomía que caracteriza al modelo de educación deportiva ha facilitado cambios en la motivación del alumnado (Hastie et al., 2011). Por ejemplo, Perlman y Goc Karp (2010) reportaron que proporcionar al alumnado un mayor nivel de control sobre ciertos aspectos del aprendizaje dentro del modelo de educación deportiva facilitó el cambio a nivel motivacional en múltiples unidades, e incluso, en contextos con estudiantes de un menor índice de autodeterminación (Perlman, 2010). En definitiva, la investigación ha determinado que un entorno de aprendizaje que fomenta la elección y la iniciativa del alumnado promueve aún más su confianza y compromiso con el aprendizaje en Educación Física, lo cual puede alcanzarse a partir del empleo de las siguientes estrategias:
- Al principio de la temporada deportiva el alumnado que conforma cada equipo debe cooperar para formar su propia identidad de equipo (nombre, imagen, escudo, cántico, mascota, etc.), además de tener la posibilidad de seleccionar el rol a desempeñar a lo largo de la temporada deportiva.

- Durante la fase de competición formal, los diferentes equipos deben de disponer de un tiempo entre partido y partido para discutir y evaluar estrategias a aplicar en el siguiente encuentro, al objeto de mejorar el rendimiento, además de dar la oportunidad al alumnado de hacer una valoración del desempeño de roles, tanto propio, como de otros compañeros, todo ello con el propósito de generar información que permita optimizar las funciones y competencias que definen a cada rol.

- Emplear estilos de enseñanza basados en la búsqueda (p. ej., resolución de problemas) para facilitar el intercambio de ideas entre los miembros del equipo. De este modo, los estudiantes son alentados para resolver problemas tácticos específicos, todo ello bajo la supervisión del docente, mostrando este ayuda cuando fuera necesario, facilitando así el aprendizaje del alumnado. 
- Ejercer funciones de liderazgo por medio de los roles. Por ejemplo, en la fase de competición formal, las prácticas de equipo son lideradas, bajo la supervisión del docente, por el alumnado que ostenta el rol de entrenador/a. Por otra parte, el estadístico es responsable de recopilar datos como el número de partidos ganados, puntos obtenidos, infracciones de reglas, etc. Esta información del estadístico se hace pública y resulta importante para guiar el proceso de enseñanza-aprendizaje hacia los objetivos del modelo de educación deportiva, incrementándose de este modo, el compromiso del alumnado.

\subsection{Buscando alumnos y alumnas competentes: un medio $y$ un fin}

Por otra parte, y como se ha mencionado anteriormente, una de las finalidades del modelo de educación deportiva es la de crear alumnos/as competentes, entendiendo la competencia como la capacidad de comprender las estrategias y habilidades que conforman un deporte dentro de todas las facetas del juego (psicomotor, cognitivo y afectivo). Además de diseñar por parte del docente de Educación Física tareas auténticas vinculadas a la realidad del deporte, las cuales son modificadas apropiadamente según el nivel aprendizaje del alumnado y los principios pedagógicos de la enseñanza comprensiva del deporte (complejidad táctica, representación y exageración), elementos estructurales del modelo de educación deportiva brindan también la oportunidad de experimentar en el alumnado el sentimiento de competencia a través del desempeño de diferentes roles más allá del de jugador (p. ej., entrenador, capitán, estadístico, etc.), los cuales pueden ser seleccionados según sus fortalezas personales (Gil-Arias et al., 2021).

Igualmente, se han realizado estudios, tanto en primaria como en secundaria, en los que se ha mostrado diferencias significativas en la competencia percibida del alumnado cuando fueron comparados con una clase enseñada mediante instrucción directa (Spittle y Byrne, 2009). Es por ello que el modelo de educación deportiva ofrece un entorno de aprendizaje equitativo donde todos el alumnado, independientemente de su nivel de competencia, tienen la oportunidad de demostrar sus habilidades en cada una de las sesiones que componen la temporada deportiva, empleando para ello, las siguientes estrategias:

- Las tareas diseñadas, tanto por el docente, como por el alumnado que ejerce el rol de entrenador, deben ser representativas del deporte a enseñar. Por otra parte, las modificaciones de tareas serán realizadas con el propósito de adaptar la complejidad táctica a las necesidades y nivel de competencia de los estudiantes. Por ejemplo, en una unidad didáctica de voleibol, al principio, se pueden diseñar tareas cooperativas (p.ej., $1+1,2+2$ ), para posteriormente incrementar la complejidad a medida que se integran objetivos tácticos, reglas, más compañeros, adversarios (p. ej., 1 vs. 1, 1vs. $1+1,2$ vs. 2 , y 3 vs. 3), e incluso otras acciones técnicas pueden ser requeridas (p. ej., saque, colocación y ataque).

- Proporcionar feedback al alumnado destacando la mejora individual, regulando así su aprendizaje según sus fortalezas y capacidades personales.

- Uso por parte del docente de estilos de enseñanza basados en la indagación, lo cual 
permite guiar al alumnado hacia la respuesta adecuada en determinados problemas tácticos. Por ejemplo, en la fase de aprendizaje y mientras el alumnado participa en diferentes tareas contextualizadas, el docente puede formular las siguientes cuestiones: ¿qué parte del campo está cubierto por la defensa del equipo adversario?, ¿qué tendencias tiene el equipo oponente en fase defensiva?

- Dar la posibilidad al alumnado de desempeñar aquel rol que mejor se ajuste a sus intereses y fortalezas personales, incrementando así su competencia percibida.

\subsection{Modelo de educación deportiva y relaciones so- ciales: una pedagogía de gran potencial}

El desarrollo de relaciones sociales dentro del modelo de educación deportiva es algo muy contrastado (MacPhail et al., 2004). En este sentido, cabe destacar el estudio realizado por Clarke y Quill (2003), quienes mostraron cómo el alumnado con un menor nivel de habilidad y tradicionalmente marginado percibía un mayor sentido de inclusión dentro de una temporada de educación deportiva, todo ello debido a características muy particulares como la afiliación a un equipo. Así pues, el modelo de educación deportiva proporciona al alumnado un clima de aprendizaje en el que se sienten más cómodos y con mayor confianza al expresar su opinión a compañeros y docente. Por tanto, las características estructurales que definen al modelo de educación deportiva permite implementar estrategias efectivas para dar la oportunidad de interactuar entre los integrantes de equipo y ser todo el alumnado aceptado, tanto por sus compañeros como por el docente. Algunas de esas estrategias pueden ser las siguientes:

- Estilos de enseñanza basados en la búsqueda y reflexión, además de estimular el intercambio de ideas entre los integrantes del equipo para resolver problemas tácticos, también favorece el sentimiento de unidad e interacción entre el alumnado.

- La formación de equipos mixtos y estables a lo largo de toda la temporada deportiva facilita la ge- neración de sentimientos de afiliación y conexión social con el resto de integrantes del equipo.

- Generación de comités para el desarrollo de tareas de gestión que favorezcan el correcto desarrollo de la temporada deportiva. Por ejemplo, crear un comité de disciplina con el alumnado que ejerza el rol de árbitro. Dentro de este comité, además de debatir, establecer y velar por la correcta implantación del reglamento (autonomía), las relaciones sociales son extendidas más allá de la pertenencia a un equipo.

A nivel general, la literatura científica ha evidenciado el efecto positivo que tiene el modelo de educación deportiva sobre el desarrollo personal y social del alumnado (Bessa et al., 2019). El alto nivel de compromiso que manifiesta el alumnado durante su participación en una temporada educación deportiva ha provocado resultados positivos a nivel afectivo, que incluye una mayor percepción de interés por el contenido a aprender y un mayor disfrute por la práctica. Proposiciones teóricas en esta línea han sugerido que estas consecuencias afectivas positivas son facilitadas por aspectos estructurales del propio modelo de educación deportiva, que dirigen al alumnado hacia formas de motivación más autodeterminadas por medio del apoyo a las necesidades psicológicas básicas (Chu y Zhang, 2018). 


\section{EL MODELO DE RESPONSABILIDAD PERSONAL Y SOCIAL}

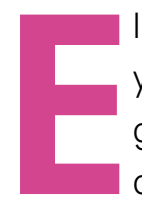

I modelo de responsabilidad personal y social es uno de los modelos pedagógicos más antiguos y que ha tenido un mayor reconocimiento por los investigadores a nivel mundial. Quizás este éxito a nivel académico no ha tenido su reflejo a nivel docente, al menos si lo comparamos con los anteriores modelos que acabamos de exponer. Sin embargo, la increíble capacidad que ha demostrado el modelo para favorecer el desarrollo de la responsabilidad individual y social, le hace ser uno de los obligatorios en la formación del docente del s. XXI.

Aunque el modelo de responsabilidad personal y social ha evolucionado de diversas formas (Belando et al., 2012), el planteamiento original fue el publicado por Don Hellison en 1978, fruto de su experiencia en utilizar la actividad física como medio para combatir la situación de precariedad en la que se encontraban multitud de niños y jóvenes socialmente vulnerables. El modelo tiene dos pilares fundamentales (Hellison, 2011). En primer lugar, establece una progresión por niveles que definen la responsabilidad y hacia lo que se debe ser responsable, desde un punto de vista de la progresión de este aprendizaje. La concreción de estos niveles es lo que permiten que se dé una auténtica pedagogía centrada en el alumnado, pues este se convierte en la referencia real del proceso de enseñanza en todos los sentidos, incluido evidentemente el motivacional. En segundo lugar, propone una serie de estrategias para el desarrollo de la responsabilidad individual y social adecuadas para cada nivel. Nos extenderemos algo más en cada uno de estos fundamentos del programa.

Los niveles de responsabilidad establecidos por Hellison (2011) son los siguientes:

0. Irresponsabilidad: se da cuando el alumnado pone excusas y culpa a los demás por sus comportamientos, negando la responsabilidad personal derivada de su comportamiento.

1. Respeto: el alumnado alcanza este nivel cuando no participan en las actividades de la sesión, o muestran alguna mejora, siendo capaces de controlar su comportamiento como para no interferir con el derecho de otros estudiantes a aprender o del docente a enseñar.

2. Participación: el alumnado que logra este nivel no solo muestra un mínimo respeto por los demás, sino que también desea jugar, aceptar los retos, practicar las habilidades motoras y entrenar a nivel condicional bajo supervisión del profesor.

3. Autogestión: el alumnado muestra respeto y participación, y además son capaces de trabajar sin supervisión directa. Pueden identificar sus propias necesidades y empezar a planear y llevar a cabo programas de Educación Física. 
4. Preocupación por los demás: además de todo lo anterior, en este nivel el alumnado está motivado a extender su sentido de la responsabilidad más allá de sí mismos, cooperando, dando apoyo, mostrando preocupación y ayudando.

5. Fuera de las clases: el modelo plantea como meta última de responsabilidad, la observación también fuera del aula de la responsabilidad desarrollada.

Es importante destacar que los niveles son flexibles (puede haber personas que sean capaces de tener más características del nivel 3 que del 2); acumulativos (el hecho de pasar a trabajar al siguiente nivel no significa que deban olvidarse los anteriores); y debe hacerse consciente al alumnado, en todo momento, de sobre qué nivel está trabajando.

Sobre el segundo pilar, solo diremos que Hellison (2011) propone una serie de estrategias que son adecuadas para desarrollar los objetivos de cada nivel de responsabilidad. Por ejemplo, para trabajar el nivel 1, Hellison propone estrategias tales como los "encuentros breves del docente con todo el alumnado", donde debe ayudar al alumnado a reconocer sus fortalezas y sus debilidades, respetar sus opiniones..., o las "estrategias de concienciación", las cuales pueden ir desde pequeñas explicaciones de los niveles de responsabilidad a carteles que sirvan de recordatorio. El lector puede acudir a los libros de Hellison o a los manuales en castellano para obtener más información sobre estas estrategias ( $p$. ej., Escartí et al., 2005; Manzano et al., 2021), cuya aplicación no es compleja.

Las revisiones de investigación en relación con el modelo de responsabilidad personal y social muestran que es uno de los modelos más contrastados de cara al desarrollo de múltiples variables psicosociales tales como las conductas prosociales, la empatía, la deportividad, las habilidades sociales y un largo etcétera (Pozo et al., 2018; Sánchez-Alcaraz et al., 2020). Sin embargo, cuando se trata del estudio de las variables motivacionales, una cuestión que es clave en el planteamiento teórico del modelo de cara al compromiso del alumando, las investigaciones realizadas no son muy numerosas. El modelo de responsabilidad personal y social mostró mejoras de la motivación intrínseca, como fruto del desarrollo de la responsabilidad individual y social en algunos estudios (Escartí et al., 2011; Hellison y Walsh, 2002; Li et al., 2008). También se comportó como un mediador adecuado entre los componentes de la teoría de las metas de logro y los indicadores de un clima motivacional positivo (Newton et al., 2006).

Teniendo estos resultados en cuenta, es fácil apreciar cómo en la progresión de niveles de responsabilidad y en las estrategias utilizadas en cada nivel, el locus de motivación parte de un tipo más externo en los primeros niveles para evolucionar a un locus más interno en los últimos niveles. Así, en los primeros niveles hay mayores recompensas externas y una mayor supervisión del cumplimiento de las tareas por parte del docente $y$, por el contrario, en los últimos niveles, la supervisión y las recompensas directas disminuyen ostensiblemente.

Por otro lado, y en relación con las necesidades psicológicas básicas, sí que existen una gran cantidad de estudios que demuestran una mayor satisfacción de las mismas (Pozo et al., 2018; Sánchez-Alcaraz et al., 2020). Pasamos a continuación a examinar el modelo, apoyándonos en algunos de estos hallazgos, desde el punto de vista de sus consecuencias para la enseñanza. 


\subsection{Autonomía: un indicador de la responsabilidad personal}

Cuando anteriormente citábamos los niveles de responsabilidad, deberíamos considerar el peso que tiene la autonomía en la responsabilidad personal. En la definición de los niveles de responsabilidad, sobre todo del o (Irresponsabilidad) al 3 (Autogestión), se puede apreciar que los dos ejes sobre los que bascula la responsabilidad personal son el respeto y la autonomía. El respeto permite la adecuada relación con los compañeros de cara al trabajo de clase. La autonomía, por su parte, es la que permite que progresivamente el alumnado pase de la necesaria supervisión por parte del docente para cualquier tipo de tarea (nivel 0), a la autogestión, donde el alumnado podrá practicar sin supervisión directa (nivel 3). Por tanto, la autonomía debe ser considerada como uno de los objetivos claves del modelo.

El estudio de Ward et al. (2012) muestra cómo el alumnado disfrutó de la relajada estructura del programa y que les sirvió para trabajar de manera más autónoma. Sin embargo, el desarrollo de esta necesidad básica entró en conflicto con la necesidad de competencia, pues dicha relajación en el clima de trabajo conllevó una disminución de los aprendizajes, según estos autores.
La progresión por niveles debe ser vinculada, por parte del docente, con la programación de aula utilizada. Si el objetivo es desarrollar la responsabilidad, y para ello hay que dar autonomía al estudiante, es necesario garantizar una oferta suficiente de decisiones que pueda tomar el alumnado. En este sentido, es recomendable ir más allá de la mera oferta alternativa de actividades, para llegar a conocer realmente sus necesidades, barreras e intereses.

Por otro lado, el currículo ofertado al alumnado también debe ayudar a la progresión en la autonomía y, en este sentido, las estrategias que propone el modelo para los sucesivos niveles también suponen desde el punto de vista metodológico una progresión en la autonomía del alumnado. Un ejemplo de cómo el contenido como elemento del currículo puede ser aprovechado, lo aporta Hellison (1995) al describir cómo unos u otros contenidos deben ser tratados: la condición física permite el desarrollo de programas individualizados, más orientados a la autogestión (autonomía), mientras que otros deportes como el baloncesto permiten trabajar más fácilmente aspectos cooperativos (relación). 


\subsection{La mejora de la competencia en el programa de responsabilidad personal y social}

En ocasiones, el hecho de favorecer una estructura que favorece la autonomía puede conllevar una disminución del desarrollo de la competencia. Ward et al. (2011) describieron esta situación, en la que priorizaron la elección del estudiante de ser responsable o irresponsable, pero siempre en un clima de trabajo seguro tanto desde el punto de vista psicológico como físico. Aunque la competencia no es algo que se haya medido habitualmente en los estudios del modelo de responsabilidad personal y social, sí que se han medido el nivel de esfuerzo y la participación, con unos resultados muy positivos (Pozo et al., 2018; Sánchez-Alcaraz et al., 2020), lo cual supone un buen punto de partida para poder alcanzar los aprendizajes.
En este sentido, las estrategias utilizadas en el modelo pueden favorecer un clima motivacional hacia el aprendizaje del alumnado. La clave estará en la oferta de actividades optativas diseñada en el programa, la cual puede permitir a los discentes elegir entre diferentes actividades, tareas, responsabilidades, y equipos, entre otros.

Para Hellison (1995), un programa de enseñanza es creíble cuando consigue desarrollar la competencia, más todavía cuando tratamos con estudiantes. En este caso, el modelo incide en el desarrollo de la competencia creando un contexto más atractivo para el alumnado que favorece su mayor implicación en las tareas de aprendizaje.

\subsection{Relaciones sociales: del crecimiento en lo per- sonal al crecimiento en lo social}

Sin duda, uno de los aciertos en el planteamiento de Hellison es el asumir que, para poder compartir socialmente, primero uno tiene que haber crecido personalmente. No se puede dar a los demás lo que no se tiene. Esto es algo que de nuevo queda muy patente en la progresión de niveles de responsabilidad: una vez desarrollada la responsabilidad personal (sobre todo hasta el nivel 3), es cuando se puede hacer un planteamiento serio de responsabilidad social (niveles 4 y 5), en los que "el otro", el compañero, tiene el papel más relevante que el de uno mismo.
Consecuentemente, las estrategias metodológicas de los últimos niveles pasan a tener un mayor componente social. Estrategias del nivel 4 son la utilización de roles de liderazgo o estilos de enseñanza como la micro-enseñanza y la enseñanza recíproca. En el nivel 5 un claro ejemplo de este tipo de estrategias es el aprendizaje-servicio. Esta metodología supone la utilización del aprendizaje de unos sujetos para prestar un servicio a otros. Valga de ejemplo la experiencia llevada a cabo por García-López et al. (2019) en la que estudiantes de Educación Secundaria desarrollaron una unidad didáctica de ringo en su centro y, paralelamente, enseñaron en diversas sesiones 
a jugar al ringo al alumnado de Educación Primaria. Con estas actividades conjuntas del alumnado de ambas etapas se logró un doble objetivo: primero, el alumnado de Educación Secundaria profundizaba en su aprendizaje al enseñar a estudiantes de Educación Primaria; y segundo, el alumnado de sexto curso de Educación Primaria tenía un primer contacto con futuros compañeros/as de Educación Secundaria, lo que mejoró sus percepciones positivas en relación a la transición de la Educación Primaria a la Educación Secundaria.

Para Hellison (1995), el individuo no tiene sentido sin su capacidad de relacionarse con los demás. Es por ello que la relación con los demás, el alcanzar los últimos niveles del modelo, es fundamental. Dado que el trabajo de Hellison, como decíamos al inicio, estaba centrado en niños y jóvenes de contextos socialmente vulnerables, dotarlos de esa capacidad de relación tenía una exigencia mayor. Este perfil de jóvenes suele tener una motivación más controlada (o incluso llegar a la desmotivación), y suele encontrarse en niveles de responsabilidad bajos. Para tratar de motivar y conseguir la participación del individuo, Hellison apostaba por la estrategia de las "pequeñas victorias" (small wins, Weik, 1985). Esta estrategia consiste en garantizar que los retos relacionales que se plantea al alumnado están a su alcance, de tal manera que el éxito en alcanzarlos suponga siempre un refuerzo emocional y motivacional. Evidentemente, esta estrategia es extensible y muy adecuada pare el alumnado en general.
La estrategia de las pequeñas victorias, interpretada desde la teoría de la autodeterminación, nos permite concebir caminos para que el alumnado pase, poco a poco, de unos escenarios de enseñanza en los que la regulación motivacional es más externa, a otros en los que la regulación motivacional es más interna. Desde este punto de vista, las pequeñas victorias suponen un enfoque salutogénico de la Educación Física que ayuda al estudiantado a percibir aquello que les ayuda a avanzar, en vez de en aquellas cuestiones que destacan los aspectos negativos que deben superar (Kirk, 2020).

Para cerrar el apartado de este modelo de responsabilidad personal y social, queremos aludir a la importancia que Hellison otorga al papel del docente. Aunque Hellison a lo largo de su trabajo no aborda explícitamente las necesidades psicológicas básicas, sí queda patente que percibe el apoyo docente cómo un medio fundamental para desarrollar la autonomía, la competencia y la relación en el alumnado. En este sentido, Hellison (1995) destaca que el profesor/a debe encarnar los niveles de responsabilidad, de tal forma que, si no es capaz de ser ejemplo para el desarrollo de los mismos, será muy difícil transmitir este tipo de aprendizajes. En otras palabras, la incoherencia del docente puede ser una clara fuente de desmotivación del alumnado en general, y especialmente del de Educación Física, dada la influencia que ejerce hacia cuestiones como la salud desde un punto de vista actitudinal. 


\section{REFERENCIAS BIBLIOGRÁFICAS}

Barker, D. M., y Quennerstedt, M. (2017). Power and group work in physical education: A Foucauldian perspective. European Physical Education Review, 23(3), 339353. https://doi.org/10.1177/1356336X15620716

Belando, N., Férriz-Morell, R., y Moreno Murcia, J. A. (2012). Mejora personal y social a través de la promoción de la responsabilidad en la actividad físico-deportiva. RICYDE. Revista Internacional de Ciencias del Deporte, 8(29), 202-222. https://doi.org/10.5232/ricyde2012.02902

Bessa, C., Hastie, P. A., Araújo, R., y Mesquita, I. (2019). What do we know about the development of personal and social skills within the sport education model: A systematic review. Journal of Sports Science \& Medicine, 18(4), 812-829.

Casey, A., y Goodyear, V. (2015). Can Cooperative Learning Achieve the Four Learning Outcomes of Physical Education? A Review of Literature, Quest, 67(1), 56-72. https://doi.org/10.1080/00336297.2014.984733

Casey, A., y Kirk, D. (2021). Models-based Practice in Physical Education. Routledge.

Cecchini, J. A., Fernandez-Rio, J., Mendez-Gimenez, A., Gonzalez, C., Sanchez-Martínez, B., y Carriedo, A. (2020). High versus low-structured cooperative learning. Effects on prospective teachers' regulation dominance, motivation, content knowledge and responsibility. European Journal of Teacher Education. https://doi.org/10.1080/02619768.2020.1774548

Chu, T. L., y Zhang, T. (2018). Motivational processes in Sport Education programs among high school students: A systematic review. European Physical Education Review, 24(3), 372-394. https://doi.org/10.1177/1356336X17751231

Clarke, G., y Quill, M. (2003). Researching sport education in action: a case study. European Physical Education Review, 9(3), 253-266. https://doi.org/10.1177/1356336X030093004

Deci, E. L., Koestner, R., y Ryan, R. M. (1999) A meta-analytic review of experiments examining the effects of extrinsic rewards on intrinsic motivation. Psychological Bulletin 125, 627-668.

Deci, E. L., y Ryan, R. M. (2000). The "what" and "why" of goal pursuits: Human needs and the self-determination of behavior. Psychological Inquiry, 11, 227-268. https://doi.org/10.1207/S15327965PLI1104_01

Escartí, A., Pascual, C., y Gutiérrez, M. (2005). Responsabilidad personal y social a través de la educación física y del deporte. Graó.

Escartí, A., Gutiérrez, M., y Pascual, C. (2011). Propiedades psicométricas de la versión española del Cuestionario de Responsabilidad Personal y Social en contextos de educación física. Revista de Psicología del Deporte, 20(1), 119-130.

Fernández-Argüelles, D., y González, C. (2018). Physical education and cooperative learning: A practical ex- perience. Journal of Sport and Health Research, 10(1), 43-64.

Fernández-Río, J. (2014). Aportaciones del Modelo de Responsabilidad Personal y Social al Aprendizaje Cooperativo. En actas del IX Congreso Internacional de Actividades Físicas Cooperativas, Vélez-Málaga.

Fernández-Río, J. (2017). El ciclo del aprendizaje cooperativo: una guía para implementar de manera efectiva el aprendizaje cooperativo en educación física. Retos, 32, 264-269.

Fernández-Río, J. (2021). Aprendizaje cooperativo. En A. Pérez Pueyo, D. Hortigüela y J. Fernández-Río (coords.). Modelos pedagógicos en Educación Física: qué, cómo, por qué y para qué (pp. 26-49). Servicio de publicaciones de la Universidad de León.

Fernández-Río, J., Hortigüela, D. y Pérez Pueyo, A. (2021). ¿Qué es un modelo pedagógico? Aclaración conceptual. En A. Pérez Pueyo, D. Hortigüela y J. FernándezRío (coords.). Modelos pedagógicos en Educación Física: qué, cómo, por qué y para qué (pp. 12-24). Servicio de publicaciones de la Universidad de León.

Fernández-Río, J., Sanz, N., Fernandez-Cando, J., y Santos, L. (2017). Impact of a sustained cooperative learning intervention on student motivation. Physical Education and Sport Pedagogy, 22(1), 89-105. https:// doi.org/10.1080/17408989.2015.1123238

García-López, L. M., y Gutiérrez, D. (2016). Aprendiendo a enseñar deporte: Modelos de Enseñanza comprensiva y educación deportiva. Barcelona: Inde.

García López, L. M., Gutiérrez, D., y Fernández Bustos, J. G. (2019). Emprendimiento docente en la transición de Educación Primaria a Educación Secundaria: una propuesta desde la Educación Deportiva y el AprendizajeServicio. Contextos Educativos. Revista de Educación, 24,113-121. https://doi.org/10.18172/con.3913

Gil-Arias, A., Harvey, S., García-Herreros, F., GonzálezVíllora, S., Práxedes, A., y Moreno, A. (2021). Effect of a hybrid teaching games for understanding/sport education unit on elementary students' self-determined motivation in physical education. European Physical Education Review, 27(2), 366-383. https:// doi.org/10.1177/1356336X20950174

Haerens, L. Kirk, D., Cardon, G., y De Bourdeaudhuij, I. (2011). Toward the Development of a Pedagogical Model for Health-Based Physical Education. Quest, 63(3,) 321-338. http://dx.doi.org/10.1080/00336297. 2011.10483684

Hastie, P. A., Martínez de Ojeda, D., y Calderón, A. (2011). A review of research on Sport Education: 2004 to the present. Physical Education and Sport Pedagogy, 16(2), 103-132. https://doi.org/10.1080/17408989.20 10.535202

Hellison, D. R. (1995). Teaching Responsibility through Physical Activity. Human Kinetics. 
Hellison, D. R. (2011). Teaching Personal and Social Responsibility through Physical Activity (3 ed.). Human Kinetics.

Kagan, S. (1992). Cooperative learning. Kagan Cooperative Learning.

Kirk, D. (2020). Precarity, Critical Pedagogy and Physical Education. Routledge.

Li, W., Wright, P. M., Rukavina, P. B., y Pickering, M. (2008). Measuring Students' Perceptions of Personal and Social Responsibility and the Relationship to Intrinsic Motivation in Urban Physical Education. Journal of Teaching in Physical Education, 27(2), 167-178. https:// doi.org/10.1123/jtpe.27.2.167

MacPhail, A., Kirk, D., y Kinchin, G. (2004). Sport education: Promoting team affiliation through physical education. Journal of Teaching in Physical Education, 23(2), 106122. https://doi.org/10.1123/jtpe.23.2.106

Manzano Sánchez, D., y Valero Valenzuela, A. (2021). Responsabilidad personal y social. En Á. Pérez-Pueyo, D. Hortigüela-Alcalá, y J. Fernández-Rio (Eds.), Los Modelos Pedagógicos en Educación Física: qué, cómo, por qué y para qué (pp.122-145). Universidad de Leon. https://buleria.unileon.es/handle/10612/13251

Méndez-Giménez, A., Cecchini-Estrada, J. A., FernandezRio, J., Mendez-Alonso, D., y Prieto-Saborit, J. A. (2017). 3x2 Achievement goals, self-determined motivation and life satisfaction in secondary education. Revista de Psicodidáctica, 22(2), 150-156. https://doi.org/10.1016/j.psicoe.2017.05.004

Metzler, M. (2005). Instructional models for physical education (2nd ed.). Holcomb Hathaway.

Nicholls, J. G. (1989). The competitive ethos and democratic education. Harvard University Press.

Perlman, D. (2010). Change in affect and needs satisfaction for amotivated students within the sport education model. Journal of Teaching in Physical Education, 29(4), 433-445. https://doi.org/10.1123/jtpe.29.4.433

Perlman, D. J., y Karp, G. G. (2010). A self-determined perspective of the Sport Education Model. Physical Education and Sport Pedagogy, 15(4), 401-418. https://doi.org/10.1080/17408980903535800

Pozo, P., Grao-Cruces, A., y Pérez-Ordás, R. (2018). Teaching personal and social responsibility modelbased programmes in physical education. European Physical Education Review, 24(1), 56-75. https://doi.org/10.1177/1356336X16664749

Rivera-Pérez, S., Fernandez-Rio, J., y Iglesias, D. (2021). Uncovering the Nexus Between Cooperative Learning Contexts and Achievement Goals in Physical Education. Perceptual and Motor Skills, 128(4), 18211835. https://doi.org/10.1177/00315125211016806
Sánchez-Alcaraz Martínez, B. J., Courel Ibáñez, J., Sánchez Ramírez, C., Valero Valenzuela, A., y Gómez Mármol, A. (2020). El modelo de responsabilidad personal y social a través del deporte: revisión bibliográfica. Retos: nuevas tendencias en educación física, deporte y recreación (37), 755-762.

Siedentop, D. (1994). Sport Education. Champaign, IL: Human Kinetics.

Siedentop, D., Hastie, P. A., y van der Mars, H. (2011). Complete guide to Sport Education. Champaign, IL: Human Kinetics.

Siedentop, D., Hastie, P. A., y van der Mars, H. (2019). Complete guide to Sport Education. Champaign, IL: Human Kinetics.

Slavin, R. E. (1996). Research for the future: Research on cooperative learning and achievement: What we know, what we need to know. Contemporary Educational Psychology, 21, 43-69. https://doi.org/10.1006/ ceps.1996.0004

Spittle, M., y Byrne, K. (2009). The influence of sport education on student motivation in physical education. Physical Education and Sport Pedagogy, 14(3), 253266. https://doi.org/10.1080/17408980801995239

Vasconcellos, D., Parker, P. D., Hilland T., et al. (2020). SelfDetermination Theory Applied to Physical Education: A Systematic Review and Meta-Analysis. Journal of Educational Psychology, 112(7), 1444-1469. https:// doi.org/10.1037/edu0000420

Wallhead, T. L., Garn, A. C., y Vidoni, C. (2014). Effect of a sport education program on motivation for physical education and leisure-time physical activity. Research Quarterly for Exercise and Sport, 85(4), 478-487. https://doi.org/10.1080/02701367.2014.961051

Wang, M. (2012). Effects of cooperative learning on achievement motivation of female university students. Asian Social Science, 8(15), 108-114. https://doi.org/10.5539/ass.v8n15p108

Ward, S., Parker, M., Henschel-Pellet, H., y Perez, M. (2012). Forecasting the storm: student perspectives throughout a teaching personal and social responsibility (TPSR)-based positive youth development program. Ágora para la Educación Física y el Deporte, 14(2), 230-247.

Weick, K. E. (1984). Small wins: Redefining the scale of social problems. American Psychologist, 39(1), 40-49. https://doi.org/10.1037/0003-066X.39.1.40 



\section{EVIDENCIAS CIENTÍFICAS}

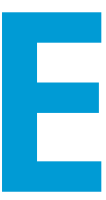

n este capítulo abordaremos qué climas motivacionales se pueden desarrollar durante las clases de Educación Física desde la teoría de las metas de logro (Ames, 1992; Nicholls, 1989). De forma resumida, esta teoría plantea que las personas se esfuerzan por demostrar su competencia (percepción de habilidad) en distintos contextos de logro. Por ejemplo, la Educación Física es un contexto donde nuestro alumnado se esforzará en demostrar su competencia. La forma de valorar la competencia o habilidad en un entorno de logro, por parte del alumnado, viene determinada por tres constructos que plantea esta teoría: la orientación motivacional, el clima motivacional y la implicación motivacional.

Comenzaremos hablando de la orientación motivacional. Esta teoría establece que existen dos maneras diferentes de valorar la habilidad o competencia en entornos de logro como son las clases de Educación Física. Se habla que un estudiante tiene una orientación a la tarea cuando valora el éxito en una sesión o tarea de forma intrapersonal, es decir, comparándose con uno mismo e ignorando la comparación con los compañeros. Para este tipo de alumnado lo importante es el esfuerzo y el progreso, por encima del resultado final (Ames, 1992). Por ejemplo, un discente que tiene una orientación a la tarea valora que tiene éxito porque ha realizado un número de pases con su compañero, sin que se le caiga el balón al suelo, mayor que la vez anterior en una tarea de voleibol. Por el contrario, un/a estudiante tiene una orientación al ego cuando valora su habi- lidad a través de la comparación con otras personas o mediante comparaciones normativas, donde lo importante es ser mejor que los demás u obtener el mejor resultado normativo de referencia (Duda, 2005). Por ejemplo, cuando en una tarea de voleibol una pareja valora que tiene éxito porque ha dado más toques sin que se le caiga el balón al suelo que el resto de las parejas de la clase, tiene una orientación al ego. Esta orientación hacia el ego o hacia la tarea viene determinada por todas las experiencias acumuladas por el alumnado a lo largo de su vida, aunque lo más frecuente es que el alumnado esté orientado hacia el ego (Sánchez-Alcaraz et al., 2016), especialmente en los chicos.

Las consecuencias que generan estas dos orientaciones motivacionales son realmente diferentes y pueden desencadenar consecuencias distintas en el proceso de enseñanza-aprendizaje. La orientación a la tarea produce en el alumnado la percepción de que el éxito es fruto del esfuerzo y del progreso personal. Este tipo de alumnado suele esforzarse en sus clases de Educación Física para mejorar su aprendizaje, no comparándose con el resto de los compañeros. La orientación a la tarea se relaciona con consecuencias positivas como el disfrute, la diversión y el aprendizaje. Sin embargo, la orientación al ego produce en el alumnado la percepción de que el éxito consiste en ser mejor que los demás (en muchos contextos deportivos se entiende que solo gana un participante o equipo). Si el alumnado entiende que en las actividades de las clases de Educación Física solo 
tienen éxito los mejores o los que quedan en los primeros puestos se producen numerosas consecuencias negativas. Los estudiantes orientados al ego desarrollan más motivación extrínseca y desmotivación, se divierten menos, muestran conductas más disruptivas y tienen una baja persistencia ante resultados negativos (Braithwaite et al., 2011; Harwood et al., 2015).

Por otro lado, en esta teoría encontramos el concepto de clima motivacional, que se refiere a aquellas señales implícitas o explícitas percibidas por el alumnado durante las clases de Educación Física. Los agentes que van a influir en el clima motivacional serán profesores, entrenadores, padres o compañeros, determinando un clima motivacional orientado a la tarea o un clima motivacional orientado al ego. Si un estudiante percibe que su docente de Educación Física valora su progreso desde el inicio hasta el final de una unidad didáctica, establece criterios individualizados y se centra en la mejora personal, estará generando un clima motivacional orientado a la tarea. Por el contrario, si un docente compara a sus discentes entre sí o evalúa o pone las calificaciones en función del resultado de los demás o de puntuaciones estandarizadas estará favoreciendo un clima motivacional orientado al ego. Por tanto, si el profesorado de Educación Física desarrolla un clima tarea todo el alumnado podría experimentar éxito ya que pueden mejorar sobre su nivel inicial, mientras que en las tareas con clima ego solo puede tener éxito uno o unos pocos, ya que no pueden ganar todos ni quedar en las primeras posiciones. Son innumerables los estudios que avalan los efectos positivos del clima tarea en diferentes consecuencias afectivas (p. ej., diversión), cognitivas (p. ej., rendimiento académico) y comportamentales (p.ej., intención de práctica de actividad física) (Abós et al., 2017; Braithwaite et al., 2011; Di Battista et al., 2019). Por otro lado, también existen numerosas evidencias de las consecuencias negativas del clima ego, como pueden ser el desinterés, aburrimiento, indisciplina, miedo a fallar y ansiedad (Braithwaite et al., 2011). Además, estas consecuencias negativas asociadas al clima ego serán experimentadas primordialmente por aquel alumnado con menor competencia motriz, que es el que más motivación necesita para adherirse a las actividades físicas y deportivas.

El último concepto importante de esta teoría es el estado de implicación (Roberts, 2001). Este se refiere a la disposición motivacional que adopta el alumnado en una situación particular, siendo el resultado de la interacción entre la orientación motivacional y el clima motivacional percibido por cada uno (ver Figura 1). La evidencia científica ha demostrado que si el alumnado tiene una orientación al ego alta (entiende que tener éxito es hacerlo mejor que los demás) y el criterio de éxito de las tareas diseñadas por el docente se orientan al ego (p. ej., una carrera de relevos donde gane el que menor tiempo hace o el que llega primero), el estado de implicación de los estudiantes será hacia el ego (Roberts, 2001). En sentido contrario, si la orientación y el clima son hacia la tarea, el estudiante se implicará hacia la tarea. Pero, ¿qué sucede cuando la orientación del alumnado y el clima motivacional no coinciden?, ¿cuál será en este caso el estado de implicación de cada alumno/a? Diferentes estudios señalan que dependerá de la fuerza que tenga cada uno de estos elementos. Por ejemplo, si hay alumnos/as que tienen una alta orientación al ego, se necesitará que el docente de Educación Física desarrolle un clima motivacional tarea de gran intensidad para que la implicación del alumnado sea hacia la tarea. Si el docente de Educación Física no consigue generar un clima tarea alto, la implicación del alumnado será hacia el ego. Sin embargo, si el docente desarrolla un clima motivacional ego, el alumnado tendrá grandes dificultades para implicarse a la tarea, aunque tenga una alta orientación a la tarea (ver Figura 1). 


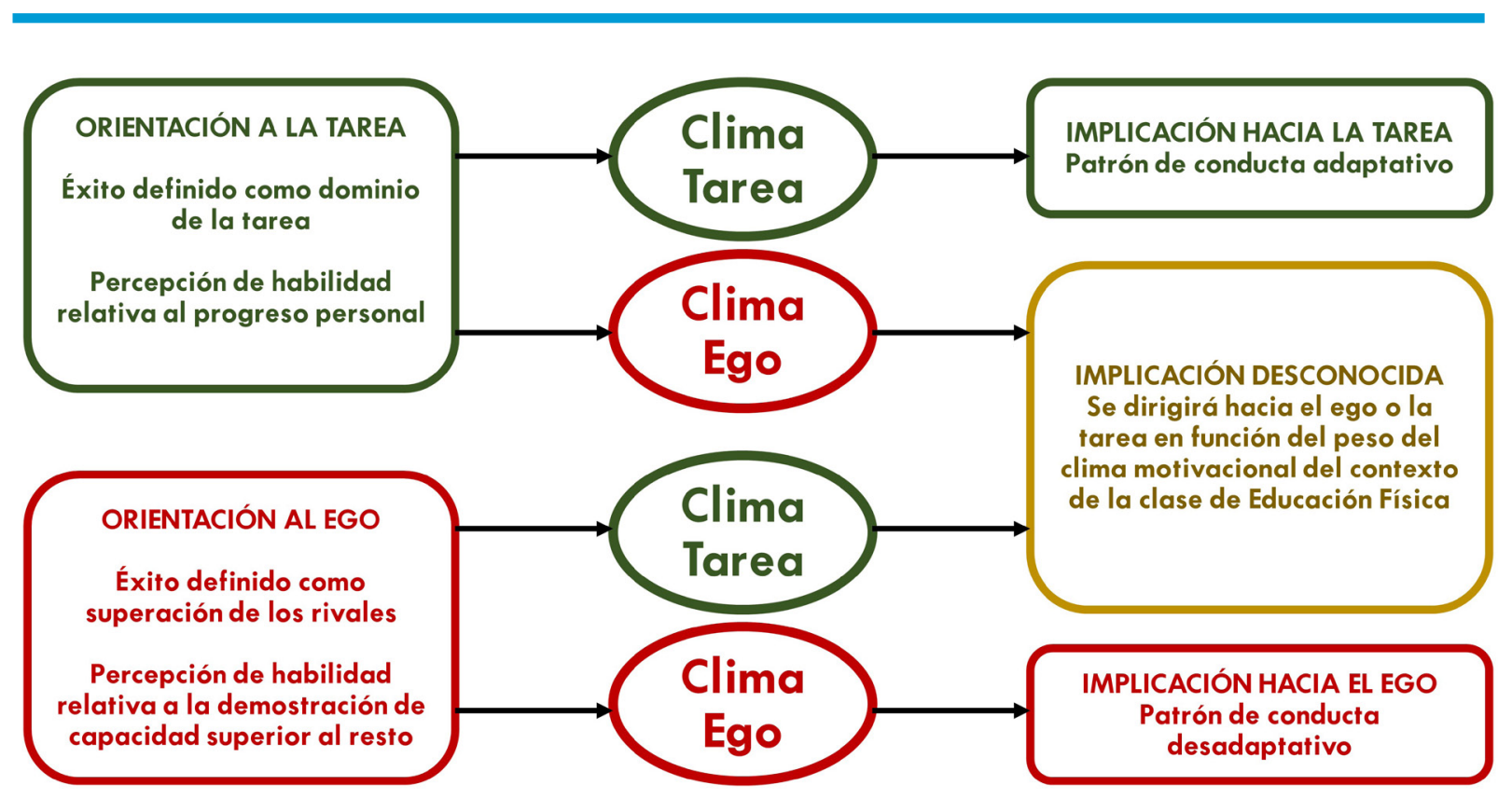

FIGURA 1. REPRESENTACIÓN DE LA INTERACCIÓN ENTRE LA ORIENTACIÓN MOTIVACIONAL, EL CLIMA MOTIVACIONAL Y LA IMPLICACIÓN. Adaptado de García-Calvo et al. (2005).

Por ello, el docente de Educación Física tiene una gran importancia en el estado de implicación que adopte finalmente su alumnado. No podemos cambiar la orientación motivacional del alumnado de un día para otro, pero sí que está en nuestras manos generar situaciones de aprendizaje que fomenten en todo momento un clima tarea y que, también, reduzcan el clima ego al máximo. De esta manera, conseguiremos que la implicación del alumnado sea mayoritariamente hacia la tarea, desarrollando consecuencias positivas en su proceso de enseñanza-aprendizaje.

Una vez expuesta la importancia de desarrollar un clima tarea para generar efectos positivos, así como la necesidad de disminuir el clima ego para reducir o evitar los efectos negativos, vamos a explicar cómo el desarrollo de estos dos tipos de climas puede afectar de diferente manera a la motivación del alumnado.
En la Figura 2 se muestra cómo el desarrollo de un clima tarea por parte del docente de Educación Física favorece la satisfacción de las necesidades psicológicas básicas de autonomía, competencia y relación social (ver Capítulo 1.1.), lo que producirá una motivación más intrínseca, desencadenando una mejor actitud afectiva hacia la Educación Física y un menor aburrimiento del alumnado. Por el contrario, el clima ego provoca la frustración de las necesidades psicológicas básicas, lo que desencadena una mayor desmotivación y aburrimiento en el alumnado (García-González et al., 2019). Si el docente valora el progreso personal a través de una evaluación criterial, todo el alumnado puede percibirse eficaz (satisfacción de la competencia), ser el origen de sus acciones (satisfacción de la autonomía) y ayudar y cooperar con los demás para mejorar (satisfacción de las relaciones sociales). Por el contrario, si el docente genera un clima en el que se prima la comparación social, muy pocos 
estudiantes pueden experimentar dicho éxito por lo que podrían percibirse ineficaces (frustración de la competencia). Asimismo, con el clima ego, el alumnado puede sentirse presionado para cumplir las expectativas planteadas por el docente (frustración de la autonomía). Por último, ese clima de competitividad puede también generar malas relaciones entre los compañeros ya que el alumnado evitará cooperar (frustración de las relaciones sociales).

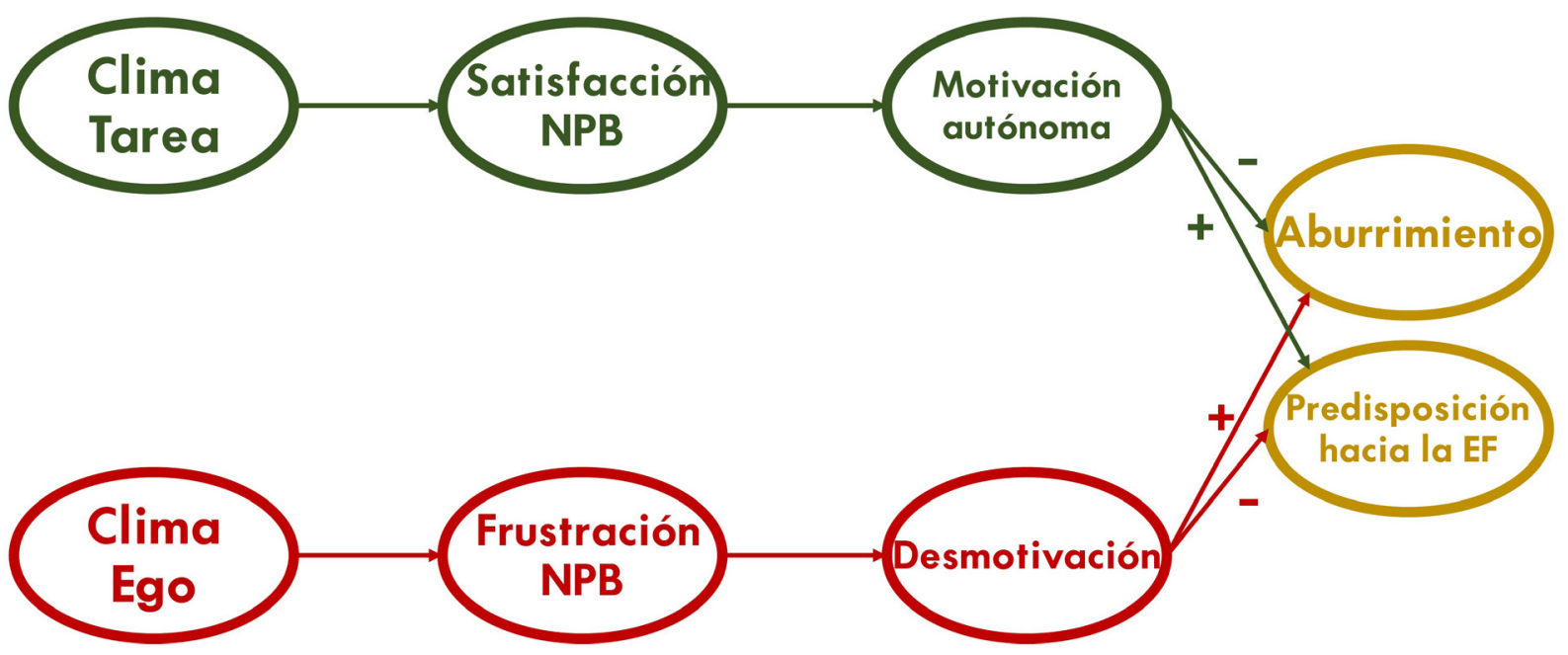

Figura 2. Relaciones de los climas motivacionales con variables motivacionales en Educación Física. Adaptado de GARCíA-González et AL. (2019).

NOTA: NPB = NECESIDADES PSICOLÓGICAS BÁSICAS; EF = EDUCACIÓN FÍSICA.

A continuación, trataremos de ejemplificar situaciones habituales en las clases de Educación Física que pueden generar clima tarea y/o clima ego. Alguna de las tareas que pueden provocar la aparición de un clima ego son, por ejemplo, hacer una carrera de relevos, donde se evidencie claramente quién gana y quién pierde, o realizar continuamente partidos o situaciones competitivas, donde el criterio de éxito es ganar al otro equipo. Estas tareas conllevan a un alto clima ego, si el foco está centrado únicamente en ganar y no hay ninguna referencia al proceso. Sin embargo, existen alternativas a estas tareas que pueden favorecer un clima tarea. Por ejemplo, si se practican relevos en una situación no com- petitiva contra otros grupos, el alumnado se centrará en mejorar esos elementos y no en competir contra los demás. De forma concreta, en una actividad de relevos, podemos cronometrar en varias ocasiones a cada grupo para ver si es capaz de mejorar su tiempo, favoreciendo un clima tarea. Además, si evitamos que las salidas de esos relevos sean simultáneas evitaremos la comparación social.

Si en una situación competitiva de un deporte de colaboración-oposición ponemos énfasis en los principios técnico-tácticos a aprender se evitará también la comparación social. Un ejemplo concreto para favorecer clima tarea sería en una actividad de 3 vs. 3 , donde un 
equipo trata de mantener la posesión de la pelota, intentando hacer un mayor número de pases con respecto a la posesión anterior. Las pruebas de condición física como la famosa "course-navette" o test de los pitidos, generan también un alto clima ego, ya que sabemos quién es el que abandona primero la prueba o quiénes llegan hasta el final. Si el docente de Educación Física además califica esta prueba, el clima ego se intensificará ya que el alumnado buscará ser el mejor para obtener una calificación más alta. La persona que llegue primero es el que sale más reforzado socialmente, mientras que los últimos tienen una evaluación o calificación negativa, aunque hayan progresado respecto a otra vez que hayan realizado esta prueba. En este caso, la alternativa podría ser utilizar el test de Cooper (consiste en recorrer la mayor distancia posible en un periodo de 12 minutos), donde no comiencen la prueba de forma simultánea, sino que vayan comenzando de forma gradual. De este modo, se evita poner el foco hacia la comparación social. Además, se podría establecer como objetivo que el alumnado mantenga un ritmo uniforme en los 12 minutos por encima de que recorra una mayor distancia. De esta forma, se evitará que el alumnado compare la distancia recorrida al final de la prueba, reduciendo con ello el clima ego. Si, además, esta prueba se realiza por parejas y el feedback que se da al alumnado se realiza de forma privada y no pública, conseguiremos que cada estudiante se centre en mejorar su ritmo uniforme, sin estar pendiente del resultado del resto de compañeros. Por ello, evitar en las clases de Educación Física la comparación social, enfocando las tareas al aprendizaje, el esfuerzo y la mejora personal, tiene que ser un objetivo prioritario, algo que no siempre es fácil de conseguir por la alta orientación al ego de los estudiantes.

Una reflexión que, a raíz de estos conceptos, suele surgir es: ¿cualquier tipo de competición es entonces negativa? La competición en el contexto de la Educación Física puede ser positiva o negativa en función del enfoque que se le dé. La competición debería plantearse como un medio para poder demostrar aprendizajes y todo lo que el estudiante ha mejorado en un contexto real. El feedback del docente debe dirigirse en todo momento a los objetivos de la sesión y no al resultado final de la competición. Si, por el contrario, el docente de Educación Física valora el resultado final, sin prestar atención a otros aprendizajes inherentes a esa actividad, la competición acabará generando un alto clima ego. El alumnado buscará ganar a los demás a toda costa, aunque eso implique hacer trampas o no poner en práctica todo lo aprendido. 


\section{APLICACIONES PRÁCTICAS PARA LA DOCENCIA DE LA EDUCACIÓN FÍSICA}

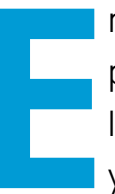

n este apartado trataremos de detallar propuestas y ejemplos que ayuden a los docentes a generar un clima tarea y reducir el clima ego en las clases de Educación Física. Para ello, Ames (1992) inicialmente enumeró seis ámbitos o elementos donde intervenir denominados áreas TARGET, que son las siglas en inglés de tarea (Task), autoridad (Authority), reconocimiento (Recognition), agrupación (Grouping), evaluación (Evaluation) y tiempo (Timing). Manipulando estos elementos conseguiremos promover un clima tarea de las actividades. De forma muy breve, trataremos de explicarlos a continuación.

- Tarea: aquellas actividades que tienen un único nivel de dificultad pueden no ser resueltas por algunos estudiantes, por lo que sería conveniente diseñar tareas con distintos niveles de dificultad para que todos consigan el objetivo planteado. Asimismo, las tareas denominadas "abiertas", utilizando estilos de enseñanza como la resolución de problemas, donde hay varias soluciones para resolver una situación, evitan la comparación y promueven el éxito de todos los estudiantes.

- Autoridad: si el alumnado puede ir tomando decisiones sobre cómo actuar seguramente adaptará elementos de su proceso de enseñanza-aprendizaje a sus capacidades, mientras que si es el docente es el que las impone, puede que no se adapten a su nivel, partiendo de la heterogeneidad que sabemos que existe en las clases. Es importante favorecer que los estudiantes tomen decisiones desde los primeros cursos; empezando con aspectos simples ( $p$. ej., elegir qué tipo de pelota usar en una tarea) para ir aumentando progresivamente la importancia de las decisiones a tomar (p. ej., elegir las tareas a realizar de un listado).

- Reconocimiento: se refiere a lo que el alumnado debe hacer para conseguir recompensas o elogios por parte de su profesor. Si la forma de conseguir ese elogio es marcar un gol, solo lo recibirán algunos. Sin embargo, si este reconocimiento viene determinado por el esfuerzo o la mejora, todos podrán recibirlo de su docente de forma individual o colectiva. Asimismo, el reconocimiento debe realizarse prioritariamente en privado y no en público, para evitar comparaciones.

- aGrupación: las agrupaciones por niveles favorecen las comparaciones $y$, por tanto, el clima ego, mientras que agrupaciones heterogéneas, flexibles y cambiantes lo reducen. La elección de grupos no es una cuestión menor y dejarla siempre en manos del "azar" o de los estudiantes podría provocar la creación de grupos por niveles. El docente debe "controlar" de manera directa o indirecta la creación de los grupos de 
estudiantes. Se puede ceder también autonomía al alumnado en la elección de las agrupaciones, siempre y cuando se establezcan una serie de requisitos establecidos por el docente.

- Evaluación: las evaluaciones o calificaciones normativas o comparativas favorecen el clima ego. Por lo tanto, es necesario desarrollar una evaluación criterial (basada en los criterios de evaluación a alcanzar), para que todo el alumnado pueda progresar en su aprendizaje. Asimismo, la evaluación debe ser formativa durante todo el proceso, no dándose exclusivamente al final de una unidad didáctica. El uso de instrumentos como las rúbricas, puede ayudar a los estudiantes a saber en qué punto de su aprendizaje se encuentran y lo que les queda por mejorar. La evaluación debe ser principalmente privada, evitando las clasificaciones públicas.
- Tiempo: es necesario que el tiempo sea ciertamente flexible para que todos tengan oportunidades de conseguir éxito en los objetivos de la tarea. Tiempos rígidos, donde todos los participantes comienzan y terminan a la vez, pueden provocar que aquellos estudiantes menos hábiles o que realizan las actividades más lentos tengan más dificultades para cumplir los objetivos de las tareas. En esta misma línea, el docente debe ayudar al alumnado a aprender a gestionar su tiempo y a programar su práctica.

A continuación, se desarrollan, en estas seis áreas TARGET, estrategias específicas en diferentes unidades didácticas para desarrollar un clima motivacional tarea. Todas están avaladas por estudios científicos previos (Morgan, 2017; Sevil et al, 2016; Weeldenburg et al., 2021). También se han identificado estrategias para generar un clima motivacional ego para que el profesorado de Educación Física pueda evitarlas. 


\section{Clima tarea: definir un criterio de éxito basado en la mejora personal o el dominio individual de una tarea}

Clima ego: definir un criterio de éxito comparativo entre el alumnado

En una unidad didáctica de carrera de larga duración de $6^{\circ}$ de Educación Primaria el objetivo principal es correr, andar o trotar a un ritmo uniforme durante 20 minutos. En este objetivo todo el alumnado puede experimentar éxito, independientemente de cuál sea su ritmo o nivel de partida.

En deportes de colaboración-oposición, el criterio de éxito de un juego reducido 4 vs. $4+$ 1 es intentar hacer más pases que la vez anterior. Cuando un equipo consigue el objetivo se intenta plantear uno más complejo. Cada equipo tiene una serie de retos individuales que debe poner en práctica en estos juegos reducidos.
En una unidad didáctica de carrera de larga duración el objetivo principal es correr el mayor número de metros posibles en 20 minutos.
En una sesión de acrosport, plantear en la ficha de la sesión hasta 5 tareas con diferentes niveles de dificultad en función del número de apoyos que pueden hacer en el suelo, que les permitan conseguir el objetivo. Si una no sale, pueden probar con otras alternativas que les llevan al mismo objetivo. Por ejemplo, 5 tareas con figuras de 5 apoyos, 4 apoyos y 3 apoyos. De cada bloque de 5 figuras, deben probar a realizar varias de menor a mayor dificultad. No es prioritario probarlas todas, sino intentar hacer al menos dos de cada bloque.
En deportes de colaboración-oposición el criterio de éxito de una tarea es hacer 10 pases antes que el equipo rival. Gana el equipo que más puntos consiga haciendo 10 pases o el que más pases haga.
En una sesión de acrosport, hasta que un grupo no consigue hacer bien la primera tarea que le plantea el profesor no puede pasar a la siguiente. Los demás avanzan, pero ese grupo se queda en la primera tarea. 


\section{Clima tarea: dejar algunas decisio- nes en manos del alumnado}

En una unidad didáctica de orientación, el alumnado puede elegir dónde y cómo se localizan las balizas. También puede consensuar el tiempo disponible para buscarlas. Si hemos definido varios niveles de dificultad, los estudiantes pueden decidir con cuál comenzar y luego subir o bajar el nivel en función de su éxito.

En una unidad didáctica de combas los estudiantes tienen que hacer una coreografía final. Pueden elegir cuántos pasos tendrá la coreografía, qué música utilizar, el orden de los pasos que van a elegir, el vestuario, el rol de cada integrante del grupo, etc. Esto hará que la coreografía se adapte a sus capacidades y puedan autorregularse para elaborarla. Además, se integrará al alumnado en la evaluación, pudiendo coevaluar a sus compañeros y consensuar los aspectos a evaluar.
Clima ego: todas las decisiones las toma el docente

En una unidad didáctica de orientación, el profesor plantea un único recorrido de orientación. Decide él mismo la dificultad de las balizas y los recorridos, siendo para unos muy difícil y para otros demasiado fácil.

En una unidad didáctica de combas, el docente prepara una coreografía y todos los grupos de estudiantes tienen que reproducirla. En la representación final, se calificará qué estudiantes y grupos lo hacen mejor y cuáles peor ante unos aspectos a valorar determinados por el docente. 
Clima tarea: los elogios y recompensas durante las clases provienen de haber mejorado y del esfuerzo en las actividades o sesiones
Clima ego: los elogios y recompensas vienen de hacerlo bien, tal y como el docente lo ha indicado, 0 de hacerlo mejor que los demás
Dar feedback privado y significativo durante toda la unidad didáctica. De esta forma, el estudiante o grupo sabe qué ha hecho bien y qué le falta por mejorar. Este feedback debe ser privado para que no se genere comparación entre estudiantes o grupos. Puede organizarse en forma de sándwich, destacando los aspectos positivos, lo que se debe mejorar y animando, finalmente, al alumnado a conseguirlo. Por ejemplo, “Muy bien!, habéis conseguido organizaros y desmarcaros y, por eso, habéis conseguido marcar. ¿Qué pensáis que podéis mejorar? Nos fijamos entonces ahora en esos aspectos. ¡Contabilizad el número de veces que recibís completamente solos!"
Celebrar y premiar cuando un/a estudiante mete gol, sin valorar el proceso por el que se ha conseguido. Por ejemplo, "¡Muy bien Luara!, ¡fantástico!”. Es posible que en ese resultado hayan participado otros jugadores, pero solo uno recibe el reconocimiento. Además, solo se valora el resultado final. El docente no tiene en cuenta los principios técnico-tácticos que se han puesto en marcha durante la acción que ha propiciado el gol. En este sentido, es importante restar valor al gol y premiar un desmarque, un pase libre de marca, las acciones técnico-tácticas de todo el equipo atacante, etc.
En unidades didácticas donde se usa la gamificación no usar clasificaciones de los equipos/grupos, ni comparaciones de los resultados entre ellos. Se debe premiar el logro (insignias) en base al esfuerzo o progreso individual y/o grupal, pero sin tener que "ganar" a los demás para conseguirlo.
En algunas propuestas de unidades didácticas, basadas en la gamificación, el uso de insignias y reconocimientos, acompañados de una clasificación pública, hace que se refuerce solo a los primeros. Esto desmotiva a aquellos que van más abajo en la clasificación, aunque se estén esforzando y hayan progresado en sus aprendizajes. Por ejemplo, el uso del Kahoot, donde aparecen en la pantalla quién va en los tres primeros puestos puede hacer que el alumnado no se esfuerce, al considerar que no tiene opciones de ganar, ya que está muy lejos de la puntación de los primeros puestos. 
En una unidad didáctica de carrera de larga duración, Alberto ha progresado con su grupo de compañeros. El docente, al organizar al alumnado en grupos reducidos, puede acercarse en cada sesión a cada uno de ellos, dando feedback basado en las mejoras conseguidas y reforzando que, si siguen esforzándose, podrán pasar a un nivel más alto en la siguiente clase.
En una unidad didáctica de carrera de larga duración, Laura ha progresado enormemente. Comenzó andando a un ritmo lento, teniendo que pararse varias veces. A final de la unidad didáctica ha sido capaz de mantener un ritmo uniforme. A lo largo de las sesiones, el docente no le ha dado ningún feedback porque ha recorrido menos metros que los demás. 
Clima tarea: agrupaciones flexibles y heterogéneas que no marquen de inicio diferencias entre los grupos
Clima ego: agrupaciones por niveles o que no cambien a lo largo de varias tareas (aunque existen excepciones que así lo requieren como las agrupaciones estables cuando se usa el Modelo de Educación Deportiva). Agrupaciones desequilibradas al hacerlas siempre al azar o por elección del alumnado
Plantear equipos conformados por el docente, que respeten criterios de amistad, equidad de género, niveles de habilidad motriz, etc.
En deportes de colaboración-oposición, nombramos dos capitanes para que hagan los equipos. Los más hábiles motrizmente son nombrados públicamente en primer lugar, mientras que los menos hábiles son elegidos los últimos.
En una sesión de palas, hacemos situaciones competitivas incidiendo en un principio táctico determinado. Cada 4 minutos se cambia rotando los campos hacia la derecha, independientemente de cuál haya sido el resultado.
En una sesión de palas jugamos al "rey de la pista". Se hacen 6 canchas de juego, con partidos de 5 minutos. Si ganas subes de nivel y rotas hacia la derecha, mientras que si pierdes bajas de nivel y rotas a la izquierda.
En deportes de colaboración-oposición, se forman equipos heterogéneos que se enfrentan entre sí. En cada partido se intenta avanzar hacia la portería contraria sin perder el balón. Cada equipo intenta mantener un tiempo mínimo la posesión independientemente del rival que tengan y se analiza, en las rotaciones, qué elementos deben mejorar para conseguir el objetivo.
En deportes de colaboración-oposición, el docente realiza varios equipos de 4-5 personas, en función de su nivel, y compiten entre ellos en una liga A y una liga B. 
Clima tarea: los criterios de éxito de las tareas, sesiones o unidad didáctica se definen en base al aprendizaje, la mejora y el esfuerzo experimentados. La evaluación y calificación se define en base al grado de adquisición de los estándares de aprendizaje, valorando el progreso del alumnado.
Clima ego: el criterio de éxito de la tarea, sesión o unidad didáctica es hacerlo mejor que los demás. La evaluación y calificación se define en base al rendimiento de unos respecto a otros o de puntuaciones estandarizadas.
En esa unidad didáctica de carrera de larga duración, mencionada anteriormente, el alumnado compara la gráfica inicial de su ritmo y la gráfica final. Pueden observar cómo pasan de un ritmo irregular a uno mucho más regular. Además, si han mejorado el ritmo, su gráfica final también lo indicará. La calificación obtenida se obtiene por el grado de adquisición de los aprendizajes, así como el progreso experimentado.
En esa unidad didáctica de carrera de larga duración, tras varias sesiones probando distintos métodos de entrenamiento de la resistencia, se hace una "course navette" que determinará la calificación obtenida. Los estudiantes que lleguen a 10 periodos tendrán un 10, descendiendo esa calificación en función del número de periodos realizados.
En deportes de colaboración-oposición o de cancha dividida se compara, en diferentes momentos de la evaluación (inicial, continua y final), el desempeño del alumnado respecto a sí mismo. Además, en esta comparación se valora mayoritariamente el aprendizaje táctico y la toma de decisiones, independientemente del resultado que se haya tenido.
En deportes de colaboración-oposición o de cancha dividida se hace un torneo final. El puesto obtenido en el torneo determina la nota de la unidad didáctica, en mayor o menor medida. Además, se otorga un punto extra a los estudiantes que mejor realizan las acciones técnicas del deporte en concreto, en situaciones aisladas y descontextualizadas. 


\section{Clima tarea: el tiempo es adaptable por el alumnado o el grupo}

En una unidad didáctica de acrosport el docente reparte un material curricular con diferentes figuras gimnásticas para que el alumnado las vaya haciendo de manera autónoma en parejas o en pequeños grupos. Las figuras tienen diferentes niveles de dificultad. De este modo, el alumnado puede autorregularse, dedicando más o menos tiempo a cada figura en función de su habilidad motriz y las preferencias del grupo. Si en la siguiente clase no ha dado tiempo a acabarlas, el alumnado puede retomar el trabajo. El alumnado con menos habilidad motriz tiene tiempo para percibirse competente en algunas figuras, mientras que el alumnado con más habilidad puede ampliar el repertorio de figuras o incluso crear algunas nuevas.

En una unidad didáctica de combas el alumnado consensua con el docente de Educación Física hacer una clase más para preparar la coreografía porque todavía existen errores en algunos pasos y enlaces. El docente accede a esta petición porque el alumnado ha aprovechado las clases y le interesa que salga la coreografía lo mejor posible para que el alumnado tenga una experiencia positiva.

El profesorado de Educación Física de un departamento plantea realizar unidades didácticas de entre 10 y 16 sesiones para que todo el alumnado pueda percibir un mayor progreso. El alumnado podrá dialogar y consensuar con el profesorado de Educación Física el número de clases finales en función del tiempo que necesite para adquirir los aprendizajes.

\section{Clima ego: el tiempo es inalterable y es el mismo para todos}

En una unidad didáctica de acrosport todas las tareas tienen la misma duración para todos. El docente indica cuándo es el inicio y el final. Los estudiantes más hábiles motrizmente se aburren porque ya han terminado la tarea 0 han conseguido el objetivo, mientras que los menos hábiles se perciben incompetentes, o tienen menos oportunidades para percibir éxito en la tarea, porque no les da tiempo nunca a terminar lo que les piden.
En una unidad didáctica de combas el alumnado tiene que hacer la coreografía en la fecha pactada porque la siguiente semana empieza otra unidad didáctica. El alumnado tiene más probabilidades de experimentar fracaso en la realización de la coreografía por falta de tiempo en su preparación.
El profesorado de Educación Física de un departamento realiza unidades didácticas de entre 5 y 6 sesiones para que el alumnado menos hábil motrizmente no se frustre si no le gusta y el alumnado más hábil no se aburra. 


\section{3.- PARA SABER MÁS...}

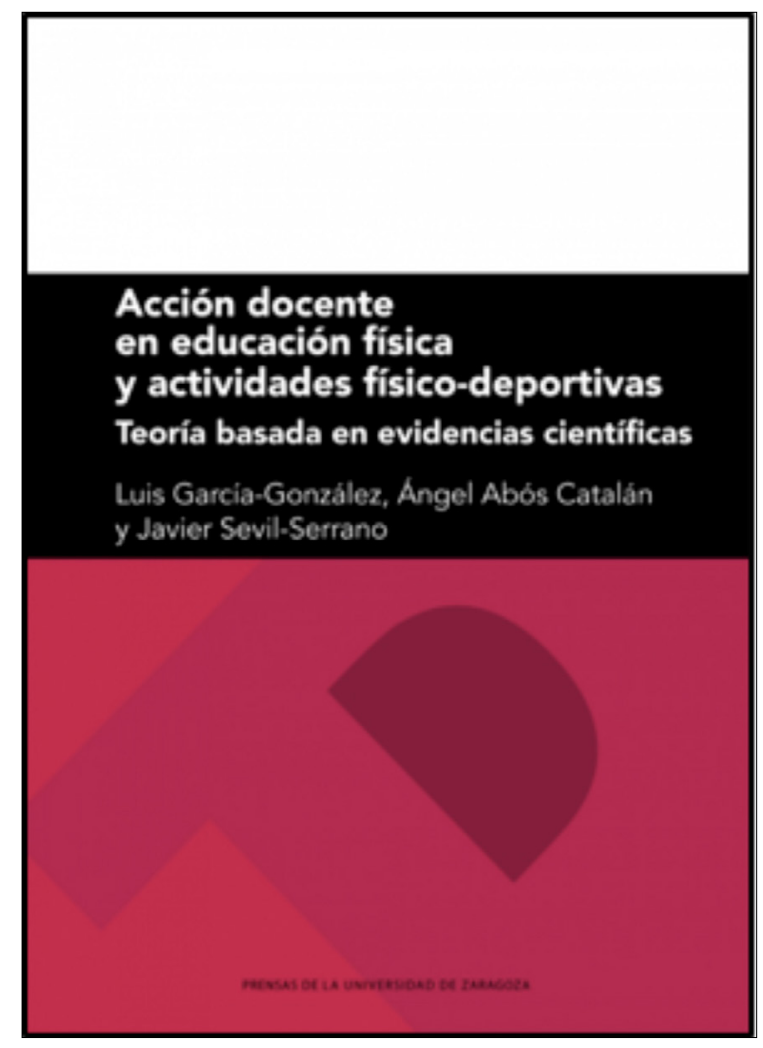

Si quieres profundizar sobre climas motivacionales y estrategias específicas para las clases de Educación Física, te proponemos, en el listado final, algunas referencias que te pueden ser útiles. Además, en un libro titulado "Acción docente en Educación Física y actividades físico-deportivas. Teoría basada en evidencias científicas" aparece un capítulo más amplio sobre el clima motivacional. Lo puedes adquirir a través de este enlace: https://puz.unizar.es/2360-accion-docenteen-educacion-fisica-y-actividades-fisico-deportivas-teoria-basada-en-evidencias-cientificas.html

\section{TBES NOELTAS La Carrera al PATOO en la escuela}

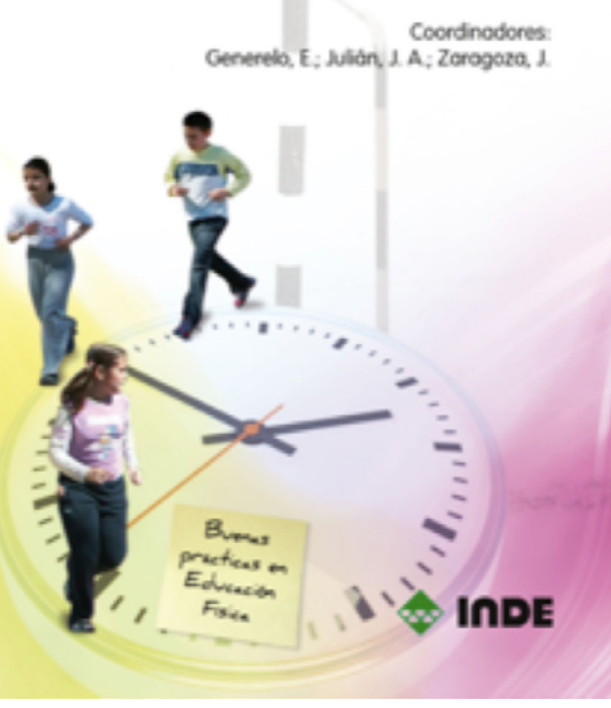

El libro "Tres vueltas al patio" desarrolla de forma muy detallada cómo realizar una unidad didáctica de resistencia denominada "Carrera de Larga Duración - CALADU". Recoge diferentes estrategias, basadas en las áreas TARGET, para desarrollar un clima motivacional tarea en esta unidad didáctica. Además, hay una web denominada "CaladuCapas" que te permite hacer la gestión de este contenido de una forma muy sencilla: https://caladu-capas.unizar.es 


\section{4.- REFERENCIAS BIBLIOGRÁFICAS}

Abós, Á., Sevil, J., Julián, J. A., Abarca-Sos, A., y GarcíaGonzález, L. (2017). Improving students' predisposition towards physical education by optimizing their motivational processes in an acrosport unit. European Physical Education Review, 23(4), 444-460. https://doi.org/10.1177/1356336X16654390

Ames, C. (1992). Classrooms: Goals, structures, and student motivation. Journal of Educational Psychology, 84(3), 261-271.

https://doi.org/10.1037/0022-0663.84.3.261

Braithwaite, R., Spray, C. M., y Warburton, V. E. (2011). Motivational climate interventions in physical education: A meta-analysis. Psychology of Sport and Exercise, 12(6), 628-638. https://doi.org/10.1016/j.psychsport.2011.06.005

Di Battista, R., Robazza, C., Ruiz, M. C., Bertollo, M., Vitali, F., y Bortoli, L. (2019). Student intention to engage in leisure-time physical activity: the interplay of taskinvolving climate, competence need satisfaction and psychobiosocial states in physical education. European Physical Education Review, 25(3), 761-777. https://doi.org/10.1177/1356336X18770665

Duda, J. L. (2005). Motivation in sport: The relevance of competence and achievement goals. En A. J. Elliot y C. S. Dweck (Eds.), Handbook of competence and motivation (pp. 318-335). Guilford Press.

García-González, L., Sevil-Serrano, J., Abós, A., Aelterman, N., y Haerens, L. (2019). The role of task and egooriented climate in explaining students' bright and dark motivational experiences in Physical Education. Physical Education and Sport Pedagogy, 24(4), 344-358. https://doi.org/10.1080/17408989.2019.1592145
Harwood, C. G., Keegan, R.J., Smith, J. M.,y Raine,A.S. (2015). A systematic review of the intrapersonal correlates of motivationalclimateperceptionsinsportand physicalactivity. Psychology of Sport and Exercise, 18, 9-25.

https://doi.org/10.1016/j.psychsport.2014.11.005

Morgan, K. (2017). Reconceptualizing motivational climate in physical education and sport coaching: An interdisciplinary perspective. Quest, 69(1), 95-112. https://doi.org/10.1080/00336297.2016.1152984

Nicholls, J. G. (1989). The competitive ethos and democratic education. Harvard University Press.

Roberts, G. C. (2001). Understanding the dynamics of motivation in physical activity: The influence of achievement goals on motivational processes. En G. C. Roberts (Ed.), Advances in motivation in sport and exercise (pp. 1-50). Human Kinetics.

Sánchez-Alcaraz, B., Gómez-Mármol, A., y Más, M. (2016). Estudio de la motivación de logro y orientación motivacional en estudiantes de educación física. Apunts Educación Física y Deportes, 32(124), 35-40. https://doi.org/10.5672/apunts.2014-0983. es.(2016/2).124.03

Sevil, J., Abós, Á., Aibar, A., Julián, J. A., y García-González, L. (2016). Gender and corporal expression activity in physical education: Effect of an intervention on students' motivational processes. European Physical Education Review, 22(3), 372-389. https://doi.org/10.1177/1356336X15613463

Weeldenburg, G., Borghouts, L. B., Slingerland, M., y Vos, S. (2021). Through students' eyes: preferred instructional strategies for a motivating learning climate in secondary school physical education. Curriculum Studies in Health and Physical Education, 1-19. https://doi.org/10.1080/25742981.2021.1889383 


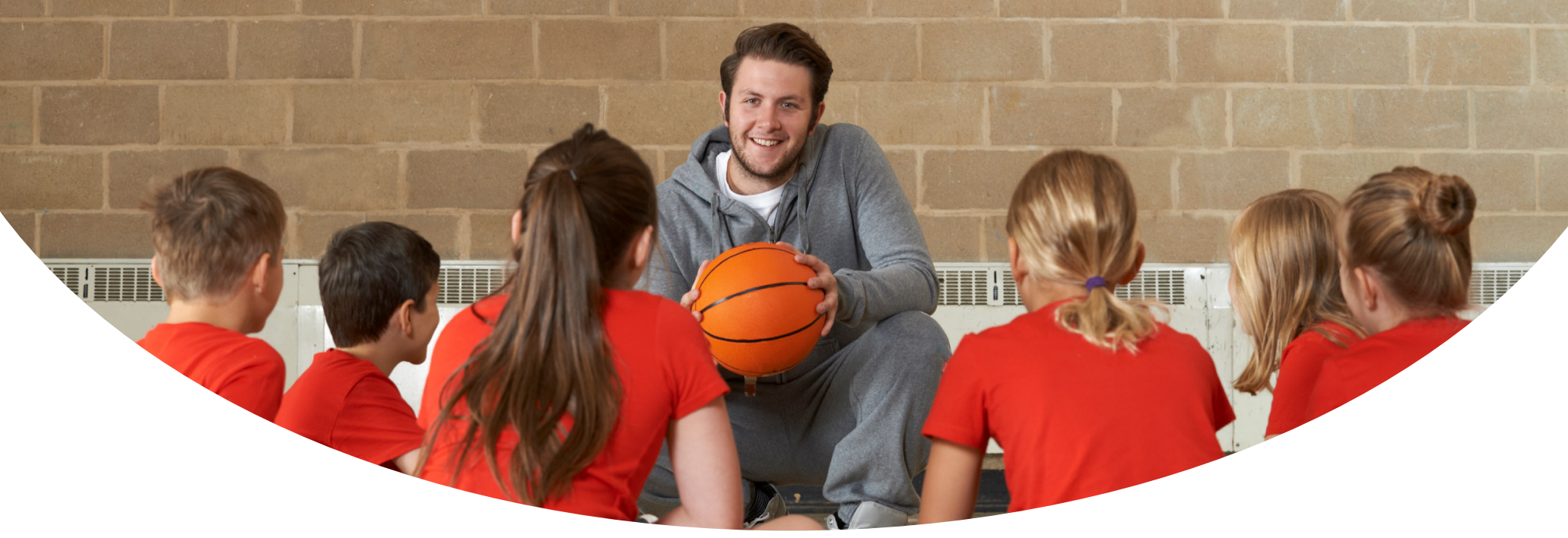

Capítulo 2.3.

\section{LA IMPORTANCIA DE LAS CONDUCTAS MOTIVACIONALES DOCENTES EN EDUCACIÓN FÍSICA: ESTRATEGIAS DIDÁCTICAS DE INTERVENCIÓN}

Autores: Luis García-González¹, Javier Sevil-Serrano², Rafael Burgueño³ y Ángel Abós.

1Universidad de Zaragoza; ${ }^{2}$ Universidad de Extremadura; ${ }^{3}$ Universidad de Almería. 


\section{1.- EVIDENCIAS CIENTÍFICAS}

n ocasiones, como docentes de Educación Física, afirmamos que tenemos estudiantes poco motivados hacia la asignatura, lo cual, muchas veces conlleva conductas disruptivas, aburrimiento, falta de interés y esfuerzo del alumnado. En este punto, debemos hacernos la siguiente pregunta: ¿La motivación del alumnado es algo inherente a cada estudiante o puede depender de lo que cada docente haga? Si pensamos que la motivación del alumnado depende exclusivamente de ellos mismos, nuestras posibilidades de cambiar esta situación son muy escasas. Sin embargo, si entendemos que nuestras conductas, como docentes, pueden influir directamente sobre la motivación del alumnado estamos yendo en la dirección adecuada. De hecho, la evidencia científica nos ayuda a resolver algunas de las siguientes cuestiones: ¿Cómo influye la forma que el docente tiene de dar clase en la motivación del alumnado?, ¿existen estrategias didácticas que pueden favorecer la motivación de los estudiantes?, ¿algunas conductas docentes pueden generar el efecto contrario, desmotivando al alumnado?

En primer lugar, hay que destacar que el docente de Educación Física, dentro y fuera de sus clases, tiene la posibilidad de favorecer experiencias positivas que fomenten no solo el aprendizaje, sino también la práctica de actividad física en la adolescencia y, posteriormente, en la vida adulta (Ladwig et al., 2018; más información en el Capítulo 1.2. sobre el modelo trans-contextual de la motivación). Para ello, según la teoría de la autodeterminación (Ryan y Deci, 2017, ver Capítulo 1.1.), el denominado estilo interpersonal, o también Ilamado estilo motivacional del docente de Educación Física, puede influir de forma destacada en la satisfacción o en la frustración de la autonomía, la competencia y las relaciones sociales del alumnado. Según dicha teoría, la satisfacción de las necesidades psicológicas básicas se relaciona con una motivación más autodeterminada y consecuencias de índole afectivo (p. ej., diversión), cognitivo (p. ej., atención) y comportamental (p. ej., intención de práctica de actividad física) en las clases de Educación Física. Para ello, el docente de Educación Física puede utilizar distintas estrategias didácticas relacionadas con el diseño de las tareas o con la propia intervención docente (González-Cutre, 2017).

Existe un modelo teórico, denominado modelo circular (Aelterman et al., 2019; EscrivaBoulley, 2021), que explica que los docentes de Educación Física pueden desarrollar hasta cuatro estilos motivacionales diferentes. Por un lado, el estilo de apoyo a la autonomía ayuda a satisfacer la autonomía del alumnado, mientras que el estilo controlador genera frustración de la autonomía. Por otro lado, el estilo estructurado apoya la percepción de competencia de los estudiantes en las clases, mientras que el estilo caótico favorece su frustración. A su vez, cada estilo motivacional docente está compuesto por dos conductas, haciendo un total de ocho conductas (ver Figura 1). A continuación, pasamos a describir cada uno de los estilos y conductas que puede adoptar el profesorado de Educación Física en su intervención docente. 


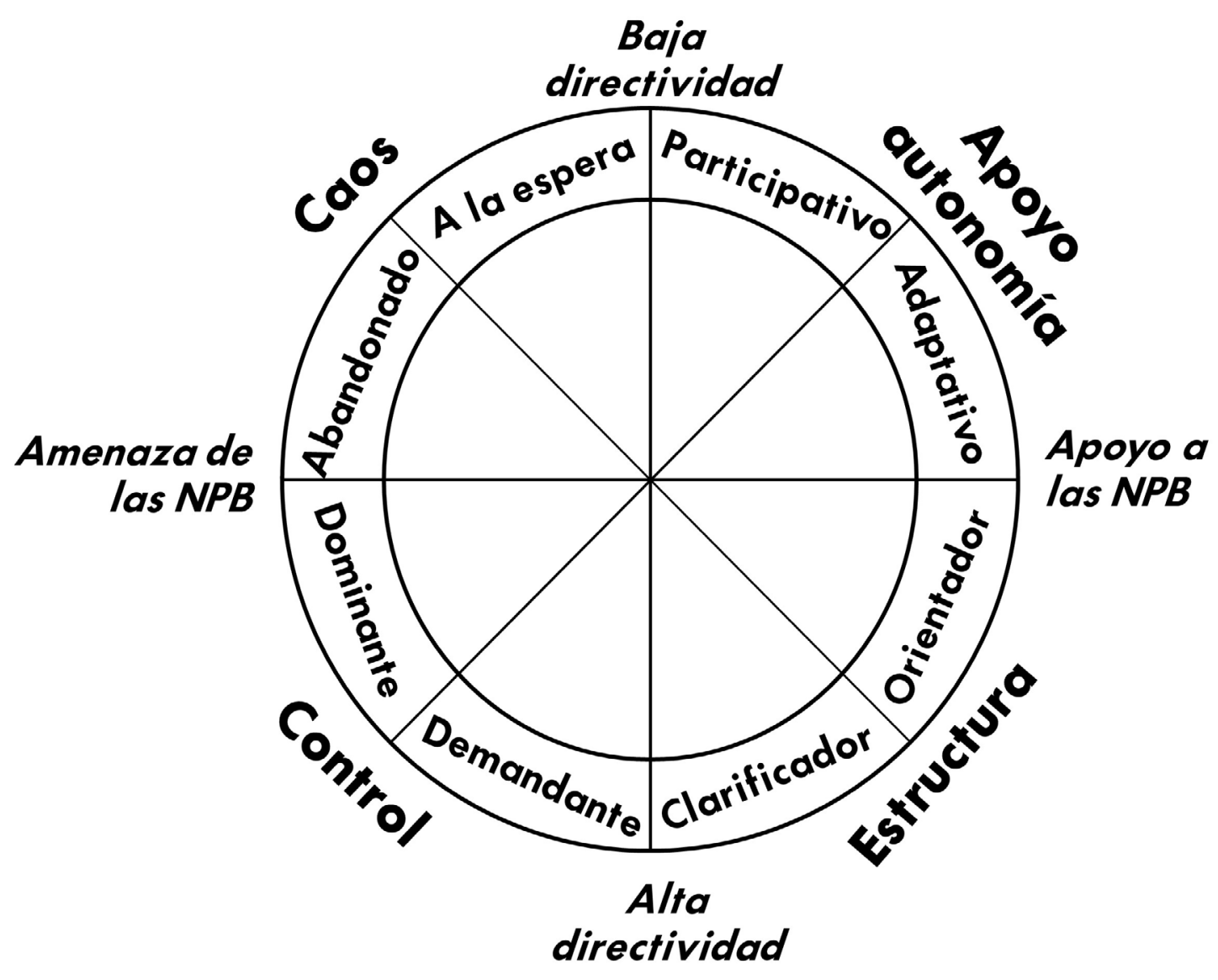

FigURA 1. REPRESENTACIÓN GRÁFICA DE LOS ESTILOS Y CONDUCTAS MOTIVACIONALES DOCENTES SEGÚN EL MODELO CIRCUlar. Traducido de Aelterman et al. (2019). Tomado de García-González et al. (2021).

NotA: NPB = NECESIDADES PSICOLÓGICAS BÁSICAS. EN LA PARTE EXTERIOR DEL CÍRCULO SE ESTABLECEN LOS CUATRO ESTILOS MOTIVACIONALES. EN LA PARTE INTERIOR DEL CÍRCULO, SE PUEDEN OBSERVAR LAS OCHO CONDUCTAS MOTIVACIONALES, APARECIENDO DOS CONDUCTAS EN CADA ESTILO MOTIVACIONAL. EN EL EJE VERTICAL, SE CLASIFICAN LOS ESTILOS Y CONDUCTAS EN FUNCIÓN DEL NIVEL DE DIRECTIVIDAD ASOCIADO A LAS CONDUCTAS MIENTRAS QUE, EN EL EJE HORIZONTAL, EN FUNCIÓN DEL NIVEL DE APOYO O AMENAZA A LAS NPB. 

mía y de las conductas participativas y adaptativas

\section{Estilo de apoyo a la autonomía}

El docente desarrolla un estilo basado en la comprensión, tratando de alimentar los intereses, opiniones y sentimientos de los estudiantes, con la finalidad de que el alumnado sea el centro del proceso de enseñanza-aprendizaje. Esto favorece su toma de decisiones, implicación y responsabilidad en las clases de Educación Física. Es un estilo que debe aplicarse de forma progresiva para que el alumnado pueda elegir o asumir las responsabilidades que se desprenden de la autonomía que se cede. Además, la aplicación de apoyo a la autonomía debe estar adaptada al contexto, grupo clase, edad o responsabilidad del grupo.

\section{Conductas participativas}

Un docente que adopta conductas participativas identifica los intereses de los estudiantes a través del diálogo para, posteriormente, intentar que participen en el proceso, tomando decisiones, eligiendo actividades y elementos de las mismas y asumiendo responsabilidades. Además, trata de implicarles, invitándoles a proponer y a sugerir actividades.

\section{Conductas adaptativas}

El docente que implementa conductas adaptativas se muestra empático con los estudiantes. Así, intenta nutrir los intereses personales del alumnado, tratando de encontrar la forma en que las actividades sean más motivantes, agradables y divertidas. Asimismo, el docente acepta posibles expresiones negativas de afecto y trata de comprender la perspectiva de su alumnado. Suele aportar explicaciones y razones sobre por qué se hacen determinadas actividades. 


\section{Descripción del estilo estructurado y de las conductas orientadoras y clarificadoras}

\section{Estilo estructurado}

El docente desarrolla un rol de guía y orientador del alumnado. Para ello, parte siempre de las capacidades de sus estudiantes, con objeto de que perciban que progresan y se sientan competentes. En este estilo, el docente trata de adaptar las tareas a las capacidades de cada estudiante, tratando de progresar en los objetivos didácticos propuestos. Este elemento es uno de los más complejos de conseguir, puesto que no es sencillo generar y desarrollar tareas adaptadas a las características heterogéneas de un grupo clase.

\section{Conductas orientadoras}

El docente que aplica conductas orientadoras fomenta el progreso de su alumnado, aportando ayuda y asistencia cuando es necesario, así como ejerciendo de guía para ellos. Aunque el alumnado tiene autonomía para progresar en su aprendizaje, puede hacer preguntas al profesorado cuando sea necesario. El docente, por su parte, les va orientado y proporcionando los pasos necesarios para progresar en su aprendizaje. Junto con los estudiantes, reflexiona sobre los errores, para que vean lo que pueden seguir mejorando y cómo hacerlo.

\section{Conductas clarificadoras}

El docente que implementa conductas clarificadoras comunica las expectativas que tiene a su alumnado de forma clara y transparente. Ofrece una visión general de los aprendizajes a conseguir, a diferentes niveles (unidad didáctica, sesión y situaciones de trabajo), y les va informando del grado de cumplimiento de los mismos. Esta información del progreso es clave para reorientar las tareas y para que el alumnado sea consciente de lo que ha conseguido y lo que le queda por aprender. 

conductas demandantes y dominadoras

\section{Estilo controlador}

El docente desarrolla un estilo basado, fundamentalmente, en la presión y el control de la clase, forzando al alumnado a pensar, sentir y comportarse de una manera prescrita, independientemente de lo que los estudiantes opinen. El profesorado controlador impone un camino de aprendizaje determinado, a pesar de saber que la heterogeneidad de los grupos hace que pueda haber múltiples opciones para llegar al mismo resultado. Este estilo frustra la autonomía del alumnado, ya que el docente es el centro de enseñanza-aprendizaje, tomando todas las decisiones. Aunque pueden parecer conductas útiles para el control de un grupo, especialmente al inicio de un curso o cuando existen conductas disruptivas, esto puede desembocar en el efecto contrario, encontrándose conductas de oposición desafiante por parte del alumnado como respuesta a un estilo excesivamente controlador.

\section{Conductas demandantes o exigentes}

El docente que implementa conductas demandantes hace uso de un lenguaje controlador, con un tono de voz y lenguaje corporal de disciplina (p.ej. "tienes que hacerlo de esta manera, tú debes..."), para ordenar y exigir al alumnado que se comporte de un determinado modo o que desarrolle una tarea de la forma en la que se le indica. El docente demandante no permite que le lleven la contraria, amenazando con sanciones o castigos si no le obedecen o si no hacen las tareas prescritas de la forma que les ha indicado.

\section{Conductas dominantes}

El docente que adopta conductas dominantes ejerce un rol de poder sobre su alumnado para que cumplan con lo que se les pide. Para ello, reprime a los estudiantes, induciendo a sentimientos de culpa, vergüenza y ansiedad, pudiendo sentir los estudiantes que es un ataque más personal. Por ejemplo, realizar gestos de desaprobación mientras se mira a un alumno/a en concreto, o algunos gestos y lenguaje no verbal de desaprobación o desencanto con el resultado del alumnado, les hace sentir cierta culpa por no conseguir la aprobación de su docente. 


\section{Estilo caótico o desestructurado}

Es un estilo basado fundamentalmente en el "dejar hacer" (laissez faire), muy identificado con un estilo de permisividad e indiferencia. Este estilo docente se caracteriza por una excesiva libertad, permitiendo al alumnado hacer lo que quiera y generando confusión sobre lo que realmente tienen que hacer, cómo deben comportarse y cómo tiene que actuar o desarrollar las tareas y actividades. Además, les impide saber si lo que hacen es correcto y, por tanto, si cumplen los objetivos didácticos propuestos.

\section{Conductas de abandono}

El docente, después de repetidas intervenciones, se desentiende, se da por vencido o no presta atención a los estudiantes o a un grupo concreto de ellos. Les permite hacer lo que quieran y ya no les incita a esforzarse, con la excusa de que ellos deben responsabilizarse de su propio aprendizaje. Expresiones como: "yo ya no lo repito más, tú sabrás lo que tienes que hacer...", así como no ofrecer estrategias para mejorar en una tarea serían ejemplos de estas conductas de abandono.

\section{Conductas a la espera}

El docente que genera estas conductas, cede la iniciativa totalmente a los estudiantes (dejar hacer) después de proponer una actividad. Existe una escasa estructuración de la sesión. El alumnado debe evolucionar sin la guía del profesor, con el posible riesgo de no estar trabajando correctamente. Por ejemplo, intentar que los estudiantes sean autónomos y tomen sus propias decisiones, cuando todavía no están preparados para ello, sería una muestra de estas conductas a la espera. 


\section{2.- APLICACIONES PRÁCTICAS PARA LA DOCENCIA DE LA EDUCACIÓN FÍSICA}

a aplicación didáctica principal de este modelo circular (Aelterman et al., 2019; Escriva-Bulley at al., 2021) es que el docente sea consciente de que existen una serie de conductas que pueden llevar a la satisfacción de las necesidades psicológicas básicas (autonomía, competencia y relaciones sociales) del alumnado. A su vez, la satisfacción de dichas necesidades les generará una motivación más autodeterminada (p. ej., motivación intrínseca) hacia la Educación Física. Es decir, si gracias a las conductas adoptadas por el docente, el alumnado percibe que puede tomar decisiones y sentirse partícipe de su proceso de enseñanza-aprendiza-

je (autonomía), progresa respecto a su nivel inicial (competencia) y se encuentra integrado en su grupo de iguales (relaciones sociales), será más probable que esté más motivado intrínsecamente en las clases de Educación Física. De igual modo, cabe destacar que, aunque a veces no nos lo parezca, existen una serie de conductas docentes que des-

\section{iza-}

encadenan una motivación más extrínseca o desmotivación, debido a la frustración de las necesidades psicológicas básicas que provocan. A continuación, se detallarán ejemplos, a nivel de unidad didáctica y de una sesión o tarea, de aquellas conductas que deben maximizarse (conductas participativas y adaptativas del estilo de apoyo a la autonomía y conductas clarificadoras y orientadoras del estilo estructurado) y minimizarse (conductas demandantes y dominantes del estilo controlador y conductas de abandono o a la espera del estilo caótico), con el objetivo de obtener

consecuencias más positivas en el alumnado.

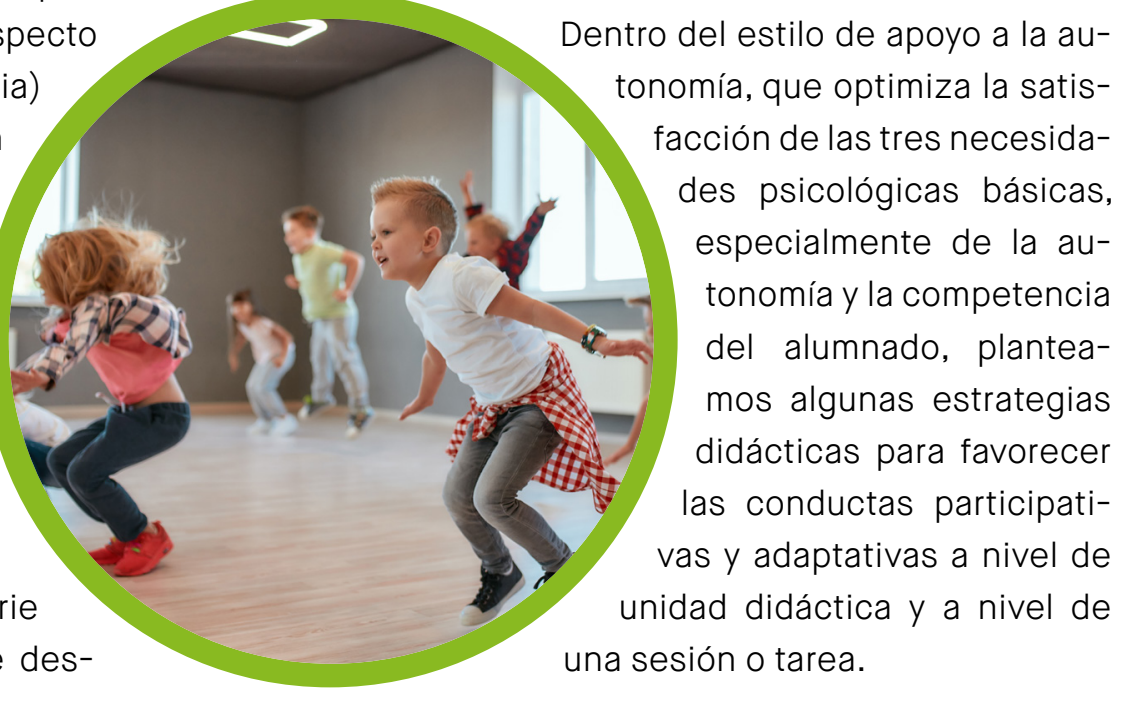




\section{Ejemplos de estrategias para desarrollar conductas parti- cipativas}

\section{A nivel de unidad didáctica:}

- Preguntar al alumnado sobre qué contenidos, dentro de un dominio de acción, quiere realizar, o darles a elegir entre varios que tengan una lógica interna muy similar. Por ejemplo, para trabajar un deporte de colaboraciónoposición el alumnado podría elegir, de forma democrática, entre hacer fútbol sala o balonmano. Los aprendizajes técnico-tácticos, vinculados a un deporte de colaboración-oposición pueden ser similares y el grupo puede consensuar cuál le interesa o motiva practicar más.

- Consensuar con el alumnado los objetivos y criterios de evaluación a trabajar en esa uni- dad didáctica. También se podría ceder autonomía en los porcentajes de calificación que tendrá cada criterio de evaluación y estándar de aprendizaje al final de la unidad didáctica. Para dar argumentos significativos, el profesorado explicará por qué deben tener un mínimo o máximo cada uno de ellos.

- Al inicio de una unidad didáctica, para establecer las normas y rutinas que van a desarrollarse a lo largo del curso, se puede invitar al alumnado a que reflexione y sugiera algunas que crean importantes. Este hecho, podría ayudarles a percibir que son ellos quienes marcan las normas, lo cual les hace conocerlas mucho mejor y respetarlas.

\section{A nivel de una sesión o una tarea:}

- Los últimos minutos de cada una de las sesiones de la unidad de combas, el alumnado puede crear diferentes pasos de comba individual, comba larga y comba doble, diferentes a los trabajados en clase. Esto les permitirá integrarlos en la coreografía que se diseñará en las tres últimas sesiones de la unidad didáctica.

- En una tarea de bate y carrera, el alumnado puede elegir el modo con el que batear (p. ej., con la mano, con una raqueta de pádel, con una raqueta de tenis o con un bate) en función del objetivo de la tarea y su nivel de habilidad. El alumnado tendrá la oportunidad de poder golpear con los distintos tipos de bates para identificar con cuál es más eficaz. Se pretende que la acción técnica de batear no sea un impedimento para realizar la actividad.

- En una actividad cooperativa, para promover conductas participativas, el profesorado les pide a los estudiantes que debatan en pequeños grupos $y$, posteriormente, les invita a que lo debatan con otros grupos para encontrar una solución conjunta. 
- Ante una situación de una figura de acrosport, puede que alguna de las figuras les dé miedo o les genere algo de ansiedad. Entonces, el profesorado puede ofrecer la posibilidad de que puedan intentar otra figura que les dé menos miedo. Igualmente, en la ficha de figuras de acrosport, el docente puede proponer distintos niveles de dificultad y preguntarles a los estudiantes en qué nivel les gustaría practicar para ir adaptándose a su nivel. 


\section{Ejemplos de estrategias para desarrollar conductas adap- tativas}

\section{A nivel de unidad didáctica:}

- A principio de curso, el docente establece la normativa sobre ropa y calzado deportivo para el desarrollo de las clases. Sin embargo, observa que, a lo largo de la primera unidad didáctica, algunos estudiantes no la cumplen. En este caso, antes de sancionarles, les explica con detalle a los estudiantes por qué es necesario llevar unas zapatillas deportivas adecuadas (higiene, evitar una lesión, etc.). Es importante asegurarse que el motivo no es por cuestiones económicas antes de amonestar a nadie.
- Si a lo largo de varias sesiones el docente percibe que hay varios estudiantes que discuten entre ellos o que molestan al resto, les puede explicar en privado las razones por las que le gustaría que se comportasen correctamente. Posteriormente, puede hablar con ellos por separado y en privado, con el objetivo de escucharlos para saber qué piensan ellos sobre lo que ha pasado estos días, animándolos a que propongan soluciones para solventarlo.

\section{A nivel de una sesión o una tarea:}

- Preparar variantes de las tareas con mayor y menor nivel de dificultad que trabajen el mismo objetivo. Si un estudiante no consigue realizar el nivel intermedio de dificultad, estas variantes les ofrecen la posibilidad de alcanzar los objetivos de la tarea de forma más simple o secuenciada. Por ejemplo, si en una tarea de baloncesto planteamos un 3 vs. 3, antes de pasar a una situación de 5 vs. 5 más real, sería importante tener como alternativa situaciones de 3 vs. 2 o de 3 vs. $3+1$ (comodín) que también puedan plantearse si la situación de 3 vs. 3 acaba resultando compleja. Será necesario argumentar al alumnado por qué es necesario hacer ese 3 vs. 2. El estudiante que sale del juego puede ejecutar el rol de entrenador/a, anotador/a o evaluador/a, dando feedback o consejos a los atacantes.

- Aportar explicaciones para razonar por qué una tarea puede ser complicada, o por las que es necesario probar a hacerlo de una determinada forma. Por ejemplo, cuando el docente se acerca a un grupo a darle feedback, que este no sea un feedback meramente correctivo o prescriptivo. Es decir, cuando el alumnado no consigue realizar una tarea, sería positivo proporcionar un feedback que incluya razones del por qué todavía no les sale esta tarea y del por qué sería necesario hacer una habilidad más sencilla antes, evitando siempre que se puedan comparar con otros grupos.

- Para cambiar de una actividad a otra dentro de una sesión, el docente debe intentar tener paciencia con aquellos estudiantes que se están esforzando por conseguirlo y decirles que todavía tienen tiempo para terminar dicha tarea. El docente puede alargar el tiempo o también podría realizar pequeñas variantes más simples para facilitar su consecución. Es importante no cambiar de actividad para no frustrar la competencia del alumnado que se está esforzando y no le sale. De igual modo, se pueden realizar variantes o retos más complejos para los estudiantes que sí han acabado la tarea, evitando que se aburran o molesten a los demás.

Dentro del estilo estructurado, que fomenta la percepción de competencia del alumnado, indicamos algunos ejemplos de conductas orientadoras y clarificadoras que pueden desarrollarse en las clases de Educación Física, tanto a nivel de unidad didáctica como a nivel de sesión. 


\section{Estrategias docentes orientadoras y clari- ficadoras}

\section{Ejemplos de estrategias para desarrollar conductas orien- tadoras}

\section{A nivel de unidad didáctica}

- Establecer, de manera sistemática, evaluaciones al comienzo y durante toda la unidad didáctica permitirá al profesorado ir reorientando las sesiones en función de la progresión del alumnado en su aprendizaje. De este modo, el alumnado podrá también autorregularse, siendo más consciente del punto en el que se encuentra y lo que le queda por mejorar. Además, al ser conscientes de sus avances, les ayudará a percibirse competentes.
- En una situación de evaluación de la unidad didáctica de carrera de larga duración, algunos estudiantes, no consiguen mantener un ritmo uniforme. A través de feedback explicativo o interrogativo, el docente puede tratar de ayudar al alumnado a mejorar en este objetivo didáctico de esta unidad. A partir de las respuestas de los estudiantes, se pueden establecer pequeños objetivos y retos a corto plazo para conseguir un ritmo más uniforme.

\section{A nivel de una sesión o una tarea:}

- Ante una tarea o situación compleja, el profesorado puede desglosar e indicar los distintos pasos que deben ir dando para solucionarla, haciéndoles conscientes de que el error forma parte del aprendizaje. Por ejemplo, en una habilidad de acrosport, deberán probar varias combinaciones de figuras, desde unas más sencillas hasta otras más complejas, para poder llegar a hacer figuras de tres niveles de altura.

- Dar feedback tipo "sándwich" (positivo/negativo/positivo), en las tareas de cada una de las sesiones, puede orientarles para que mejoren posteriormente. Por ejemplo, en una tarea de $3 \times 3$, en la que uno de los equipos no consigue avanzar hacia la portería contraria, el profesorado puede dar un feedback de este tipo: "Veo que sois capaces de mantener la posesión del balón (positivo), pero todavía no acabáis de acercaros a la portería contraria (negativo). ¿Por qué creéis que esto sucede?, ¿qué estrategias podemos establecer para conseguir progresar?". ;Genial chicos! Tratamos de seguir intentándolo con desmarques por delante del compañero (positivo). 


\section{Ejemplos de estrategias para desarrollar conductas clari- ficadoras}

\section{A nivel de unidad didáctica:}

- Al iniciar una unidad didáctica, con un modelo pedagógico de Educación Deportiva, el profesorado debe explicar el sistema de normas de comportamiento y fair play que se va a aplicar y por qué es necesario realizarlo. Además puede aportar sus expectativas sobre cómo espera que va a realizarse la unidad: "Vamos a decidir las normas de las competiciones. Me gustaría que me ayudaseis a decidirlas y, además, espero que haya fair play entre todos los equipos."

- Lo mismo podría pasar cuando se apliquen actividades del modelo pedagógico de Aprendizaje Cooperativo. El docente explicará cuáles son las expectativas que tiene del grupo sobre cooperar en vez de competir. Por ejemplo: "Se van a plantear una serie de retos cooperativos. Cada grupo puede empezar por el reto que quiera. El objetivo es cooperar entre todos los integrantes del grupo para conseguir resolver cada uno de los retos. No importa el número de retos que resolváis, sino que se valorará que todos los integrantes del grupo hayan participado en su consecución”.

- Al inicio de un curso académico, el docente explica la normativa referente a la higiene personal a todo el alumnado de un curso de $1^{\circ}$ de ESO que acaba de llegar al centro. Además, explica cuáles son sus expectativas sobre lo que debe traerse en el neceser para la higiene personal, cambio de camiseta, entre otras medidas, y comentará el por qué de la necesidad y la importancia de cumplirlo.

- Siguiendo con el ejemplo del establecimiento de normas y rutinas para una unidad didáctica en concreto, el profesorado anuncia al alumnado las expectativas y las reglas que cree que pueden ser necesarias para que haya una buena cooperación durante las clases de esa unidad didáctica (p. ej., no hacerme daño a mí, no hacer daño a los demás, etc.).

\section{A nivel de una sesión o una tarea:}

- Es necesario que los estudiantes conozcan al inicio de la actividad cuál es el criterio de éxito de una tarea. Por ejemplo, en una situación de juego de baloncesto de 2x2+1 (comodín), el docente explicará que el criterio de éxito del equipo atacante es que los estudiantes ocupen el espacio de forma correcta donde, al menos, un alumno esté libre para poder recibir un pase y, de esa forma, evitar la pérdida del balón. También, se puede explicar que esto, más adelante, les permitirá anotar libres de marca con más facilidad. Cada grupo podrá también establecer un número de pases

a conseguir en cada posesión, independientemente de los pases conseguidos por el otro equipo.

- Informar del progreso en la consecución del objetivo de una tarea. De esta forma, siguiendo con el ejemplo anterior, cada grupo debe informar sobre si ha conseguido aumentar el número de pases correctos sin perder el balón. El docente les reforzará si lo consiguen y los animará a seguir mejorando. Si no lo consiguen superar, el docente puede reunirlos y darles feedback, especialmente de tipo explicativo o interrogativo. Por ejemplo: "¿Por qué pensáis que no estáis consiguiendo superar el número de desmarques y pases?, ¿qué estrategias 
podemos usar para tratar de mejorar uno de estos dos aspectos? (esperar a que el alumnado responda y buscar soluciones con ellos). Recordamos, paso y me muevo hacia un hueco libre". También se pueden rotar los grupos o a algún compañero si existen muchas diferencias de nivel entre los equipos. Otra opción es modificar determinados elementos del juego como las reglas, el espacio o el número de jugadores.

Con relación a las conductas demandantes y dominadoras, propias del estilo controlador, ejemplificamos algunas estrategias o ejemplos que deben tratar de reducirse al máximo, de forma que se evite la frustración de competencia y, especialmente, de autonomía del alumnado. 


\section{Ejemplos de conductas demandantes (a evitar)}

\section{A nivel de unidad didáctica:}

- El profesorado plantea los objetivos y criterios de evaluación de una unidad didáctica de cualquier contenido a sus alumnos y les dice: "Esto es lo que tenéis que conseguir en estas seis sesiones y ino quiero excusas!". La alternativa sería adoptar un lenguaje menos directivo (p. ej., ¿Qué os parece si establecemos como objetivo...?) o consensuar las decisiones sobre los diferentes elementos curriculares (objetivos, criterios de evaluación, etc.) con el propio alumnado.

- Después de varias sesiones trabajando elementos técnico-tácticos de un deporte (p. ej., mantener la posesión del balón), el docente plantea una situación más global de juego real y le dice que tienen que poner en práctica todo lo que han aprendido: "Es la hora de demostrar todo lo que os he enseñado y debéis ponerlo en práctica sin ningún tipo de excusas". Como alternativa, sería más empático con el alumnado, plantear cuáles son las expectativas del docente y decirles que, si no lo consiguen, podemos analizar qué les falta por aprender para conseguirlo (conducta adaptativa).

- El profesorado presenta una unidad didáctica de expresión corporal. Algunos chicos se quejan de que no les gusta ya que es "de chicas", mientras que otros no quieren hacerla o prefieren practicar otro deporte. Entonces, el docente les responde: "¿Quién es el profesor, vosotros o yo? Es lo que hay, vosotros no podéis decidir qué hacer o qué no hacer y, además, hay que aprender cosas que no os gusten. Asi es la vida". La alternativa podría ser que el docente les explique los beneficios de la expresión corporal y en qué situaciones cotidianas del día a día podrían aplicarlo (conducta adaptativa). Por ejemplo, la importancia de desinhibirse para hablar y mejorar las destrezas comunicativas en público. De igual modo, se podrían mostrar diferentes vídeos, con muchos hombres realizando expresión corporal, para romper los estereotipos sociales de género.

\section{A nivel de una sesión o una tarea:}

- El docente plantea una pregunta y nadie se atreve a contestar. En consecuencia, elige a un estudiante al azar y le obliga a que responda, sin preocuparse de si lo sabe o no. Si, además, contesta mal, muestra cierto enfado. Es importante no obligar a ningún estudiante a contestar, públicamente, para no dejarle en evidencia ante los demás si no sabe la respuesta.
- Expresiones del tipo: "Tenéis que hacer 5 pases como mínimo" o darles a entender que, si no lo hacen, pueden suspender, ejerciendo algunas amenazas relacionadas con la calificación. Sería más adecuado pactar el número de pasar con el propio alumnado. De igual modo, en ningún caso, se debe amenazar al alumnado con una menor calificación, ya que lo importante es su aprendizaje.

- Estás viendo que un grupo de alumnos lleva mucho tiempo con una actividad y no les acaba 
de salir. El docente se acerca y les dice: "Venga, daros prisa y terminad cuanto antes que tenemos que pasar a hacer otra cosa". Sería más correcto interesarse por las dificultades que están teniendo y aportar feedback o ayuda para que terminen la actividad satisfactoriamente. Otra opción es individualizar una variante más sencilla para ellos y una más compleja para los que ya hayan terminado (conducta adaptativa). En ningún caso se debe finalizar la actividad por cuestio- nes de tiempo para no frustrar su competencia si no les está saliendo.

- Ante una conducta disruptiva de un alumno o un pequeño grupo, el docente les advierte y les dice: "Como no cambiéis vuestra actitud, os vais con un parte a dirección". Como alternativa, sería más óptimo mostrar interés por lo que sucede e intentar hablar con ellos de forma individual, para que puedan explicar qué es lo que ocurre (conducta adaptativa). 


\section{Ejemplos de conductas dominadoras (a evitar)}

\section{A nivel de unidad didáctica:}

- Un estudiante ha llegado varias veces tarde en las sesiones de una unidad didáctica. Delante de toda la clase le indicas que no te parece bien que llegue tarde y que es una decepción: "Otro día más que llegas tarde, no sé qué te pasa, pero esto asi no puede continuar". Una solución mejor sería que después de clase y, apartados del resto del grupo, le preguntes si pasa algo y que te diga por qué está llegando tarde a clase. De igual modo, se podría reforzar positivamente a aquellas personas que han llegado pronto.

- Hay varios estudiantes que muestran conductas disruptivas en una unidad didáctica de gimnasia deportiva. El docente les ignora completamente o les manda miradas desafiantes cuando observa que no se están comportando correctamente. En ningún momento accede al diálogo para tratar de resolver la situación. Lo ideal sería que el profesorado mostrase preocupación por lo que está ocurriendo, tratando de comprender las emociones del alumnado.

- El profesorado asiente negativamente cada vez que observa un fallo en la unidad didáctica. El alumnado se siente cohibido y con miedo a cometer errores, escondiéndose delante de los demás o evitando participar de nuevo. Para revertir esta situación, es importante que el docente trate de ofrecer un clima de confianza y ofrezca feedback afectivo a su alumnado.

\section{A nivel de una sesión o una tarea:}

- El docente plantea una tarea compleja y le dice a su alumnado: "Se acabaron las cosas fáciles, vamos a hacer hoy algo más difícil, ahora me tenéis que demostrar todo lo que sabéis hacer". Esto generará una gran presión en el alumnado, especialmente en el menos hábil motrizmente. Como alternativa, sería mejor plantear que se van a enfrentar a una tarea algo más compleja que las anteriores, pero que si tienen cualquier duda o problema, pueden preguntarle al docente para que les ayude a resolverla (conducta clarificadora).

\begin{abstract}
- Otro ejemplo sería cuando un grupo de estudiantes tienen que realizar una tarea difícil o que les genera miedo. Por ejemplo, en una sesión de escalada, un alumno manifiesta que le da miedo subir una vía. Si el profesor reacciona diciéndole que debe superar ese miedo y que debe actuar de una forma más madura, que ya no es un niño, estaría actuando de forma dominadora, imprimiendo cierto sentimiento de culpabilidad hacia él. Por ello, sería más adecuado plantear una tarea previa más sencilla que le dé menos miedo (conducta orientadora) o comentarle qué cosas sabe y decirle que confías en que pueda hacerlo, pero que si intenta algo más sencillo antes no pasará nada (conducta adaptativa).
\end{abstract}

Por último, dentro del estilo caótico, que favorece la frustración de competencia del alumnado, debemos evitar aquellas conductas identificadas como de abandono o a la espera. Para ello, algunos ejemplos de conductas que deben evitarse o reducirse al máximo podrían ser las siguientes. 


\section{Ejemplos de conductas de abandono (a evitar)}

\section{A nivel de unidad didáctica:}

- Un estudiante no progresa en su aprendizaje a lo largo de una unidad didáctica, a pesar del feedback proporcionado por el docente en las últimas sesiones. A partir de aquí, el docente decide que ya ha invertido suficiente tiempo y que no puede dedicarle más. Esta actitud de abandono hacia aquellos que tienen un ritmo de aprendizaje más lento debería sustituirse por estrategias en las que el docente le pregunte qué es lo que le resulta difícil al alumno (conducta adaptativa) o que le aclare cómo realizar algunas tareas y cómo puede hacer para que le salgan bien (conducta orientadora).
- Cuando el docente plantea la evaluación de una unidad didáctica, no avisa al alumnado con anterioridad de qué les va a evaluar, ni le indica nada sobre esta evaluación. Esta conducta es de abandono porque no implica una planificación de la evaluación. Debería plantearse a los estudiantes que ellos sepan cuándo y cómo se les va a evaluar (que conozcan los criterios e indicadores mínimamente, que conozcan la rúbrica que se va a utilizar) o, incluso, que ellos tuvieran cierto margen de elección en la evaluación o que participaran a través de la coevaluación o autoevaluación.

\section{A nivel de una sesión o una tarea:}

- Cuando el docente pregunta al grupo y nadie responde, toma la decisión de darles la respuesta y seguir con la clase. Piensa que deben entender que aprenderán menos si no participan. Esta estrategia debería cambiarse por otras más orientadoras o participativas. Por ejemplo, ante una pregunta al grupo, si nadie responde, habría que tener preparadas preguntas alternativas, más sencillas, o basadas en aspectos trabajados en la tarea o sesión anterior o, tal vez, si da tiempo, que lo debatan entre varios estudiantes para ver si pueden encontrar una respuesta de forma conjunta.
Otra opción es volver a realizar la misma tarea y preguntarles de nuevo al final de esta o esperar a que resuelvan la pregunta a medida que avance la sesión.

- Ante quejas por una tarea que se considera difícil, una conducta de abandono del docente sería ignorarlas y pensar que deben aprender a superar las dificultades y miedos por sí mismos, o bien pensar que ya sabrán ellos cuánto deben esforzarse para conseguirlo. Sería mejor tener esas quejas en cuenta y explicarles la importancia o utilidad de la tarea y para qué les va a servir posteriormente. 


\section{Ejemplos de conductas a la espera (a evitar)}

\section{A nivel de unidad didáctica:}

- Una conducta a evitar sería no establecer algunas normas y reglas al inicio de una unidad didáctica y esperar a intervenir cuando surja un problema. Estas normas y reglas deberían consensuarse con el alumnado al principio de la unidad didáctica (conducta participativa), antes de que emerjan posibles problemas. El alumnado tiene que comprender la importancia de establecer reglas en las actividades para que se pueda jugar más tiempo.
- Cuando se detecta algún aspecto que el alumnado no cumple en varias ocasiones, por ejemplo, no llevar ropa deportiva a clase o llegar tarde de forma reiterada, una conducta a la espera sería no decir nada y esperar a ver si en la clase siguiente lo hacen. Sin embargo, sería mucho mejor comentar cuáles son tus expectativas o explicarles por qué es necesario que traigan ropa adecuada o cómo afecta a la clase que ellos lleguen tarde (conducta adaptativa).

\section{A nivel de una sesión o una tarea:}

- En una tarea que todos comienzan por la misma situación inicial, nos vamos a encontrar distintos ritmos de aprendizaje, por lo que unos alumnos la conseguirán realizar antes y otros después. Si tenemos una conducta a la espera, no tendremos previstas posibles variantes o alternativas más complejas para los más habilidosos motrizmente, ni tampoco habremos planteado otras tareas más simples para desarrollarla. Este tipo de docentes que adopten estas conductas tienen que improvisar e intervenir sobre la marcha. Sería mucho mejor tener planificadas, al menos, una variante de esta situación inicial de mayor y menor complejidad para adaptarte al alumnado (conducta adaptativa).

- En una sesión de expresión corporal, el docente plantea que van a comenzar a elaborar una coreografía de 2 minutos durante esa sesión. Con esta simple consigna les deja trabajar, tratando de favorecer la autonomía al alumnado. Sin embargo, es una conducta a la espera, ya que el alumnado no ha recibido indicaciones precisas de los aspectos a valorar. Por ejemplo, ¿cuántas figuras diferentes hay que hacer?, ¿tiene que haber transiciones?, ¿tenemos que ir al ritmo de una música?, ¿todos tienen que hacer las mismas figuras o pueden combinarse y hacer figuras diferentes a la vez? Tratar de aportar un instrumento de evaluación (p.ej., rúbrica) en la elaboración de la coreografía será muy necesario para evitar sentimientos de no saber si lo estoy haciendo bien, o no saber cómo puedo progresar en mi aprendizaje (conducta clarificadora). Este libertinaje se convierte en una conducta a la espera que influye negativamente en la percepción de autonomía y competencia del alumnado. 


\section{3.- PARA SABER MÁS...}

¿Cómo puedo saber cuál es mi estilo docente predominante?, ¿cuáles de estos estilos suelo utilizar más en mis clases de Educación Física?

Los docentes de Educación Física pueden evaluar sus conductas motivacionales a través de un instrumento denominado Situations in School-Physical Education (SIS-PE; EscrivaBoulley et al.,2021), en su versión en castellano. También, pueden evaluar la percepción de su alumnado de sus propias conductas docentes a través de una adaptación de este instrumento para estudiantes. Se puede contactar con el autor principal de este capítulo (Igarciag@uni- zar.es) para obtener dichos instrumentos, en papel u online, así como para asesorarte sobre cómo interpretar los resultados.

Con los datos obtenidos, se pueden realizar informes individualizados, tanto a nivel docente como de los estudiantes.

Si quieres saber y profundizar más sobre este modelo circular de las conductas motivacionales de los docentes, en este enlace puedes acceder a la referencia donde se valida el instrumento propuesto (SIS-PE): https://www.mdpi.com/1660-4601/18/14/7342 


\section{4.- REFERENCIAS BIBLIOGRÁFICAS}

Aelterman, N., Vansteenkiste, M., Haerens, L., Soenens, B., Fontaine, J. R. J., y Reeve, J. (2019). Toward an integrative and fine-grained insight in motivating and demotivating teaching styles: The merits of a circumplex approach. Journal of Educational Psychology, 111(3), 497-521. https://doi.org/10.1037/edu0000293

Escriva-Boulley, G., Guillet-Descas, E., Aelterman, N., Vansteenkiste, M., Van Doren, N., Lentillon-Kaestner, V., y Haerens, L. (2021). Adopting the situation in school questionnaire to examine physical education teachers' motivating and demotivating styles using a circumplex approach. International Journal of Environmental Research and Public Health, 18(14), 7342. https://doi.org/10.3390/ijerph18147342
González-Cutre, D. (2017). Estrategias didácticas y motivacionales en las clases de educación física desde la teoría de la autodeterminación. E-Motion: Revista de educación, motricidad e investigación, (8), 44-62.

Ladwig, M. A., Vazou, S., y Ekkekakis, P. (2018). "My best memory is when I was done with it": PE memories are associated with adult sedentary behavior. Translational Journal of the American College of Sports Medicine, 3(16), 119-129.

https://doi.org/10.1249/TJX.0000000000000067

Ryan, R. M., y Deci, E. L. (2017). Self-determination theory: Basic psychological needs in motivation, development, and wellness. Guilford Publications. https://doi.org/10.7202/1041847ar 
Capítulo 2.4.

\section{ESTRATEGIAS MOTIVACIONALES PARA INCLUIR NOVEDAD Y VARIEDAD EN EDUCACIÓN FÍSICA}

Autores: David González-Cutre1, Alejandro Jiménez-Loaisa², Ángel Abós ${ }^{3}$ y Roberto Ferriz ${ }^{4}$

${ }^{1}$ Universidad Miguel Hernández de Elche; 2Universidad de Castilla-La Mancha; 3Universidad de Zaragoza; ${ }^{4}$ Universidad de Valencia

Palabras clave: innovación, teoría de la autodeterminación, necesidades psicológicas básicas, diversificar. 


\section{EVIDENCIAS CIENTÍFICAS ¿POR QUÉ INTRODUCIR NOVEDAD Y VARIEDAD EN EDUCACIÓN FÍSICA?}

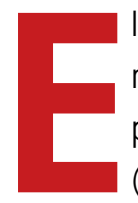

I ser humano, desde que nace, se muestra como un ser curioso que explora todo lo que hay a su alrededor (Deci y Ryan, 1985). El descubrimiento de cosas nuevas cuando interaccionamos con el entorno puede hacer que las personas disfrutemos de las experiencias (Kashdan y Silvia, 2009). Un juguete nuevo, algo que aprendemos, un paisaje sorprendente, una actividad de ocio diferente, una oportunidad laboral, o la desconexión de la rutina diaria, son ejemplos de elementos novedosos y variados que pueden servirnos de estímulo y motivarnos a lo largo de nuestra vida. De hecho, como se comenta en el Capítulo 1.1. dedicado a la explicación de la teoría de la autodeterminación, la novedad ha sido recientemente conceptualizada como una necesidad psicológica básica que, junto a las ya conocidas necesidades de autonomía, competencia y relación social, las personas tenemos que satisfacer para mejorar nuestra motivación. De esta manera, la satisfacción de la necesidad de novedad ayudaría a alcanzar una motivación autodeterminada y a desencadenar consecuencias adaptativas a nivel conductual (participar en determinadas actividades), cognitivo (estar centrados en la actividad con una buena disposición mental) y afectivo (disfrutar de las actividades) y, por tanto, a mejorar nuestro bienestar
(González-Cutre et al., 2016, 2020). Bajo esta perspectiva, la novedad se define como la necesidad innata de experimentar algo que no se ha hecho antes o que es diferente de lo que habitualmente se hace (González-Cutre et al., 2016).

En este sentido, parece lógico tratar de fomentar la novedad en los diferentes contextos vitales, siendo uno de ellos el que nos compete aquí, el de la educación (Stoa y Chu, 2020), y más concretamente el de la Educación Física (González-Cutre y Sicilia, 2019). Mucho se ha abogado por fomentar la innovación en Educación Física, pero no siempre se han aportado las evidencias científicas para ello. La conceptualización de la novedad como una necesidad psicológica básica y su relación con consecuencias positivas en el proceso de enseñanza-aprendizaje puede ayudar a dar soporte a la innovación educativa. Desde este prisma, la investigación ha revelado que la satisfacción de la necesidad de novedad en Educación Física se ha asociado positivamente con que el estudiante se sienta orgulloso de su participación en la asignatura (Fierro-Suero, Almagro, y Sáenz-López, 2020), con la motivación intrínseca (FernándezEspínola et al., 2020; FierroSuero, Almagro, Sáenz-López,

Carmona-Márquez, $\quad$ 2020; 
González-Cutre y Sicilia, 2019; GonzálezCutre et al., 2016; Koka et al., 2021; Trigueros, Mínguez et al., 2019), satisfacción (GonzálezCutre y Sicilia, 2019) y disfrute con las clases (Fierro-Suero, Almagro, y Sáenz-López, 2020), vitalidad (González-Cutre y Sicilia, 2019), estado psicológico óptimo de concentración e implicación (flow disposicional) (GonzálezCutre y Sicilia, 2019) e intención de ser físicamente activo (Aibar et al., 2021). Además de desencadenar consecuencias positivas, la satisfacción de novedad puede contribuir a evitar consecuencias menos adaptativas como el aburrimiento, el enfado y la desesperación por no ser capaz de hacer las cosas correctamente en las clases de Educación Física (Fierro-Suero, Almagro, y Sáenz-López, 2020). Paralelamente, la frustración de la necesidad de novedad en Educación Física se ha relacionado positivamente con la desmotivación (Trigueros, Maldonado et al., 2020) y negativamente con el desarrollo de la inteligencia emocional (capacidad de regular y reconocer las emociones) (Trigueros, Aguilar-Parra et al., 2019) y resiliencia (habilidad para adaptarse a circunstancias adversas) (Trigueros, Mínguez et al., 2020). Por tanto, atendiendo a estos resultados, la inclusión de aspectos novedosos en Educación Física puede facilitar que el alumnado valore más la asignatura y esté más motivado por las formas diferentes y sorprendentes en las que la enseñanza se plantea, provocando, consecuentemente, que esté más concentrado, satisfecho, se divierta y se sienta más vital. Asimismo, todo lo anterior puede promover en el estudiante el deseo de trasladar los aprendizajes adquiridos en el aula de Educación Física a su práctica extraescolar, incrementando sus niveles de actividad física en el tiempo de ocio y adoptando un estilo de vida más activo y saludable. Además, esa novedad ayudaría a evitar que el estudiante se desmotive, se aburra y se enfade por hacer siempre lo mismo. La novedad puede incluso promover que el estudiante se desespere menos y se sienta más competente, ya que ante una actividad no realizada previamente, todos los estudiantes pueden mostrar un nivel de destreza similar. Finalmente, hay que destacar que si se presentan adecuadamente las cosas nuevas, que a veces pueden resultar estresantes, el estudiante podría regular mejor sus emociones negativas, afrontando los retos de una manera positiva gracias al desarrollo de su capacidad de adaptación y superación.

La novedad debe ser complementada con la alternancia de cosas conocidas para tener un efecto estimulante en la motivación (White et al., 2021). Experimentar cosas nuevas y/o alternar cosas conocidas en un contexto determinado es lo que se define en la literatura científica como variedad (Sylvester et al., 2014). En este sentido, la variedad en Educación Física se ha relacionado positivamente con una motivación más autónoma del alumnado (disfrutar y valorar su importancia), con una menor desmotivación y con la intención de ser más activo físicamente en el tiempo de ocio (Abós et al., 2021; White et al., 2021). Además, la variedad de actividades físicas en la infancia y adolescencia parece favorecer un buen desarrollo motor y la realización de actividad física a largo plazo, dada la oportunidad de aprender un amplio abanico de habilidades motrices (Sylvester et al., 2018). Aunque novedad y variedad pueden parecer un mismo concepto, debemos diferenciar algunos matices. Está claro que toda novedad supone una variedad con respecto a algo anterior, pero no todo lo variado es novedoso (Sylvester et al., 2018). Por ejemplo, en las clases de Educación Física podemos incluir actividades nuevas que nunca han realizado los estudiantes y, por tanto, es algo que varía con respecto a lo experimentado. No obstante, podemos también alternar actividades diferentes a lo largo de las sesiones, que aunque no son novedosas porque las han hecho antes, aportan variedad al conjunto de lo realizado. 
En relación a esto, la variedad podría ser una experiencia psicológica que combinara en cierto modo la satisfacción de las necesidades de novedad y competencia. Es decir, el estudiante necesita un equilibrio entre la novedad que se le presenta y su capacidad para realizar lo planteado, pues de lo contrario podría experimentar ansiedad y frustración (Csikszentmihalyi, 1990; Stoa y Chu, 2020). Lo ideal es dejar el suficiente tiempo para experimentar algo, variando la forma de llevarlo a cabo, para una vez obtenido el aprendizaje, incluir aspectos nuevos. Un ejemplo de esto sería realizar una progresión didáctica basada en la enseñanza comprensiva del deporte en la que el alumnado va pasando por diferentes niveles de dificultad respecto a los principios técnico-tácticos solicitados. De esta manera, el estudiante se sentirá capaz de hacer las cosas y tendrá estímulos nuevos que le motiven. Así, la clave para optimizar los procesos motivacionales de los estudiantes en las clases de Educación Física podría pasar por co- nocer la dosis adecuada de novedad y variedad. Dicha dosis no tiene por qué ser excesivamente grande, ya que una simple modificación de las clases tradicionales podría incrementar la percepción de novedad y variedad en los estudiantes (Stoa y Chu, 2020). En la agenda de los investigadores está desde hace unos años conocer el tamaño de esta dosis, sin olvidar que debemos adaptarnos a las características individuales de cada estudiante. Para implementar adecuadamente estrategias motivacionales que fomenten la percepción de novedad y variedad, es necesario conocer bien a los estudiantes y saber qué cosas saben y qué han experimentado previamente.

A continuación, presentamos algunas estrategias para promover la novedad y variedad en Educación Física. Dichas estrategias, aunque se basan en la revisión de la literatura científica, deberán ser adaptadas por el docente a su contexto, contenido y grupo de estudiantes. 


\section{2.- APLICACIONES PRÁCTICAS PARA LA DOCENCIA DE LA EDUCACIÓN FÍSICA: ¿CÓMO FOMENTAR LA NOVEDAD Y VARIEDAD?}

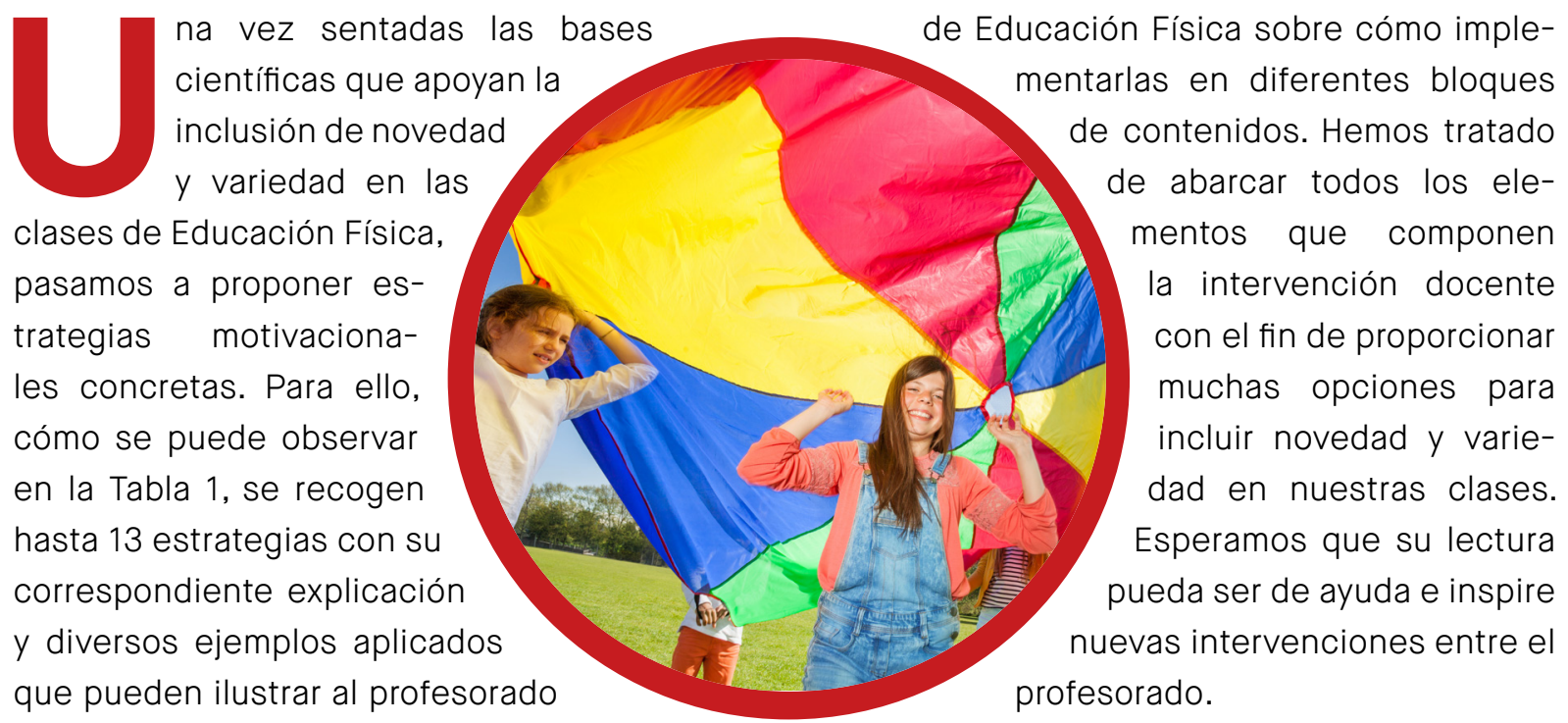




\section{Tabla}

Estrategias motivacionales para fomen1 tar la novedad y variedad en Educación Física

1. Animar a los estudiantes a involucrarse en nuevos retos y aprendizajes

2. Poner en práctica situaciones de aprendizaje, contenidos, unidades didácticas o proyectos novedosos

3. Modificar los elementos estructurales y funcionales de las actividades

4. Promover la adquisición de nuevos recursos y conocimientos por parte de los estudiantes para que puedan llevar un estilo de vida saludable

5. Combinar diferentes estilos de enseñanza

6. Aplicar modelos pedagógicos basados en la evidencia que resulten innovadores para el alumnado

7. Usar materiales variados y novedosos

8. Utilizar las tecnologías de la información y comunicación con objetivos educativos

9. Llevar a cabo actividades en espacios diferentes

10. Implementar procesos de evaluación formativos y compartidos que sean novedosos para los estudiantes

11. Invitar a otras personas a presentar información o enseñar algún contenido

12. Explicar de una forma creativa utilizando anécdotas personales y el sentido del humor

13. Participar en un proceso de formación continua 


\section{1.- Animar a los estudiantes a involucrarse en nue- vos retos y aprendizajes.}

Es importante que conectemos los aspectos nuevos del proceso de enseñanza-aprendizaje con lo que el alumnado ha aprendido previamente, destacando lo que es diferente y su utilidad (Stoa y Chu, 2020). Por ejemplo, si vamos a abordar una unidad didáctica "sobre ruedas" para trabajar acciones motrices indi- viduales, podemos preguntarles qué medios dominan (p. ej., patines, patinete, monopatín, bicicleta) y darles a conocer nuevos medios y habilidades, relacionándolos con la importancia del desplazamiento activo para la salud.

\section{2.- Poner en práctica situaciones de aprendizaje, contenidos, unidades didácticas o proyectos no- vedosos (González-Cutre y Sicilia, 2019), siempre dentro de la coherencia de la legislación educa- tiva y de la programación didáctica, teniendo en cuenta el aprendizaje competencial.}

Por ejemplo, para trabajar los lanzamientos y las recepciones, un ejercicio con un carácter más tradicional sería intercambiar un móvil por parejas a diferentes distancias. No obstante, en función de las experiencias previas y del nivel de competencia de nuestro alumnado, podemos plantear una actividad cooperativa, novedosa y variada a la vez, en la que varios estudiantes se coloquen de pie formando un círculo, con un Fitball metido en una cesta en el centro de dicho círculo. Un estudiante deberá lanzar al Fitball una pelota (p. ej., de gimnasia rítmica) que saldrá rebotada con una trayectoria inesperada, teniendo que ser recibida por la persona que esté más cerca. Como variantes, podemos trabajar con diferentes pelotas a la vez (p. ej., gimnasia rítmica, tenis, goma-espuma, etc.) o marcar una circunferencia a diferentes distancias del Fitball para ubicarse fuera de ella, incrementando la dificultad de la actividad para adaptarnos a los diferentes niveles de competencia de nuestro alumnado, a la vez que seguimos satisfaciendo la novedad y la variedad (Abós et al., 2021). Otra idea novedosa y variada para trabajar contenidos ligados al medio natural, como por ejemplo la orientación, podría ser la realización de un escape-room en el que el alumnado deberá ir resolviendo diferentes acertijos, descifrando códigos y problemas, para adquirir los aprendizajes necesarios que le permitan finalizar el juego. Los elementos básicos de la orientación podrían ser abordados entre los diferentes "escenarios" del escape-room de una forma estimulante para el alumnado. Al aplicar este tipo de estrategias no debemos olvidar 
que hay que priorizar los aprendizajes competenciales para la vida (saber, saber hacer y saber ser), pues de lo contrario la novedad se convertiría en un envoltorio de aprendizajes vacíos. En cuanto a contenidos y unidades didácticas, siempre con la normativa curricular como referencia y teniendo presente trabajar los cinco tipos de situaciones motrices que establece (acciones motrices individuales en entornos estables, en situaciones de oposición, de cooperación, de adaptación al entorno físico y de índole artística y de expresión), podemos ir variando con el objetivo de sorprender al alumnado. Algunas propuestas más alejadas de contenidos etiquetados como "tradicionales" podrían ser el trabajo de actividades dirigidas para la mejora de la condición física como el Bodycombat, Bodypump o la Zumba; deportes alternativos como el Kinball, Colpbol o Goubak para trabajar acciones motrices de cooperación-oposición; activida- des artístico-expresivas combinando elementos como combas, malabares y acrobacias; técnicas de escalada y rápel dentro del bloque de medio natural; o contenidos transversales sobre primeros auxilios. Finalmente, el trabajo por proyectos podría ayudar también a mejorar la percepción de novedad y variedad entre los estudiantes. Por ejemplo, un proyecto interdisciplinar que involucre a diferentes asignaturas para el desarrollo de un musical. Desde Educación Física se podría elaborar la coreografía a llevar a cabo; desde Educación Plástica y Visual se podría trabajar en la elaboración del vestuario y del escenario; desde Música nos centraríamos en todo el montaje de canciones; desde Tecnología se podría abordar la parte de efectos especiales e incluso su retransmisión; $y$, finalmente, desde Lengua y Literatura e Inglés podríamos ocuparnos de la elaboración y ajuste de las letras de las canciones.

\section{3.- Modificar los elementos estructurales y funcio- nales de las actividades (Abós et al., 2021).}

Para abordar esta estrategia tenemos múltiples opciones como variar el número y los componentes de un grupo, las reglas (p. ej., salen tres números a la vez en el juego del pañuelo) y objetivos de la actividad (p. ej., conseguir 10 pases en un equipo para obtener punto; conseguir siete pases y derribar un cono para obtener punto), las dimensiones del terreno de juego, los roles y responsabilidades (p. ej., jugador, observador, entrenador, árbitro, responsable del material), la técnica de ejecución a emplear (p. ej., tipos de lanzamiento en balonmano; botar el balón con la mano menos hábil; diferentes variantes de planchas para el acondicionamiento del tronco como parte de un programa de educación para la salud) o el número de repeticiones. Del mismo modo, evolucionar de menor a mayor complejidad puede suponer una novedad y variedad (Sylvester et al., 2018). Un ejemplo podría ser enseñar progresivamente algún ejercicio para trabajar la fuerza (p. ej., sentadilla, sentadilla con peso, sentadilla con peso más curl de bíceps) dentro de un programa que los estudiantes puedan ir diseñando, o incrementar el número de defensores y su grado de actividad (p. ej., 2 vs. 1, 2 vs. 2, 2 vs. 3) para trabajar una situación de ataque en algún deporte de cooperación-oposición. 


\section{4.- Promover la adquisición de nuevos recursos y conocimientos por parte de los estudiantes para que puedan llevar un estilo de vida saludable (Ferriz et al., 2020).}

Por ejemplo, dar a conocer las recomendaciones de actividad física, sueño y tiempo recreativo de pantalla que la evidencia establece para niños y adolescentes y trabajar sobre ellas desde la Educación Física, o colaborar en la organización y promoción de eventos que fomenten la actividad física en familia pueden ser retos estimulantes que favorezcan la novedad y variedad en el área de Educación Física. También se podría crear un programa de actividad física extraescolar orientado a la mejora de la salud en general (González-Cutre et al., 2018) y no solo al aprendizaje de habilidades deportivas, que suele ser lo habitual. Otra alternativa podría ser enseñar al alumnado a dar solución a situaciones que se pueden dar en su día a día, cuestiones que generalmente no abordamos en Educación Física como parte de los contenidos de algunas unidades didácticas. Por ejemplo, si pensamos en una unidad de bicicleta de montaña o de patines, podría- mos coincidir en que algunos contenidos a trabajar serían la posición de equilibrio o básica, el frenado, diferentes tipos de posturas en subidas y bajadas o recursos técnicos específicos. No obstante, también podría ser novedoso y con gran transferencia de cara a la futura práctica autónoma, que el alumnado aprenda a poner a punto la bicicleta o los patines, desmontando, arreglando y montando algunos de sus elementos. En relación a todo lo comentado en este apartado, hay que destacar que una intervención escolar que abarcaba diferentes actuaciones para la promoción de la actividad física (Sevil-Serrano et al., 2020), incluyendo al profesorado de Educación Física, a otros docentes, al tutor y a los padres, mostró un incremento de la percepción de novedad y variedad en los estudiantes, mayor motivación autónoma, actitudes positivas, sentimiento de apoyo del entorno e intención de hacer actividad física extraescolar. 


\section{5.- Combinar diferentes estilos de enseñanza (Delgado-Noguera, 1991) a lo largo de nuestra programación didáctica de manera que no nos limitemos a estilos de enseñanza tradicionales (mando directo y asignación de tareas) (Aibar et al., 2021).}

Algunos ejemplos podrían ser los siguientes: a) Aplicación de una enseñanza recíproca para el aprendizaje técnico de algunas acciones vinculadas a la mejora de la salud, como la realización de una plancha frontal o la elevación de una carga desde el suelo a una mesa; diferentes saltos a la comba y sus fases; actividades atléticas como el salto de altura; de cancha dividida como el clear en bádminton; o para el aprendizaje técnico-estratégico de la ocupación de espacios. Un estudiante se encargaría de realizarlo, mientras otro le observa y le da feedback apoyándose en una hoja de observación compuesta por 3-4 ítems que describen de forma sencilla y objetiva la ejecución correcta. Luego cambiarían los roles. Además, podrían utilizar la grabación de forma complementaria; b) Puesta en práctica de una microenseñanza en la que los estudiantes de forma grupal deben buscar diferentes actividades para mejorar la condición física, con el objetivo de dirigir una sesión a sus compañeros en la que se implementen estas actividades y se reflexione sobre las cualidades físicas trabajadas en cada una. Otro ejemplo podría ser buscar tres danzas del mundo para llevar a cabo este contenido artístico-expresivo con los compañeros y reflexionar sobre el impacto de dichas danzas en el contexto social de la población (origen, objetivo, etc.); c) Desarrollo de un programa individual multinivel para trabajar la escalada. Se establecen tres niveles de dificultad, con diferentes vías y actividades, situándose el alumnado en el nivel que mejor se ajusta a su competencia motriz tras una autoevaluación inicial; d) Descubrimiento guiado para adquirir los fundamentos técnicos relacionados, por ejemplo, con la carrera en atletismo, el golpeo de revés en tenis, el saque de seguridad en voleibol, el lanzamiento a canasta o el levantamiento (take off) en una tabla de surf. En este último ejemplo, podríamos trabajar en el aula con un elemento inestable como el Bosu y pedirle al estudiante que trate de levantarse desde una posición de decúbito prono y subirse al Bosu lo más rápidamente posible. $\mathrm{A}$ partir de ahí le surgirá la disonancia cognitiva y plantearemos el proceso de indagación con diferentes preguntas sobre la ejecución más eficaz (p.ej., ¿Cómo debemos colocar las piernas?), llegando al final del proceso a descubrir la técnica correcta que representa la única solución; e) Resolución de problemas para conocer las mejores soluciones tácticas a una determinada situación deportiva, como por ejemplo la búsqueda de desmarques de apoyo o de ruptura en fútbol, en función del número de atacantes y defensores y su posición en el terreno de juego, o el algoritmo de ataque y defensa en una unidad de bate y carrera $(p$. ej., decidir a qué zona lanzar, si permanecer en una base o correr para lograr una carrera, si le paso a otro jugador o corro para cortar carrera); f) Desarrollo de un estilo creativo en situaciones de índole artística y de expresión, al practicar acrosport, gimnasia rítmica o deportiva o natación sincronizada. El alumnado podría elaborar una composición grupal en la 
que deba intercalar figuras, elementos gimnásticos y/o artístico-expresivos, a partir de diferentes opciones que les proporcionemos (o creen ellos desde cero), tratando de representar un tema concreto e integrar contenidos transversales (p. ej., los juegos olímpicos, un día del fin de semana, cómo actuar ante una situación de emergencia, comportamientos ligados a la educación en valores, etc.).

\section{6.- Aplicar modelos pedagógicos basados en la evidencia (Pérez-Pueyo et al., 2021) que resulten innovadores para el alumnado.}

Por ejemplo, la enseñanza comprensiva del deporte, que implica cognitivamente al alumnado, o el modelo de educación deportiva, que permite experimentar, además del papel tradicional de jugador adoptado en las clases de Educación Física, diferentes roles novedosos y variados, cargados de aprendizajes, como el de árbitro o juez, preparador físico, mánager y anotador, entre otros. Recientes investigaciones cuasi-experimentales (GilArias et al., 2021; Hernández-Martínez et al., 2019; Manso-Lorenzo et al., 2020; Martínez de Ojeda et al., 2021) han mostrado que el desarrollo de intervenciones didácticas con ambos modelos (juntos o por separado) influye positivamente en la percepción de novedad y variedad, aumentando la motivación autónoma de los estudiantes. También podríamos emplear el modelo de Educación Física relacionada con la salud para trabajar contenidos de condición física y salud, el modelo de educación aventura para actividades en el medio natural, o modelos más transversales como el de autoconstrucción de materiales, el modelo de res- ponsabilidad personal y social o el modelo de aprendizaje cooperativo. A nivel de novedad y variedad, la gamificación podría resultar también interesante por la sorpresa que resulta la creación de una historia ficticia, la asignación de personajes y el establecimiento de misiones. No obstante, no debemos olvidar que el uso de recompensas (p. ej., premiar con insignias, cartas o similares por adoptar un comportamiento, o emplear rankings para comparar o hacer visible el progreso de unos respecto a otros) se asocia con una regulación externa y, aunque la gamificación tenga un componente importante de diversión, no podemos abusar de ella. En este sentido, desde la óptica que aquí nos compete, con objeto de satisfacer la necesidad de novedad y promover la variedad, recomendamos la combinación de diferentes estilos de enseñanza y modelos pedagógicos a lo largo del curso escolar, evitando intervenciones docentes rutinarias centradas en la repetición de un estilo o modelo independientemente del contenido. 


\section{7.- Usar materiales variados y novedosos (González-Cutre y Sicilia, 2019).}

En este sentido, se podrían combinar materiales más tradicionales como balones, picas, cuerdas, conos, aros, bancos suecos o colchonetas, con otros más alternativos como indiacas, discos voladores, palos de hockey, palas, paracaídas o materiales vinculados al mundo del circo (p. ej., diábolos, palos del diablo, platos chinos, cariocas, etc.), así como la utilización directa de material en desuso (p. ej., botes de plástico, bolsas, cajas, neumáticos, palos de escoba) o la elaboración de material autoconstruido (ver el canal de Youtube de Antonio Méndez-Giménez para conocer múltiples recursos: https://www.youtube.com/ channel/UC8CSAgyxqkTQNCzIEVCSPGQ). También sería interesante dar a conocer al alumnado materiales propios del ámbito del fitness, como el Fitball, el Bosu, las bandas elásticas, las kettlebells o el TRX, que pueden resultar novedosos para los estudiantes, dotándoles de muchas posibilidades para trabajar la condición física en su día a día.

\section{8.- Utilizar las tecnologías de la información y comunicación con objetivos educativos (p. ej., Rodrigo-Sanjoaquín et al., 2019).}

Algunas alternativas podrían ser las siguientes: a) Usar las redes sociales para compartir información sobre la asignatura, para fomentar el debate y la expresión de opiniones y para dar a conocer la oferta de actividades físicas de la zona; b) Promover la búsqueda de información en buscadores de internet, enseñando a reconocer la información veraz y a poner en tela de juicio la información que no tiene base científica; c) Utilizar plataformas o portafolios digitales para facilitar documentos e implicar a los estudiantes de forma activa en el proceso de enseñanza-aprendizaje; d) Animar al alumnado a utilizar medios tecnológicos para elaborar y presentar trabajos; e) Emplear aplicaciones para que el alumnado registre y analice su progreso individual o en grupo, siempre sin comparar con los demás. Por ejemplo, se pueden consultar los pasos realizados en un día o los niveles de actividad física, controlar la intensidad del esfuerzo, montar y analizar vídeos, buscar tesoros escondidos en el medio natural, o realizar una autoevaluación o coevaluación. No obstante, ante el rol emergente de las tecnologías en el ámbito educativo, parecer recomendable advertir de la importancia de un uso responsable y consciente, dados los efectos nocivos que el abuso de las mismas puede provocar en la salud (Lissak, 2018). 


\section{9.- Llevar a cabo actividades en espacios diferentes (González-Cutre y Sicilia, 2019).}

Podemos combinar el uso de todas las instalaciones deportivas del centro con otras instalaciones no específicas para la práctica deportiva. Por ejemplo, se puede utilizar el patio del centro para realizar algún juego de pistas o de orientación, crear espacios para practicar diferentes juegos tradicionales o adaptar una pared para trabajar la iniciación a la escalada. También puede resultar de interés realizar alguna clase en instalaciones deportivas cercanas que puedan ser más desconocidas, como una pista de atletismo, una piscina o un centro de fitness, o aprovechar otros espacios de la localidad (p. ej., centro urbano, playa, ladera del río, parque, etc.) para hacer actividades como entrenamiento funcional o parkour, siempre respetando el entorno y las normas de convivencia. Finalmente podemos organizar algunas salidas a espacios naturales sorprendentes, en entornos cercanos con interés paisajístico, para realizar actividades como senderismo, bicicleta de montaña, escalada, barranquismo o deportes náuticos, o incluso llevar a cabo un viaje a algún lugar más alejado (p. ej., semana blanca para practicar esquí o snowboard).

\section{0.- Implementar procesos de evaluación formativos y compartidos que sean novedosos para los estudiantes.}

Teniendo en cuenta que tradicionalmente la evaluación de los estudiantes ha sido realizada por el propio profesorado de Educación Física (heteroevaluación), podrían establecerse también sistemas basados en la autoevaluación y coevaluación por parte del propio alumnado y heteroevaluación por parte de las familias u otro profesorado del centro. Con relación a ejemplos anteriores de este capítulo en los que el alumnado tenía que llevar a cabo una coreografía o composición grupal, podemos utilizar una hoja de registro para que los estudiantes vayan cumplimentando diariamente en grupo diferentes ítems relacionados con su participación en el proceso. Esta información puede ser comparada con la regis- trada por el docente y ayudar al estudiante a mejorar durante la elaboración de la composición. La coreografía final se puede representar en un festival a los compañeros, familia y otro profesorado del centro, que pueden felicitar a los estudiantes por los aspectos bien realizados y proporcionar feedback de las cosas que se podrían corregir para el futuro. Además de variar las personas que intervienen en el proceso de evaluación, podemos modificar las formas de llevarlo a cabo. Algunas ideas podrían ser el uso de una aplicación informática para que el estudiante se implique en el proceso de evaluación formativa, la preparación de exposiciones orales para aprender a hablar en público, o enfocar el uso de los test de 
condición física para que el alumnado conozca pruebas que le permiten valorar parámetros relacionados con su salud, en lugar de ser meros instrumentos de calificación. Para tener más ejemplos de cómo aplicar la evaluación de forma novedosa se puede consultar el ca- pítulo de este libro dedicado a evaluación formativa y motivación (Capítulo 2.8.), así como otras fuentes actuales (p. ej., Pérez-Pueyo, Hortigüela-Alcalá, Gutiérrez-García, y LópezPastor, 2021).

\section{1.- Invitar a otras personas a presentar información o enseñar algún contenido (Benlahcene et al., 2020).}

Cambiar de forma puntual la persona que transmite la información puede resultar un estímulo novedoso para el estudiante y despertar su interés. Por ejemplo, un deportista local que viene un día a enseñarnos algo de su deporte, un antiguo estudiante del centro que se ha formado en el ámbito de la actividad física y viene a compartirlo, un docente de otra asignatura que ha desarrollado un proyecto que puede ser de interés, un docente de Educación Física de otro centro de secun- daria o de la universidad que nos imparte una sesión, o un familiar que acude a explicarnos juegos populares de su infancia o incluso que viene algún día a participar motrizmente en la sesión con los estudiantes. Si ponemos en práctica este tipo de estrategias, sería recomendable que antes de que la persona intervenga con nuestro alumnado, confirmemos que la información que va a transmitir es rigurosa y está en línea con lo que queremos que nuestros estudiantes aprendan.

\section{2.- Explicar de una forma creativa utilizando anécdo- tas personales y el sentido del humor (Birdsell, 2018).}

Para llamar la atención del alumnado, por ejemplo, podemos hacer alusión a alguna anécdota divertida que nos pasó al impartir el contenido de esa sesión otro año, a algo que hemos visto en un programa o serie de televisión, o referirnos a experiencias con nuestra familia durante la práctica deportiva (p. ej., una salida al medio natural o la participación en una carrera popular durante el fin de semana). Contar las cosas de una manera diferente, atractiva, con un lenguaje más cercano a los niños y adolescentes, y con algo de humor, podría ayudar a satisfacer la necesidad de novedad de nuestros estudiantes y motivarles positivamente en nuestras clases. 


\section{3.- Participar en un proceso de formación continua.}

Para poder incluir novedad y variedad en las clases de Educación Física, resulta fundamental que el profesorado se comprometa con un proceso de formación permanente (Braga et al., 2017). El docente debe continuar aprendiendo a lo largo de toda su carrera si quiere incorporar nuevas ideas, contenidos, estrategias o modelos a sus clases. La lectura de

\section{Consideraciones finales}

Aunque hemos tratado de hacer un esfuerzo para sintetizar algunas ideas que han aparecido en la literatura científica en los últimos años, aportando estrategias y ejemplos prácticos concretos para proporcionar novedad $y$ variedad en las clases de Educación Física, debemos tener en cuenta algunas consideraciones. En primer lugar, esta publicación solo pretende ser una fuente de inspiración para que cada docente escoja las ideas que mejor se adapten a su realidad educativa y las implemente sabiendo que existe una evidencia científica detrás que muestra la importancia de satisfacer la necesidad de novedad del estudiante. En segundo lugar, son necesarios artículos científicos y libros sustentados en la evidencia, la asistencia a cursos y congresos y el intercambio de experiencias con otros docentes y estudiantes en prácticas, se convierten en elementos clave para que los docentes aumenten su repertorio de recursos didácticos con el objetivo de enriquecer el proceso de enseñanza-aprendizaje.

más programas de intervención en Educación Física que examinen los efectos de estas estrategias de apoyo a la novedad y variedad sobre la motivación y otras consecuencias adaptativas con el fin de mejorar la actuación docente. De esta manera, podremos conocer qué estrategias pueden resultar más efectivas para determinadas circunstancias, permitiéndonos acercarnos a establecer dosis de novedad y variedad óptimas para mejorar la calidad de los aprendizajes y las experiencias en Educación Física. 


\section{3.- PARA SABER MÁS...}

Para profundizar en la conceptualización teórica de la novedad como necesidad psicológica básica recomendamos leer los trabajos de González-Cutre et al. (2016, 2020). En dichos trabajos se hace una revisión de los criterios y características que posee la novedad para ser considerada una necesidad psicológica básica, sembrando las bases para entender la importancia de la innovación en todos los ámbitos de la vida. Estas bases han sido testadas en el contexto de la Educación Física (ver González-Cutre y Sicilia, 2019).

Para entender mejor el concepto de variedad, resulta de interés el capítulo de libro de Sylvester et al. (2018) donde se explica este constructo desde diferentes perspectivas, aplicándolo al ámbito de la actividad física. Además, el trabajo de Abós et al. (2021) supone la primera aproximación al análisis de los efectos de la variedad de las tareas en el contexto de la Educación Física.

Finalmente, enlazando con el Capítulo 1.1 referido a la teoría de la autodeterminación, recordar que podemos evaluar la novedad percibida por el estudiante con el cuestionario desarroIlado por Fierro-Suero, Almagro, Sáenz-López, y Carmona-Márquez (2020), e incluso podemos autoevaluar nuestra conducta docente de apoyo a la novedad o evaluarnos entre compañeros de profesión utilizando la herramienta observacional de Fierro-Suero, Almagro, Castillo, y Sáenz-López (2020). 


\section{4.- REFERENCIAS BIBLIOGRÁFICAS}

Abós, A., García-González, L., Aibar, A., y Sevil-Serrano, J. (2021). Towards a better understanding of the role of perceived task variety in Physical Education: A selfdetermination theory approach. Psychology of Sport and Exercise, 56, 101988.

https://doi.org/10.1016/j.psychsport.2021.101988

Aibar, A., Abós, A., García-González, L., González-Cutre, D., y Sevil-Serrano, J. (2021). Understanding students' novelty satisfaction in physical education: Associations with need-supportive teaching style and physical activity intention. European Physical Education Review, 27(4), 779-797. https://doi.org/10.1177/1356336X21992791

Benlahcene, A., Kaur, A., y Awang-Hashim, R. (2020). Basic psychological needs satisfaction and student engagement: the importance of novelty satisfaction. Journal of Applied Research in Higher Education. Publicación en línea avanzada. https://doi.org/10.1108/JARHE-062020-0157

Birdsell, B. J. (2018). Understanding students' psychological needs in an English learning context. Journal of Liberal Arts Development and Practices, 2, 1-14.

Braga, L., Jones, E., Bulger, S., y Elliot, E. (2017). Empowering teachers to implement innovative content in physical education through continuous professional development. Teacher Development, 21(2), 288-306. https:// doi.org/10.1080/13664530.2016.1235608

Csikszentmihalyi, M. (1990). Flow: The psychology of optimal experience. Harper \& Row.

Deci, E. L., y Ryan, R. M. (1985). Intrinsic motivation and self-determination in human behavior. Plenum. https:// doi.org/10.1007/978-1-4899-2271-7

Delgado Noguera, M. A. (1991). Los estilos de enseñanza en la educación física. Propuesta para una reforma de la enseñanza. Instituto de Ciencias de la Educación de la Universidad de Granada.

Fernández-Espínola, C., Almagro, B. J, y Tamayo Fajardo, J. A. (2020). Predicción de la intención de ser físicamente activo del alumnado de Educación Física: un modelo mediado por la necesidad de novedad. Retos, 37, 442-448. https://doi.org/10.47197/retos.v37i37.70946

Ferriz, R., González-Cutre, D., y Balaguer-Giménez, J. (2020). Agentes sociales de la comunidad educativa, satisfacción de novedad y actividad física. Cultura, Ciencia y Deporte, 15(46), 519-528. http://dx.doi.org/10.12800/ccd.v15i46.1602

Fierro-Suero, S., Almagro, B. J., Castillo, I., y Sáenz-López, P. (2020). Herramienta de Observación del Clima Interpersonal Motivacional (OCIM) para docentes de Educación Física. Cultura, Ciencia y Deporte, 15(46), 575-596. http://dx.doi.org/10.12800/ccd.v15i46.1647

Fierro-Suero, S., Almagro, B. J., y Sáenz-López, P. (2020). Validation of the Achievement Emotions Questionnaire for Physical Education (AEQ-PE). International Journal of Environmental Research and Public Health, 17(12), 4560. http://dx.doi.org/10.3390/ijerph17124560
Fierro-Suero, S., Almagro, B. J., Sáenz-López, P., y Carmona-Márquez, J. (2020). Perceived novelty support and psychological needs satisfaction in physical education. International Journal of Environmental Research and Public Health, 17(11), 4169. http://dx.doi.org/10.3390/ijerph17114169

Gil-Arias, A., Diloy-Peña, S., Sevil-Serrano, J., GarcíaGonzález, L., y Abós, A. (2021). A hybrid TGfU/SE volleyball teaching unit for enhancing motivation in physical education: A mixed-method approach. International Journal of Environmental Research and Public Health, 18(1), 110. http://dx.doi.org/10.3390/ijerph18010110

González-Cutre, D., Romero-Elías, M., Jiménez-Loaisa, A., Beltrán-Carrillo, V. J., y Hagger, M. S. (2020). Testing the need for novelty as a candidate need in basic psychological needs theory. Motivation and Emotion, 44(2), 295-314. https://doi.org/10.1007/s11031-019-09812-7

González-Cutre, D., y Sicilia, A. (2019). The importance of novelty satisfaction for multiple positive outcomes in physical education. European Physical Education Review, 25(3), 859-875. https://doi.org/10.1177/1356336X18783980

González-Cutre, D., Sicilia, A., Sierra, A. C, Ferriz, R., y Hagger, M. S. (2016). Understanding the need for novelty from the perspective of self-determination theory. Personality and Individual Differences, 102, 159-169. https://doi.org/10.1016/j.paid.2016.06.036

González-Cutre, D., Sierra, A. C., Beltrán-Carrillo, V. J., Peláez-Pérez, M.,y Cervelló, E. (2018). A school-based motivational intervention to promote physical activity from a self-determination theory perspective. The Journal of Educational Research, 111(3), 320-330. https://doi.org/10.1080/00220671.2016.1255871

Hernández-Martínez, A., Martínez-Urbanos, I., y CarriónOlivares, S. (2019). El Colpbol como un medio para incrementar la motivación en Educación Primaria. Retos, 36, 348-353.

https://doi.org/10.47197/retos.v36i36.70396

Kashdan, T. B., y Silvia, P. J. (2009). Curiosity and interest: The benefits of thriving on novelty and challenge. En S. J. Lopez y C. R. Snyder (Eds.), Handbook of positive psychology (2a ed., pp. 367-374). Oxford University Press. https://doi.org/10.1093/oxfordhb/9780195187243.013.0034

Koka, A., Tilga, H., Hein, V., Kalajas-Tilga, H., y Raudsepp, L. (2021). A multidimensional approach to perceived teachers' autonomy support and its relationship with intrinsic motivation of students in physical education. International Journal of Sport Psychology, 52(3), 266286. https://doi.org/10.7352/IJSP.2021.52.266

Lissak, G. (2018). Adverse physiological and psychological effects of screen time on children and adolescents: Literature review and case study. Environmental Research, 164, 149-157. https://doi.org/10.1016/j.envres.2018.01.015

Manso-Lorenzo, V., Evangelio, C., Ruiz-Tendero, G., y González-Víllora, S. (2020). Teacher or student-cen- 
tred model? Step-by-step analysis of basic psychological needs of a new sport - goubak. Journal of Physical Education and Sport, 20, 3212-3221. https://doi.org/10.7752/jpes.2020.s6436

Martínez de Ojeda, D., Puente-Maxera, F., y MéndezGiménez, A. (2021). Efectos motivacionales y sociales de un programa plurianual de educación deportiva. Revista Internacional de Medicina y Ciencias de la Actividad Física y el Deporte, 21(81), 29-46. https:// doi.org/10.15366/rimcafd2021.81.003

Pérez-Pueyo, A., Hortigüela-Alcalá, D., y FernándezRío, J. (2021). Modelos pedagógicos en Educación Física: Qué, cómo, por qué y para qué. Servicio de Publicaciones de la Universidad de León.

Pérez-Pueyo, A., Hortigüela-Alcalá, D., Gutiérrez-García, C., y López-Pastor, V. (2021). Evaluación formativa y compartida. En A. Pérez-Pueyo, D. Hortigüela-Alcalá y J. Fernández-Río (Eds.), Modelos pedagógicos en Educación Física: Qué, cómo, por qué y para qué (pp. 400-433). Servicio de Publicaciones de la Universidad de León.

Rodrigo-Sanjoaquín, J., Sevil-Serrano, J., Julián, J. A., Generelo, E., y Pérez-Ordás, R. (2019). Implementación de las tecnologías de la información y la comunicación en la promoción de hábitos saludables. Servicio de Publicaciones de la Universidad de Zaragoza.

Sevil-Serrano, J., Aibar, A., Abós, A., Generelo, E., y GarcíaGonzález, L. (2020). Improving motivation for physical activity and physical education through a school-based intervention. Journal of Experimental Education. Publicación en línea avanzada. https://doi.org/10.108 o/00220973.2020.1764466

Stoa, R., y Chu, T. L. (2020). An argument for implementing and testing novelty in the classroom. Scholarship of Teaching and Learning in Psychology. Publicación en línea avanzada. https://doi.org/10.1037/stl0000223

Sylvester, B. D., Jackson, B., y Beauchamp, M. R. (2018) The effects of variety and novelty on physical activity and healthy nutritional behaviors. En A. J. Elliot (Ed.), Advances on motivation science: Vol 5 (pp. 169-202). Academic Press. https://doi.org/10.1016/ bs.adms.2017.11.001
Sylvester, B. D., Standage, M., Dowd, A. J., Martin, L. J., Sweet, S. N., y Beauchamp, M. R. (2014). Perceived variety, psychological needs satisfaction and exercise-related well-being. Psychology \& Health, 29(9), 1044-1061. https://doi.org/10.1080/08870446.2014. 907900

Trigueros, R., Aguilar-Parra, J. M., López-Liria, R., y Rocamora, P. (2019). The dark side of the self-determination theory and its influence on the emotional and cognitive processes of students in physical education. International Journal of Environmental Research and Public Health, 16(22), 4444. https://doi.org/10.3390/ ijerph16224444

Trigueros, R., Maldonado, J. J., Vicente, F., González-Bernal, J. J., Ortiz, L., y González-Santos, J. (2020). Adaptación y validación al contexto de la educación física de la escala de la frustración de las necesidades psicológicas en el ejercicio físico, con la inclusión de la novedad como necesidad psicológica. Revista de Psicología del Deporte, 29(3), 91-99.

Trigueros, R., Mínguez, L. A., González-Bernal, J. J., AguilarParra, J. M., Padilla, D., y Álvarez, J. F. (2019). Validation of the Satisfaction Scale of Basic Psychological Needs in Physical Education with the incorporation of the novelty in the Spanish context. Sustainability, 11(22), 6250. http://dx.doi.org/10.3390/su11226250

Trigueros, R., Mínguez, L. A., González-Bernal, J. J., AguilarParra, J. M., Soto-Cámara, R., Álvarez, J. F., y Rocamora, P. (2020). Physical education classes as a precursor to the Mediterranean diet and the practice of physical activity. Nutrients, 12(1), 239. https://doi.org/10.3390/ nu12010239

White, R. L., Bennie, A., Vasconcellos, D., Cinelli, R., Hilland, T., Owen, K. B., y Lonsdale, C. (2021). Self-determination theory in physical education: A systematic review of qualitative studies. Teaching and Teacher Education, 99,103247.https://doi.org/10.1016/j.tate.2020.103247 


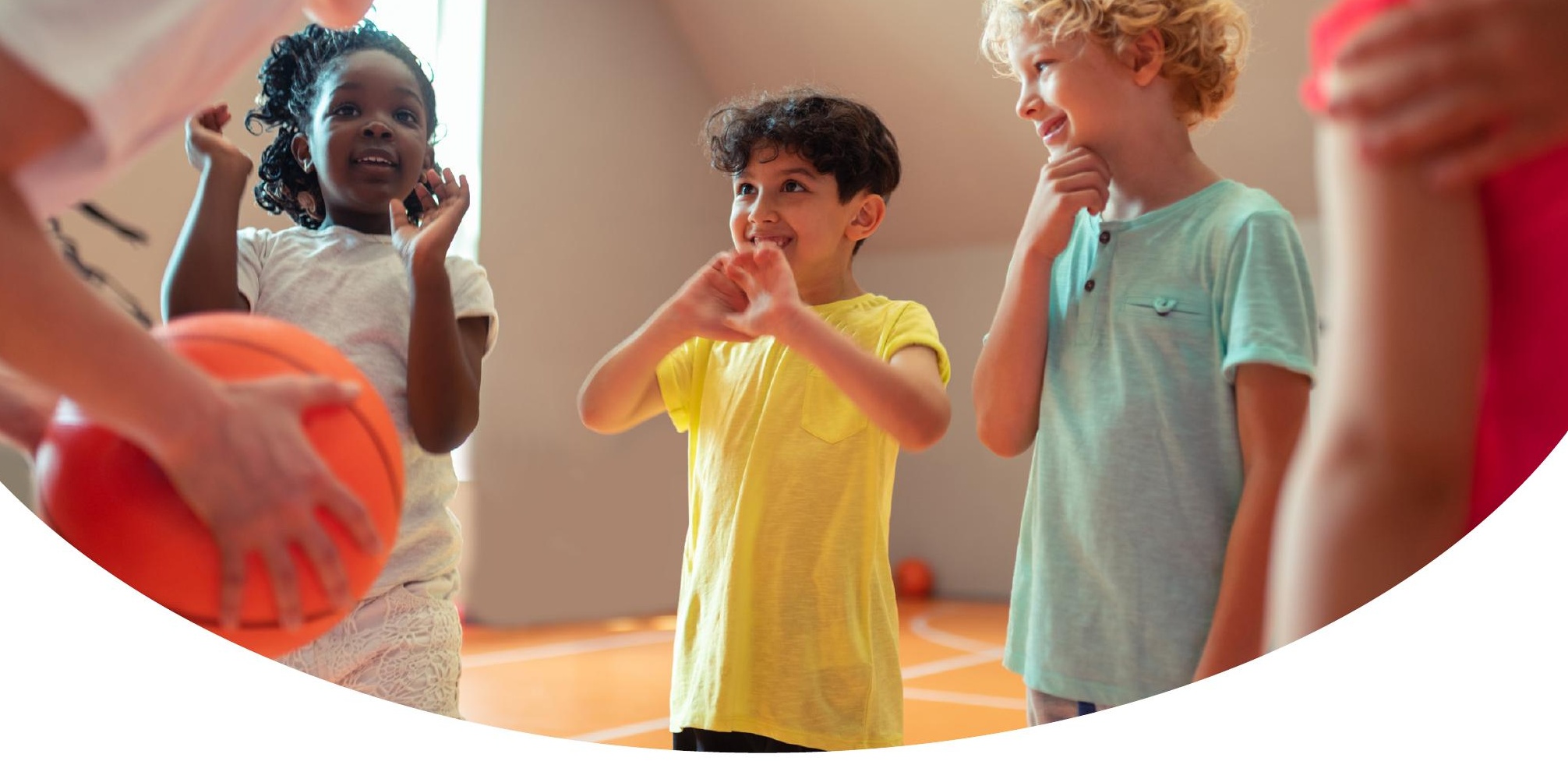

Capítulo 2.5.

\section{¿CÓMO INFLUYEN LAS \\ DESTREZAS DOCENTES EN LA MOTIVACIÓN DEL ALUMNADO EN EDUCACIÓN FÍSICA?}

Autores: Luis García-González¹ , Jorge Lizandra² y Javier Sevil-Serrano³

1 Universidad de Zaragoza; ${ }^{2}$ Universidad de Valencia; ${ }^{3}$ Universidad de Extremadura

Palabras clave: información inicial, feedback, organización, normas, rutinas, tiempo de práctica. 
Sara, maestra de Educación Física en Educación Primaria, considera la motivación como uno de los motores fundamentales en el aprendizaje del alumnado. En el Grado de Magisterio en Educación Primaria, que finalizó hace unos años, examinaron las diferentes destrezas docentes. Sin embargo, después de unos años de experiencia como interina, le asaltan algunas cuestiones que le gustaría conocer con más detalle ¿Cómo se puede transmitir la información inicial para generar más autonomía en el alumnado?, ¿cómo se relacionan los diferentes tipos de feedback con la motivación?, ¿qué tipos de agrupaciones pueden ser las más recomendadas para no frustrar la competencia del alumnado?

Estas y otras cuestiones se abordarán en este capítulo, profundizando en cómo, a través de distintas destrezas docentes, el profesorado de Educación Física puede contribuir a satisfacer las tres necesidades psicológicas básicas de autonomía, competencia y relación social del alumnado, así como a evitar su frustración. Según la teoría de la autodeterminación (Ryan y Deci, 2017), satisfacer las necesidades psicológicas básicas es fundamental para que el alumnado esté más motivado intrínsecamente (ver Capítulo 1.1.). Para ello, abordaremos las siguientes destrezas docentes: información inicial, feedback, organización y control del grupo y la distribución del tiempo de práctica. Además, plantearemos algunos ejemplos prácticos sobre cómo las diferentes destrezas pueden ayudar a satisfacer las necesidades psicológicas básicas, así como evitar su frustración. 


\section{1.- EVIDENCIAS CIENTÍFICAS}

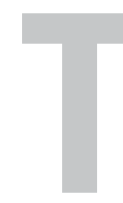

odos los docentes de Educación Física han evidenciado cómo las destrezas docentes (información inicial, feedback, organización y control del grupo y la distribución del tiempo de práctica) son interdependientes entre sí, determinando el carácter multidimensional de la intervención docente (Calderón et al., 2005). En este capítulo, se analizará la influencia de cada destreza docente sobre las tres necesidades psicológicas básicas de autonomía, competencia y relaciones sociales. Sin embargo, cabe destacar que, debido a su interdependencia, en ocasiones se puede aludir a varias de ellas. Por ejemplo, las decisiones que se tomen sobre la información inicial aportada pueden influir, también, sobre el feedback docente y viceversa.
La información inicial hace referencia a todos aquellos aspectos que el docente aporta a su alumnado, tanto al inicio de una unidad didáctica como en cada sesión y en cada tarea o situación motriz. Los objetivos que persigue esta información inicial son: conocer qué saben, comprender y relacionar la información con aprendizajes previos y posteriores, contextualizar la sesión, motivarles y predisponerles hacia la tarea y destacar algunos aspectos de interés antes de acometer la tarea. Además, para que sea eficaz, no debe ser superior al 20\% del total de la clase para evitar reducir el tiempo de compromiso motor y de aprendizaje (Fuentes et al., 2005). Algunos autores proponen que se desarrolle en cuatro fases secuenciadas: 
1.- Ganar la atención del alumnado. Es importante elegir siempre el mismo sitio y disposición espacial para transmitir la información, tratando de que el docente tenga una posición destacada y no se le dé la espalda a nadie. Se pueden usar complementos como una pizarra o una tableta para centrar la atención del alumnado.

2.- Introducción de la tarea. Es el momento de generar interés y predisposición, de darle valor y utilidad a la sesión o tarea que se va a presentar y de reforzar cuál es la finalidad de esta.

3.- Explicación de la tarea. Puede ayudar a añadir detalles, identificar las reglas, así como a proporcionar demostraciones, si es necesario, sobre la tarea. Al final de esta, se debe indicar los aspectos organizativos y el criterio de éxito.

4.- Lanzamiento a la tarea. Se debe aprovechar este último mensaje al alumnado para motivar, estimular al reto, recordar un elemento importante, una regla o advertir de algún peligro.

Una información inicial eficaz puede contribuir a satisfacer las necesidades psicológicas básicas de autonomía, competencia y relaciones sociales de la siguiente manera:

- Autonomía. Informar sobre los objetivos didácticos y la importancia de la tarea, sesión o unidad didáctica va a favorecer que el alumnado comprenda por qué las realiza y no las vea como algo impuesto por su profesor (p. ej., "Tú tienes que hacer esto"). Por ello, en la fase de introducción de la tarea, es muy importante expresar alguna razón, algún por qué o para qué hacemos esta tarea o sesión. Además, si la vinculamos a aprendizajes anteriores, es más probable que el alumnado esté predispuesto hacia ella (p. ej., "En la sesión anterior estuvimos trabajando el principio táctico de mantener la posesión del balón. ¿Qué os parece si, hoy, trabajamos de manera especifica los desmarques para consolidar este principio?"). Conocer los beneficios y la utilidad de las tareas también puede predisponerle a realizarlas en su tiempo libre (p. ej., "Mantener un ritmo uniforme nos puede ayudar a poder aguantar más tiempo corriendo en las actividades que hagamos"). De igual modo, involucrar al alumnado en la explicación de juegos o tareas ya conocidas, en las demostraciones, en diferentes roles (p. ej., cronometrador, árbitro, fotógrafo, etc.) o en la elección de determinados elementos (p. ej., agrupaciones, tiempo, material, reglas de juego, evaluación, etc.), puede favorecer también su autonomía. Si la información inicial es muy exhaustiva o si el docente no involucra al alumnado durante la información inicial, es más probable que adopte conductas más controladoras, favoreciendo menos la autonomía.

- Competencia. Explicar correctamente la tarea (p. ej., organización, tiempo, material, reglas de juego, criterio de éxito, etc.) puede favorecer que el alumnado no realice incorrectamente la actividad por una falta de comprensión. Para ello, adaptar el lenguaje al nivel madurativo del alumnado, así como la utilización del canal visual a través de demostraciones o la ayuda visual (p.ej., pizarras, material curricular, instrumentos tecnológicos, etc.) puede ser de gran utilidad. Asimismo, se pueden formular preguntas a un estudiante o al grupo para asegurarnos de que se ha comprendido bien (p. ej., "¿Cómo se consigue entonces punto en esta actividad?"). En el lanzamiento a la tarea, se puede también reforzar que se valorará el esfuerzo y progreso personal y no se comparará su ejecución o rendimiento respecto al de otros compañeros (p. ej., "Recordad que voy a fijarme en que os movéis constantemente para ocupar los huecos libres y podéis recibir un pase del compañero").

- Relaciones sociales. Es importante iniciar la clase con preguntas sobre su vida personal, 
académica o deportiva para que el alumnado sienta que el docente se preocupa por ellos. De igual modo, adoptar una actitud empática, comprensiva y de escucha activa cuando hable el alumnado puede mejorar el clima emocional del aula. Favorecer que todo el alumnado tenga la oportunidad de explicar o proponer una tarea, así como demostrar la realización de una actividad, puede favorecer que el alumnado no perciba favoritismos por parte del profesorado, sintiéndose todos integrados en el grupo. En el lanzamiento a la tarea, también se puede favorecer, siempre que sea posible, la cooperación, evitando la exacerbada competitividad entre compañeros en algunas tareas.

La segunda destreza docente que vamos a abordar es el feedback o retroalimentación. El feedback docente es una de las destrezas más importantes dentro de las clases de Educación Física por su alta frecuencia y las consecuencias positivas que puede generar (p. ej., aprendizaje, motivación, diversión, etc.) (Zhou et al., 2021). Esta destreza está estrechamente ligada con la evaluación, debido a que se proporciona continua retroalimentación a los estudiantes para que estos mejoren sus conductas motrices (para más información ver Capítulo 2.8). Aunque existen numerosas clasificaciones, en este capítulo nos centraremos especialmente en algunos de los tipos de feedback que existen en función de la intención (Del Villar y Fuentes, 1999; Fuentes et al., 2005), ente los que destacamos:

1.- Feedback descriptivo. El docente solo describe lo que sucede. Normalmente, se utiliza cuando el alumnado no es capaz de percibir o ver su ejecución (p. ej., cuando el alumnado hace un volteo hacia delante). En una tarea de un deporte de colaboración-oposición, donde se trabaja el principio táctico de mantener la posesión, un feedback descriptivo sería:
"Cuando has ido a pasar a tu compañero, éste no estaba desmarcado".

2.- Feedback explicativo. El docente trata de informar por qué ha salido bien o mal una ejecución o una tarea. Siguiendo con el ejemplo anterior, un feedback explicativo sería "No habéis podido mantener la posesión del balón porque no ha habido desmarques. Como tu compañero se ha quedado quieto esperando el balón, vuestro rival ha podido robárselo".

3.- Feedback evaluativo/comparativo. El docente valora lo que ha observado con relación a 1) un criterio o una ejecución correcta, 2) una ejecución anterior del alumno/a o grupo, - 3) con respecto al resto de compañeros. Un ejemplo de feedback evaluativo respecto a una ejecución anterior sería "Ese desmarque ha estado mucho mejor que la anterior vez porque has identificado el espacio libre". Es importante explicar la causa por la que un comportamiento está mal o bien. Aquí podemos ver cómo se suele combinar un feedback evaluativo/comparativo y un posterior feedback explicativo donde se indica el porqué de haberlo hecho bien o mal, mejor o peor.

4.- Feedback prescriptivo. El docente se centra en indicar qué debe hacer el alumnado para solventar el problema observado, aportando la solución. Un ejemplo sería "Si te mueves hacia un espacio vacío, tu compañero te podrá pasar el balón".

5.- Feedback interrogativo. El docente trata de que el alumnado identifique el porqué de un error o el acierto, sin darle en ningún caso la solución, estimulándolo cognitivamente. Un ejemplo sería "¿Habéis visto donde estaba colocado Javi para recibir el balón?, ¿tenía algún rival cerca?, ¿qué ocurre si paso a alguien que tiene un rival cerca?, ¿qué tendré que hacer entonces para recibir el balón por parte de mis compañeros?". De esta forma, 
intentamos estimular que piensen que es necesario desmarcarse de los rivales y moverse hacia un espacio libre para recibir el balón. Posteriormente, es importante volver a realizar la tarea, poniendo en práctica las soluciones identificadas, para comprobar si son correctas las respuestas. Es importante plantear feedback interrogativo de manera individual tanto grupal para que no siempre contesten los mismos. Este tipo de feedback es muy usual dentro de la enseñanza comprensiva del deporte.

Estas tipologías de feedback se combinan continuamente en las clases de Educación Física. Algunos estudios como el de Drost y Todorovich (2017) o el de Mabbe et al. (2018) nos muestran la influencia de estos tipos de feedback sobre cada una de las necesidades psicológicas básicas. A continuación se muestran algunos ejemplos:

- Autonomía. El tipo de feedback que más autonomía produce es el interrogativo. Este feedback interrogativo permite al alumnado responder a las preguntas planteadas por el docente para, posteriormente, intentar ponerlas en práctica. El feedback descriptivo o explicativo también pretende ayudar al alumnado a conocer lo que está pasando para que sea autónomo en su práctica. Sin embargo, si continuamente utilizo feedback prescriptivo, en el que les indico en todo momento lo que tienen que hacer y cómo lo tienen que hacer, el estilo docente será excesivamente controlador ("Debes hacerlo así") y, por tanto, la autonomía del alumnado quedará totalmente frustrada. Por ejemplo, un docente de Educación Física en una situación real de juego de un deporte de colaboración-oposición desde la banda atosiga continuamente a los jugadores que tienen la posesión del balón indicando lo que tienen que hacer "Sigue Laura, pasa a Clara, pasa ahora a Sara, vamos Diana tira tú que vas sola, ivamooosss!" e impidiendo, por tanto, la toma de decisiones.
- Competencia. El uso de un feedback evaluativo/comparativo puede ser positivo o negativo, en función del criterio con el que se compare. Si el docente compara la ejecución entre los estudiantes, se puede frustrar la competencia de los menos hábiles motrizmente. Sin embargo, si el feedback comparativo se hace con relación a una ejecución anterior, destacando lo que se ha mejorado, se favorece que el alumnado perciba un progreso $y$, por tanto, se perciba más competente. Además, se puede combinar con un feedback explicativo que indiqué por qué ahora lo han hecho mejor. Por ejemplo, "En esta ocasión habéis ocupado mucho mejor los espacios. Jorge se ha movido hacia donde no habia nadie $y$, por eso, María le ha podido pasar sin problema". De igual modo, el feedback interrogativo también favorece que el alumnado aprenda de sus errores y pueda dar respuesta a las preguntas planteadas por el docente, aunque no necesariamente, sepa resolverlas en la práctica. El feedback prescriptivo podría mejorar o frustrar la competencia, en función de la tarea, el tipo de alumnado, el contexto, etc. Por un lado, a corto plazo puede mejorar la percepción de competencia ya que le das la solución para resolver el problema planteado. Sin embargo, algunos estudiantes podrían percibir que no han sido capaces de resolver el reto por sí mismos, frustrando también su competencia. Además, puede crear en el alumnado dependencia del profesorado en la búsqueda de soluciones. Por último, es importante que el docente aporte especialmente feedback relacionado con los objetivos o el criterio de éxito de la actividad. Si el docente aporta feedback sobre otros aspectos que no se han trabajado, puede frustrar la competencia del alumnado. De igual modo, utilizar frecuentemente feedback negativo, ridiculizar al alumnado en sus respuestas o valorar únicamente el resultado final puede frustrar la competencia del alumnado. 
- Relaciones sociales. Algunos feedback comparativos o explicativos pueden incidir negativamente en las relaciones sociales entre los propios estudiantes y entre el docente y su alumnado. Por ejemplo, aquellos docentes que indican que una acción o tarea no se ha realizado bien por culpa de un estudiante en concreto, o aquellos feedback comparativos respecto a otros grupos u otros compañeros contribuyen a generar clima motivacional ego (ver Capítulo 2.3.) y afectan negativamente a las relaciones sociales del grupo. Por ejemplo, tras una carrera de relevos, felicitar y dejar bien claro quién ha sido el ganador contribuye a este clima ego (p. ej., "Muy bien el equipo azul, que ha ganado claramente al equipo rojo, un aplauso para ellos"). Por ello, es importante que, en el caso de usar feedback comparativo, se haga respecto a una actuación anterior a nivel individual o del propio grupo. El uso de un feedback privado puede evitar la competitividad entre diferentes estudiantes o grupos, favoreciendo las relaciones sociales entre el profesorado y el alumnado.

La tercera y cuarta destreza docente que se abordarán en este capítulo es la organización y el tiempo de práctica. La organización de las tareas incide directamente sobre el tiempo de práctica motriz y puede determinar la motivación del alumnado (Calderón et al., 2005). Las agrupaciones (individual, por parejas, pequeños grupos o grandes grupos) y la organización (simultánea, alternativa o consecutiva) de las clases de Educación Física dependerán del contexto, el tipo de alumnado, su nivel madurativo, etc., influyendo directamente en el tiempo de práctica del alumnado. La evidencia científica ha demostrado que algunas estructuras organizativas permiten un mayor tiempo de práctica motriz que otras. Las tareas simultáneas permiten que todo el alumnado participe a la vez y, por tanto, se maximiza el tiempo de práctica. Estas tareas simultáneas, además, pueden ser individuales o grupales. Por otro lado, las tareas alternativas en las que solo participa una persona, reducen el tiempo de práctica en función del número de integrantes del grupo. Y, por último, la organización consecutiva, como puede ser una fila, reduce el tiempo de práctica en función del número de integrantes de esa fila. Por ejemplo, si son grupos de seis, uno participa y cinco esperan, esto es algo verdaderamente poco eficaz.

Las agrupaciones y los diferentes tipos de organizaciones pueden afectar a la satisfacción y frustración de las necesidades psicológicas básicas de la siguiente forma:

- Autonomía. Con relación a las agrupaciones, facilitar que el alumnado pueda elegir a los compañeros con los que realizar una tarea puede favorecer su autonomía. Sin embargo, como se verá posteriormente, también pueden frustrarse la competencia y las relaciones sociales si no se realiza correctamente. Para una organización preventiva eficaz, el establecimiento de normas y rutinas con el alumnado permite no solo optimizar el tiempo de compromiso motor, sino que también favorece que el alumnado consensue las mismas y se responsabilice de su cumplimiento.

- Competencia. Podría ser la más afectada por las distintas agrupaciones y fórmulas organizativas propuestas. Con relación a las agrupaciones, los grupos homogéneos pueden permitir individualizar la enseñanza (p. ej., grupos de nivel en una unidad didáctica de carrera de larga duración), permitiendo que el alumnado pueda progresar más rápidamente. Sin embargo, si siempre se realiza este tipo de agrupaciones y se realiza una distinción de los mismos (p. ej., grupo A, B, C, D, etc.) puede llegar a frustrar la competencia del alumnado al percibirse menos hábiles que los demás. En deportes de oposición interindividual y de colaboración-oposición, cambiar de adversario continuamente puede favorecer que no 
existan resultados abultados y, por tanto, evitar la frustración de la competencia (p. ej., cada tres puntos, independientemente de quién los consiga, se rota a la derecha). De igual modo, se debe evitar que haya eliminados en los juegos para no frustrar la competencia. Con relación a las estructuras organizativas, aquellas que fomentan el tiempo de práctica aumentan las posibilidades de que el alumnado sea capaz de dominar una habilidad y percibirse competente. Sin embargo, aquellas que exponen al alumnado delante de sus compañeros (p. ej., filas, relevos, etc.) influyen negativamente sobre el tiempo de práctica y la percepción de competencia de los menos hábiles motrizmente.

- Relaciones sociales. Con relación a las agrupaciones, utilizar formas de agrupación flexibles y heterogéneas, que además vayan cambiando a lo largo de la sesión, puede favorecer que todos los integrantes de una clase puedan conocerse. También, en ocasiones, es interesante mantener las agrupaciones a lo largo de una unidad didáctica para reforzar la afiliación del grupo (ver Capítulo 2.1. en el que se habla del modelo de educación deportiva). Las agrupaciones libres pueden favorecer que el alumnado trabaje con el compañero o compañeros con los que tenga más confianza o amistad ( $p$. ej., montaje de una coreografía). Sin embargo, si siempre se usa este tipo de agrupaciones se limita la posibilidad de que todo el grupo se conozca y, por tanto, de reforzar la cohesión grupal. Por otro lado, favorecer que dos estudiantes elijan a sus compañeros puede originar que algunos estudiantes se sientan rechazados al ser elegidos en último lugar. Esta forma de realización de los agrupamientos puede frustrar la competencia del alumnado. Con relación a las estructuras organizativas, la exposición de una tarea o habilidad delante de los compañeros puede, no solo frustrar la competencia, sino también las relaciones sociales. Por ello, las tareas simultáneas permiten evitar que el alumnado se sienta expuesto a la mirada de los compañeros. 


\section{2.- APLICACIONES PRÁCTICAS PARA LA DOCENCIA EN EDUCACIÓN FÍSICA}

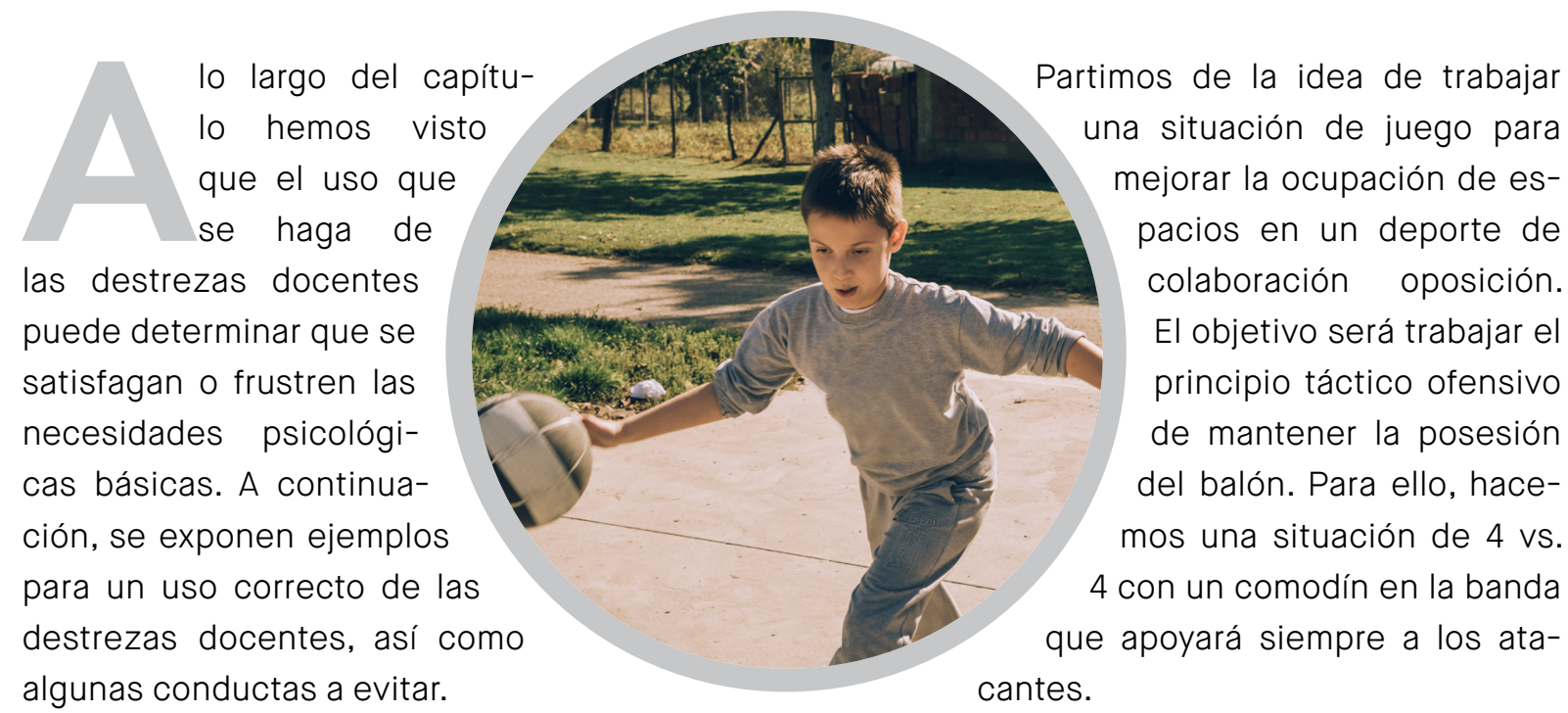




\section{Satisfacción de las necesidades psi- | Frustración de las necesidades psi- cológicas básicas cológicas básicas}

\section{Información inicial}

"Por favor, atendedme todos un momento. Como hemos observado que perdemos muchas veces el balón, cuando intentamos avanzar hacia el otro campo, vamos a realizar una tarea de 4 vs. 4 en la que tendremos un comodín que ayudará a los que ataquen. Ya sabéis que el objetivo es mantener la posesión el mayor tiempo posible y, para ello, es necesario que nos movamos y busquemos los huecos libres, como ya hemos visto en las sesiones anteriores. Seguimos con la misma organización de la tarea anterior y recordad, si nos quedamos parados es muy probable que nos roben el balón".

La explicación de la tarea puede hacerse directamente $\mathrm{o}$ introduciendo preguntas como "¿Para qué creéis que vamos a realizar esta actividad?, ¿qué tenemos que hacer para mantener la posesión del balón?, ¿qué tenemos que hacer para tener éxito en la tarea?".

\section{Feedback}

Cuando se esté realizando la tarea se puede congelar el juego y hacer las siguientes preguntas: "¿Habéis visto cuándo os han robado el balón?, ¿el que recibe estaba quieto o buscaba un hueco libre?, ¿qué alternativas hay?".

Posteriormente, se reanuda el juego para poner en práctica las respuestas planteadas. De pronto, una vez avanza el juego y el docente identifica que se cumple el objetivo de la tarea, puede volver a pararla y aportar nuevos feedback: "Esta vez está mucho mejor que antes. ¿Por qué creéis que ha salido mejor? Si os habéis fijado, Laura estaba intentando buscar un hueco a su derecha y, así, Javi ha podido pasarle"

\section{Información inicial}

"Escuchad de una vez. Voy a explicarlo aunque estéis hablando. Vamos a hacer una tarea de oleadas, para ver si sois capaces de mantener el balón lo máximo posible y no perderlo todo el rato como ahora. Un equipo de 4 ataca y, cuando pierda el balón, pierde la posesión y entra el equipo que está esperando a defender. El que está de comodín sigue atacando. ¿Lo habéis entendido?, ¿alguna duda?".

En el lanzamiento a la tarea, preguntas genéricas como "¿alguna duda?" son excesivamente genéricas y no favorece la respuesta del alumnado. Es preferible hacer una pregunta concreta de algún elemento importante, como por ejemplo "¿tenéis claro cuando se cambia el equipo que ataca?".

\section{Feedback}

El docente únicamente lanza algunos feedback, mientras se desarrolla la tarea. Algunos ejemplos de feedback afectivos, comparativos y prescriptivos que pueden afectar negativamente podrían ser:

"Sara, otra vez estás parada. Espabila que te la roban siempre".

"Jorge, cuantas veces os he dicho que miréis primero a vuestro compañero antes de pasarle...".

"Fijaos en el equipo de Andrea y Pepe, no paran de moverse y no les quitan nunca el balón" 
"¿Os habéis fijado en que hay un comodín en la banda?, ¿para qué nos sirve?".

Posteriormente, se debe dejar tiempo de práctica nuevamente para practiquen tras el último feedback, antes de pasar a la siguiente actividad.

\section{Organización y tiempo}

La tarea simultánea, en grupos reducidos, ayuda a que todos practiquen a la vez, existiendo un elevado tiempo de compromiso motor. Eso también permite que no se estén comparando unos con otros. Además, cada 5 minutos los equipos rotarán para evitar resultados abultados o que se marquen muchas diferencias entre equipos.
"Alejandra, ¿no os dais cuenta de que el comodín siempre está libre? Venga, abrid los ojos que os la van a quitar enseguida".

"Os he dicho que tenéis que llegar al área contraria con 4 pases como mínimo, no con 3".

\section{Organización y tiempo}

En la tarea propuesta no solo hay un grupo que espera fuera, sino que además sale siempre el equipo que pierde el balón. Esto origina una mayor frustración de competencia del equipo que falla, así como un menor compromiso motor. Otras fórmulas organizativas, como pueden ser aquellas que, en un tiempo establecido, el que más puntos hace se queda en el campo y el que pierde se va a jugar contra otro equipo también dejan claro qué equipo es mejor y cuál es peor. 


\section{3.- PARA SABER MÁS...}

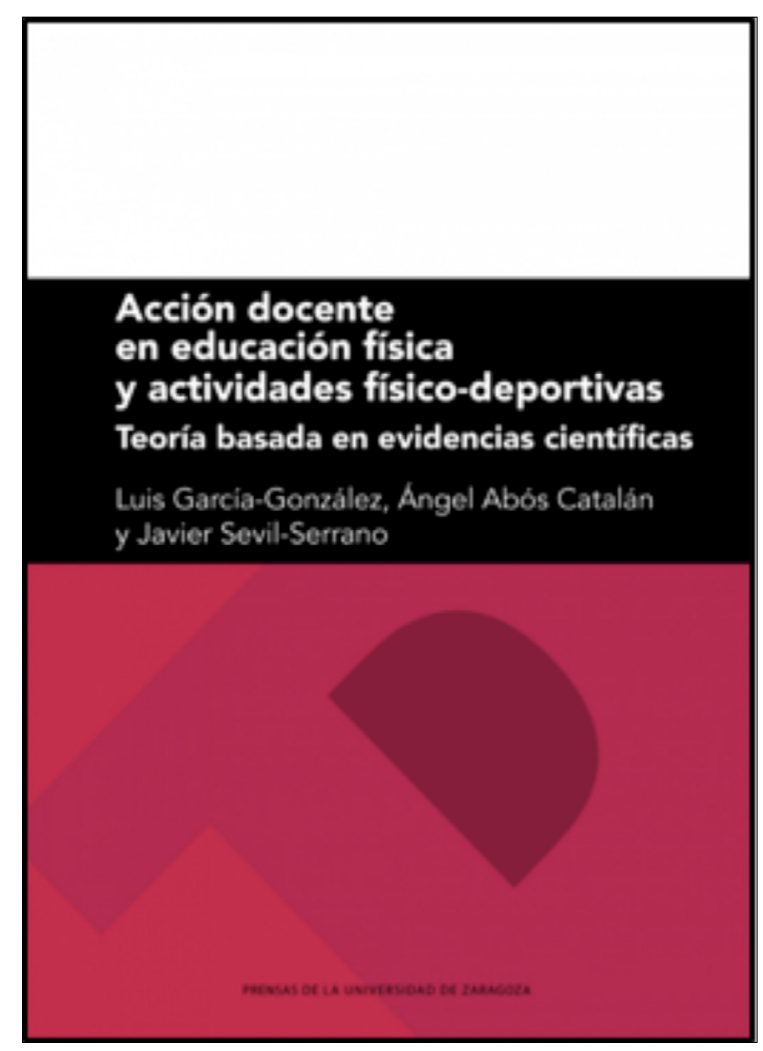

Si quieres profundizar sobre cuestiones relacionadas con las destrezas docentes en las clases de Educación Física, te proponemos, en el listado final, algunas referencias que esperamos que te sean útiles. De igual modo, este libro, al que ya nos hemos referido en el capítulo anterior, titulado "Acción docente en Educación Física y actividades físico-deportivas. Teoría basada en evidencias científicas" aborda a lo largo de cuatro capítulos, de forma más exhaustiva, distintas cuestiones sobre la información inicial, el feedback, la organización y el control de la clase o la gestión del tiempo: https://puz.unizar.es/2360-acciondocente-en-educacion-fisica-y-actividadesfisico-deportivas-teoria-basada-en-evidencias-cientificas.html 


\section{4.- REFERENCIAS BIBLIOGRÁFICAS}

Calderón, A., Palao, J. M., y Ortega, E. (2005). Incidencia de la forma de organización sobre la cantidad y la calidad de práctica, el feedback impartido y la percepción de motivación en la enseñanza de habilidades atléticas. Cultura, Ciencia, y Deporte, 1, 145-155.

Del Villar, F. y Fuentes, J. P, (1999). Las destrezas docentes en la enseñanza del tenis. En J. P Fuentes (Ed.) Enseñanza y entrenamiento de tenis. Fundamentos didácticos y científicos. (pp.1-36). Cáceres: Universidad de Extremadura.

Drost, D. K., y Todorovich, J. R. (2017). Perceived competence and skill development in physical education: the effect of teacher feedback. Journal of Sports Science, 5, 291-304.

Fuentes, J. P., García-González, L., Sanz, D., Moreno, M. P., y Del Villar, F. (2005). Estudio del feedback docente de los entrenadores de tenis de alta competición. Kronos, 7.52-62.
Mabbe, E., Soenens, B., De Muynck, G. J., y Vansteenkiste, M. (2018). The impact of feedback valence and communication style on intrinsic motivation in middle childhood: Experimental evidence and generalization across individual differences. Journal of Experimental Child Psychology, 170, 134-160. https:// doi.org/10.1016/j.jecp.2018.01.008

Ryan, R. M., y Deci, E. L. (2017). Self-determination theory: Basic psychological needs in motivation, development, and wellness. Guilford Publications.

Zhou, Y., Shao, W. D., y Wang, L. (2021). Effects of feedback on students' motor skill learning in physical education: a systematic review. International Journal of Environmental Research and Public Health, 18(12), 6281. https://doi.org/10.3390/ijerph18126281 


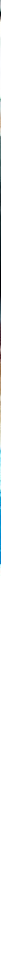

Capítulo 2.6.

\section{DESARROLLO DE LA COHESIÓN Y LAS RELACIONES SOCIALES EN CLASE PARA OPTIMIZAR LA MOTIVACIÓN E IMPLICACIÓN EN EDUCACIÓN FÍSICA}

Autores: Francisco M. Leo¹, Miguel A. López-Gajardo', Javier Fernández-Río² y Juan J. Pulido ${ }^{1}$

${ }^{1}$ Universidad de Extremadura; ${ }^{2}$ Universidad de Oviedo

Palabras clave: estrategias docentes, integración grupal, relaciones sociales, trabajo en grupo. 


\section{1.- EVIDENCIAS CIENTÍFICAS: LA COHESIÓN DE CLASE Y LAS RELACIONES SOCIALES COMO ELEMENTOS CLAVE EN LOS PROCESOS MOTIVACIONALES Y DE APRENDIZAJE}

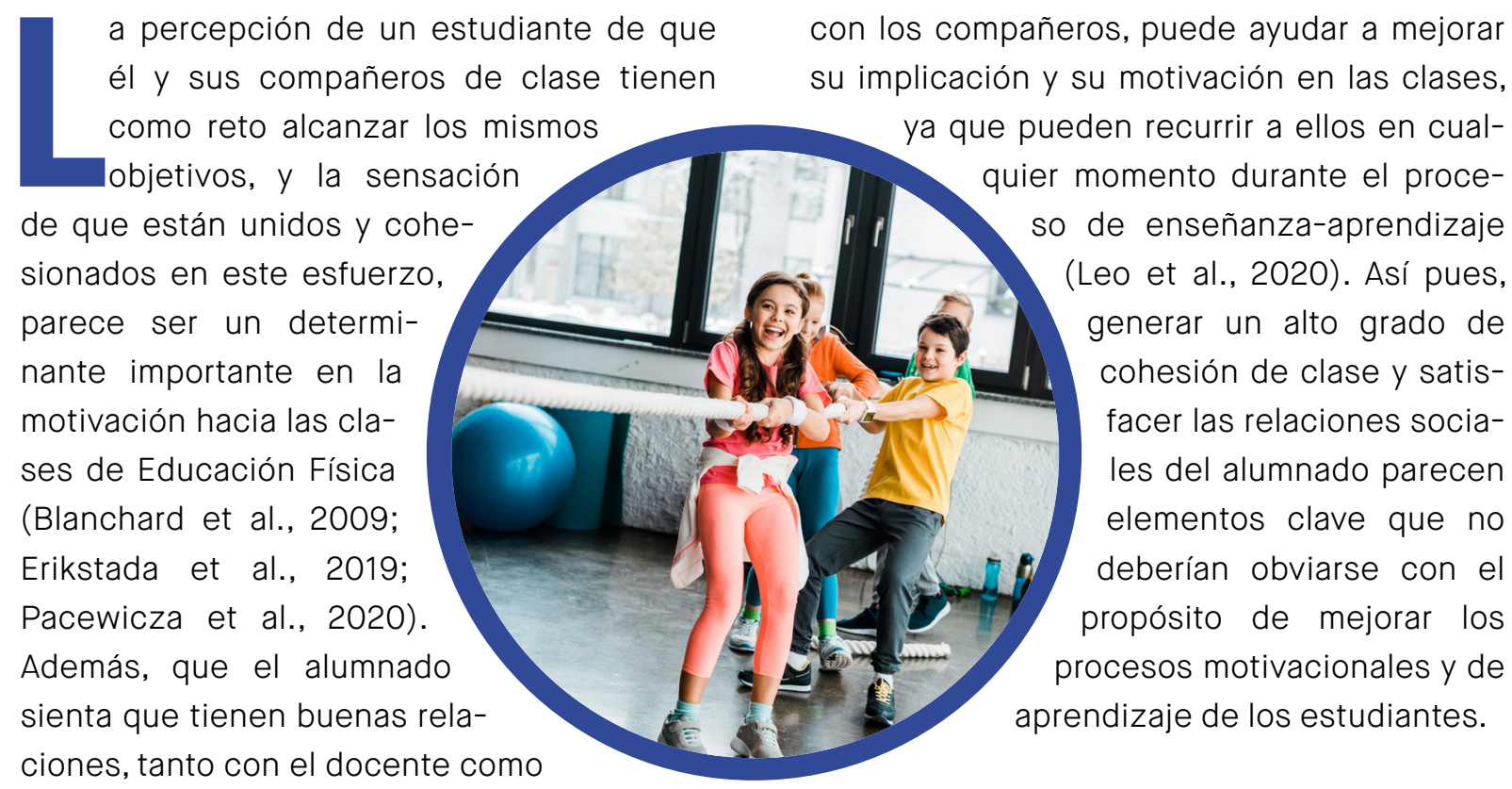




\section{1.- Cohesión de clase desde el modelo conceptual de cohesión}

El término cohesión de grupo fue definido por Carron et al. (1998) como un estado emergente "dinámico reflejado en la tendencia de un grupo a no separarse y permanecer unido en la búsqueda de sus metas y objetivos instrumentales y/o para la satisfacción de las necesidades afectivas de sus miembros" (p. 213). Esta percepción de cohesión puede estar re- lacionada con la tarea, cohesión tarea, que en el ámbito educativo refleja el grado en que el alumnado de una clase trabaja unido para alcanzar objetivos comunes, o por aspectos de bienestar social, cohesión social, que refleja el grado en que los estudiantes de una clase empatizan unos con otros y disfrutan del compañerismo del grupo (Carron et al., 1985, 1998). 


\section{Comportamientos docentes que favorecen la cohesión de grupo}

El docente desarrolla dentro y fuera del aula dinámicas grupales y actividades en pequeños y gran grupo con el objetivo de que los estudiantes cooperen entre ellos, donde se generan roles, funciones y responsabilidades interdependientes, donde se favorecen las relaciones entre el alumnado y aparecen procesos comunicativos entre iguales, el desarrollo de habilidades sociales y la interacción entre todos los estudiantes de la clase.

\section{Conductasparafomentarlacohesión area}

Un docente que trata de fomentar la cohesión tarea propone objetivos comunes a desarrollar por toda la clase, donde se establecen roles individuales e interdependientes para que entre todos se ayuden y traten de alcanzar los retos propuestos.

\section{Conductas para fomentar la cohesión social}

El docente que trata de fomentar la cohesión social propone actividades dentro y fuera del aula donde todos los estudiantes de la clase tienen que interaccionar unos con otros para conocerse mejor y compartir sus intereses inquietudes y motivaciones.
Para tratar de valorar la cohesión se han desarrollado diversos instrumentos centrados principalmente en la construcción de cuestionarios adaptados al deporte (Eys et al., 2020). A pesar del extenso número de escalas existentes, el Group Environment Questionnaire (GEQ; Carron et al., 1985) ha sido el más utilizado en el contexto deportivo. Este instrumento consta de 18 ítems que miden tanto la cohesión tarea como la cohesión social y ha sido adaptado y validado a diferentes idiomas y poblaciones (Leo et al., 2015). Sin embargo, en el ámbito educativo solo existen escalas para medir la cohesión de grupos de trabajo en el ámbito universitario (Bosselut et al., 2018; Checa y
Bohórquez, 2020) pero no para medir la cohesión de clase en su conjunto. En este sentido, Leo et al. (2021) está desarrollando una escala para medir la cohesión de clase en Educación Primaria y Secundaria.

Con respecto a la literatura que ha analizado la asociación de la cohesión de grupo con otras variables, se ha basado en el modelo teórico desarrollado por Eys et al. (2020) para el estudio de grupos en deporte. Este modelo está formado por tres grandes bloques: inputs (entradas), throughputs (procedimientos) y outputs (salidas). Aplicado al ámbito educativo, los inputs hacen referencia a las características 
individuales de los estudiantes y al entorno del grupo. Los throughputs están formados por la estructura del grupo (comportamientos docentes, clima motivacional, roles, etc.), la cohesión de grupo y los procesos grupales (motivación, cooperación, implicación, etc.).
Finalmente, los outputs son las principales consecuencias en los grupos, tales como los resultados individuales (satisfacción, aprendizaje o rendimiento académico individual) y los resultados grupales (rendimiento de la clase).

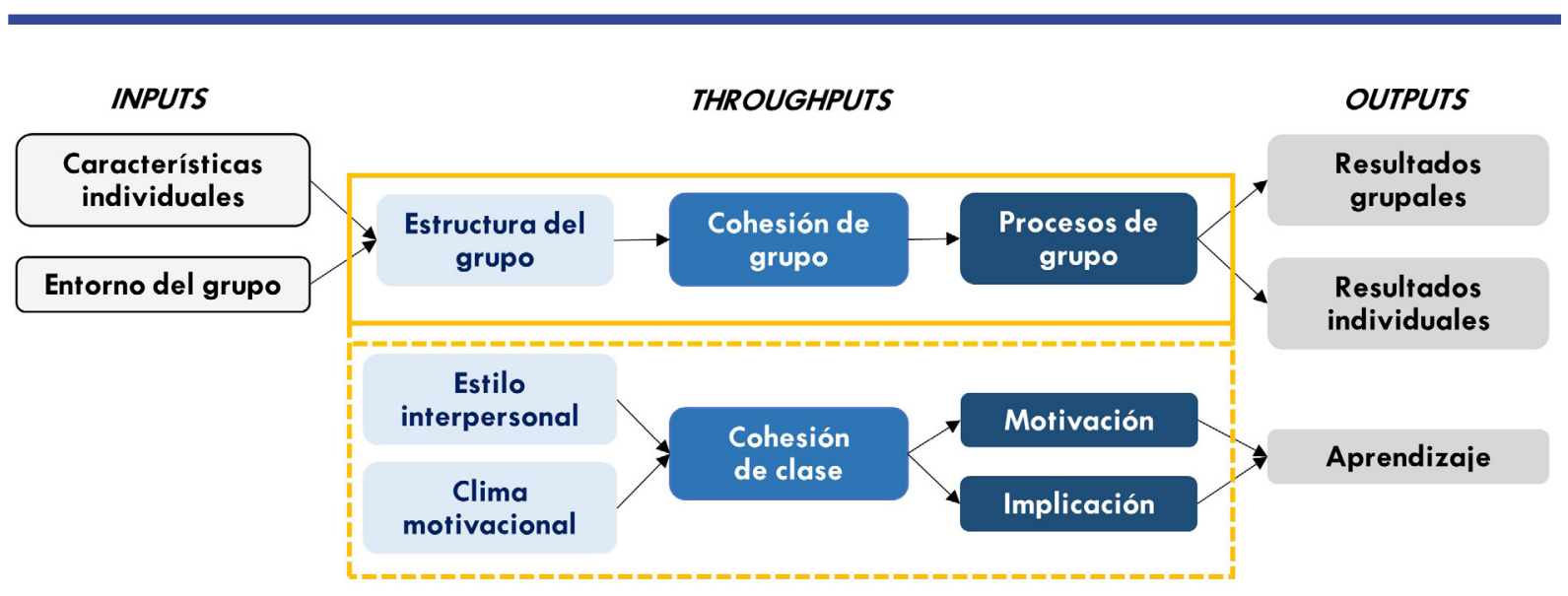

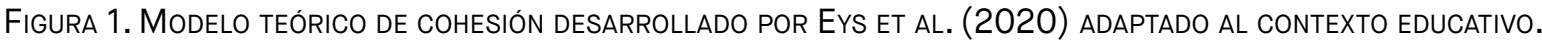

En base a este modelo, la mayoría de estudios se han desarrollado en el ámbito deportivo, siendo muy escasos en el ámbito educativo. En línea generales, estilos interpersonales de apoyo hacia las necesidades psicológicas básicas y climas motivacionales que implican a la tarea se han asociado con mayor cohesión de grupo (De Backer et al., 2011; García-Calvo et al., 2014). De la misma manera, la cohesión de grupo se ha relacionado de forma positiva con la satisfacción de las necesidades psicológicas básicas, la motivación autónoma y la implicación (Blanchard et al., 2009; Bosselut et al., 2020; Erikstada et al., 2019; Pacewicza et al., 2020). 


\section{2.- Relaciones sociales desde la teoría de la autode- terminación}

Existen multitud de estudios basados en la teoría de la autodeterminación (Deci y Ryan, 2020) que han mostrado la importancia que adquiere el estilo interpersonal que adopta el profesorado sobre la satisfacción y/o frustración de las necesidades psicológicas básicas y sobre los tipos de motivación del alumnado (ver Capítulo 1.1). Concretamente, el apoyo a las necesidades psicológicas básicas se ha asociado positivamente con la satisfacción de las necesidades psicológicas básicas y los tipos de motivación más autodeterminadas, mientras que un estilo controlador se ha relacionado con la frustración de las necesidades psicológicas básicas y las motivaciones menos autodeterminadas (Vasconcellos et al., 2020).

A pesar de que el estilo de apoyo o de control puede satisfacer o frustrar las tres necesidades psicológicas (autonomía, competencia y relaciones sociales), el apoyo a las relaciones sociales ha tenido un menor protagonismo y actuales clasificaciones del estilo interpersonal no las han tenido en cuenta (modelo circular, ver Capítulo 2.3.). A pesar de ello, el apoyo a las relaciones sociales se ha identificado como un elemento clave en los procesos motivacionales en las clases de Educación Física (Leo et al., 2020).

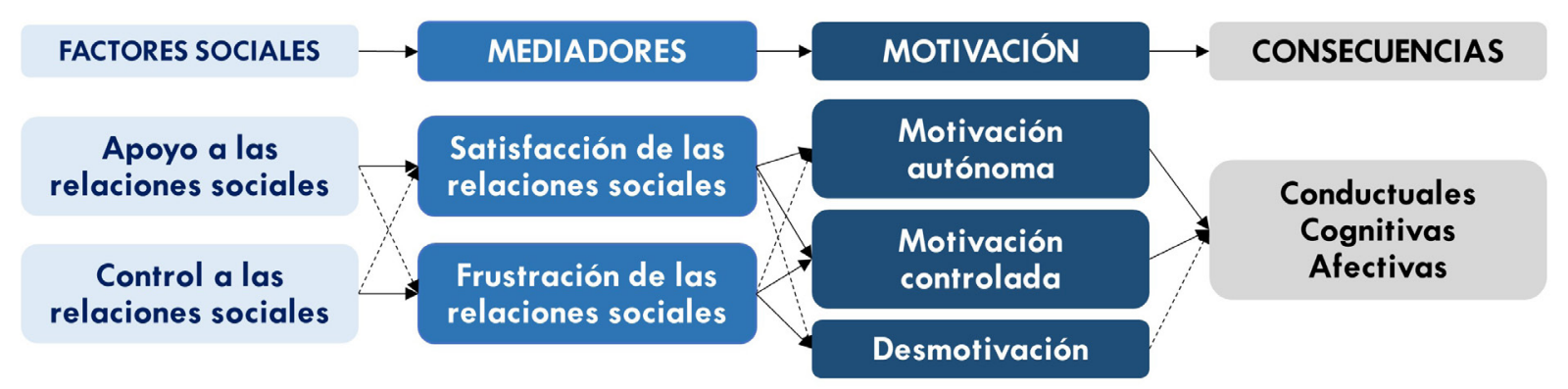

Figura 2. Modelo de la teoría de la autodeterminación (Deci y Ryan, 2000) focalizado en las Relaciones SOCIALES.

El estilo interpersonal de apoyo a las relaciones sociales hace referencia al grado de empatía que el docente ofrece a los estudiantes, estando relacionado con el fomento de la integración de todos los componentes de la clase. Por el contrario, en cuanto al control en las relaciones sociales, el profesorado no se preocupa por su relación con el alumnado y muestra desinterés por los procesos sociales entre sus estudiantes (Tabla 2). 


\section{Estilo interpersonal relacionado con las relaciones sociales}

El profesorado desarrolla un estilo interpersonal en el que se preocupa de cómo se producen las interacciones dentro de un grupo, tanto docente-discente como entre discentes, teniendo en cuenta no solo aquellas relaciones sociales orientadas al desarrollo de apartados académicos, sino que también desarrolla un estilo basado en las preocupaciones personales del alumnado. El profesorado trataría de alimentar las relaciones sociales del aula mediante el uso de estrategias en el que predominen actividades cooperativas e interdependientes, dedicando tiempo y recursos a sus estudiantes y utilizando un enfoque de consideración y cálido para promover la integración de todos los estudiantes. Además, la aplicación de apoyo a las relaciones sociales debe estar adaptada al contexto, grupo clase, edad o responsabilidad demostrada por el grupo anteriormente.

\section{Conductas de apoyo a las relaciones sociales}

Un docente que apoya las relaciones sociales suele adoptar una actitud empática, establece una comunicación fluida y adecuada, siendo cercano, amigable y ofrecer ayuda constante al alumnado. Favorecer las relaciones entre el alumnado, fomentando el aprendizaje de forma colaborativa y cooperativa y apostando por el trabajo en grupo con variabilidad para la formación de dichos grupos y promueve actividades para desarrollar las habilidades sociales entre el alumnado (empatía, escucha activa, etc.). Por último, se preocuparía no solo del desarrollo académico, sin que también se centraría en el bienestar personal atendiendo a las necesidades del alumnado y su desarrollo personal.

\section{Conductas de control a las relaciones sociales}

El docente que controla las relaciones sociales suele mostrar a través de su conducta verbal una absoluta despreocupación por el buen ambiente del grupo, empleando castigos actitudinales y usando expresiones con carga afectiva negativa cuando los discentes no responden a sus expectativas. No suele manifestar interés por los sentimientos y pensamientos del alumnado y priorizaría el resultado académico individual mediante el uso de recompensas tangibles que disminuyen los sentimientos de colaboración y cooperación.
Para analizar la percepción del alumnado respecto al estilo interpersonal de su profesorado de Educación Física, es decir el apoyo o control del profesorado hacia la autonomía, la competencia y las relaciones sociales de los estudiantes, se han elaborado diferentes instrumentos en el ámbito educativo y en español. Se pueden destacar tres escalas principalmente (ver Tabla 3), de las cuales entre sus factores se valora el apoyo a las relaciones sociales (CANPB) o el apoyo y control docente a las relaciones sociales (IBQ-PE y TISQ-PE). 


\section{Cuestionarios para valorar el estilo interper- sonal docente en español} 3

\section{Basic Psychological Need-Supportive Questionnaire (CANPB)}

Sánchez-Oliva, D., Leo, F.M., Amado, D., Cuevas, R., y García-Calvo, T. (2013). Development and validation of the Questionnaire of Basic Psychological Needs Support in physical education. European Journal of Human Movement, 30, 53-71.

\section{Interpersonal Behaviors Questionnaire in Physical Education (IBQ-PE)}

Burgueño, R., y Medina-Casaubón, J. (2021). Validity and reliability of the Interpersonal Behaviors Questionnaire in Physical Education with Spanish secondary school students. Perceptual and Motor Skills, 128, 522-545.

\section{Teaching Interpersonal Style Questionnaire in Physical Education (TISQ-PE)}

Leo, F. M., Sánchez-Oliva, D., Fernández-Rio, J., López-Gajardo, M. A., y Pulido, J. J. (2021). Validation of the Teaching Interpersonal Style Questionnaire in Physical Education. Journal of Sport Psychology, 30. 


\section{2.- APLICACIONES PRÁCTICAS PARA LA DOCENCIA DE LA EDUCACIÓN FÍSICA}

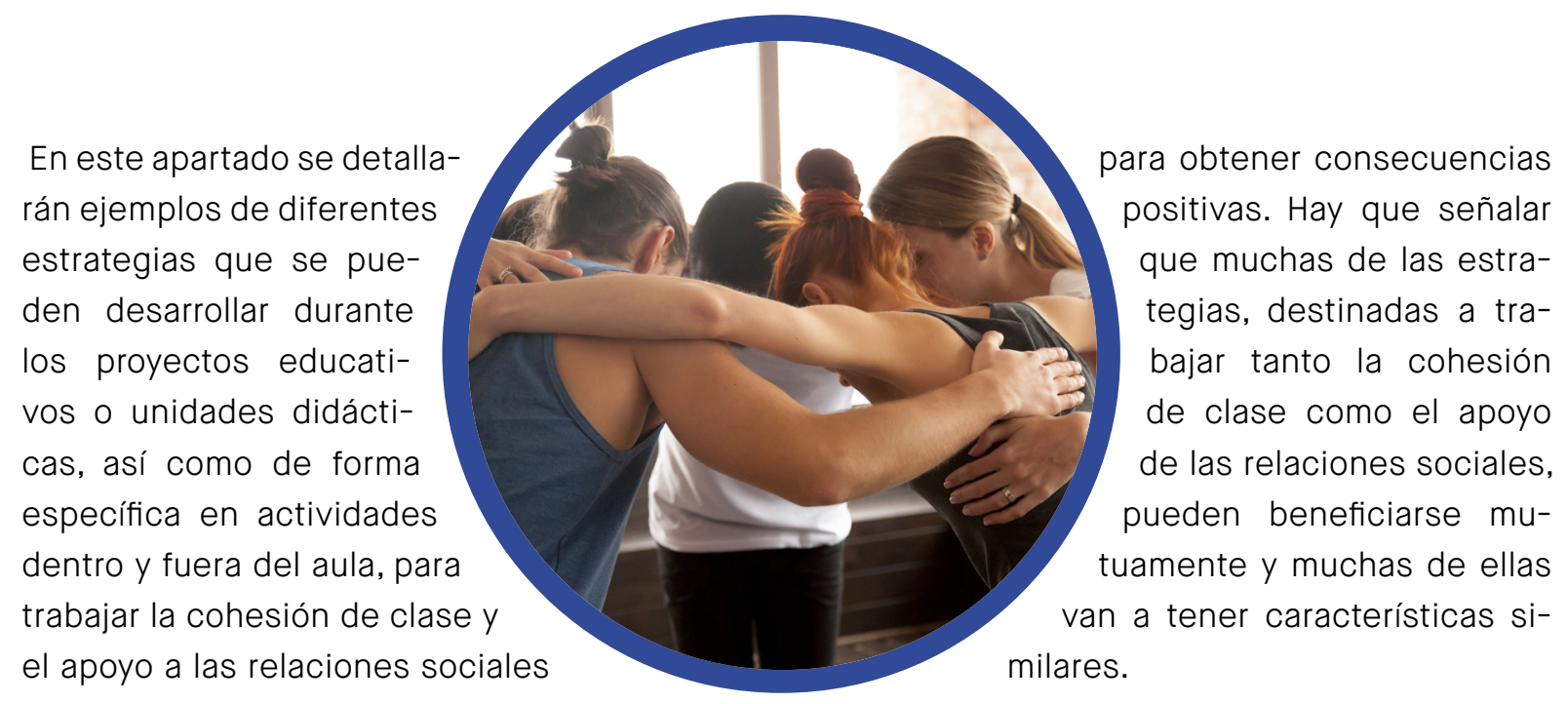




\section{Tabla \\ Estrategias y ejemplos para fomentar la co- 4 hesión de clase}

\section{A nivel de proyecto educativo o unidad didáctica:}

- Diseñar objetivos directamente relacionados con la colaboración y cooperación entre los miembros del grupo para la consecución de aprendizajes.

- Establecer pautas de trabajo donde el alumnado pueda expresar sus opiniones, consensuar propuestas comunes y exponerlas en su grupo y a toda la clase para tener en cuenta la opinión de todo el alumnado.

- Fomentar el trabajo cooperativo bien estructurado durante las clases y promoverlo incluso fuera del aula.

- Proponer la participación activa de todo el alumnado, donde pueda debatir y discutir en pequeños y gran grupo durante el desarrollo de proyectos de diversa magnitud (desde una actividad a grandes producciones).

- Propiciar momentos donde el alumnado sea el principal protagonista durante el proceso de aprendizaje, donde cada discente, con su pequeño grupo o gran grupo, pueda establecer que quiere aprender, incluso diseñando y proponiendo a sus compañeros actividades.

- Plantear tareas de auto-evaluaciones y co-evaluaciones grupales como procedimientos de ayuda mutua para aprender y no solo para obtener una nota, estableciendo momentos para compartir y comparar en pequeños grupos o gran grupo las evaluaciones establecidas.

- Plantear procesos de evaluación a través de índices intrapersonales e intragrupales, es decir respecto a uno mismo, poniendo en valor los retos alcanzados por los procesos de aprendizaje del estudiante/grupo y no comparando unos estudiantes/grupos con otros.

- Incluir criterios de evaluación que hagan mención específica a la colaboración y cooperación entre los miembros del grupo. 


\section{A nivel de actividades de clase:}

- Desarrollar actividades de conocimiento (gustos, intereses, aficiones, etc.) y de confianza entre los estudiantes. Por ejemplo, preguntando sobre los tipos de actividad física realizada durante el último fin de semana.

- Diseñar actividades en grupos donde todo el alumnado pueda aportar ideas para diseñar y seleccionar tareas a desarrollar en clase. Por ejemplo, elegir una variante de una actividad que se esté practicando.

- Realizar dinámicas grupales, resolución de problemas, juegos de rol, gamificaciones (e.g., scape rooms en gran grupo) donde cada miembro tenga un rol protagonista y participativo.

- Plantear actividades en las que haya muchos cambios de compañeros/as durante cada una de ellas.

- Desarrollar procedimientos privados de evaluación, huyendo de la exposición pública, tanto del procedimiento evaluador como de la comunicación de los resultados (notas).

- Establecer momentos para que el alumnado analice su proceso de aprendizaje, compartiéndolo con compañeros y analizando dicho proceso. Por ejemplo, realizar un parada a mitad de clase para que los estudiantes hablen sobre cómo están desarrollando una determinada actividad.

- Evitar la hipercompetitividad en tareas donde haya competición, evitando dar importancia a la victoria y/o a la derrota.

- Plantear partidos a tanteos bajos (3-5 puntos) para que las derrotas no sean tan "amargas" que dañen la cohesión del grupo.

- Evitar la eliminación en los partidos o disminuir el tiempo "fuera de la actividad" al mínimo posible para, al igual que en el caso anterior, los compañeros de clase no se conviertan en enemigos. 


\section{Tabla Estrategias y ejemplos para desarrollar las 5 relaciones sociales de los estudiantes}

\section{A nivel de proyecto educativo o unidad didáctica:}

- Adoptar una actitud empática como docentes con comportamientos de cercanía, amabilidad y sirviendo como agentes facilitadores en la consecución de objetivos de todos los estudiantes.

- Desarrollar una comunicación adecuada con absolutamente todos los discentes.

- Favorecer constantemente las relaciones entre el alumnado antes, durante y después de las clases.

- Heterogeneidad para la formación de grupos y flexibilidad y variabilidad constante durante las diferentes actividades de enseñanza-aprendizaje.

- Promover el respeto hacia las actividades, material, compañeros, profesorado, etc.

- Tener un comportamiento ejemplar tanto dentro como fuera del contexto educativo, favoreciendo una personalidad positiva en el alumnado. 


\section{A nivel de actividades de clase:}

- Mejorar las habilidades sociales (respetar turnos, ayuda entre compañeros, etc.) con trabajos en parejas, pequeños grupos y posteriormente en gran grupo.

- Promover actividades específicas en las que haya debates dirigidos por los propios discentes, para desarrollar las habilidades sociales (empatía, escucha activa, etc.).

- Ejemplificación de comportamientos inapropiados que puedan darse durante el desarrollo de las clases de Educación Física como escenario tipo para la reflexión y debate de por qué ese tipo de actitudes no son apropiadas para el buen funcionamiento de un grupo.

- Utilización de feedback interrogativo en los distintos grupos de trabajo fomentando el debate interno y la búsqueda de soluciones consensuada entre el alumnado del grupo. Es decir, establecer preguntas dirigidas sobre cómo están desarrollando o tratando de resolver la actividad.

- Evitar situaciones de trabajo en las que algún discente se pueda sentir expuesto públicamente. Por ejemplo, actividades donde un estudiante compite contra el resto de la clase o con ejemplificaciones con estudiantes que puedan sentirse avergonzados.

- Reconocimiento por parte del docente a cada uno de los miembros del grupo, y sobre todo a los procesos cooperativos y colaborativos entre el alumnado.

- Permitir la consecución de éxito en las tareas de todo el alumnado en cada uno de los grupos de trabajo con soluciones a diferentes niveles de dificultad. 


\section{3.- PARA SABER MÁS...}

A pesar de que este capítulo ha tratado de proporcionar mayor conocimiento sobre la importancia del fomento de la cohesión de clase y las relaciones sociales, mediante estrategias docentes encaminadas a nutrir los procesos motivacionales de los discentes en las clases de Educación Física, con las evidencias científicas existentes en la literatura, tanto los investigadores como el profesorado pueden consultar con mayor profundidad las referencias empleadas a lo largo del mismo, con el propósito de aumentar el conocimiento sobre estas variables.

Por otro lado, si el profesorado quiere conocer cómo de cohesionado está el alumnado o el grado en el que sus relaciones sociales son satisfechas o frustradas, existen herramientas que nos permiten evaluar las percepciones de los discentes sobre estas dimensiones. Para valorar la cohesión de clase se está desarrollando en la actualidad un cuestionario que permite valorar la cohesión tarea y social entre los estudiantes. Para su adquisición y utilización se puede contactar con el autor principal de este capítulo (franmilema@unex.es). Para conocer el nivel de satisfacción o frustración de las relaciones sociales de los estudiantes han sido extensivamente empleado la escala BPNES-EF (Moreno et al., 2008) y la escala PNTS adaptada a la Educación Física (Leo et al., 2020), respectivamente. Además, para aquellos docentes interesados en examinar la percepción del alumnado sobre su estilo interpersonal hacia las relaciones sociales se han expuesto previamente las escalas con factores diseñados para este objetivo (CANPB, $I B Q-P E$ y $T I S Q-P E)$. Finalmente, para obtener cualquiera de estos instrumentos (en formato papel u online), conocer la utilización de los mismo, así como para asesorarte sobre cómo interpretar los resultados obtenidos, puede consultar a los autores del capítulo. Se pueden realizar informes individualizados con los datos obtenidos, tanto a nivel docente como de su alumnado. 


\section{4.- REFERENCIAS BIBLIOGRÁFICAS}

Blanchard, C. M., Amiot, C. E., Perreault, S., Vallerand, R. J., y Provencher, P. (2009). Cohesiveness, coach's interpersonal style and psychological needs: Their effects on self-determination and athletes' subjective wellbeing. Psychology of Sport and Exercise, 10, 545-551. https://doi.org/10.1016/j.psychsport.2009.02.005

Bosselut, G., Heuzé, J. P., Castro, O., Fouquereau, E., y Chevalier, S. (2018). Using Exploratory Structure Equation Modeling to validate a new measure of cohesion in the university classroom setting: The University Group Environment Questionnaire (UGEQ). International Journal of Educational Research, 89, 1-9. https://doi.org/10.1016/j.ijer.2018.03.003

Carron, A. V., Brawley, L. R., y Widmeyer, W. N. (1998). The measurement of cohesiveness in sport groups. En J. L. Duda (Ed.), Advances in sport and exercise psychology measurement (pp. 213-226). Fitness Information Technology.

Carron, A. V., Widmeyer, W. N., y Brawley, L. R. (1985). The development of an instrument to assess cohesion in sport teams: The Group Environment Questionnaire. Journal of Sport \& Exercise Psychology, 7, 244-266. doi:10.1123/jsp.7.3.244

Checa, I., y Bohórquez, M. R. (2020). Medidas psicométricas de la cohesión en equipos de trabajo universitarios. Retos. Nuevas tendencias en Educación Física. Deporte y Recreación, 37, 108-114.

De Backer, M., Boen, F., Ceux, T., De Cuyper, B., Høigaard, R., Callens, F., ... y Broek, G. V. (2011). Do perceived justice and need support of the coach predict team identification and cohesion? Testing their relative importance among top volleyball and handball players in Belgium and Norway. Psychology of Sport and Exercise, 12, 192-201. https://doi.org/10.1016/j.psychsport.2010.09.009

Deci, E. L., y Ryan, R. M. (2000). The" what" and" why" of goal pursuits: Human needs and the self-determination of behavior. Psychological Inquiry, 11, 227-268. https://doi.org/10.1207/S15327965PLI1104_01

Erikstad, M. K., Martin, L. J., Haugen, T., y Høigaard, R. (2018). Group cohesion, needs satisfaction, and selfregulated learning: A one-year prospective study of elite youth soccer players' perceptions of their club team. Psychology of Sport and Exercise, 39, 171-178. https://doi.org/10.1016/j.psychsport.2018.08.013
Eys, M. A., Blair, M. B., y Benson, A. J. (2020). Group dynamics in sport (5th ed.). Fitness Information Technology.

García-Calvo, T., Leo, F. M., Gonzalez-Ponce, I., SánchezMiguel, P. A., Mouratidis, A., y Ntoumanis, N. (2014). Perceived coach-created and peer-created motivational climates and their associations with team cohesion and athlete satisfaction: Evidence from a longitudinal study. Journal of Sports Sciences, 32, 1738-1750. https://doi.org/10.1080/02640414.2014.918641

Leo, F. M., González-Ponce, I., Sánchez-Oliva, D., Pulido, J. J., y García-Calvo, T. (2015). Adaptation and validation in Spanish of the Group Environment Questionnaire (GEQ) with professional football players. Psicothema, 27, 261-268.

https://doi.org/10.7334/psicothema2014.247

Leo, F. M., Mouratidis, A., Pulido, J. J., López-Gajardo, M. A., y Sánchez-Oliva, D. (2020). Perceived teachers' behavior and students' engagement in physical education: The mediating role of basic psychological needs and self-determined motivation. Physical Education and Sport Pedagogy, 1-18. https://doi.org/10.1080/17408 989.2020.1850667

Leo, F. M., López-Gajardo, M. A., Fernández-Rio, J., y Pulido, J. J. (2021). Development and validation of the Class Cohesion Questionnaire. Manuscrito en preparación.

Moreno, J. A. M., González-Cutre, D., Chillón, M., y Parra, N. (2008). Adaptación a la Educación Física de la Escala de las Necesidades Psicológicas Básicas en el Ejercicio. Revista Mexicana de Psicología, 25, 295303.

Pacewicz, C. E., Smith, A. L., y Raedeke, T. D. (2020). Group cohesion and relatedness as predictors of self-determined motivation and burnout in adolescent female athletes. Psychology of Sport and Exercise, 50, 101709. https://doi.org/10.1016/j.psychsport.2020.101709

Vasconcellos, D., Parker, P. D., Hilland, T., Cinelli, R., Owen, K. B., Kapsal, N., ... y Lonsdale, C. (2020). Self-determination theory applied to physical education: A systematic review and meta-analysis. Journal of Educational Psychology, 112, 1444-1469. http://dx.doi.org/10.1037/edu0000420 


\section{1.- EVIDENCIAS CIENTÍFICAS: LA MOTIVACIÓN Y LAS EMOCIONES EN LAS CLASES DE EDUCACIÓN FÍSICA}

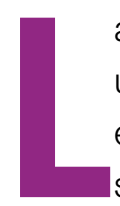

a profesión docente es clasificada como una de esas labores emocionalmente exigente. Todos recordaremos alguna situación en la que tras actuar y pasado unas horas hemos pensado "me dejé llevar por lo que sentía". La realidad es que no únicamente en esa situación que recuerdas te dejaste llevar por tus emociones. Un dicho que va cogiendo peso en los últimos años, en la línea de las investigaciones sobre la temática, dice "la razón sirve para justificar las decisiones que tomamos con la emoción". Este dicho, aunque debe ser tomado con prudencia, hace referencia a la gran importancia que tiene el componente emocional en cualquier decisión y no solo en esas que reconocemos como "realmente emocionales".

Y... ¿qué son las emociones? Las emociones han sido definidas como una serie de procesos psicológicos interrelacionados que incluyen aspectos cognitivos, expresivos, fisiológicos y motivacionales (Reeve, 2010). Estas emociones surgen de la evaluación que hacemos de cualquier evento que nos sucede. La evaluación en algunos casos puede ser consciente y en muchos otros surge sin darnos cuenta. Entonces... ¿para qué sirven las emociones? Las emociones tienen o han tenido utilidad para la supervivencia y el desarrollo del ser humano. Por ejemplo, el miedo, que se experimenta ante un estímulo peligroso, nos hace protegernos (Sáenz-López, 2020).

Llegados a este punto, estarás pensado ¿por qué me hablan de emociones en un libro sobre motivación? La respuesta es sencilla, emoción y motivación está interrelacionadas y tienen muchos aspectos en común. Tal es así, que ambas palabras comparten raíz etimológica proveniente del latín "movere", que significa movimiento. Además, si analizamos la definición de emoción (aportada hace pocas líneas) se incluye en ella los componentes motivacionales.

Visualicemos por un momento nuestra clase de Educación Física. Imaginemos y recreemos mentalmente lo que sucede en nuestro pabellón o patio escolar. Pongamos el foco en ese alumno/a que participa intrínsecamente en la actividad, es decir, de forma voluntaria (por el placer, disfrute o satisfacción de hacerlo). Posiblemente percibamos que está sintiendo alegría, entusiasmo u orgullo. Sin embargo, si giramos la cabeza y miramos hacia el otro lado, podemos ver que hay estudiantes a los que les cuesta participar mucho más. Posiblemente esos estudiantes sientan vergüenza, desesperanza o incluso ira al escuchar algún comentario. Estaremos de acuerdo en que la motivación de estos últimos discentes será de peor 
calidad que la de los primeros. Lo que está claro, es que la respuesta emocional ayuda a generar un tipo de motivación u otro y, a su vez, la conducta motivada generará una serie de emociones, produciéndose así un sistema de retroalimentación entre ambos: emoción y motivación (Fernández-Abascal et al., 2003) .

Cuando pretendemos generar experiencias satisfactorias en las clases de Educación Física tenemos que pensar principalmente en dos aspectos: profesorado como ejemplo y profesorado como guía. Es decir, ¿qué siente el docente? y ¿qué puedo hacer para que mi alumnado sientan lo que yo quiero? La primera pregunta (¿qué siente el docente?) tiene un peso muy importante, ya que en muchas ocasiones tratamos de trasmitir emociones positivas a los estudiantes $y$, sin embargo, nuestra experiencia emocional está siendo desagradable. Las investigaciones han mostrado que existen contagios emocionales entre docentes y estudiantes (Frenzel et al., 2009). De tal forma que las emociones experimentadas por los docentes, además de repercutir sobre su propio bienestar (Fierro-Suero, Almagro et al., 2021), han mostrado tener una influencia sobre el aprendizaje y la motivación del alumnado durante las clases de Educación Física (Løvoll et al., 2020). Por tanto, centrarnos en el bienestar propio como docentes es clave. Para ello, conoceremos estrategias en la parte práctica de este capítulo.

Por otro lado, el segundo aspecto va enfocado en aplicar estrategias que resulten efi- caces para mejorar la experiencia emocional del alumnado. En este sentido, la teoría control-valor de las emociones de logro (Pekrun, 2006) ha sido aplicada a la Educación Física en los últimos años. Esta teoría plantea que en función del ambiente que se cree en el entorno educativo, los estudiantes realizarán unas evaluaciones que generarán una serie de emociones que repercutirán en consecuencias finales (Pekrun y Stephens, 2010) (ver Figura 1). Es decir, el clima generado en el aula influye en las emociones de los estudiantes de Educación Física (Fierro-Suero, VelázquezAhumada et al., 2021). Entre el clima generado por el docente y las emociones median las evaluaciones que realizan los estudiantes. Estas evaluaciones dependen del valor que el alumnado le dé a la tarea (intrínseco o extrínseco) y del control que tengan sobre ella (expectativas, aportaciones realizadas, etc.). De esta forma, la teoría control-valor de las emociones de logro clasifica las emociones en función de si son positivas/negativas, activadoras/desactivadoras o si están enfocadas en la actividad/resultado. Por ejemplo, cuando un estudiante da valor a la tarea que está aprendiendo y siente que sus aportaciones son tenidas en cuenta experimentará disfrute (emoción positiva que activa al alumnado). Por el contrario, cuando la tarea planteada carece de ningún valor por parte del alumnado (ni intrínseco, ni extrínseco) experimentará aburrimiento (emoción negativa desactivadora). Esto puede suceder en clases demasiado repetitivas o monótonas (Fierro-Suero et al., 2020).

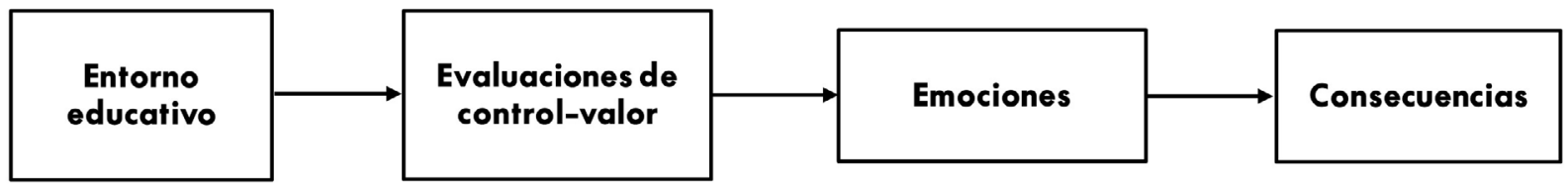

Figura 1. MOdelo ILUSTRATIVO dE LA TEORÍA DEL CONTROL-VALOR DE LAS EMOCIONES DE LOGRO 
Para comprender mejor las conductas de los estudiantes, resulta necesario abordar tanto el rol emocional como el motivacional, dada la interrelación entre ambos constructos (Roseman, 2013). Sin embargo, la mayoría de los estudios en el ámbito de la Educación Física que abordan las conductas del alumnado (p. ej., comportamientos prosociales, comportamientos saludables, intención de ser físicamente activo en el futuro, etc.) (Cheon et al., 2018; Ferriz et al., 2016; Sevil-Serrano et al., 2020) lo han hecho poniendo el foco principalmente en la motivación, sin tener en cuenta el componente emocional. Como se ha tratado ya en otros capítulos de este libro, la teoría de la autodeterminación (Ryan y Deci, 2017) ha sido ampliamente usada en Educación Física, mostrando ser eficaz en la aplicación de programas de intervención para aumentar la motivación de los estudiantes (Vasconcellos et al., 2020). En esta línea, la teoría de la autodeterminación y la teoría control-valor de las emociones de logro han mostrado por separado ser consistentes y eficaces para explicar comportamientos como la intención de ser físicamente activo o los comportamientos disruptivos en las clases de Educación Física (Franco y Coterón, 2017; Simonton y Garn, 2020). Recientemente, Fierro-Suero, Castillo et al. (2021) han testado la integración de ambas teorías para mejorar la comprensión de las consecuencias que pueden tener las emociones y la motivación experimentada en las clases de Educación Física.

En el entorno educativo, el alumnado experimentará un tipo de emoción en función de si se cumplen o no sus expectativas (Meyer y Turner, 2006). El cumplimento de las expectativas está mediado por las evaluaciones conscientes o inconscientes de lo que nos sucede (Pekrun y Stephens, 2010). Estos procesos regulatorios están asociados con el grado de satisfacción de las necesidades psicológicas básicas. Es decir, las emociones pueden ser entendidas como el resultado de la satisfacción o frustración de las necesidades psicológicas básicas (Flunger et al., 2013). Por ejemplo, un estudiante experimentará disfrute durante el proceso de enseñanza-aprendizaje si se siente competente para cumplir las exigencias de la tarea y valora el contenido desarrollado (Pekrun y Stephens, 2010), como se ha puesto de manifiesto en las clases de Educación Física (Fierro-Suero et al., 2020; Leisterer et al., 2019). De esta forma, en función de si establecen estilos interpersonales de apoyo o control de las necesidades psicológicas básicas en las clases de Educación Física (entorno de aprendizaje), las necesidades psicológicas básicas se verán satisfechas o frustradas y simultáneamente se despertarán motivaciones autónomas y emociones positivas o negativas (Yoo, 2015). Por último, tanto las emociones como los diferentes tipos de motivación han mostrado tener capacidad para predecir las consecuencias citadas anteriormente. De esta forma, se puede establecer una coherencia entre los postulados de la teoría de la autodeterminación y la teoría control-valor de las emociones de logro, que pueden observarse en la Figura 2. 


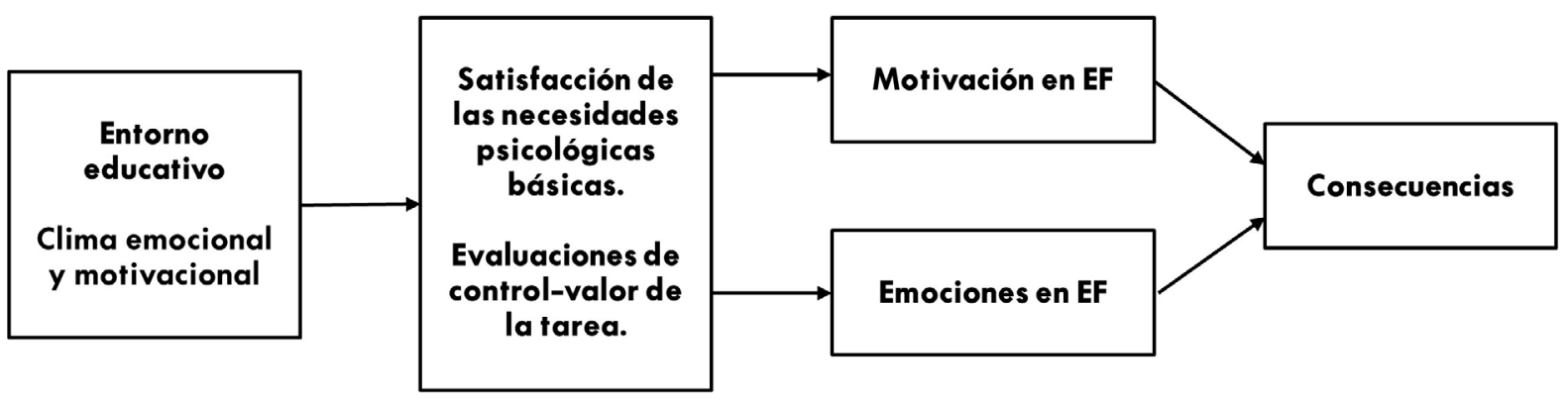

Figura 2. Modelo ILUSTRATIVO DE LA INTEGRACIÓN DE LA TEORÍA DE LA AUTODETERMINACIÓN Y LA TEORÍA CONTROL-VALOR de LAS EMociones de logro (FIERRo-Suero, CAStillo et al., 2021) 


\section{2.- APLICACIONES PRÁCTICAS PARA LA DOCENCIA DE LA EDUCACIÓN FÍSICA: ESTRATEGIAS PARA MEJORAR EL CLIMA EMOCIONAL}

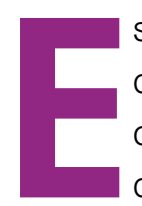

s necesario tratar de traducir las evidencias científicas en estrategias concretas de intervención. En este sentido, la mejora del clima de aula, a través de propuestas prácticas resultantes de diferentes investigaciones, ha sido una constante de nuestro grupo de investigación (Conde et al., 2015; Sáenz-López et al., 2019; SáenzLópez, 2021). A continuación, se presentarán una serie de propuestas dirigidas a mejorar el clima emocional en las clases de Educación Física. Este conjunto de estrategias, se van a agrupar en dos: el papel del docente y estrategias para utilizar en el aula.

El papel del docente es fundamental en el tipo de clima que se va a establecer en el aula (Sáenz-López, 2020). Autores como Bisquerra y Hernández (2017) exponen la necesidad de que el profesorado mejore sus competencias emocionales con el fin de influir positivamente en la motivación, en el aprendizaje y en el bienestar del alumnado. Para ello, se han seleccionado tres aspectos clave que pueden ayudar al docente en este fascinante reto: entusiasmo, habilidades sociales y resolución de conflictos. En primer lugar, el entusiasmo, que se manifiesta a través de la comunicación no verbal y que el alumnado detectará y valorará positivamente. En segundo lugar, las habilidades sociales que se ponen en práctica en la comunicación con el alumnado, mostrando mensajes positivos o practicando la escucha activa. En tercer lugar, la resolución de conflictos en la que el profesorado tiene la oportunidad de mostrar sus competencias a través de la regulación emocional, así como de la capacidad de generar emociones positivas. A continuación, en la Figura 3, se exponen ejemplos para desarrollar estas competencias. 


\subsection{Entusiasmo}

- Saluda y despídete mostrando afecto, respeto y pasión

- Sé expresivo, gesticula y sonríe con asiduidad

- Mantén el contacto visual cuando hables con el alumnado

- Muévete por el aula y acércate al alumnado

- Aporta unas expectativas mejoradas sobre las tareas

- Da a conocer el "error" como parte esencial del proceso

\subsection{Resolución de conflictos}

\subsection{Habilidades sociales}

- Practica la escucha activa

- Ten sentido del humor

- Pregunta mucho para hacerles pensar

- Utiliza lenguaje emocional contando anécdotas, cuentos, noticias de prensa, vídeos, etc

- Provoca que pregunten

- Comunica de forma positiva

- Muéstrate tranquilo y dialogante

- Tranquiliza a las personas implicadas

- Cuida el tono

- Genera emociones positivas

- Da y asume responsabilidades

-Aprovecha el conflicto para mejorar

competencias emocionales

FIGURA 3. EJEMPLOS DEL PAPEL DOCENTE EN LA MEJORA DEL CLIMA EMOCIONAL

Esta actitud del docente producirá una mejora del clima emocional y motivacional en las clases de Educación Física. Desde estas competencias basadas en la vocación y el interés por ayudar a formar personas más motivadas, más empáticas, más comprometidas socialmente, más saludables, más felices, etc., el profesorado tiene la oportunidad de convertir sus clases en espacios de aprendizaje emocionantes a través de diversas estrategias que sintetizamos en tres: abrir la puerta de las emociones, desarrollo de competencia emocionales y diseño de tareas (ver Figura 4). Con relación a "abrir la puerta de las emociones", nos referimos a desarrollar la conciencia emocional propia y de los demás. Para completar el desarrollo de competencias emocionales, nos centramos en el desarrollo de la autonomía emocional o la empatía. Por último, en el diseño de tareas se plasmarán muchos aspectos que influirán en la generación de emociones y en la motivación del alumnado. 


\subsection{Competencia emocional}

Empatía

- Pregúntate cómo crees que se siente el alumnado en determinados momentos

- Escucha sin juzgar, observando la reacción emocional del alumnado

Autonomía emocional

-Pregunta cuándo les gustaría recibir comentarios sobre su actuación - Incide en la idea de que las habilidades son modificables, es decir, ocurrirá el error, pero la habilidad se puede mejorar

- Fomenta el espíritu crítico y genera un ambiente democrático

- Practica y fomenta la asertividad

- Hazles responsables de sus actos

Independiza sus actos de sus personas

2.3. Abre la puerta a las emociones: conciencia emocional

- Conoce al alumnado en el mayor número de facetas

- Utiliza lenguaje emocional: habla de tus sentimientos, amplía el vocabulario emocional, pregunta sobre su estado de ánimo

- Mejora su percepción de competencia, por ejemplo, a través de feedbacks positivos para aumentar su motivación y su autoestima

- Hablar y enseñar a hablar desde el cómo me siento o cómo percibo, en lugar de "me haces sentir" o

hacer juicios de valor

- Habla sin herir

Figura 4. Ejemplos de estrategias para utilizar en CLASES de Educación Física
2.2. Diseño de tareas:

- Diseña juegos y tareas que desarrollen competencias emocionales

- Diseña juegos y tareas que desarrollen emociones concretas (Sáenz-López, 2020b)

- Sé consciente de qué emociones se generan en función del tipo de tarea: individual, oposición, cooperación o cooperación-oposición (Lavega, March, y Filella, 2013)

- Que las tareas tengan una dificultad progresiva y siempre existan oportunidades de éxito.

- Las mejores explicaciones de un gesto se realizan mediante metáforas.

- Tareas con la mayor participación del alumnado

- Desarrolla la creatividad
En definitiva, el papel del docente y las estrategias para utilizar en Educación Física (Figuras 3 y 4 ) son magníficas oportunidades para mejorar el clima emocional en las clases, que, junto con las estrategias para satisfacer las necesidades psicológicas básicas, aumentarán la calidad del proceso de enseñanzaaprendizaje en el que tanto trabajamos los docentes. 


\section{3.- PARA SABER MÁS...}

En este apartado se ha incluido documentación que consideramos interesante para profundizar más en este apasionante tema. Además, se comenta brevemente qué podría aportar al docente de Educación Física.

- Cury, A. (2010). Padres brillantes, maestros fascinantes. Planeta.

Este libro aborda la apasionante labor de padres/madres y docentes, en la que la perspectiva emocional es la que marca la diferencia entre ser buenos o ser fascinantes.

- Bisquerra, R. (2018). Universo de emociones. PalauGea comunicación.

Un libro maravilloso, escrito por una persona emocionante. Este libro ayuda a entender la funcionalidad de las emociones básicas, aumenta el autoconocimiento y mejora el vocabulario emocional. Altamente recomendable.

- Lavega, P., March, J., y Filella, G. (2013). Juegos deportivos y emociones. Propiedades psicométricas de la escala GES para ser aplicada en la Educación Física y el Deporte. Revista de Investigación Educativa, 31(1), 151-165. http://dx.doi.org/10.6018/rie.31.1.147821

EI GES es un instrumento que sirve para conocer el tipo de emociones que generan diferentes tipos de tareas motrices, además de mejorar la conciencia emocional. Por ejemplo, las tareas sin oposición suelen tener poca intensidad en emociones negativas o en las tareas con oposición y con victoria/derrota aumenta la intensidad de emociones positivas y negativas.
- Pellicer, I. (2011). Educación física emocional. De la teoría a la práctica. Inde.

Este libro aborda la educación emocional del alumnado partiendo de las competencias propias de la Educación Física. De hecho, incluye ejemplo de sesiones de los diferentes bloques de contenidos que el currículo contempla para Educación Física, en los que se trabaja la conciencia, la regulación y la autonomía emocional. Un libro imprescindible para tu biblioteca.

- Sáenz-López, P. (2020). Circuito de emociones para la clase de educación física. eMotion. Revista de Educación, Motricidad e Investigación, 14, 66-80. http://dx.doi.org/10.33776/remo.v0i14.4706

En este artículo se presenta una propuesta de circuito para trabajar las emociones en clases de Educación Física. En concreto, las actividades del circuito facilitan conocer e identificar emociones, regularlas, practicar la empatía y las habilidades sociales.

- Sáenz-López, P. (Coord.) (2021). Cómo mejorar el clima emocional en las aulas universitarias. Servicio de Publicaciones de la Universidad de Huelva.

http://www.uhu.es/publicaciones/?q=libros\&co de $=1243$

En este libro se presenta una herramienta de observación del clima emocional del docente y se desarrollan estrategias para mejorar aspectos como el entusiasmo, la conciencia emocional, la regulación emocional, las habilidades sociales o algunas competencias didácticas. Aunque el contexto es el universitario, es aplicable a cualquier nivel educativo. 


\section{4.- REFERENCIAS BIBLIOGRÁFICAS}

Bisquerra, R., y Hernández, S. (2017). Psicología positiva, educación emocional y el Programa Aulas Felices. Papeles del Psicólogo, 38(1), 58-65. https://doi.org/10.23923/pap.psicol2017.2822

Conde, C., Sáenz-López, P., Almagro, B. J., y Moreno Murcia, J. A. (2015). Motivación en baloncesto: claves para el entrenador. Servicio de Publicaciones de la Universidad de Huelva. http://www.uhu.es/publicaciones/?q=libros\&code=939

Fernández-Abascal, E., Jiménez, M., y Martín, M. (2003). Emoción y motivación: la adaptación humana. Editorial Centro de Estudios Ramón Areces, S.A.

Ferriz, R., González-Cutre, D., Sicilia, Á., y Hagger, M. S. (2016). Predicting healthy and unhealthy behaviors through physical education: A self-determination theory-based longitudinal approach. Scandinavian Journal of Medicine \& Science in Sports, 26(5), 579592. https://doi.org/10.1111/sms.12470

Fierro-Suero, S., Almagro, B. J., Becker, E. S., y SáenzLópez, P. (2021). Basic psychological needs, classrelated emotions and satisfaction with life in Spanish teachers. Manuscrito en revisión.

Fierro-Suero, S., Almagro, B. J., y Sáenz-López, P. (2020). Validation of the Achievement Emotions Questionnaire for Physical Education (AEQ-PE). International Journal of Environmental Research and Public Health, 17, 4560. https://doi.org/doi:10.3390/ijerph17124560

Fierro-Suero, S., Castillo, I., Almagro, B. J., y Sáenz-López, P. (2021). Understanding academic achievement and intentions to be active: The role of motivation and emotions. Manuscript en revisión.

Fierro-Suero, S., Velázquez-Ahumada, N., y FernándezEspínola, C. (2021). La influencia del clima de aula sobre las emociones del alumnado. Retos, 42, 434442. https://doi.org/10.47197/retos.v42i0.87305

Flunger, B., Pretsch, J., Schmitt, M., y Ludwig, P. (2013). The role of explicit need strength for emotions during learning. Learning and Individual Differences, 23(1), 241-248. https://doi.org/10.1016/j.lindif.2012.10.001

Franco, E., y Coterón, J. (2017). The effects of a Physical Education intervention to support the satisfaction of basic psychological needs on the motivation and intentions to be physically active. Journal of Human Kinetics, 59, 5-15. https://doi.org/10.1515/hukin2017-0143

Frenzel, A. C., Goetz, T., Lüdtke, O., Pekrun, R., y Sutton, R. E. (2009). Emotional transmission in the classroom: Exploring the relationship between teacher and student enjoyment. Journal of Educational Psychology, 101(3), 705-716. https://doi.org/10.1037/a0014695

Leisterer, S., Jekauc, D., y Insights, T. (2019). Students' emotional experience in Physical Education-A qualitative study for new theoretical insights. Sports, 7(1), 10. https://doi.org/10.3390/sports7010010

Løvoll, H. S., Bentzen, M., y Säfvenbom, R. (2020). Development of positive emotions in Physical Education: Person-centred approach for understan- ding motivational stability and change. Scandinavian Journal of Educational Research, 64(7), 999-1014. https://doi.org/10.1080/00313831.2019.1639818

Meyer, D. K., y Turner, J. C. (2006). Re-conceptualizing emotion and motivation to learn in classroom contexts. Educational Psychology Review, 18(4), 377-390. https://doi.org/10.1007/s10648-006-9032-1

Pekrun, R. (2006). The control-value theory of achievement emotions: Assumptions, corollaries, and implications for educational research and practice. Educational Psychology Review, 18, 315-341. https:// doi.org/10.1007/s10648-006-9029-9

Pekrun, R., y Stephens, E. J. (2010). Achievement emotions: A control-value approach. Social and Personality Psychology Compass, 4(4), 238-255. https://doi.org/10.1111/j.1751-9004.2010.00259.x

Reeve, J. (2010). Motivation and Emotion. McGraw Hill.

Roseman, I. J. (2013). Appraisal in the emotion system: Coherence in strategies for coping. Emotion Review, 5(2), 141-149. https://doi.org/10.1177/1754073912469591

Ryan, R., y Deci, E. (2017). Self-Determination Theory: Basic Psychological Needs in Motivation, Development, and Welness. Guilford Publications.

Sáenz-López, P. (2020). Educar Emocionando. Servicio de Publicaciones de la Universidad de Huelva. http://www.uhu.es/publicaciones/index. php?q=libros\&code $=1205$

Sáenz-López, P. (Coord.) (2021). Cómo mejorar el clima emocional en las aulas universitarias. Servicio de Publicaciones de la Universidad de Huelva. http://www.uhu.es/publicaciones/?q=libros\&code=1243

Sáenz-López, P., Fernández-Ozcorta, E. J., Almagro, B. J., y De Las Heras, M. A. (2019). Formación del profesorado y estrategias para desarrollar la inteligencia intra e inter personal en las aulas. E-balonmano.com: Revista de Ciencias del Deporte, 15(1), 79-90. http://e-balonmano.com/ojs/index.php/revista/article/view/462/pdf

Sevil-Serrano, J., Aibar, A., Abós, Á., Generelo, E., y GarcíaGonzález, L. (2020). Improving motivation for physical activity and physical education through a schoolbased intervention. The Journal of Experimental Education. https://doi.org/10.1080/00220973.2020.1 764466

Simonton, K. L., y Garn, A. C. (2020). Negative emotions as predictors of behavioral outcomes in middle school physical education. European Physical Education Review, 26(4), 764-781. https://doi.org/10.1177/1356336X19879950

Ulstad, S. O., Halvari, H., Sørebø, Ø., y Deci, E. L. (2016). Motivation, learning strategies, and performance in Physical Education at secondary school. Advances in Physical Education, 6, 27-41. https://doi.org/10.4236/ape.2016.61004 
Vasconcellos, D., Parker, P. D., Hilland, T., Cinelli, R., Owen, K. B., Kapsal, N., Antczak, D., Lee, J., Ntoumanis, N., Ryan, R. M., y Lonsdale, C. (2020). Self-determination theory applied to physical education: A systematic review and meta-analysis. Journal of Educational Psychology, 112(7), 1444-1469.

https://doi.org/10.1037/edu0000420
Yoo, J. (2015). Perceived autonomy support and behavioral engagement in Physical Education: A conditional process model of positive emotion and autonomous motivation. Perceptual and Motor Skills, 120(3), 731-746. https://doi.org/10.2466/06.pms.120v20x8 


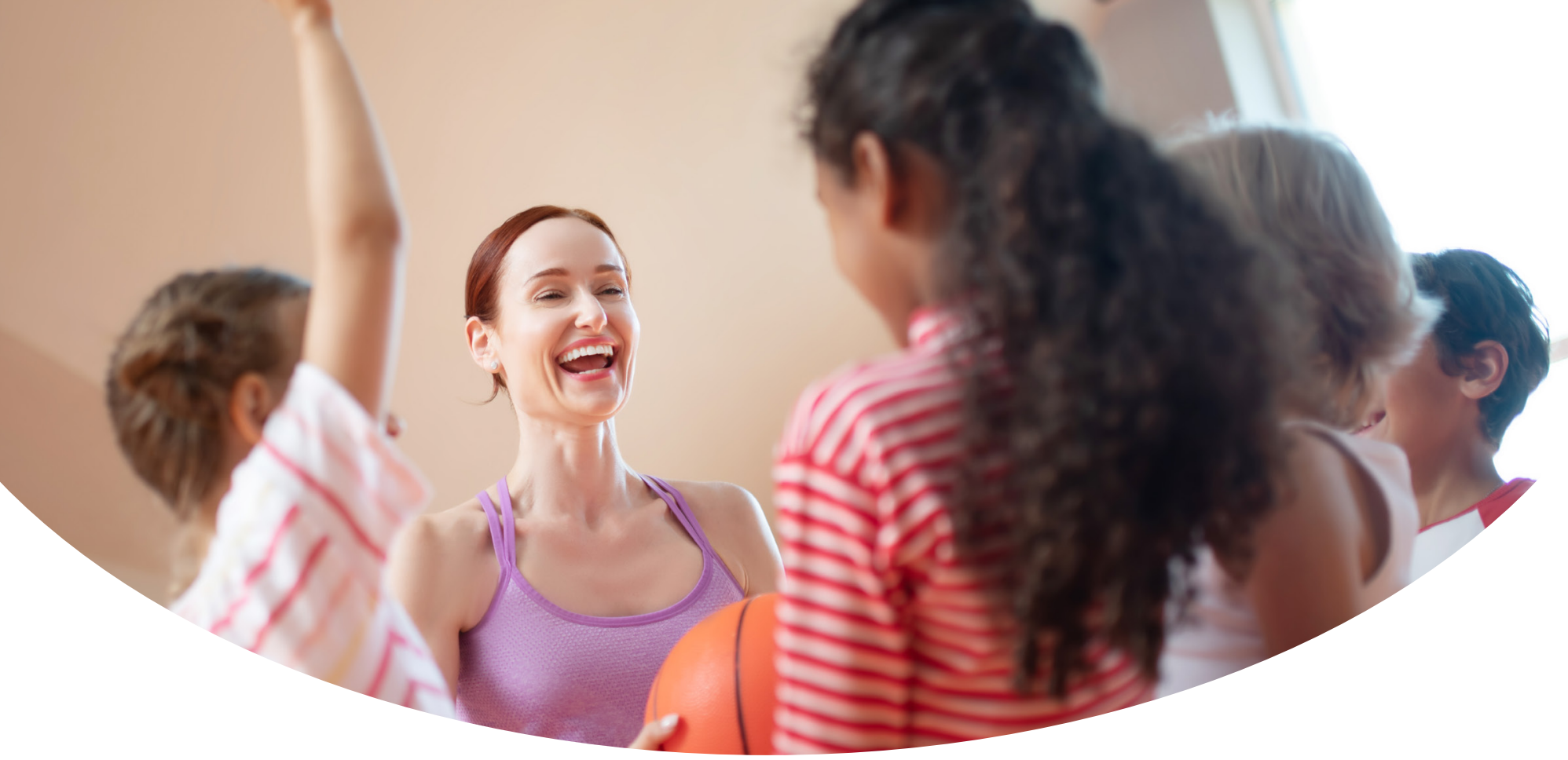

Capítulo 2.8.

\section{CÓMO APLICAR LA EVALUACIÓN FORMATIVA PARA FAVORECER LA MOTIVACIÓN Y EL APRENDIZAJE EN EDUCACIÓN FÍSICA}

Autores: Laura Cañadas ${ }^{1}$, Alexandra Valencia-Peris ${ }^{2}$ y Javier Sevil-Serrano ${ }^{3}$

${ }^{1}$ Universidad Autónoma de Madrid; ${ }^{2}$ Universitat de València; ${ }^{3}$ Universidad de Extremadura.

Palabras clave: evaluación formativa, Educación Física, autonomía, competencia, relaciones sociales, autorregulación, feedback. 


\section{1.- EVIDENCIAS CIENTÍFICAS}

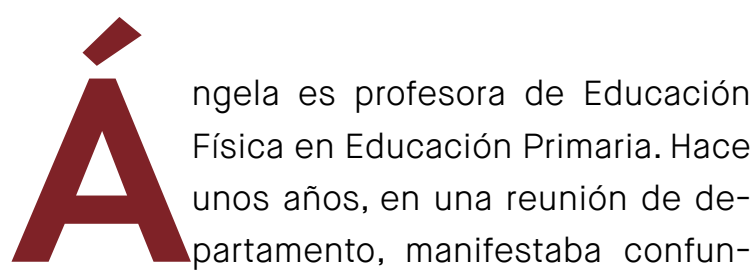
dir los términos de evaluación y calificación, usándolos indistintamente. Afortunadamente, debido a su formación continua, afirma que ya tiene bastante claros estos dos conceptos, aunque tiene dificultades a la hora de aplicar procesos de evaluación formativa y compartida en sus clases. Durante este tercer trimestre del curso académico, está empezando a involucrar al alumnado en la evaluación. Sin embargo, sus primeras experiencias están siendo bastante negativas y se está planteando volver a ser ella la que únicamente evalúe y califique. Concretamente, ayer realizó una tarea en la que la mitad de la clase tenía que coevaluar a sus compañeros/as y, posteriormente, todos tenían que autocalificarse.

A lo largo de la clase, se escucharon expresiones del alumnado como "No entiendo por qué tenemos que poner una nota a los demás", "mi compañero se va a enfadar cuando le diga que hace todo mal", "yo le estoy poniendo que 10 hace mejor para que asíno se disguste", "no comprendo a qué hacen referencia estos items, ni qué tengo que poner en cada una de estas casiIlas en las que pone: experto, avanzado y aprendiz", "¿ya hay que cambiar de rol? Mi compañero solo ha tocado en dos ocasiones el balón", "yo no sé qué nota me merezco en la unidad didáctica. Creo que lo hago mejor que algunos, pero peor que otros", "me voy a poner un 10 porque tengo que subir un poco la media para que me dejen salir más tiempo", etc.

Ángela no sabe qué está haciendo mal y se cuestiona si no será contraproducente involucrar al alumnado en la evaluación para mejorar su motivación y aprendizaje. Ante este tipo de situaciones, tan habituales en las clases de Educación Física, creemos conveniente reflexionar en torno a las siguientes preguntas: ¿Por qué, en algunas ocasiones, el uso de la evaluación formativa puede generar en el alumnado el efecto contrario al que se busca?, ¿qué características debe tener la evaluación para ser realmente formativa?, ¿cómo se debe enfocar la evaluación formativa para conseguir

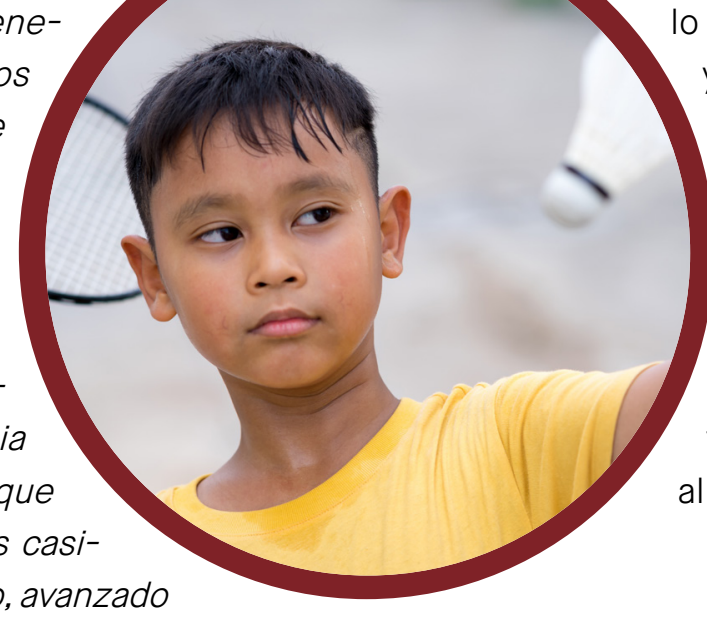

una mayor motivación y aprendizaje en el alumnado? En este capítulo se pretende resolver estas y otras cuestiones para ayudar a que el profesorado de Educación Física haga un buen uso de la evaluación formativa en sus clases, favoreciendo con ello una mayor motivación y aprendizaje de su alumnado. 


\section{1.- La evaluación formativa en Educación Física}

La evaluación es un elemento fundamental de los procesos de enseñanza y aprendizaje. Tradicionalmente, los términos evaluación y calificación se han empleado como sinónimos, asimilando evaluar con establecer una nota sobre el desempeño del alumnado. Sin embargo, la evaluación es un proceso mucho más amplio que la calificación. La evaluación se define como un proceso sistemático de recogida de información para emitir un juicio de valor, mientras que la calificación es la transformación de dicho juicio de valor en una nota (López-Pastor, 2017). Por ello, todo proceso de calificación debe ir precedido de un proceso de evaluación, pero no todo proceso de evaluación tiene que ir acompañado de una posterior calificación.

En la asignatura de Educación Física, la finalidad de la evaluación ha evolucionado desde una perspectiva fundamentada en la certificación del desempeño físico o motor del alumnado a través de pruebas, principalmente de condición física, a una evaluación que busca potenciar un aprendizaje significativo que favorezca el desarrollo integral del alumnado (Chng y Lund, 2018). Así, aparece la evaluación formativa, definida como el proceso sistemático de recogida de información sobre el proceso de enseñanza y aprendizaje, con el objetivo de mejorar tanto la enseñanza del profesorado como el aprendizaje del alumnado (Black y Wiliam, 2018). La literatura recoge 4 estrategias clave para el desarrollo de procesos de evaluación formativa (Wiliam y Leahy, 2015):

1.- Clarificar, compartir, consensuar y comprender los objetivos de aprendizaje y los criterios de evaluación con el alumnado: de forma previa al comienzo de una unidad didáctica, el profesorado debe compartir información sobre qué se espera del alumnado al finalizar el periodo formativo, así como el sistema de evaluación a emplear. Para ello, es importante informarles de los objetivos, criterios, técnicas, actividades y momentos de evaluación y/o calificación, etc., así como de las personas responsables de esta. También, es importante dar a conocer o consensuar, durante la unidad didáctica, los instrumentos que se utilizarán en las diferentes pruebas de evaluación para que el alumnado pueda conocerlos y autorregularse. La autorregulación es un proceso que permite al alumnado representar mentalmente el objetivo que se quiere conseguir, elaborando un mapa de acción que le permita planificar, realizar y evaluar su desempeño (Panadero et al., 2012).

2.- Fomentar, en diferentes momentos del proceso, la realización de debates, preguntas, discusiones y tareas en clase que pongan en evidencia el aprendizaje del alumnado: con el objetivo de poder ir valorando el progreso del alumnado y realizar los ajustes necesarios en el proceso de enseñanza y aprendizaje, deben implementarse actividades de evaluación tanto de carácter formal como informal. Por un lado, las actividades de evaluación formal hacen referencia al diseño sistematizado de situaciones motrices que permitan constatar el grado de consecución de los objetivos de aprendizaje. Por otro lado, las actividades de evaluación informal se llevan a cabo diariamente a través de tareas o encuentros no sistematizados de evaluación donde se proporciona información al alumnado sobre su proceso de aprendizaje. Todas estas actividades deben: 1) estar integradas en el proceso de enseñanza y aprendizaje, 2) ser tareas auténticas de evaluación (aplicadas en situaciones reales y no descontextualizadas) y 3 ) estar 
ajustadas a los propósitos de aprendizaje y la metodología y/o modelos de enseñanza utilizados.

\section{3.- Dar retroalimentación, durante todo el pro- ceso de enseñanza y aprendizaje, vinculada con los objetivos de aprendizaje: para que la} evaluación sea formativa debe proporcionarse al alumnado retroalimentación durante todo el proceso de enseñanza y aprendizaje, que le permita no solo saber dónde se sitúa en relación con los objetivos de aprendizaje (feedback), sino también qué puede hacer para reducir la distancia entre su conducta motriz actual y el grado de aprendizaje requerido (feedforward) (Boud y Molloy, 2013). A la hora de dar feedback al alumnado en Educación Física, debemos tener en cuenta sus características y emplearlo según la persona, el grupo, la intencionalidad y el contexto (ver capítulo 2.5 sobre los tipos de feedback para más información).

Por otra parte, a la hora de proporcionar feedback al alumnado, debemos tener en cuenta las características que Gibbs y Simpson (2005) enuncian para que este sea efectivo. Estas son:

(i) suficiente feedback, tanto en lo referente a las veces que se proporciona (aunque sin sobrecargar o generar dependencia) como a la calidad de este (es importante evitar feedback genérico como: "Tienes que progresar", "¡Bien!”, tratando de que sea lo más específico posible; "¡Muy bien Lucía! Al meterte por dentro, te han seguido los rivales, dejando a tu compañero solo");

(ii) centrado en el aprendizaje y en las acciones que están bajo control del alumnado;

(iii) centrado en una evaluación criterial (comparando el desempeño con unos criterios de evaluación previamente delimitados) y no nor- mativo (comparando el desempeño con unos valores estandarizados o con otros compañeros).

(iv) recibido por el alumnado cuando todavía les permite prestar atención a los aprendizajes futuros o recibir apoyos (es importante no darlo únicamente en la última sesión de la unidad didáctica, ya que no tiene margen de mejora);

(v) apropiado para el propósito de la evaluación y los criterios de éxito/objetivos establecidos (p. ej., si en una clase se trabaja el principio táctico ofensivo de mantener la posesión del balón, el feedback que proporcione el profesorado debe ir acorde a ese principio);

(vi) que sea un feedback principalmente privado, comunicando de forma individualizada el desempeño y posibles mejoras (puede ser público cuando se pretende que sea extensible al resto del grupo ya que se observa que es común a muchos/as estudiantes);

(vii) de utilidad, es decir, se recibe y, posteriormente, se utiliza para mejorar el aprendizaje (es importante no cambiar de actividad, cuando se proporciona el feedback, para que el alumnado pueda volver a realizar la tarea).

\section{4.- Implicar al alumnado en su propia eva-} luación y la de sus compañeros/as: según López-Pastor y Sicilia-Camacho, (2018) esto se puede llevar a cabo a través de: (i) la autoevaluación, que hace referencia a la valoración que un/a estudiante realiza sobre su propio trabajo, proceso o nivel de aprendizaje, de forma que pueda reorientarlo en caso de que fuese necesario; (ii) la coevaluación o evaluación entre pares, que es la valoración de los/ as estudiantes de sus propios compañeros/ as sobre su proceso, trabajo, resultado, etc., facilitándole un feedback sobre su desempeño. Puede ser coevaluación intergrupal, cuando se evalúa a personas de otro/s grupo/s, o 
coevaluación intragrupal, cuando se evalúan entre los integrantes de un mismo grupo; y, por último, (iii) la evaluación compartida, que hace referencia a los procesos de diálogo, individuales o grupales, sobre el aprendizaje y los diferentes elementos del proceso de enseñanza y aprendizaje entre el profesorado y el alumnado, pudiendo estar precedida de procesos de autoevaluación y/o coevaluación.

Finalmente, en los procesos de evaluación formativa se deben emplear diversas técnicas (estrategias que se usan para la recogi- da de información), métodos (orales, escritos y prácticos) e instrumentos (procedimientos estandarizados que permiten obtener una información objetiva) que permitan valorar las diferentes competencias, triangulando la información obtenida, ya que cada procedimiento $y / 0$ instrumento permite movilizar unos determinados aprendizajes. Estos instrumentos deben estar en sintonía con los criterios de evaluación, incluyendo aquellos aspectos trabajados durante la unidad didáctica. Además, deben emplearse aplicando las estrategias de evaluación formativa anteriormente expuestas.

\subsection{Las necesidades psicológicas básicas en Educación Física}

Aunque la investigación todavía es incipiente, diferentes estudios han señalado que la evaluación formativa se ha asociado a una mayor motivación del alumnado en Educación Física (Krijgsman, 2021). ¿Por qué podría existir una relación entre evaluación y motivación? Según la teoría de la autodeterminación (Ryan y Deci, 2017), la motivación del alumnado está influenciada por la satisfacción o frustración de las necesidades psicológicas básicas de autonomía, competencia y relaciones sociales. A continuación, se explica brevemente a qué hace referencia la satisfacción y frustración de cada una de estas necesidades psicológicas básicas (Ryan y Deci, 2017) para facilitar una mayor comprensión de la relación entre evaluación y motivación.

La satisfacción de la necesidad de autonomía se produce cuando el alumnado percibe que es el origen de sus propias acciones, pudiendo elegir y responsabilizarse de su aprendizaje. Por otro lado, la frustración de la necesidad de autonomía se produce cuando el alumnado manifiesta un sentimiento de obligatoriedad, alienación y presión en las actividades que se realizan.

La satisfacción de la necesidad de competencia tiene lugar cuando el alumnado siente que es eficaz o habilidoso en las acciones o actividades llevadas a cabo. Por otro lado, la frustración de la necesidad de competencia se produce cuando el alumnado experimenta un sentimiento de inferioridad y fracaso para resolver con éxito las actividades planteadas.

Finalmente, la satisfacción de las relaciones sociales se da cuando el alumnado tiene relaciones positivas con el resto de sus compañeros/as y el profesorado, estando integrado en su grupo-clase. Por otro lado, la frustración de las relaciones sociales se produce cuando el alumnado se percibe rechazado, aislado o marginado dentro de su grupo de iguales. 
La satisfacción de estas tres necesidades psicológicas básicas se asocia con una motivación más autónoma. En sentido contrario, su frustración se relaciona con una motivación más controlada o desmotivación (Ryan y Deci, 2017; Vasconcellos et al., 2020). Según esta teoría, el profesorado de Educación Física desempeña un papel clave en la satisfacción y frustración de estas necesidades psicológicas básicas (Vasconcellos et al., 2020). Por ello, tal y como se puede observar en la Figura 1 , el modo en el que el profesorado aplique estos procesos de evaluación formativa podría afectar a la satisfacción o, por el contrario, a la frustración de estas necesidades psicológicas básicas lo que, a su vez, determinará el tipo de motivación y consecuencias experimentadas por el alumnado (Krijgsman, 2021). Por esta razón, es muy importante comprender qué procesos motivacionales subyacen en el uso de la evaluación formativa, teniendo un abanico de recursos y estrategias para orientar los procesos de evaluación de la manera adecuada.
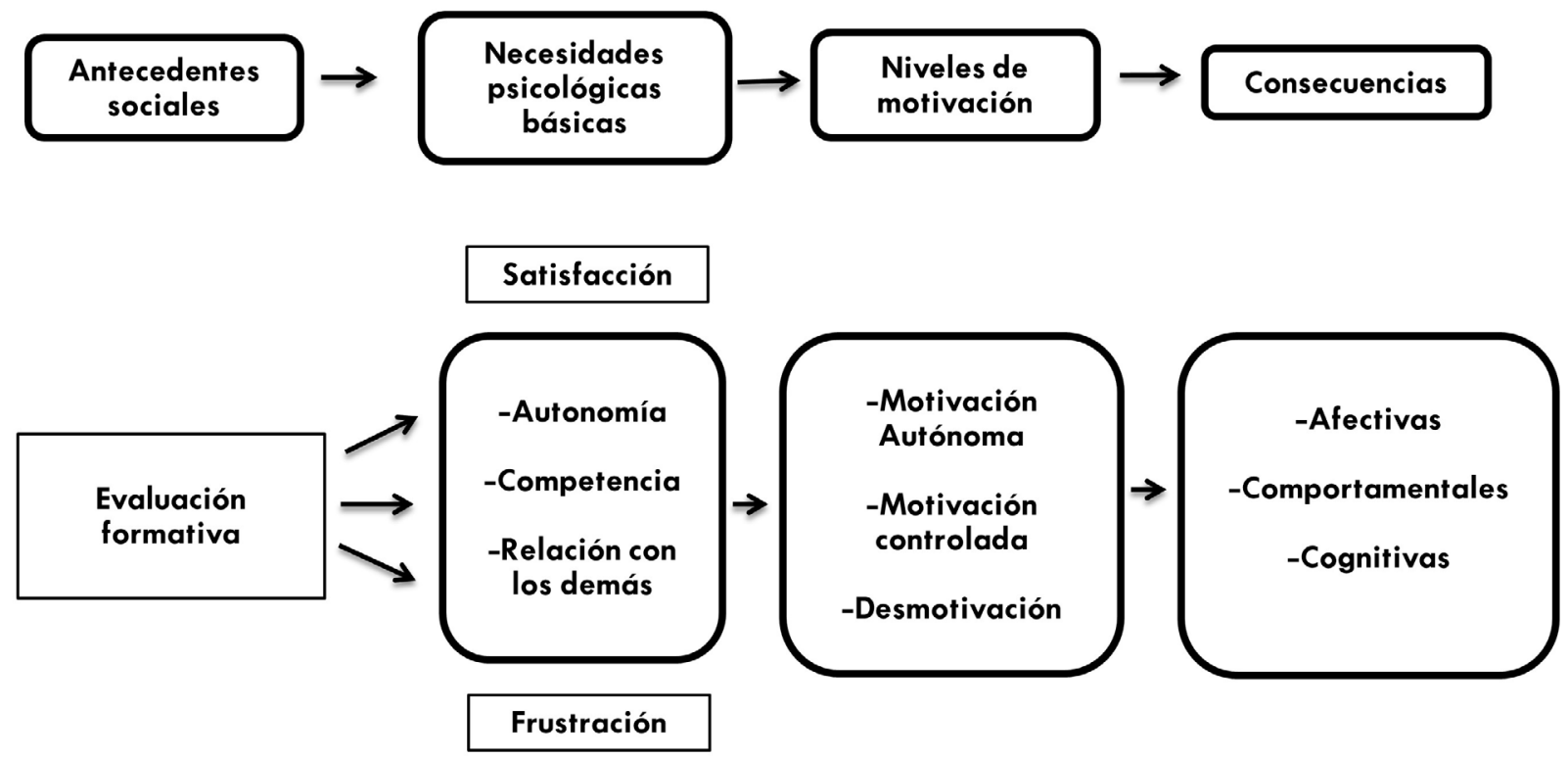

FIgURA 1. SECUENCIA EN LA RELACIÓN ENTRE LA EVALUACIÓN FORMATIVA Y LA SATISFACCIÓN O FRUSTRACIÓN DE LAS NECESIDADES PSICOLÓGICAS BÁSICAS SEGÚN LA TEORÍA DE LA AUTODETERMINACIÓN. 


\subsection{La influencia de la evaluación formativa en la motivación del alumnado en Educación Física}

Aunque algunos estudios señalan que el uso de la evaluación formativa podría favorecer una motivación más autónoma, la realidad docente nos muestra cómo la aplicación de la evaluación formativa no es siempre tan sencilla como indica la teoría, pudiendo generar en el alumnado desmotivación, indisciplina, aburrimiento, etc., si no se enfoca o aplica correctamente. Llegados a este punto, cabe preguntarse: ¿Por qué la evaluación formativa, si está bien enfocada, puede favorecer una mayor motivación o, en caso de no estarlo, desmotivar al alumnado? A continuación, atendiendo a estudios previos (Bores-García et al., 2021; Krijgsman, 2021; Leenknecht et al., 2021; Slingerland et al., 2017), tratamos de justificar, con diferentes argumentos y ejemplos, la relación existente entre la evaluación formativa y la satisfacción y frustración de cada necesidad psicológica básica.

Necesidad de autonomía. Compartir los objetivos y/o criterios de evaluación podría favorecer que el alumnado conozca qué se espera que aprenda al finalizar una clase, unidad didáctica, proyecto o curso académico. Esto puede facilitar los procesos de autorregulación del aprendizaje, teniendo más autonomía para acometer su aprendizaje. De igual modo, el alumnado podría dialogar, consensuar e incluso construir de forma conjunta con el profesorado su propio mapa de aprendizaje, definiendo los diferentes elementos curriculares a trabajar. Esto podría favorecer una mayor autonomía, al ser más consciente de los aprendizajes que debe alcanzar. Además, podría elegir (dentro de unos márgenes) o consensuar con el/la docente, el porcentaje de calificación de cada criterio o estándar de una tarea a evaluar, en función de la importancia que se le otorgue. Sin embargo, si el profesorado impone o no da a conocer los elementos curriculares a trabajar en su proceso de enseñanza-aprendizaje, el alumnado podría frustrar su autonomía, al no poder dirigir su comportamiento hacia los aprendizajes deseados. Además, si el/la docente utiliza un lenguaje dominador a través de expresiones como: "Tú debes..." o "tú tienes que...", en lugar de con expresiones más participativas como: "¿Qué os parece que el objetivo de la unidad didáctica sea mantener un ritmo uniforme?", se podría frustrar la autonomía del alumnado al percibir el mensaje como una obligación.

Asimismo, facilitar instrumentos de evaluación al alumnado, al comienzo o a medida que avanza una unidad didáctica, podría ayudarle a poner su foco de atención sobre los aspectos relevantes del aprendizaje, sabiendo dónde se encuentra respecto a ellos y qué le falta por mejorar para alcanzar los mayores niveles de logro. Por ejemplo, la entrega de una rúbrica en el diseño de una coreografía en una unidad didáctica de combas puede favorecer que el alumnado, de manera autónoma, se pueda autorregular en su proceso de enseñanzaaprendizaje. Además, si se añaden aspectos a valorar como la originalidad o creatividad en dichos instrumentos se podría favorecer la autonomía del alumnado. Si, por el contrario, no conocen los criterios de evaluación, ni se les entrega ningún tipo de instrumento para saber qué se valora en el diseño de la coreografía, su autonomía puede verse frustrada al no saber qué aprendizajes se espera que aparezcan en ella. Finalmente, la cocreación de instrumentos puede también favorecer la autonomía del 
alumnado, al permitirle consensuar, dialogar o elegir junto al docente los aspectos a evaluar.

El desarrollo de un clima motivacional tarea, en el que el/la docente use una evaluación criterial, puede favorecer la autonomía, ya que el alumnado puede percibir que existen unos criterios en los que puede progresar en su aprendizaje, no comparándose con el resultado o rendimiento de sus compañeros/as. Sin embargo, si el profesorado promueve un clima motivacional ego, a través de una evaluación normativa, se puede frustrar su autonomía, al no percibir unos referentes claros de mejora y progresión, estando supeditados al rendimiento de sus compañeros/as.

Favorecer una evaluación sistemática en diferentes momentos de la unidad didáctica (p.ej., al principio o en varias sesiones intermedias), también le permite al alumnado desarrollar más autonomía en su aprendizaje, siendo más consciente de dónde se encuentra y qué debe hacer para mejorar. De igual modo, acompañar la calificación final de una evaluación más formativa puede permitir al alumnado emplear dicha retroalimentación para ajustar o corregir los siguientes aprendizajes de un periodo formativo. Por el contrario, si solo se califica a los/ as estudiantes al final de una unidad didáctica, sin feedback durante todo el proceso, el alumnado no puede autorregularse en su proceso de enseñanza y aprendizaje, frustrando su autonomía. También, se podría favorecer la autonomía del alumnado permitiéndole consensuar o elegir entre varias tareas a realizar en la evaluación, instrumentos (p. ej., rúbrica, escala de valoración, diana de evaluación, etc.) o seleccionando a la persona, o el grupo, con el que trabajar y al que evaluar.

El uso de feedback (p. ej., "¿con qué parte tienes que conducir el balón para ir más rápido?") y feedforward (p. ej., "¿en qué aspectos crees que deberías prestar más atención para mejo- rar tu aprendizaje?") de carácter interrogativo permiten que el alumnado pueda responder, por sí mismo, las preguntas planteadas por el profesorado, favoreciendo una mayor autonomía en su aprendizaje. Para ello, es importante plantear no solo cuestiones en pequeños y grandes grupos, sino también individuales, en las que cada alumno/a deba pensar en las posibles soluciones. Es importante que el/la docente nunca dé la respuesta al feedback interrogativo planteado. Si el alumnado no sabe todavía la respuesta, el/la docente puede reformular la pregunta o esperar a que la resuelva en posteriores sesiones. Asimismo, se debe favorecer que el alumnado pueda volver a poner en práctica las soluciones identificadas, favoreciendo su autonomía. Sin embargo, el uso frecuente de un feedback más prescriptivo, en el que el profesorado le dice al alumnado lo que tiene que hacer en todo momento (p. ej., "pasa a Ana que está sola", "lanza el frisbee de esta forma", etc.), puede frustrar la autonomía de los/as estudiantes, no pudiendo elegir y tomar decisiones por sí mismos/as.

El feedback descriptivo o explicativo también puede favorecer que el alumnado comprenda qué ha hecho bien o mal, favoreciendo su autonomía en los siguientes intentos. Describir lo que ocurre es recomendable cuando el alumnado no está siendo consciente de lo que hace (p. ej., en baloncesto, no se da cuenta que está haciendo pasos todo el rato) o el tipo de actividad se lo dificulta (p. ej., no es capaz de ver cómo está haciendo la voltereta o la patada de braza). Proporcionar una explicación a lo que ocurre puede ser interesante cuando el alumnado no es capaz de comprender por qué no es correcto lo que está haciendo (p. ej., "estás fallando este paso de comba porque saltas demasiado"). Por tanto, combinar feedback descriptivo y explicativo, junto a feedback interrogativo, puede ser una buena fórmula para promover la autonomía del alumnado. 
Si el alumnado observa que el profesorado le involucra en procesos de autoevaluación y autocalificación puede sentir que se tiene en cuenta su propia percepción individual sobre el punto en el que se encuentra y lo que le falta por mejorar, favoreciendo los procesos de reflexión y autorregulación de los aprendizajes. Para ello, el uso de instrumentos puede favorecer estos procesos de autoevaluación y autocalificación. De igual modo, implicar al alumnado en la coevaluación y cocalificación de sus compañeros, ejerciendo un rol diferente al de jugador, puede favorecer una mayor responsabilidad, autonomía e implicación en el proceso de enseñanza-aprendizaje. Aprender a evaluar correctamente o saber transmitir el feedback a sus compañeros/as les proporcionan autonomía para que ellos mismos sepan identificar errores y mejorar su aprendizaje. También, en función de la unidad didáctica, el curso o el nivel de responsabilidad, se podría favorecer la autonomía del alumnado permitiéndole proponer diferentes tareas de refuerzo a sus compañeros/as. Sin embargo, si el único agente evaluador es el profesorado (heteroevaluación), impidiendo que el alumnado pueda participar en la misma, se puede frustrar su autonomía. De igual modo, si la autoevaluación o coevaluación se realiza sin instrumentos de evaluación o sin una formación o pautas previas sobre cómo evaluar correctamente, el alumnado puede tener dificultades para conocer en qué punto se encuentra en su proceso de enseñanza y aprendizaje, pudiendo frustrarse su autonomía. Para ello, se recomienda que el proceso de cesión de autonomía en la evaluación se realice de manera progresiva en el alumnado, empezando con instrumentos con pocos ítems y la ayuda del profesorado, hasta la máxima cesión de autonomía, donde ellos/as tengan que tomar todas las decisiones.

La evaluación del alumnado al profesorado (heteroevaluación) también permite que los/ as estudiantes puedan ayudarle a reorientar el proceso, favoreciendo su autonomía y opinión durante las sesiones (p. ej., Profesor/a - "¿Qué os está pareciendo esta actividad?", Alumnado - "Hay muy poco espacio para poder mantener la posesión en este juego ¿Se podría aumentar su extensión?" Profesor/a "Podemos aumentarlo a lo ancho para no cambiar el objetivo que tengo en la tarea"). Si el alumnado no puede evaluar al profesorado, es complicado que este último tenga información del grupo que le ayude a mejorar sus destrezas docentes o a reorientar el proceso de enseñanza y aprendizaje de cada uno de sus estudiantes, pudiendo frustrar con más facilidad su autonomía.

Finalmente, en el uso de una evaluación compartida y una calificación dialogada, el alumnado también puede percibir una mayor autonomía y responsabilidad. Los/as estudiantes y el profesorado dialogan y contrastan la información obtenida en su proceso de enseñanza y aprendizaje, tratando de favorecer decisiones mutuas o compartidas. Para ello, deben apoyarse en los diferentes instrumentos de evaluación, teniendo como referencia en todo momento los criterios de evaluación. Sin embargo, si todos los procesos de evaluación y/o calificación recaen en el profesorado, el alumnado puede percibir que el proceso no es democrático, pudiendo frustrarse su autonomía.

Necesidad de competencia. Clarificar los elementos curriculares (p. ej., objetivos, criterios de evaluación, etc.) que van a trabajarse, establecer una temporalización con metas claras, así como proporcionar al alumnado diferentes instrumentos de evaluación (p. ej., rúbricas), le ayudará a ser más consciente de qué debe lograr en la unidad didáctica, dónde se encuentra en relación con los objetivos de aprendizaje y qué le falta para alcanzarlos. Sin embargo, si el alumnado no conoce, en una unidad didáctica, qué se evalúa, cuándo se evalúa o 
cómo se evalúa, no tendrá referencias sobre los aspectos en los que el profesorado quiere incidir en el proceso de enseñanza-aprendizaje, siendo más difícil progresar y percibirse competente en ellos.

La realización de evaluaciones sistematizadas en diferentes tareas (o las mismas tareas), durante el proceso de enseñanza-aprendizaje (p. ej., al principio, en varias sesiones intermedias y al final), podría favorecer una mayor percepción de competencia, al poder comparar su progreso el alumnado en diferentes momentos temporales. En todas estas tareas de evaluación no debe recibirse, necesariamente, una calificación, pero sí un feedback. Sin embargo, si solo se evalúa y/o califica al alumnado de forma sumativa, al final de un proceso de enseñanza-aprendizaje, el alumnado no puede comparar su aprendizaje respecto a evaluaciones anteriores, dificultando conocer lo que ha progresado. De igual modo, al aportarse la información en la última sesión, no puede tener más oportunidades de mejorar su aprendizaje, frustrando su competencia. Además, en muchos casos, se circunscribe su calificación a la información recogida en una única tarea de evaluación, lo cual puede frustrar su competencia al haber podido tener un mal día.

Dentro de estas tareas, en deportes de oposición interindividual o de colaboración-oposición, utilizar tareas contextualizadas de evaluación (p. ej., 3 vs. $3+1$ ), en las que se evalúen y/o califiquen acciones técnico-tácticas en situación real de juego, podría favorecer que el alumnado pueda experimentar un mayor éxito que si solo se evalúan y/o califican acciones técnicas en situaciones descontextualizadas (p. ej., un saque en voleibol). De igual modo, en estas tareas de evaluación no solo se debería evaluar la ejecución o el resultado final, sino también la toma de decisiones previa (p. ej., un/a jugador/a toma la mejor decisión, pero ejecuta incorrectamente). De igual modo, se pueden evaluar estas acciones técnico-tácticas a través de pruebas escritas, que recreen situaciones reales de juego, en las que el alumnado tiene que indicar cuál es la acción más correcta. Esto permite evaluar si el alumnado es capaz de comprender el juego, aunque no necesariamente sepa decidir y ejecutar correctamente en la propia situación real de la tarea, reforzando su competencia. Sin embargo, realizar tareas en las que solo se evalúen gestos técnicos propios de cada deporte, de manera descontextualizada, podrían frustrar la competencia del alumnado menos hábil motrizmente.

El desarrollo de un clima motivacional tarea, en el que el profesorado use una evaluación criterial, también puede favorecer que el alumnado perciba que se valora su progreso individual, favoreciendo su satisfacción de competencia (p. ej., "Estás progresando muy bien en este objetivo"). Sin embargo, si el/la docente promueve un clima motivacional ego, a través de una evaluación normativa, es más probable que la mayoría de los/as estudiantes experimenten una frustración de su competencia, especialmente los/as menos hábiles motrizmente (p. ej., "Tienes que espabilar Marina. Sonia y Alejandro lo están haciendo mejor que tú").

También, se podría favorecer la satisfacción de competencia si el profesorado proporciona, a lo largo de todo el periodo formativo, un feedback afectivo positivo, interrogativo y privado. De este modo, el alumnado podría identificar, por sí mismo, las diferentes reglas de acción y principios operacionales de cada actividad, obteniendo un mayor conocimiento declarativo y procedimental que le permita tener más probabilidades de éxito en las tareas. Sin embargo, un feedback negativo y/o público (p. ej., ranking de tiempos en una carrera) podrían frustrar su competencia al compararse con los demás. 
De igual modo, implicar al alumnado en la evaluación de sus compañeros/as también puede generar una mayor percepción de competencia ya que permite, entre otros aspectos, favorecer los procesos metacognitivos sobre el aprendizaje, identificar los aciertos y errores en las tareas y reflexionar sobre su propio aprendizaje. Además, permite que el alumnado pueda recibir mucho más feedback que el aportado por su profesor/a, lo que puede ofrecerle más información sobre en qué punto se encuentra del proceso y cómo mejorar. Para ello, es muy importante la formación progresiva del alumnado sobre cómo evaluar correctamente, dar feedback a sus compañeros/as, etc. También, es fundamental, educar al alumnado a la hora de recibir críticas constructivas por parte de sus compañeros/as para no frustrar su necesidad de competencia. El profesorado, por su parte, debe comenzar por dotar al alumnado de instrumentos con pocos ítems (p. ej., vuelve al centro de la pista tras cada golpeo) e indicadores de logro (p. ej., sí/no en cada acción) sencillos de evaluar para, progresivamente, aumentar el número, la variedad y complejidad de los ítems, indicadores e instrumentos a utilizar. De igual modo, es importante que, durante las tareas, el/la docente resuelva las dudas y dé feedback al alumnado que está evaluando para que aprenda cómo hacerlo correctamente y para que la transmisión de información al compañero/a sea la adecuada. Mejorar en este rol como evaluador/a también puede reforzar la competencia del propio alumnado, ya que puede percibir que está ayudando a los demás a aprender. Si el alumnado no tiene un amplio conocimiento sobre la finalidad de este proceso y sobre cómo coevaluar a sus compañeros/as, incluso se puede producir el efecto contrario. El alumnado podría desesperarse al no saber qué o cómo tiene que evaluar, cómo debe transmitir la información a sus compañeros/as, etc. Asimismo, el profesorado podría percibir que su alumnado no tiene las compe- tencias suficientes para llevar a cabo esta función.

Favorecer que el alumnado también participe en su evaluación, a través de procesos de autoevaluación o autocalificación, también podría favorecer su competencia, ya que le puede permitir ser más consciente sobre en qué punto se encuentra de su aprendizaje y lo que le falta por aprender. Permitir que el alumnado participe en la propia evaluación docente (heteroevaluación), también puede satisfacer la competencia de los/as estudiantes al ayudar a su profesorado a mejorar sus destrezas profesionales y a reconducir la unidad didáctica (p. ej., "podrías establecer tres niveles de dificultad en estos recorridos, ya que son muy complejos").

Asimismo, implicar al alumnado en la modificación y/o construcción de sus propios instrumentos de evaluación también puede reforzar su percepción de competencia, ya que puede percibir que es capaz de identificar aquellos ítems que son necesarios para lograr una progresión en su aprendizaje. Sin embargo, si la cocreación de dichos instrumentos se realiza sin una formación previa y sin un conocimiento profundo de la actividad se podría frustrar la percepción de competencia de los/as estudiantes, al no saber identificar los aspectos clave para valorar en su aprendizaje. Es importante también que los indicadores de logro establecidos en los instrumentos de evaluación permitan que el alumnado pueda percibir un progreso (p. ej., experto, avanzado, amateur y aprendiz). Si los indicadores de logro no permiten que el alumnado pueda visualizar una progresión en su aprendizaje (p. ej., sí/no), o algunos están redactados en términos negativos (p. ej., bueno, regular y malo), se puede frustrar la competencia del alumnado.

Necesidad de relaciones sociales. Las estrategias de apoyo a la autonomía utilizadas en 
la evaluación como dialogar, consensuar o permitir la elección del alumnado de los objetivos, criterios de evaluación, instrumentos utilizados, aspectos a valorar, tareas de evaluación, porcentajes de calificación, etc. pueden favorecer que el alumnado perciba que su profesorado le tiene en cuenta en el diseño de su proceso de enseñanza-aprendizaje. Esta forma de liderazgo más democrático por parte de los/as docentes, en el que se consensúan todas las decisiones, puede favorecer un clima cálido en el que el alumnado pueda opinar, dialogar y construir su propio mapa de aprendizaje, favoreciéndose relaciones sociales positivas entre ambos. Para ello, el uso de un lenguaje más participativo (p. ej., "¿Qué queréis aprender en esta unidad didáctica?, ¿qué os parece si establecemos este criterio de evaluación?, ¿qué tarea, entre estas tres opciones, queréis que usemos para realizar la evaluación?") predispone al alumnado a participar e implicarse en su aprendizaje. Sin embargo, si se adopta un lenguaje dominador o se imponen todos los elementos curriculares a trabajar, así como otros aspectos vinculados a la evaluación, el alumnado puede percibir que el profesorado adopta todas las decisiones en su itinerario de aprendizaje, pudiendo frustrar las relaciones sociales respecto a él.

Generar un clima motivacional tarea, en el que el profesorado use una evaluación criterial, también, puede favorecer la cohesión grupal del alumnado, ya que pueden percibir que el objetivo es que cada uno mejore respecto así mismo, no comparándose con los demás. Eso favorece que se produzcan conductas más colaborativas en el aula e imperen valores como el juego limpio, respeto, superación, deportividad, compañerismo, etc. Sin embargo, el desarrollo de un clima motivacional ego, a través de una evaluación normativa, puede desencadenar una competitividad exacerbada entre los/as estudiantes, generando malas relaciones sociales y un clima negativo de aula.
El alumnado puede percibir que, si ayuda a los demás, puede perjudicarle en su desempeño, por lo que tratará de rehuir del uso de conductas colaborativas.

Favorecer una evaluación sistemática en diferentes momentos de la unidad didáctica ( $p$. ej., al principio o en varias sesiones intermedias), y no solo al final, favorece que la evaluación y/o calificación sea más adecuada o justa, permitiéndole al alumnado interactuar con el/ la docente durante todo el periodo formativo. Por el contrario, si solo se califica a los/as estudiantes al final de una unidad didáctica, el alumnado puede percibir que el profesorado no se preocupa por su aprendizaje. Si, además, el profesorado no dispone de ningún instrumento de evaluación para justificar esta calificación, el alumnado puede percibir que esta ha sido completamente a ojímetro y subjetiva, desencadenando malas relaciones sociales entre ambos.

\section{El uso de feedback y feedforward por parte del} profesorado, en cantidad y calidad, también pueden mejorar las relaciones sociales entre el profesorado y alumnado, siempre y cuando se enfoque correctamente. Si los/as estudiantes perciben que su docente se preocupa por su aprendizaje, dirigiéndose a todos ellos ( $y$ no solo a algunos de ellos), dándoles feedback que les permitan mejorar (p. ej., interrogativo, afectivo, privado e individualizado) o mostrando una actitud receptiva y empática ante sus problemas, se puede mejorar la relación social entre ambos. Sin embargo, si el/la docente proporciona feedback negativo, prescriptivo, público o de carácter normativo, estableciendo además una barrera en la comunicación con sus discentes, es más probable que las relaciones sociales sean negativas. Además, si el alumnado es ignorado, no recibiendo prácticamente ningún tipo de feedback o siendo este muy inespecífico, puede percibir que al profesorado no le preocupa 
su aprendizaje, empeorando las relaciones sociales entre ambos.

Si el profesorado involucra al alumnado en la coevaluación de otros/as estudiantes, durante gran parte de la unidad didáctica o el curso académico, también puede favorecer las relaciones sociales y la cohesión grupal, siempre y cuando se enfoque este proceso de manera correcta. Si se realiza una formación en el alumnado sobre qué es la evaluación y cómo evaluar, dar y recibir feedback, este puede proporcionar información más precisa a sus compañeros/as sobre cómo mejorar su aprendizaje. Sin embargo, si no se establecen criterios claros sobre cómo evaluar, es muy probable que no se haga correctamente ( $p$. ej., un/a estudiante pone en una evaluación diagnóstica que su compañera lo sabe hacer todo perfecto) o la transmisión de información no sea la correcta (p. ej., "Haces todo mal"), pudiendo no solo frustrarse la competencia, sino también las relaciones sociales entre el grupo. Es importante que el profesorado ayude al alumnado a transmitir dicha información las primeras veces, especialmente si es muy vergonzoso o le resulta incómoda esta situación. Por ello, al comienzo de estos procesos de coevaluación, puede ser positivo que el alumnado pueda elegir la persona o el grupo al que evaluar, para que tenga una mayor confianza $y$, progresivamente, se vaya haciendo con el resto de los/as compañeros/as. Es importante hacer ver a la persona o grupo que recibe el feedback que la evaluación es una parte fundamental del proceso de enseñanza-aprendizaje, que le va a ayudar a progresar en su desempeño. Esto puede generar un buen clima de aula, ya que se produce una ayuda mutua, es decir, el alumnado percibe que ayuda a los demás a progresar a la vez que también le ayuden a él.

En línea con el punto anterior, cabe destacar que si, además, se quiere realizar una cocali- ficación intragrupal (entre los miembros del grupo) es importante que el grupo acepte este sistema de evaluación, ya que puede generar mucha tensión entre el alumnado al percibir que las calificaciones de los demás pueden depender de él. Por ejemplo, cuando se realiza una cocalificación intragrupal, lo que implica un reparto de notas entre los miembros de un grupo, es importante que se hayan usado diferentes instrumentos para cuantificar el trabajo realizado por cada estudiante (p. ej., diario de reuniones, registro de las horas invertidas, etc.). De igual modo, es importante que el alumnado se pueda coevaluar durante todo el proceso con el objetivo de conseguir un trabajo más equilibrado por parte de todos/ as los/as integrantes. De este modo, si alguien no está trabajando lo suficiente, puede revertirse esta situación. Esto puede favorecer una calificación más justa en la que, verdaderamente, se refleje lo que ha trabajado cada uno y no todos tengan la misma calificación, aunque su trabajo no haya sido proporcional. Sin embargo, si se realiza una cocalificación intragrupal al final de un proceso, sin tener en cuenta ningún tipo de instrumento o coevaluación previa, es muy probable que el reparto de notas se perciba injusto y, por ello, pueda generar mucha tensión y frustrar las relaciones sociales entre el grupo, al ser complicado cuantificar el trabajo de cada uno.

El uso de instrumentos de evaluación para realizar procesos de coevaluación y/o cocalificación es fundamental. El alumnado podría conocer en qué aspectos del aprendizaje tiene que progresar, pudiendo mejorar sus relaciones sociales si se realizan tareas en grupo. Por ejemplo, si el profesorado entrega una rúbrica al alumnado en el diseño de una coreografía, estos pueden dialogar y consensuar los pasos a realizar para autorregular su aprendizaje. Sin embargo, si el profesorado no proporciona ningún tipo de instrumento, pueden surgir más conflictos dentro de un grupo, al no tener muy 
claro qué aspectos se tienen en cuenta en el diseño de la coreografía.

Además, si el alumnado aprecia que el profesorado le involucra en procesos de autoevaluación y autocalificación puede percibir que confía en su capacidad para evaluarse y/o calificarse, en base a unos criterios establecidos. Esto puede favorecer que el alumnado también sea justo en este proceso, mostrándole que tiene la capacidad, madurez y honestidad de hacerlo correctamente. Sin embargo, si estos procesos de autoevaluación y autocalificación se establecen sin tener en cuenta ningún tipo de instrumento de evaluación, la percepción entre discentes y docentes puede ser muy diferente, pudiendo generarse conflictos entre ambos (p. ej., un/a estudiante considera que tiene un 10 porque ha progresado mucho, mientras que el profesor cree que hay muchos aspectos en los que no ha alcanzado el máximo indicador de logro).

La evaluación del alumnado al docente (heteroevaluación) también puede favorecer las relaciones sociales entre ellos. Si el profesorado se muestra receptivo a recibir feedback por parte de su alumnado, este último puede ayudarle a reconducir el proceso de enseñanzaaprendizaje, mejorando las relaciones sociales entre ambos. Sin embargo, si el profesorado, en ningún momento, deja que el alumnado le pueda evaluar, se genera un clima más frío, de distancia social entre ambos, que puede frustrar las relaciones sociales.

Finalmente, el uso de una evaluación compartida y una calificación dialogada también puede permitir que el alumnado y su profesor/a contrasten la información obtenida a través de los diferentes instrumentos de evaluación, facilitando el salto a la calificación en el caso de que sea necesario. Estos procesos de diálogo y consenso favorecen las relaciones sociales entre ambos, al contrastar el punto de vista de las dos partes implicadas en el aprendizaje. Sin embargo, impedir que el alumnado pueda participar en estos procesos de evaluación y/o calificación, especialmente si no está de acuerdo en la evaluación de una tarea y/o en una calificación, pueden frustrar la relación social entre docentes y discentes.

\section{2.- Aplicaciones prácticas para la docencia de la Educación Física}

En las Tablas 1, 2 y 3, hacemos una síntesis sobre aquellas conductas docentes, relacionadas con los procesos de evaluación y califi- cación en Educación Física, que pueden contribuir a satisfacer o frustrar las necesidades psicológicas básicas del alumnado. 


\section{AUTONOMIA}

\section{SATISFACCIÓN
- Compartir, consensuar o construir con el} alumnado los objetivos y/o criterios de evaluación.

- Consensuar o elegir el porcentaje de calificación de cada criterio o estándar.

- Facilitar los instrumentos de evaluación al alumnado al comienzo o durante la unidad didáctica, pudiendo llegar a cocrearlos de forma conjunta con el alumnado.

- Emplear una evaluación criterial donde el alumnado pueda autorregularse respecto a sus objetivos de aprendizaje.

- Evaluar al alumnado en diferentes momentos del proceso, proporcionando feedback continuo.

- Utilizar feedback de carácter descriptivo, explicativo, interrogativo y feedforward.

- Dejar elegir o consensuar una serie de aspectos de la evaluación (la tarea a realizar, la persona o el grupo al que evaluar, instrumentos, los aspectos a valorar, etc.).

- Participar, de manera progresiva, en la evaluación a partir de procesos de auto y coevaluación y, posteriormente, de auto y cocalificación.

- Facilitar procesos de evaluación del alumnado al docente.

- Usar una evaluación compartida y una calificación dialogada.

\section{FRUSTRACIÓN}

- Imponer o no dar a conocer los objetivos o los aspectos que van a ser evaluados.

- Usar un lenguaje dominador para imponer todos los elementos curriculares referentes a la evaluación.

- No facilitar los instrumentos de evaluación al alumnado para que pueda autorregularse y sepa cómo va a ser calificado.

- Realizar una evaluación normativa, comparando al alumnado con los demás.

- Dar únicamente una calificación final, sin feedback durante todo el proceso.

- Usar frecuentemente un feedback prescriptivo o respondiendo él mismo a las preguntas formuladas al alumnado.

- No permitir la participación del alumnado en la evaluación ni en la construcción de diferentes instrumentos

- No dar a conocer al alumnado la finalidad de la evaluación.

- Pedir al alumnado que evalúe sin una formación o pautas previas en procesos de auto o coevaluación.

- Ser el profesorado el único agente evaluador y/o calificador. 


\section{Tabla \\ Elementos de la evaluación que contribuyen 2 a satisfacer o frustrar la competencia}

\section{COMPETENCIA}

SATISFACCIÓN

- Clarificar o consensuar los objetivos y criterios de evaluación.

- Realizar una evaluación sistematizada, en diferentes momentos temporales, para favorecer la percepción de progreso del alumnado. - Diseñar actividades e instrumentos de evaluación coherentes con lo trabajado en clase y ajustados al nivel y capacidades del alumnado.

- Emplear una evaluación criterial, centrada en el progreso individual respecto a un criterio de evaluación.

- Proporcionar feedback durante toda la unidad de enseñanza-aprendizaje, favoreciendo la autorregulación del aprendizaje.

- Utilizar un feedback comparativo respecto a sí mismo, en lugar de respecto a los demás.

- Proporcionar feedback afectivo, interrogativo, positivo y privado.

- Involucrar al alumnado en la evaluación (auto y coevaluación), bajo la supervisión docente, que partan de un aprendizaje previo sobre cómo evaluar o dar feedback, así como recibir críticas constructivas.

- Diseñar diferentes instrumentos de evaluación, con indicadores de logro claros, y en progresión de adquisición de los aprendizajes.

- Implicar al alumnado en la modificación, consenso o construcción de los instrumentos de evaluación.

\section{FRUSTRACIÓN}

- No dar información sobre qué, cuándo y cómo se va a evaluar.

- Evaluar y/o calificar únicamente de forma sumativa al final de la unidad didáctica, sin tener margen para poder implementar mejoras.

- Proponer tareas de evaluación descontextualizadas con respecto a lo trabajado en la unidad didáctica.

- Evaluar, exclusivamente, gestos técnicos propios de un deporte.

- Emplear una evaluación normativa, comparando a los estudiantes entre sí.

- Dar feedback negativo y/o público, en lugar de manera privada.

- Publicar un ranking de notas o resultados del alumnado.

- No evaluar y/o calificar el progreso.

- No implicar al alumnado en su propia evaluación o la evaluación de sus compañeros.

- No dar formación al alumnado sobre cómo evaluar a sus compañeros, transmitir o recibir feedback o no facilitar criterios de evaluación de referencia para el proceso.

- Dotar al alumnado de instrumentos con numerosos ítems e indicadores de logro para evaluar a sus compañeros.

- Establecer indicadores de logro en un instrumento que no permitan visualizar una progresión en el aprendizaje (sí/no) o estén redactados de forma negativa (regular, malo). 
RELACIONES SOCIALES

SATISFACción
- Usar un diálogo más democrático, a través de un lenguaje más participativo, en el que se consensúen diferentes decisiones sobre la evaluación.

- Emplear una evaluación criterial en la que se favorezca la cooperación y el progreso individual.

- Generar procesos continuos de evaluación en el que los intercambios comunicativos entre el/la docente y el alumnado sean frecuente.

- Utilizar un feedback afectivo, privado e individualizado, en cantidad y calidad.

- Permitir al alumnado seleccionar con qué compañero/s trabajar o evaluar en los procesos de coevaluación.

- Formar sobre cómo dar y recibir feedback al alumnado para que se haga de una forma positiva y formativa.

- Emplear instrumentos de evaluación que permitan al alumnado consensuar qué van a realizar y cómo lo van a hacer.

- Favorecer que el alumnado se autoevalúe y autocalifique, dándole confianza en este proceso.

- Promover que el alumnado evalúe al profesorado.

- Realizar evaluaciones y/o calificaciones dialogadas.

\section{FRUSTRACIÓN}

- Imponer todos los elementos del proceso de evaluación.

- Emplear una evaluación normativa que provoque que se cree un clima competitivo y comparativo entre estudiantes.

- Utilizar únicamente una evaluación final y sumativa, no aportando feedback durante todo el proceso.

- Evaluar sin instrumentos de evaluación que justifiquen el juicio de valor y/o calificación dada por el profesorado.

- Proporcionar un feedback negativo, prescriptivo o público.

- No enseñar al alumnado a dar feedback o a recibir críticas constructivas.

- Emplear procesos de coevaluación o cocalificación, sin instrumentos o criterios claros sobre cómo evaluar al compañero.

- Obligar al alumnado a cocalificar a sus compañeros, sin un proceso gradual y siempre aceptado por el alumnado.

- No facilitar procesos de participación del alumnado en la evaluación y/o calificación. 
Por tanto, en función de cómo se apliquen los procesos de evaluación formativa, en el diseño y la propia intervención docente, se pueden satisfacer o, por el contrario, frustrar las necesidades psicológicas básicas de autonomía, competencia y relación social. Estas estrate- gias u orientaciones pretenden favorecer que el profesorado de Educación Física identifique buenas y malas praxis docentes en el uso de la evaluación formativa para favorecer una mayor motivación y aprendizaje en sus clases. 


\section{3.- PARA SABER MÁS...}

Actualmente, existen muy pocos estudios que hayan profundizado en la relación entre la evaluación formativa y la motivación. En el estudio llevado a cabo por Bores-García et al. (2021), se recogen las percepciones y testimonios de estudiantes de Educación Secundaria sobre los efectos de una unidad didáctica de expresión corporal, en el que se aplicó una evalua- ción formativa y compartida, en la satisfacción de las necesidades psicológicas básicas de autonomía, competencia y relaciones sociales. De igual modo, en la tesis doctoral de Krijgsman (2021), se puede profundizar más en algunos aspectos claves de la evaluación formativa para satisfacer y evitar frustrar las necesidades psicológicas básicas. 


\section{4.- REFERENCIAS BIBLIOGRÁFICAS}

Black, P., y Wiliam, D. (2018). Classroom assessment and pedagogy, Assessment in Education: Principles, Policy \& Practice, 25(6), 551-575. https://doi.org/10.1080/0 969594X.2018.1441807

Bores-García, D., Hortigüela-Alcalá, D., Hernando-Garijo, A., y González-Calvo, G. (2021). Analysis of student motivation towards body expression through the use of formative and share assessment. Retos. Nuevas Tendencias en Educación Física, Deporte y Recreación, 40, 198-208. https://doi.org/10.47197/ retos.v1i40.83025

Boud, D.,y Molloy, E. (2013). Rethinking models of feedback for learning: the challenge of design. Assessment \& Evaluation in Higher Education, 38(6), 698-712. https://doi.org/10.1080/02602938.2012.691462

Chng, L. S. y Lund, J. (2018). Assessment for learning in physical education: what, why and how. Journal of Physical Education, Recreation \& Dance, 89(8), 29-34. https://doi.org/10.1080/07303084.2018.1503119

Gibbs, G., y Simpson, C. (2005). Conditions under which assessment supports students' learning. Learning and Teaching in Higher Education, 1, 3-31.

Krijgsman, C. (2021). A self-determination theory perspective on performance grading, goal clarification and process feedback in physical education (Doctoral dissertation, Ghent University).

Leenknecht, M., Wijnia, L., Köhlen, M., Fryer, L., Rikers, R. y Loyens, S. (2021). Formative assessment as practice: the role of students' motivation. Assessment \& Evaluation in Higher Education, 46(2), 236-255. https://doi.org/10.1080/02602938.2020.1765228

López-Pastor, V. M. (2017). Evaluación formativa y compartida: evaluar para aprender y la implicación del alumnado en los procesos de evaluación y aprendizaje. En V. M. López-Pastor y Á. Pérez-Pueyo (Coords). Evaluación formativa y compartida en educación: experiencias de éxito en todas las etapas educativas (pp.34-68). León: Universidad de León.
López-Pastor, V. M.,y Sicilia Camacho, A. (2018). Formative and shared assessment in higher education. Lessons learned and challenges for the future. Assessment \& Evaluation in Higher Education, 42(1), 77-97. https:// doi.org/10.1080/02602938.2015.1083535

Panadero, E., Tapia, J. A., y Huertas, J. A. (2012). Rubrics and self-assessment scripts effects on self-regulation, learning and self-efficacy in secondary education. Learning and Individual Differences, 22(6), 806-813. https://doi.org/10.1016/j.lindif.2012.04.007

Ryan, R. M., y Deci, E. L. (2017). Self-determination theory: basic psychological needs in motivation, development, and wellness. Guilford Publications. https://doi. org/10.7202/1041847ar

Slingerland, M., Borghouts, L., Jans, L., Weeldenburg, G., van Dokkum, G., Vos, S., y Haerens, L. (2017). Development and optimisation of an in-service teacher training programme on motivational assessment in physical education. European Physical Education Review, 23(1), 91-109. https://doi.org/10.1177/1356336X16639212

Vasconcellos, D., Parker, P. D., Hilland, T., Cinelli, R., Owen, K. B., Kapsal, N., Lee, J., Antczak, D., Ntoumanis, N., Ryan, R. M., y Lonsdale, C. (2020). Self-determination theory applied to physical education: A systematic review and meta-analysis. Journal of Educational Psychology, 112(7), 1444-1469. https://doi.org/10.1037/edu0000420

Wiliam, D. y Leahy, S. (2015). Embedding formative assessment: Practical techniques for K-12 classrooms. West Palm Beach, FL: Learning Sciences International. 
